\title{
ASSOCIAÇÃO ENTRE BRUXISMO DO SONO E DOR MIOFASCIAL: UM ESTUDO POLISSONOGRÁFICO
}

Tese apresentada à Faculdade de Odontologia de Bauru, da Universidade de São Paulo, como parte dos requisitos para obtenção do título de Doutor em Odontologia, na Área de Reabilitação Oral.

(Edição Revisada) 


\section{ASSOCIAÇÃO ENTRE BRUXISMO DO SONO E DOR MIOFASCIAL: UM ESTUDO POLISSONOGRÁFICO}

\section{LEYLHA MARIA NUNES ROSSETTI}

Tese apresentada à Faculdade de Odontologia de Bauru, da Universidade de São Paulo, como parte dos requisitos para obtenção do título de Doutor em Odontologia, na Área de Reabilitação Oral.

(Edição Revisada)

Orientador: Prof. Dr. Carlos dos Reis Pereira de Araujo Co-orientador: Prof. Dr. Paulo César Rodrigues Conti 


\begin{tabular}{|} 
ROSSETTI, Leylha Maria Nunes \\
Associação entre bruxismo do sono e dor miofascial: \\
um estudo polissonográfico / Leylha Maria Nunes Rossetti. - \\
Bauru, 2006. \\
239 p. : il. ; $30 \mathrm{~cm}$ \\
Tese (Doutorado) - Faculdade de Odontologia de \\
Bauru. USP \\
Orientador: Prof. Dr. Carlos dos Reis Pereira de Araujo \\
Co-orientador: Prof. Dr. Paulo César Rodrigues Conti
\end{tabular}

Autorizo, exclusivamente para fins acadêmicos e
científicos, a reprodução total ou parcial desta dissertação, por
processos fotocopiadores e/ou meios eletrônicos.
Assinatura do autor (a):
Data:

Projeto aprovado pelo Comitê de Ética em Pesquisa da Faculdade de Odontologia de Bauru - USP. Protocolo de pesquisa №. 021 / 2002. 


\section{LEYLHA MARIA NUNES ROSSETTI}

05 de maio de 1974 - NASCIMENTO - TIANGUÁ - CE

Filiação: $\quad$ FRANCISCA LÚCIA DE OLIVEIRA

LUIZ NUNES NETO

1992-1995

Curso de Graduação em Odontologia na Universidade Federal do Ceará - UFC.

1996-1998

Professora Substituta de Prótese Parcial II do curso de Odontologia da Universidade Federal do Ceará - UFC

1996-1996

Curso de Atualização em Diagnóstico e Tratamento de Problemas Oclusais da Universidade Federal do Ceará - UFC.

1996-1996

Curso de Aperfeiçoamento em Endodontia da Universidade Federal do Ceará - UFC.

1998-1998

Curso de Atualização em Odontologia Cosmética da Escola de Aperfeiçoamento Profissional - (EAP- ABO-CE) Associação Brasileira de Odontologia - ABO-CE.

$1999-2000$

Curso de Especialização em Prótese Dental da Escola de Aperfeiçoamento Profissional (EAP - ABO-CE).

$2000-2000$

Curso de Aperfeiçoamento em Implantes Osseointegrados da Escola de Aperfeiçoamento Profissional (EAP - ABO-CE)

2001-2003

Curso de Mestrado em Odontologia, área de concentração Reabilitação Oral (FOB-USP)

\section{ASSOCIAÇÕES DE CLASSE E SOCIEDADES CIENTÍFICAS}

Associação Brasileira de Odontologia - ABO - Secção Ceará

Conselho Regional de Odontologia - Ceará 
ADeus,

Por guiar meus passos, por jamaís ter me deíxado só, por iluminar meu camínho por provar, das mais variadas formas, que Seu amor é infinito e que, portanto, vale a pena acreditar.

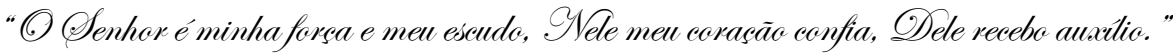

A meu mais que amado filho, Gabriel, meu maior presente de Deus, minha maior bênção, com quem redescubro a vida, com quem reaprendo a respirar.

A meu querído e amado marido, Paulo co-autor dos meus dias, apóia-me, alegra-me, ajuda-me, fortalece-me e acalma-me. Por todo o amor que você me dá e por toda paz e felicídade que você me faz sentír

$$
\begin{array}{r}
\text { A minha tão amada familia } \\
\text { Mínha mãe Lúcia, meus írmãos Leydiane, Carlinhos e meu pai Luiz } \\
\text { Da qual jamais ímaginei sentír tão índescritível saudade... }
\end{array}
$$

A meus queridos avós, Sebastião e Vitória, e a meus amados e ínesqueciveís tíos (as) e prímos(as), cuja presença em mínha infância, trazem as mínhas maís doces lembranças. O carinho e o afeto de vocês aquecem meu coração e A companhía que vocês conseguem me fazer, apesar do tempo e da dístâncía, É a medida do amor que sentímos. Sou grata a Deus pela dádiva do amor de vocês.

Ao Sr. Rossetti, D. Alice e Fernando, Minha segunda familia, Que aquece meus dias com companheirísmo, amor e respeíto.

Com amor, Dedico este trabalho 


\section{AGRADECIMENTOS}

\section{Ao Professor Dr. Carlos dos Reis Pereira de Araujo}

Ser sua orientada é, sem dúvida, uma experiência única. A confiança em mim depositada colocou sobre meus ombros o peso de uma grande responsabilidade. Mas nenhum aprendizado se faz sem confiança. Pois é acreditando que somos capazes que vamos além, que nos descobrimos melhores, que crescemos. Devo isso a você. Além disso, ser sua orientada me presenteou com sua inestimável amizade. Presente caro que levarei comigo para onde eu for.

Ao Professor Dr. Paulo César Rodrigues Conti,

Eu diria que ter o privilégio de ser sua aluna me ensinou muito.

Descobri um novo impulso científico e profissional. Uma nova paixão sobre a qual me debruçar o universo no qual está imerso o conteúdo deste estudo. Pois, sem paixão não se vive, não se estuda, não se trabalha. E não é só isso

Tê-lo como amigo representa uma honra e um tesouro a zelar. 


\section{AGRADECIMENTOS}

À Faculdade de Odontologia de Bauru que me acolheu e me possibilitou mais esse importante passo em minha vida.

Ao Prof. Paulo Conti, de novo, pela carinhosa e firme condução do nosso curso.

Ao Prof. Pegoraro, pela dedicação e incansável disposição de ensinar.

À Fundação de Amparo à Pesquisa do Estado de São Paulo - FAPESP, pelo financiamento e apoio a todos os aspectos deste estudo.

À Coordenadoria de Aperfeiçoamento Superior - CAPES pelo apoio financeiro constante durante todo esse curso.

A todos os amigos, colegas, voluntários e pacientes que, corajosamente, participaram desta pesquisa.

Ao Instituto de Medicina do Sono e à Clínica de Distúrbios do Sono, nas pessoas do Dr. Luiz Alberto dos Santos, Dra. Maria Rita e Dr. Carlos Henrique, bem como a todos os seus funcionários.

Ao Prof. Lauris, pela atenção e apoio indispensável, nas inúmeras vezes em que precisei.

Ao Prof. Alceu Trindade, pela colaboração sempre solícita com que tive o privilégio de contar.

A todos os professores do Departamento de Prótese, pela atenção, carinho e conhecimento, de que dispõem.

Às secretárias do Departamento de Prótese, pela ajuda permanente e sorriso revigorante que nunca nos nega.

Às meninas e meninos da pós-graduação, pela atenção e apoio em horas tão importantes. 


\section{AGRADEDIMENTOS ESPECIAIS}

Aos meus eternos mestres e professores Prof. Dr. Talapala Gowindaswami Naidu, Prof. Dr. Marcos Aurélio Rabelo Limaverde e Prof. Dr. Antônio Materson da Silva. Levarei comigo seus nomes, ensinamentos, exemplos, palavras de incentivo e de carinho em meu coração, para sempre. Nos momentos mais difíceis e mais felizes de minha vida profissional, penso em como meus queridos professores agiriam, penso em pedir-lhes conselhos, em dividir com eles os melhores frutos de minha vida. Pois sei, sinto e quero que também tenham a certeza de que são responsáveis pela boa colheita.

meu mais sincero carinho e toda minha gratidão

Aos meus amigos irmãos INCONDICIONAIS Aldo Angelim Dias, Cid Farias, Fabrícia Arraes, Mariana Mandim, Ricardo Lira de Oliveira e Roberta Dalcico

Por se manterem perto, mesmo distantes... Por continuarem fazendo parte da minha vida (celebrando ou não). A nossa amizade resistiu às maiores das provas:

Ao tempo e à distância. Por isso meu tesouro é imenso Obrigada por tudo 


\section{SUMÁRIO}

ÍNDICE DE FIGURAS__ $X$

ÍNDICE DE TABELAS___ Xi

LISTA DE ABREVIATURAS E SÍMBOLOS__ Xiv

RESUMO _

1 - Introdução — 2

2 - Revista da Literatura __ 6

2.1 Bruxismo do Sono 6

2.1.1 Diagnóstico _ 6

2.1.2 Epidemiologia __ 17

2.1.3 Etiopatogenia — 19

2.2 Sono _ 27

2.2.1 Fisiopatologia __ 27

2.2.2 Sono e Dor 29

2.3 Disfunção Temporomandibular __ 32

2.3.1 Epidemiologia___ 32

2.3.2 Diagnóstico __ 38

2.3.3 Etiopatogenia __ 41

2.4 Integração Sensorial-Motora na Dor Muscular e Articular _ 44

2.4.1 Teorias sobre atividade muscular como fator etiológico da DTM _ 44

2.4.2 Atividade Muscular e Alterações Somato-Motora __ 49

2.4.3 Dor e Alterações Motoras ___ 62

3 - PROPOSIÇÃO _ 77

4 - MATERIAL E MÉTODOS

4.1 Estabelecimento dos Grupos___ 79

4.2 Critérios de Inclusão e Exclusão___ 80

4.2.1 Critérios de exclusão iniciais _ـ 80

4.2.2 Critérios de inclusão e exclusão específicos___ 81 
4.3 Exame Clínico de Dor Miofascial 83

4.3.1. Diagnóstico de dor miofascial (Examinador 1) 83

4.3.2 Diagnóstico Clínico de Bruxismo do Sono (Examinadores 1 e 2) 85

4.4. Polissonografia 87

4.4.1 Dados técnicos 90

4.5 Avaliação Pré-Polissonográfica (Examinador 1) 91

4.6 Avaliação Pós-Polissonográfica (Examinador 2) 93

4.7 Análise dos Dados Polissonográficos 94

4.8 Análise Estatística 96 98

5.1 Triagem 99

5.2 Avaliação Prévia ao Exame Polissonográfico (PSG) 109

5.3 Reavaliação de dtm Após o Exame Polissonográfico 119

5.4 Dados Polissonográficos 110

5.4.1 Variáveis do Sono 111

5.5 Associação entre Bruxismo do sono e Dor Miofascial 116

5.6 Bruxismo do Sono e Limiar de Dor à Pressão Pós-PSG 118

5.6.1 Grupo Controle

5.6.2 Grupo Experimental 123

5.7 Efeito Inibitório da Dor Sobre ARMM 130

5.7.1 Limiar de dor à pressão pré-psg e ARMM 132

5.8 Bruxismo do Sono e EAV 140

5.9 Bruxismo Clínico 142

6.1 Amostra 152

6.2 Diagnóstico de Bruxismo do Sono e de Dor Miofascial 155

6.3 Variáveis Oromotoras 158

6.4 Influência da Atividade Muscular sobre a Dor 159 
6.5 Limiar de Dor à Pressão e Disfunção Temporomandibular 165

6.5.1 Relação Temporal e Gradiente Dose-Resposta 167

6.6 Influência da Dor sobre a ARMM 173

6.7 Confiabilidade do Exame Clínico de Bruxismo 179

7. CONCLUSÕES 184

ANEXOS 186

REFERÊNCIAS BIBLIOGRÁFICAS 222

ABSTRACT 239 


\section{ÍNDICE DE FIGURAS}

Figura 1 Representação de como o registro foi realizado durante o sono ........................................................ 87 Figura 2 Posicionamento do fio terra (A); EOG (B e C); microfone (D); EMG do músculo mentoniano (E); registro de fluxo aéreo oral/nasal (F) e eletromiografia do músculo masseter $(G)$.

Figura 3 Exemplos de episódios de bruxismo fásico (A), tônico (B) e misto (C), registrado de um músculo masseter direito. Modificado de LAVIGNE; ROMPRÉ; MONTPLAISIR, ${ }^{83} 1996$. 95

Figura 4 Relações entre LDP pré-PSG e ARMM nos bruxômanos do Grupo Controle ... 136

Figura 5 Relações entre LDP pré-PSG e ARMM nos NÃO BRUXÔMANOS do Grupo Experimental 137 


\section{ÍNDICE DE TABELAS}

Tabela 1 Características clínicas (triagem) do grupo CONTROLE 100

Tabela 2 Freqüência das respostas ao questionário de índice de DTM ${ }^{32}$ no grupo CONTROLE 101

Tabela 3 Características clínicas (triagem) do grupo EXPERIMENTAL 102

Tabela 4 Características clínicas (triagem) do grupo EXPERIMENTAL__ 103

Tabela 5 Freqüência das respostas ao questionário de índice de DTM ${ }^{32}$ no grupo EXPERIMENTAL __ 104

Tabela 6 Características Gerais (triagem) dos Grupos CONTROLE e EXPERIMENTAL _ 105

Tabela 7 Distribuição dos horários de piora da dor no grupo EXPERIMENTAL __ 106

Tabela 8 Variáveis oromotoras dos NÃO-BRUXÔMANOS do grupo EXPERIMENTAL com e sem piora da dor

pela manhã _ـ 106

Tabela 9 Variáveis oromotoras dos Bruxômanos com e sem piora da dor pela manhã __ 106

Tabela 10 Valores das EAVs do grupo EXPERIMENTAL __ 107

Tabela 11 Características clínicas dos Bruxômanos e Não-Bruxômanos do GRUPO EXPERIMENTAL __ 108

Tabela 12 Limiares de Dor à Pressão pré-PSG (LDP pré-PSG) dos grupos CONTROLE e EXPERIMENTAL 109

Tabela 13 Índice Apnéia/Hipopnéia, microdespertares/hora e índice de movimentos periódicos dos membros nas duas noites de PSG __ 110

Tabela 14 Variáveis gerais do sono nos grupos CONTROLE e EXPERIMENTAL __ 111

Tabela 15 Variáveis gerais do sono nos BRUXÔMANOS e NÃO-BRUXÔMANOS __ 112

Tabela 16 Distribuição dos episódios e bursts nas diferentes fases do sono nos Grupos CONTROLE e EXPERIMENTAL 112

Tabela 17 Distribuição dos episódios e bursts nas diferentes fases do sono no grupo CONTROLE ___ 113

Tabela 18 Distribuição dos episódios e bursts nas diferentes fases do sono no grupo EXPERIMENTAL__ 113

Tabela 19 Variáveis oromotoras de corte na amostra total ___ 114

Tabela 20 Variáveis oromotoras de corte dos não-bruxômanos___ 115

Tabela 21 Tabela de contingência do BS _ـ 116

Tabela 22 Limiares de Dor à Pressão pós-PSG (LDP pós) dos grupos CONTROLE e EXPERIMENTAL__ 118

Tabela 23 Limiares de Dor à Pressão (LDP) pré e pós-PSG do grupo CONTROLE___ 119

Tabela 24 Limiares de Dor à Pressão (LDP) pré e pós-PSG nos bruxômanos do grupo CONTROLE ___ 120

Tabela 25 Limiares de Dor à Pressão (LDP) pré e pós-PSG nos não-bruxômanos do grupo CONTROLE _ 120

Tabela 26 LDP pós-PSG dos bruxômanos e não-bruxômanos do grupo CONTROLE__ 120

Tabela 27 Correlação de Pearson entre ARMM e LDP pós-PSG nos BRUXÔMANOS DO GRUPO CONTROLE

Tabela 28 Correlação de Pearson entre ARMM e LDP pós-PSG nos NÃO-BRUXÔMANOS DO GRUPO

CONTROLE 122

Tabela 29 LDPs pré e pós-PSG do grupo EXPERIMENTAL __ 123 
Tabela 30 LDPs pré e pós-PSG dos bruxômanos do grupo EXPERIMENTAL 123

Tabela 31 LDPs pré e pós-PSG dos não-bruxômanos do grupo EXPERIMENTAL 124

Tabela 32 LDPs pós-PSG do grupo EXPERIMENTAL (bruxômanos x não-bruxômanos) 124

Tabela 33 Correlação de Pearson ARMM e o LDP pós-PSG nos BRUXÔMANOS DO GRUPO EXPERIMENTAL

Tabela 34 Correlação de Pearson entre ARMM e LDP pós-PSG nos NÃO-BRUXÔMANOS do grupo experimental 126

Tabela 35 Regressão Linear Simples entre ARMM e LDPs pós-PSG 127

Tabela 36 Regressão Linear Simples e Múltipla entre ARMM e LDPs pós-PSG nos grupos EXPERIMENTAL e CONTROLE 129

Tabela 37 Características clínicas dos Bruxômanos com e sem DMF 130

Tabela 38 ARMM entre BRUXÔMANOS dos grupos CONTROLE e EXPERIMENTAL 131

Tabela 39 Variáveis do sono dos BRUXÔMANOS dos grupos CONTROLE e EXPERIMENTAL 131

Tabela 40 Correlação de Pearson entre LDP pré-PSG e ARMM nos BRUXÔMANOS DO GRUPO CONTROLE 132

Tabela 41 Correlação de Pearson entre LDP pré-PSG e ARMM nos NÃO-BRUXÔMANOS DO GRUPO CONTROLE 133

Tabela 42 Correlação de Pearson entre o LDP pré-PSG e ARMM nos BRUXÔMANOS DO GRUPO EXPERIMENTAL

Tabela 43 Correlação de Pearson entre LDP pré-PSG e ARMM nos NÃO-BRUXÔMANOS DO GRUPO EXPERIMENTAL

Tabela 44 Regressão Linear entre os LDPs pré-PSG e variáveis oromotoras dentre as quais houve correlação 135

Tabela 45 Variáveis oromotoras nos bruxômanos do grupo controle (s/DMF) e do grupo experimental com relato de intensidade de dor leve (c/DMF leve) 137

Tabela 46 Correlação de Pearson entre LDP pré-PSG e ARMM e do Grupo CONTROLE 138

Tabela 47 Correlação de Pearson entre LDP pré-PSG e ARMM do Grupo EXPERIMENTAL 138

Tabela 48 Regressão Linear Simples e Múltipla entre LDP pré-PSG e ARMM 139

Tabela 49 Correlação de Pearson entre ARMM e EAV no grupo EXPERIMENTAL__ 140

Tabela 50 Correlação de Pearson entre ARMM e EAV nos não-bruxômanos do grupo EXPERIMENTAL 140

Tabela 51 Correlação de Pearson entre ARMM e EAV nos bruxômanos do grupo EXPERIMENTAL 141

Tabela 52 EAVs pré e pós PSG do grupo EXPERIMENTAL

Tabela 53 Distribuição das concordâncias entre os examinadores 1 e 2 na realização do Exame Clínico de Bruxismo (ECB)

Tabela 54 Distribuição dos diagnósticos clínicos e polissonográficos na amostra total 143

Tabela 55 Distribuição dos diagnósticos clínicos e polissonográficos no grupo CONTROLE 143

Tabela 56 Distribuição dos diagnósticos clínicos e polissonográficos no grupo EXPERIMENTAL 143 Tabela 57 Sensibilidade e Especificidade do ECB 144 
Tabela 58 Confiabilidade do critério da ASDA em relação à PSG

Tabela 59 Valores de contingência, sensibilidade, especificidade, teste de associação** e de kappa de cada uma das questões do ECB

Tabela 60 Confiabilidade do auto-relato e do relato de terceiros na amostra total e nos grupos com e sem DMF 146

Tabela 61 Valores de contingência, sensibilidade e especificidade da Hipótese 1 e Hipótese 2 do ECB 147

Tabela 62 Confiabilidade da resposta SIM ao ECB de 2 ou mais e 3 ou mais perguntas 149

Tabela 63 Combinações de respostas ao ECB com maiores índices de confiabilidade nos grupos com e sem DMF 


\section{LISTA DE ABREVIATURAS E SÍMBOLOS}

$\begin{array}{ll}\text { \% } & \text { Porcentagem } \\ \text { AAOP: } & \text { Analógico/ digital } \\ & \text { American academy of orofacial pain (Academia } \\ \text { AASM } & \text { americana de dor orofacial) } \\ & \text { American academy of sleep medicine (Academia } \\ \text { ARMM: } & \text { americana de medicina do sono) } \\ \text { ASDA: } & \text { Atividade rítmica dos músculos mastigatórios. } \\ \text { B/ epi } & \text { American sleep disorders association (Associação } \\ \text { B/hora: } & \text { americana de desordens do sono) } \\ \text { BS: } & \text { Bursts por episódio } \\ \text { BS-ECB } & \text { Bursts por hora de sono } \\ \text { BS-PSG: } & \text { Bruxismo do sono } \\ \text { Burst/s: } & \text { Bruxismo do sono diagnosticado pelo exame clínico } \\ \text { Cm/ s: } & \text { de bruxismo } \\ \text { CVM: } & \text { Bruxismo diagnosticado pelo critério } \\ \text { dB: } & \text { polissonográfico } \\ \text { DIG } & \text { Burst por segundo } \\ \text { DIGD } & \text { Centímetro por segundo } \\ \text { DIGE } & \text { Contração voluntária máxima } \\ \text { DMF } & \text { Decibel } \\ \text { dp } & \text { Ventre posterior do músculo digástrico } \\ \text { DTM: } & \text { Ventre posterior do músculo digástrico direito } \\ \text { EAV: } & \text { Ventre posterior do músculo digástrico esquerdo } \\ \text { ECG: } & \text { Dor miofascial } \\ & \text { Desvio padrão } \\ & \text { Eisfunção temporomandibular } \\ & \text { Eletrocardiograma } \\ & \end{array}$


EDOF-HC

EEG:

EMG:

EOG:

Epi/hora:

Epi/noite:

FOVM:

GC:

GE:

h

$\mathrm{Hz}$ :

IC

ICSD

$\mathrm{Kgf} / \mathrm{cm}^{2}$

Kgf:

LDP pós-PSG

LDP pré-PSG

LDP:

LPD

LR

LR-

LR+

LTD

MC

MCD

MCE

MD

$\mathrm{MD} / \mathrm{h}$
Equipe de Dor Orofacial - Hospital das Clínicas

Eletroencefalograma

Eletromiográfica ou eletromiografia

Eletrooculograma

Episódios de bruxismo por hora de sono

Episódios de bruxismo por noite

Força oclusal voluntária máxima

Grupo controle

Grupo experimental

Hora

Hertz

Intervalo de confiança

International classification of sleep disorders

(Classificação internacional de desordens do sono)

Quilogramaforça por centímetro quadrado

Quilogramaforça

Limiar de dor à pressão após o exame

polissonográfico (matinal)

Limiar de dor à pressão prévio ao exame

polissonográfico (noturno)

Limiar de dor à pressão

Limiar de percepção à dor

likelihood ratio

likelihood ratio negativo

likelihood ratio positivo

Limiar de tolerância à dor

Corpo do masseter

Corpo do masseter direito

Corpo do masseter esquerdo

Microdespertar

Microdespertares por hora 


\begin{tabular}{ll} 
MI & Inserção do masseter \\
MID & Inserção do masseter direito \\
MIE & Inserção do masseter esquerdo \\
min: & Minuto \\
$\mathrm{ml}:$ & Mililitro \\
$\mathrm{mm}:$ & Milímetro \\
MO & Origem do masseter \\
MOD & Origem do masseter direito \\
MOE & Origem do masseter esquerdo \\
MP & Masseter profundo \\
MPD & Masseter profundo direito \\
MPE & Masseter profundo esquerdo \\
MPM & Movimentos periódicos dos membros \\
Ms: & Milisegundo \\
NBS & Não-bruxômanos \\
Nm: & Newton metro \\
NREM: & Não REM \\
OR & odds ratio \\
PAC & Padrão cíclico alternado \\
PMB: & Placas de medição de bruxismo \\
PSG: & Polissonografia \\
PTERIG & Músculo pterigóideo medial \\
PTERIGD & Músculo pterigóideo medial direito \\
PTERIGE & Músculo pterigóideo medial esquerdo \\
QDM: & Questionário de dor de McGill \\
$r$ & Coeficiente de correlação de Pearson \\
$R$ & Risco \\
$r^{2}$ & Quadrado do coeficiente de correlação de Pearson \\
REM & Rapid eye movement \\
RMS: & Root mean square: (retificação e integração do \\
& sinográfico) \\
\hline &
\end{tabular}




$\begin{array}{ll}\text { RR } & \text { Risco relativo } \\ \text { S/h } & \text { Segundos por hora } \\ \text { S: } & \text { Segundo } \\ \text { SAOS: } & \text { Síndrome da apnéia obstrutiva do sono } \\ \text { SNC: } & \text { Sistema nervoso central } \\ \text { TA } & \text { Músculo temporal anterior } \\ \text { TAD } & \text { Músculo temporal anterior direito } \\ \text { TAE } & \text { Músculo temporal anterior esquerdo } \\ \text { TM } & \text { Músculo temporal médio } \\ \text { TMD } & \text { Músculo temporal médio direito } \\ \text { TME } & \text { Músculo temporal médio esquerdo } \\ \text { TP } & \text { Músculo temporal posterior } \\ \text { TPD } & \text { Músculo temporal posterior direito } \\ \text { TPE } & \text { Músculo temporal posterior esquerdo } \\ \text { TRAP } & \text { Músculo trapézio } \\ \text { TRAPD } & \text { Músculo trapézio direito } \\ \text { TRAPE } & \text { Músculo trapézio esquerdo } \\ \Omega: & \text { Ohm } \\ \alpha: & \text { Alfa } \\ \gamma: & \text { Gama } \\ \mu g: & \text { Micrograma } \\ \mu \mathrm{V} / \mathrm{cm}: & \text { Microvolt por centímetro } \\ \mu \mathrm{V}: & \text { Microvolt }\end{array}$




\section{RESUMO}

Objetivos: Verificar 1) a presença de associação entre bruxismo do sono (BS) e dor miofascial (DMF); 2) se há correlação entre atividade rítmica dos músculos mastigatórios (ARMM) e os valores de limiar de dor à pressão matinais (LDP-pósPSG); 3) se maiores níveis de dor ou sensibilidade à palpação correlacionam-se com menores índices de ARMM em bruxômanos e não bruxômanos com e sem DMF e 4) avaliar a confiabilidade do exame clínico de bruxismo (ECB) Material e Métodos: Após exame clínico de disfunção temporomandibular, para determinação dos grupos, realizaram-se exame PSG (2 noites consecutivas) e ECB em 30 pacientes com DMF e 30 indivíduos assintomáticos, correspondentes em sexo e em idade. Previamente à PSG ( $2^{a}$ noite) verificou-se o LDP (préPSG) da origem, corpo, inserção e porção profunda do masseter e porções anterior, média e posterior do temporal; além da EAV pré-PSG e palpação muscular e articular. Na manhã seguinte, verificou-se o LDP pós-PSG nos mesmos sítios musculares, EAV pós-PSG e palpação articular e muscular. Resultados: Todos os pacientes com DMF apresentaram queixa de dor nos músculos mastigatórios (temporal e/ou masseter), 90\% relataram dor leve ou moderada, com duração média de 34,67 \pm 36,96 meses (2 a 120). Não houve diferenças entre os grupos quanto à macroestrutura do sono. Houve associação significativa entre BS e DMF $[($ Qui-quadrado $=4,27, \mathrm{p}=0,039)$; odds ratio $=3,45($ IC 95\% 1,066 - 11,194) e risco relativo:1,83 e LR+: 1,9. Apenas entre os pacientes de DMF houve correlações negativas entre ARMM e LDP pós-PSG. As correlações foram mais fortes entre os pacientes nãobruxômanos do que nos pacientes bruxômanos. Apenas entre os bruxômanos assintomáticos houve correlações positivas entre LDP pré-PSG e ARMM. Conclusões: 1) Encontrou-se associação significativa entre $\mathrm{BS}$ e DMF; 2) a DMF parece ser fator predisponente à maior sensibilidade matinal à palpação, em função da ARMM; 3) não bruxômanos com DMF parecem responder com maior sensibilidade matinal à palpação, a aumentos na intensidade da ARMM do que bruxômanos com DMF; 4) apenas entre os bruxômanos assintomáticos encontrou-se suporte à ocorrência do mecanismo de adaptação à dor e 5) o ECB apresentou valores distintos de confiabilidade para a população com DMF e assintomática, apresentando valores mais altos na população com DMF, embora não tenha atingido os níveis adequados de sensibilidade $(75 \%)$ e especificidade $(90 \%)$.

Palavras-chave: Bruxismo do sono. Síndromes da dor miofascial. Polissonografia. 



\section{INTRODUÇÃO}




\section{1 - INTRODUÇÃO}

O bruxismo foi definido em 1996, pela Academia Americana de Dor Orofacial, ${ }^{4}$ como uma atividade parafuncional diurna ou noturna, incluindo apertamento ou ranger dos dentes. Já a Academia Americana de Medicina do Sono, ${ }^{6}$ refere-se especificamente ao bruxismoo sono (BS) como uma atividade oral caracterizada por ranger ou apertar de dentes durante o sono, usualmente associada a microdespertares, excluindo, portanto, atividades parafuncionais diurnas (em vigília).

Disfunção temporomandibular (DTM) é um termo genérico empregado a um conjunto de problemas musculoesqueletais do sistema mastigatório. ${ }^{4}$ Por se tratar de um termo genérico, a DTM tem sido atualmente abordada por subtipos ou subgrupos principais: ${ }^{44}$, 88, 89, 125 1) Dor miofascial (DMF) ou DTM miogênica; 2) desarranjos internos da articulação temporomandibular (ATM); 3) artralgia, artrite e artrose e combinações.

O termo DMF adquiriu dois significados, sendo um referente à dor muscular regional de qualquer origem de tecido mole associada à sensibilidade muscular e outro referente à dor miofascial causada por pontos-gatilho (trigger points), os quais consistem em uma hiperritabilidade focal no músculo. ${ }^{145}$ Referente ao primeiro significado, DWORKIN et al. $^{44}$ publicaram os Critérios para Diagnóstico em Pesquisa sobre Disfunções Temporomandibulares (RDC/TMD), os quais definem a DMF como um dos subtipos da DTM, independente da presença de pontos-gatilho. O termo DMF será utilizado neste trabalho, considerando o segundo significado, independente da presença de pontos-gatilho.

A DMF constitui o subgrupo mais enigmático das desordens temporomandibulares (DTM), representando, ao mesmo tempo, a categoria mais prevalente das DTMs (entre 30 e $80 \%$ entre pacientes com dor). ${ }^{105}$ Embora a seqüência de eventos que leva ao desenvolvimento dessas desordens permaneça desconhecida, atributos chave, tais como sensibilidade muscular à palpação, com ou sem limitação de abertura, alteração da percepção da oclusão dental e alterações de humor, são conceitualizadas como conseqüências da dor. ${ }^{149}$ As DTMs musculares não devem ser entendidas como uma entidade única ou 
discreta, ${ }^{129-131,149}$ mas como várias condições relacionadas e, muitas vezes, que se sobrepõem e têm a dor como seu principal sintoma. ${ }^{149}$

A heterogeneidade relacionada à etiologia, progressão e resposta ao tratamento é um dos maiores empecilhos à determinação dos fatores causais, da predisposição individual e do melhor tratamento da DMF. Verificou-se que a presença de dor em outras partes do corpo (comorbidade) pode predizer maior duração ${ }^{130}$ e pior resposta à terapia com placas oclusais. ${ }^{129}$

LASKIN,$^{74}$ em 1969, propôs a teoria psicofisiológica para a etiologia das DTMs, baseada no trabalho de SCHWARTZ, ${ }^{138}$ no qual sugere-se que espasmos musculares são o principal fator para a ocorrência dos sinais e sintomas de DTM. Como se acreditava que a fadiga muscular, devido ao apertamento e ranger de dentes, fosse a principal causa de mioespasmos, LASKIN $^{74}$ hipotetizou então uma condição auto-perpetuante onde um padrão anormal de atividade muscular reforçaria o mioespasmo original e a dor, gerando um ciclo vicioso entre um problema funcional (bruxismo) e uma doença orgânica (DTM). Entretanto, de acordo com MENSE, ${ }^{104}$ não há nenhuma prova experimental de que esse ciclo vicioso de eventos realmente exista. Muito embora a etiologia precisa da DMF ainda não seja conhecida, LOBBEZZO; LAVIGNE ${ }^{90}$ sustentam a hipótese de uma etiologia multifatorial, substanciada pela ação conjunta de fatores estruturais (oclusão, anatomia das articulações temporomandibulares e esqueleto); psicológicos e funcionais (neuromuscular).

Vários estudos desenvolvidos nas últimas décadas com a finalidade de esclarecer a relação existente entre BS e DTM dividem-se em duas correntes principais, a primeira, que acredita no papel etiológico da hiperatividade muscular no desencadeamento de dor e DTM e na existência do ciclo vicioso entre essas entidades; ${ }^{29,74,110,111,136,138,159,169,175}$ e a segunda,

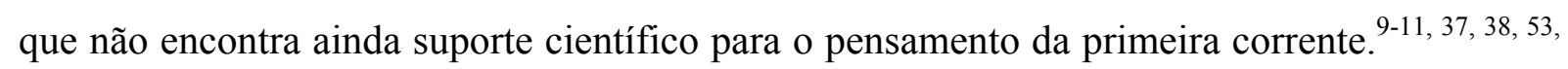
66, 94, 102, 106, 150, 151, 153-155, 157

Outro fator limitante ao esclarecimento dessa questão refere-se à subjetividade inerente ao diagnóstico clínico do BS. ${ }^{90}$ Devido às limitações do auto-relato ${ }^{87}$ e da análise do desgaste dentário ${ }^{139}$ como meios de diagnóstico, a partir da década de 1970 passou-se a utilizar unidades de registro eletromiográfico para a medição da atividade do músculo masseter durante o sono. ${ }^{137}$ Em 1988, RUGH; HARLAN ${ }^{136}$ desenvolveram um sistema de 
escore para a contagem dos eventos eletromiográficos dos músculos mastigatórios no intuito de diferenciar a atividade muscular noturna, como, sonilóquio, deglutição e outras contrações musculares, da atividade de bruxismo. Esse passou a ser o critério mais comumente utilizado nesse tipo de estudo e baseia-se na contagem de bursts eletromiográficos.

A utilização do registro eletromiográfico para o diagnóstico de bruxismo tornouse um método ainda mais objetivo quando aliado ao registro polissonográfico, ${ }^{83}$ por meio do qual é possível identificar as fases do sono, funções motoras e autonômicas, além do recurso audiovisual. ${ }^{165}$

Apesar da evolução no método de diagnóstico do BS, bem como na classificação das DTMs, a literatura ainda não definiu o papel do BS sobre a etiopatogenia das DTMs, mais especificamente sobre a DMF.

* Elevações ou surtos de atividade muscular que, se ocorrem próximos, em seqüência rápida e em número igual ou maior a três, compõem um episódio fásico de bruxismo e, se ocorrem isolados e com duração de 2,0 segundos ou mais, caracterizam um episódio tônico de bruxismo 


\section{2 - REVISTA DA LITERATURA}

\subsection{BRUXISMO DO SONO}

\subsubsection{Diagnóstico}

Em 1974, LIPINSKI; NELSON ${ }^{87}$ avaliaram a reatividade e a confiabilidade do auto-relato e, como objetivo secundário, avaliaram o papel da consciência da verificação da confiabilidade pelos participantes sobre o auto-relato. Dez estudantes foram analisados quanto à confiabilidade do auto-relato do comportamento de toque na face. Os estudantes dividiam-se em dois grupos de cinco. Dois observadores ocultos e dois não ocultos e conhecidos pelos estudantes foram usados para verificar a confiabilidade dos auto-relatos. O estudo foi conduzido por quatro períodos: 1) Período inicial: em que os estudantes foram observados apenas pelos observadores ocultos e não sabiam que estavam participando da pesquisa; 2) período de observação pelos observadores ocultos; 3) período de observação pelos observadores não-ocultos e 4) período de observação em que os estudantes achavam que a pesquisa já havia terminado. Verificou-se redução no número de toques na face quando os estudantes estavam conscientes do seu próprio comportamento, demonstrando a natureza reativa do auto-relato. A confiabilidade entre os observadores ocultos e os estudantes diminuiu quando os estudantes achavam que não estavam sendo observados. Assim, os autores concluíram que, devido à natureza reativa e não confiável do auto-relato, seu papel na coleta de dados é limitada.

Até o início da década de 50 do século XX, quando surgiram os laboratórios de estudo do sono, a atividade de bruxismo ainda não havia sido medida. Nos anos 70 do mesmo século, utilizaram-se as unidades portáteis de registro eletromiográfico desenvolvidas por RUGH; SOLBERG, ${ }^{137}$ em 1975, para registrar a atividade do músculo masseter na própria residência do paciente. Esse dispositivo fornecia o registro elétrico na faixa de $20 \mu \mathrm{V}$ acumulado durante a noite e trouxe novos e importantes dados sobre os níveis de atividade do músculo masseter. A maioria dos estudos que utilizou a unidade eletromiográfica portátil considerou a faixa de $20 \mu \mathrm{V}$ como aquela a partir da qual o paciente apresentaria bruxismo, não registrando índices de contração inferiores, presumindo-se que as mesmas não fariam 
parte determinante do quadro. A maior desvantagem desse método é que níveis de bruxismo segundo a segundo não eram mensurados e não havia a possibilidade de traçar a correlação entre a atividade motora e os estágios do sono. WAGNER, ${ }^{168}$ em 1981, desenvolveu um sistema de registro eletromiográfico portátil, que incluía um amplificador eletromiográfico, um filtro e um integrador. Diferente da unidade portátil de medição cumulativa de RUGH; SOLBERG, ${ }^{137}$ o bruxismo foi definido como uma atividade superior a $5 \mu \mathrm{V}$ (média integral). O autor também determinou que deveria haver no mínimo 3 segundos de silêncio no registro eletromiográfico para separar os episódios de bruxismo.

Em 1982, PICCIONE et al. ${ }^{120}$ definiram os eventos de bruxismo usando critérios de amplitude, ritmo e duração da atividade eletromiográfica, no músculo masseter, a partir de registros poligráficos. Eles propuseram que os eventos de bruxismo estariam presentes apenas se a amplitude eletromiográfica excedesse $20 \mu \mathrm{V}$ e se a atividade eletromiográfica permanecesse nesse nível por, no mínimo, 0,5 segundo e, no máximo, 1,5 segundo. Os eventos deveriam ocorrer em uma série de duas ou mais contrações separadas por, no máximo, 2,5 segundos.

Em 1983, STOCK; CLARKE ${ }^{148}$ descreveram um sistema de detecção de bruxismo, que consistia em um dispositivo de registro eletromiográfico, um conversor analógico/digital, um microprocessador e um gravador de fita cassete. Os eventos de bruxismo eram selecionados automaticamente se os mesmos satisfizessem os seguintes critérios: 1) os surtos deveriam ser maiores do que o quarto menor bit significativo de um amplificador de 8 bits, cujo ganho foi ajustado para não disparar com movimentos orofaciais ordinários; 2) os surtos deveriam durar 2 segundos ou mais e 3) intervalos de duração iguais ou inferiores a 1 segundo entre os surtos eram unidos e isso caracterizava um evento.

RUGH; HARLAN, ${ }^{136}$ em 1988, esclareceram que o bruxismo noturno e o diurno são duas entidades diferentes, ocorrendo em diferentes estágios de consciência, com diferentes etiologias e que requereriam diferentes modalidades de tratamento. Segundo eles, o BS não apresentaria finalidade funcional, podendo levar a condições patológicas, incluindo DTM, desgaste dental, dor periodontal, hipertrofia dos músculos mastigatórios e dores de cabeça. Afirmaram ainda que, embora os episódios de BS pareçam ocorrer no estágio 2 do 
sono NREM e durante atividades de microdespertar, os episódios que ocorrem durante o sono REM podem ser mais danosos às estruturas orais.

Em 1988, WARE; RUGH ${ }^{169}$ desenvolveram um sistema de escore de bruxismo com a finalidade de analisá-los e relacioná-los aos episódios de microdespertar. Caracterizouse como um episódio de bruxismo fásico aquele onde pelo menos três bursts eletromiográficos encontravam-se separados por dois intervalos (2 intervalos eram necessários para caracterizar um ritmo). Cada burst fásico deveria durar de 0,25 a 2 segundos. Se um episódio apresentasse um burst com duração superior a 2 segundos, o mesmo era caracterizado como tônico. Os episódios deveriam ser separados por um intervalo maior que 3 segundos. Se um conjunto de bursts fásicos (caracterizando um episódio fásico) estivesse a uma distância igual ou menor que $3 \mathrm{seg}$ de um ou mais bursts tônicos (episódio tônico), ele seria considerado um único episódio misto. O sinal eletromiográfico (EMG) deveria ser maior que $75 \mu \mathrm{V}$ ou o dobro da atividade de base. Os autores hipotetizaram ainda, que não bastaria a presença de bruxismo durante o sono para causar sintomatologia dolorosa no sistema mastigatório, mas que seu padrão e relacionamento com os estágios do sono eram os fatores que afetariam os sintomas clínicos. Os resultados indicaram que os pacientes com severa sintomatologia atribuída à atividade de BS apresentaram mais atividade na fase REM do que os outros grupos.

PIERCE; GALE, ${ }^{122}$ em 1989, realizaram o monitoramento do sono, na residência de 100 pacientes com atividade de bruxismo, por meio de uma unidade modificada de medição eletromiográfica e placas interoclusais para a medição do bruxismo. O estudo demonstrou que as placas podem influenciar a atividade de bruxismo, uma vez que no grupo que a utilizou houve uma redução da atividade eletromiográfica em relação ao grupo sem placas. Verificou-se também baixa correlação entre a quantidade de desgaste das placas e a atividade eletromiográfica (EMG) dos grupos, discordância atribuída ao fato de as placas registrarem apenas atividade de ranger de dentes, e não de apertamento.

OKESON et al., ${ }^{117}$ em 1990, definiram um evento de bruxismo como a atividade do músculo masseter que excedesse $40 \%$ da força de apertamento máximo, com duração maior ou igual a 2 segundos. 
O diagnóstico clínico do BS é complicado por sua flutuação com o tempo e da não confiabilidade dos relatos de ranger de dentes. O bruxismo pode ainda ser confundido com muitos outros movimentos orofaciais realizados durante o sono, tais como os relacionados à movimentação do corpo, deglutição, abertura e fechamento da boca, contraturas faciais, contrações mioclônicas, movimentos de mastigação e sonilóquio. No intuito de precisar o diagnóstico de atividade de bruxismo, VELLY-MIGUEL et al., ${ }^{165} \mathrm{em}$ 1992, realizaram exames polissonográficos de bruxômanos por meio dos quais foi possível diferenciar o BS das demais atividades orais motoras. Observou-se que os bruxômanos apresentaram numerosos tipos de movimentos orofaciais, os quais poderiam ser facilmente confundidos com bruxismo. Isso ressalta a importância dos estudos poligráficos do sono, acompanhados de monitoramento audiovisual, nos estudos da atividade de bruxismo

MARCEL et al., ${ }^{101}$ em 1995, examinaram, por meio de espectroscopia de ressonância magnética ( $\left.{ }^{31} \mathrm{P}-\mathrm{NMR}\right)$, os músculos masseteres de 6 bruxômanos (4 homens e 2 mulheres) e 6 não-bruxômanos (5 homens e 1 mulher) durante a mastigação. Durante a mastigação, os indivíduos com bruxismo apresentaram um aumento significativamente inferior do fosfato inorgânico em relação aos não bruxômanos. Os níveis de $\mathrm{pH}$ durante o repouso e durante a mastigação foram similares para ambos os grupos. Esses resultados preliminares sugerem que os indivíduos com bruxismo possuem o metabolismo do fosfato alterado durante o repouso e mastigação, quando comparados aos indivíduos sem bruxismo.

Em 1995, SELIGMAN; PULLINGER ${ }^{139}$ concluíram, em seu estudo sobre atrição dental na sociedade moderna que, além de atividade parafuncional, uma parte significativa do desgaste dentário observado é atribuída a fatores tais como idade e geometria das relações de contatos oclusais.

IKEDA et al., ${ }^{61}$ em 1996, realizaram um estudo, em que nove indivíduos (5 homens e 4 mulheres) realizaram exame polissonográfico por 4 noites consecutivas em ambiente domiciliar. Os autores relataram que a natureza variável do bruxismo muitas vezes resultou em registros improdutivos durante as duas primeiras noites e que houve um pequeno, mas consistente aumento no nível de bruxismo ao longo das 4 noites estudadas. Uma vez que $20 \%$, e mais seguramente, $40 \%$ tratam-se de valores elevados para serem utilizados como limites mínimos de detecção de eventos de bruxismo - em particular se se utiliza o método de 
média eletromiográfica integral suavizada - elegeu-se o valor de $10 \%$ da contração voluntária máxima para essa finalidade. Os autores sugeriram uma associação de critérios para a detecção de eventos de bruxismo, dentre eles: 1) o intervalo mínimo entre episódios de 5 segundos; 2) a eliminação de quaisquer elevações eletromiográficas de duração inferior a 3 segundos, com o objetivo de excluir artefatos ou mioclonia e 3) uma alteração na freqüência cardíaca maior do que 5\% durante o evento eletromiográfico.

LAVIGNE; ROMPRÉ; MONTPLAISIR ${ }^{83}$ em 1996, enfatizaram a necessidade de diferenciação entre as atividades oromotoras distintas de bruxismo, por meio do registro áudio-visual concomitante ao registro polissonográfico de uma noite inteira de sono. Tantos requisitos necessários a uma análise desse porte inviabilizam sua realização em ambiente ambulatorial (em casa). Com o objetivo de validar a PSG com relação aos critérios da ASDA, os autores propuseram-se a: 1) caracterizar as variáveis motoras orofaciais durante o sono de pacientes com bruxismo definido clinicamente e compará-las àquelas apresentadas por uma população assintomática; 2) estabelecer valores limítrofes de atividade EMG indicadora de bruxismo durante o sono e 3) testar a sensibilidade e a especificidade desses valores limítrofes no diagnóstico do BS. Para isso, foram selecionados 18 indivíduos com bruxismo e 18 indivíduos sem bruxismo, distribuídos eqüitativamente em idade (20 a 45 anos) e sexo. Para o grupo experimental, os autores utilizaram os seguintes critérios de inclusão: idade entre 20 e 45 anos, ter apresentado, nos últimos 6 meses, em pelo menos 5 noites por semana, sons de ranger de dentes durante o sono; e um ou mais dos seguintes critérios subjetivos: desgaste dentário ou pontos brilhantes nas restaurações metálicas; relato de fadiga ou dor nos músculos mastigatórios ao acordar ou hipertrofia do músculo masseter. Os critérios de exclusão eram: ausência de dois ou mais dentes (excluindo-se os terceiros molares); utilização de prótese dental; presença de má-oclusão grosseira; uso de medicação com possíveis efeitos sobre a atividade motora durante o sono, estar sob tratamento dentário ou físico, apresentar grandes desordens neurológicas ou psiquiátricas e outras desordens do sono. Para o grupo controle, os autores utilizaram como critérios de inclusão: indivíduos de ambos os sexos, distribuídos de maneira o mais similar possível ao grupo experimental e, como critérios de exclusão, os mesmos utilizados para o grupo experimental, adicionando-se a apresentação de qualquer sinal ou sintoma sugestivo da presença de bruxismo. A polissonografia foi realizada por duas noites seguidas em laboratório. A primeira noite tinha por finalidade permitir a adaptação do 
paciente ao ambiente e captar o padrão de outras desordens do sono. Somente na segunda noite era realizada a coleta dos dados experimentais. Como resultados, os autores verificaram que a polissonografia e o registro áudio-visual confirmaram uma atividade motora orofacial durante o sono significativamente maior nos pacientes com bruxismo do que nos indivíduos do grupo controle. Os dados demonstraram que os indivíduos do grupo experimental exibiram três vezes mais episódios de bruxismo por noite e seis vezes mais bursts de bruxismo por hora. Como divergências entre as manifestações laboratoriais durante a PSG e os dados fornecidos pelo exame clínico, verificou-se que, ao exame clínico, todos os pacientes do GE manifestavam ruídos típicos de ranger de dentes enquanto nenhum dos indivíduos do GC o fazia. Já durante o sono no laboratório, quatro indivíduos do GE não manifestaram tais sons e 1 indivíduo do grupo controle o fez em 5 episódios. Apesar da divergência, houve diferença estatisticamente significativa para a manifestação de episódios de bruxismo acompanhados de sons de ranger de dentes entre os grupos experimental e controle. Os autores elaboraram os seguintes critérios para se utilizar uma PSG como exame de diagnóstico de BS: pelo menos 2 episódios de ARMM com sons de ranger de dentes, por noite, seguido de 1 ou mais dos seguintes critérios: mais de 4 episódios de ARMM por hora de sono; mais de 5 bursts eletromiográficos por episódio de ARMM ou mais de 25 bursts eletromiográficos por hora de sono. A maioria dos episódios de BS ocorreu durante os estágios 1 e 2 do sono não REM (NREM).Verificou-se também que há, durante o sono tanto de indivíduos normais quanto de indivíduos portadores de BS (BS), episódios de ARMM; sendo, a freqüência dos eventos o fator de diferenciação dos grupos.

Apesar da obscuridade que permeia os conhecimentos sobre a etiopatogenia do BS, REIMÃO, ${ }^{133}$ em 1996, considerou as seguintes hipóteses: 1) hipótese da alteração primária do sono, como conseqüência de distúrbio inespecífico, frente a estímulos de ativação. Essa hipótese apóia-se na observação da deflagração imediata do bruxismo em resposta a estímulos externos, auditivos, visuais e tácteis, a qual é acompanhada do aparecimento de características de microdespertar no registro polissonográfico; 2) hipótese relacionada a fatores emocionais e/ou de estresse como desencadeadores e 3) hipótese relacionada a fatores oclusais. O autor relata ainda que a maioria dos episódios de BS ocorre durante os estágios 1 e 2 do sono NREM, primariamente no estágio 2 e, em menor grau, no estágio 1 e transição entre estágios do sono NREM. 
BADER, et al., ${ }^{14}$ em 1997 relatam que em cerca de 1/4 dos eventos de BS há movimento corpóreo brusco acompanhado de episódios de ranger de dentes e aumento da freqüência cardíaca, embora de curta duração, ou seja, restrito ao período do bruxismo.

A ACADEMIA AMERICANA DE DESORDENS DO SONO, ${ }^{7}$ em 1997, atualizou a Classificação Internacional de Desordens do Sono (International Classification of Sleep Disorders - ICSD) e estabeleceu critérios de diagnóstico para cada uma delas. O BS foi definido como uma desordem de movimentos estereotipados caracterizada por apertar ou ranger de dentes durante o sono. Os sons de fricção dos dentes são geralmente percebidos como desagradáveis pelo companheiro de quarto. A queixa mais comum relacionada ao BS relaciona-se aos ruídos, embora, os primeiros sinais possam ser reconhecidos pelo dentista. $\mathrm{O}$ bruxismo pode levar ao desgaste anormal dos dentes, dano periodontal ou dor facial. $\mathrm{O}$ bruxismo também pode ocorrer durante a vigília. Entretanto o BS e o bruxismo diurno parecem ser fenômenos etiologicamente diferentes com efeitos similares sobre a dentição. Chama-se a atenção para a variabilidade do bruxismo, devido a qual, podem ser necessárias duas noites de registro PSG para a demonstração da desordem. Acrescenta-se ainda que, mesmo duas noites de avaliação podem produzir resultados falso-negativos, por que, mesmo em pacientes com condições clínicas significativas o bruxismo pode não ocorrer durante muitas noites. A $\mathrm{ASDA}^{7}$ estabeleceu como critério de diagnóstico do BS:

A) Queixa de ranger ou apertar os dentes durante o sono

B) Um ou mais dos seguintes critérios:

1) Desgaste dentário anormal

2) Sons associados com bruxismo

3) Desconforto nos músculos mandibulares

C. O monitoramento polissonográfico demonstra as seguintes características:

1) Atividade dos músculos mandibulares durante o sono

2) Ausência de atividade epilética associada 
D. Ausência de outra desordem médica ou mental (ex.: epilepsia relacionada ao sono, desordens de movimento durante o sono).

E. Outras desordens do sono (ex. síndrome da apnéia obstrutiva do sono (SAOS), pode estar presente).

A $\operatorname{ASDA}^{7}$ estabelece como critério mínimo de diagnóstico os itens A mais B.

Os achados polissonográficos e estudos clínicos de LAVIGNE et al., ${ }^{82}$ em 1997, têm relacionado o BS ao campo das desordens do sono e a fatores que indicam sua superficialização, tais como a presença dos complexos K no traçado eletroencefalográfico, atividade rápida e transitória das pernas e do corpo, pequenos aumentos na freqüência cardíaca e elevação do estágio do sono para estágios mais superficiais (1 e 2).

MACALUSO et al., ${ }^{95}$ em 1998 estudaram, por meio de registro polissonográfico, a ocorrência e as características do BS em 6 bruxômanos ( 2 mulheres e 4 homens) e 6 nãobruxômanos, correspondentes em idade. Os grupos não apresentaram diferenças significativas entre as variáveis do sono, mas os bruxômanos mostraram um número significativamente maior de microdespertares, caracterizados por dessincronização ao EEG. Os episódios de bruxismo foram igualmente distribuídos entre as fases REM e NREM do sono, embora fossem mais freqüentes nos estágios 1 e 2 ( $p<0,0001)$ do que nos estágios profundos $(3$ e 4$)$ do sono NREM. A grande maioria dos episódios de bruxismo detectada durante o sono NREM (88\%) estava associada ao padrão de mudança de estágio cíclica do sono e sempre ocorria durante um microdespertar. A freqüência cardíaca durante os episódios de bruxismo $(69,3 \pm 18,2)$ foi significativamente maior $(\mathrm{p}<0,0001)$ do que durante o período pré episódio $(58,1 \pm 15,9)$. Quase $80 \%$ de todos os episódios de bruxismo estavam associados com espasmos dos músculos tibiais anteriores.

Embora muitas vezes tenha-se creditado ao bruxismo um importante papel na etiologia da DTM, ainda não havia sido registrada a atividade dos músculos mastigatórios em relação à posição mandibular durante a atividade de BS. Com essa finalidade, em 1998, MINAGI et al. ${ }^{108}$ realizaram EMG bilateral de superfície dos músculos masseter, concomitantemente ao registro da posição mandibular durante o sono. Observou-se marcante predominância de atividade do músculo masseter do lado de não-trabalho durante o ranger de 
dentes noturno. Durante o BS, os bursts eletromiográficos do músculo masseter foram observados principalmente com o movimento mandibular mediotrusivo, a partir da posição de topo-a-topo do canino. Os resultados sugeriram que a dinâmica muscular durante o sono é única, quando comparada aos movimentos de apertamento diurno e exerce uma maior carga mecânica na ATM do lado de não-trabalho.

KATO et al., ${ }^{69}$ 2001. referenciam a classificação do bruxismo em duas formas, primária (idiopática) e secundária (iatrogênica). Na ausência de história médica iniciadora do bruxismo, tem-se a forma primária (bruxismo diurno ou noturno). A forma secundária do encontra-se associada a outras desordens neurológicas, psiquiátricas ou do sono, podendo, ainda, ocorrer em decorrência da administração de algumas drogas.

KATO et al., ${ }^{68}$ em 2001 verificaram que os bruxômanos apresentaram um número de episódios de ARMM por hora de sono 8 vezes maior do que os não bruxômanos; a incidência de eventos de microdespertar não diferiu entre os grupos; não houve diferença entre os grupos quanto à duração dos episódios ou à porcentagem de episódios relacionados à mudança de estágio do sono ou à atividade motora dos músculos esternocleidomastóideo e/ou tibial anterior; as diferenças apresentadas no EEG só se mostraram evidentes entre os grupos nos 4 segundos imediatamente anteriores ao início do episódio de ARMM, onde foi observado um aumento significativo na amplitude tanto das ondas alfa quanto delta nos bruxômanos. Ao ECG verificou-se um pequeno, mas significativo aumento na freqüência cardíaca dos bruxômanos durante os 10 batimentos cardíacos anteriores ao início do episódio e 1 ciclo cardíaco antes ocorreu um significativo aumento na freqüência cardíaca, embora durante e após a ARMM, nos não bruxômanos, também tenha ocorrido um aumento significativo na freqüência cardíaca. Assim, neste estudo verificou-se que os episódios de ARMM nos pacientes com BS foram claramente precedidos primeiramente por mudanças corticais ao EEG e depois por um aumento da freqüência cardíaca. Nos pacientes de ambos os grupos os episódios de ARMM também se associavam à atividade motora do pescoço e das pernas. Assim, os autores constataram: 1) um aumento da atividade alfa, ao EEG, em 50\% dos episódios de ranger de dentes e 2) um aumento da freqüência cardíaca entre 10 e $27 \%$ dos episódios de bruxismo iniciando-se antes ou concomitante ao início do mesmo. Também foi demonstrado que 70 a $80 \%$ dos episódios de ARMM foram precedidos por atividade dos 
músculos supra-hioídeos, o que confirma a informação de que a ativação desses músculos é um sinal eletromiográfico clássico de ativação do sono, confirmando-se que a ativação eletroencefalográfica (por exemplo, a intrusão de ondas alfa) precede a ARMM. Entretanto, a eficiência do sono e o número de microdespertares e despertares por hora de sono dos pacientes com BS foram similares aos dos pacientes normais. Os autores concluíram que a ARMM durante o sono dos pacientes com BS é uma resposta oromotora potencializada, associada a fenômenos espontâneos de microdespertar e que $60 \%$ dos não bruxômanos exibiram ARMM sem ranger de dentes durante a noite.

LAVIGNE et al., ${ }^{85}$ no mesmo ano, com o objetivo de avaliar a freqüência da ARMM em indivíduos com e sem BS, realizaram uma avaliação por meio de PSG, em apenas uma noite, de 82 não bruxômanos (44 mulheres e 38 homens, com idade média de 40,0 \pm 1,5 anos) e 33 bruxômanos. (15 mulheres e 18 homens, com idade média de 26,8 $\pm 1,0$ anos). Observou-se que os episódios de ARMM também ocorreram em aproximadamente $60 \%$ dos não bruxômanos, embora com menor freqüência do que nos não-bruxômanos. Os grupos não diferiram quanto à organização do sono. Os bruxômanos apresentaram duas vezes mais bursts por episódio e episódios com maior amplitude em relação aos não-bruxômanos com ARMM. O número de epi/hora e de $\mathrm{MD} /$ hora dos bruxômanos foi significativamente maior do que dos não bruxômanos com ARMM. Os bruxômanos também apresentaram mais bursts/s dentro dos episódios, mas os não bruxômanos apresentaram bursts mais longos $(p=0,009)$. Em ambos os grupos, a ARMM do músculo masseter estava sempre associada à ativação dos músculos supra-hióideos, sendo que esta ocorria em média $804 \mathrm{~ms}$ antes da ativação dos músculos masseteres. Essa alta prevalência de ARMM observada em indivíduos normais sugere que essa atividade relaciona-se a certas funções fisiológicas, incluindo ativação autonômica.

NISHIGAWA; BANDO; NAKANO, ${ }^{114}$ em 2001, mediram a força de mordida associada ao BS em 10 indivíduos por meio de dispositivos intra-orais de acrílico munidos de transdutores em miniatura aferidores de tensão. A amplitude média dos eventos de bruxismo foi de $22,5 \mathrm{Kgf} \pm 13,0$, com duração média de 7,1s $\pm 5,3$. A amplitude média de força de mordida máxima, durante o sono, foi $42,3 \mathrm{Kgf}(15,6-81,2 \mathrm{Kgf})$. A força de mordida voluntária máxima durante a vigília foi $79,0 \mathrm{Kgf}(51,8$ a 99,7Kgf) e a proporção média de 
força máxima de mordida noturna/diurna foi de 53,1\%. Esses dados indicam que a força de mordida durante o BS pode exceder a amplitude da força de mordida voluntária máxima durante a vigília. 


\subsubsection{Epidemiologia}

Em 1981, GLAROS ${ }^{46}$ estimou por meio de questionário, em uma amostra de 1052 estudantes (19 anos de idade em média, correspondentes em sexo), a prevalência do bruxismo exclusivamente diurno, como atividade presente $(13,4 \%)$ ou passada $(12,0 \%)$; bruxismo exclusivamente noturno, como atividade presente $(3,3 \%)$ ou passada $(6,6 \%)$ e atividade de bruxismo noturno e diurno presente $(4,5 \%)$ ou passada $(4,8 \%)$.

HARTMANN,${ }^{58}$ em 1994, lembrou que as estimativas de incidência de bruxismo dependem de como a questão é feita e de quem a responde. Muitos bruxômanos desconhecem sua própria condição; assim, baixas estimativas são obtidas quando os indivíduos simplesmente respondem se têm ou não bruxismo. O autor relata que parece haver uma distribuição eqüitativa entre os sexos e uma maior incidência em crianças e adultos jovens, sendo bem menos comum a partir dos 40 anos. O autor descreve um curso de evolução típico que envolve o início na adolescência, assumindo um curso que flutua de acordo com períodos de maior ou menor emocional e diminui gradualmente após os 40 anos. O bruxismo na infância parece tratar-se de uma entidade separada.

LAVIGNE; MONTPLAISIR, ${ }^{80}$ em 1994, estimaram a prevalência do bruxismo por meio de entrevista realizada com 2019 pessoas. A prevalência diminuiu de 13\%, na faixa etária entre 18 e 29 anos, para 3\%, na população com idade igual ou superior a 60 anos. Não se notou diferença na prevalência entre os sexos. O relato de ranger de dentes ocorreu em $8 \%$ da população geral. Os autores comentam que a prevalência de outras atividades oro-motoras (atividade rítmica ou movimentos de mastigação durante o sono) também reduz-se de forma significativa com a idade.

WILDMALM et al. ${ }^{171}$ relataram, em 1995 , a prevalência de $20 \%$ de bruxismo em crianças brancas e negras de 4 a 6 anos de idade e reconheceram que uma associação significativa não prova a existência da relação causa-e-efeito, mas pode atuar como possível fator de risco. 
Na população em geral, MIGRAINE et al., ${ }^{107}$ em 1996, observaram, por meio de questionário enviado às mães de 2000 crianças de 11 anos de idade de Quebec, que a prevalência de bruxismo foi de aproximadamente $14,1 \%$ 


\subsubsection{Etiopatogenia}

Em 1987, HICKS; CHANCELLOR ${ }^{59}$ calcularam a incidência do auto relato de BS em uma população de 127 estudantes dividida em dois grupos de tipos de personalidade (Tipo A e Tipo B). Os autores explicam que Em contraste com o Tipo B, as pessoas com comportamento Tipo A caracterizam-se por um senso exagerado de urgência, o qual frequentemente resulta em pensamento pré-programado, um constante esforço por conseguir o que amenize um estado de insegurança crônica e altos níveis de agressividade, que podem evoluir para hostilidade crônica. Empregou-se para a análise a versão de Glass do Teste de Atividade de Jenkins e um questionário de saúde. Os autores encontraram associação significativa entre auto-relato de BS e comportamento tipo A. e concluíram que aparentemente, os relacionamentos entre estresse, personalidade e bruxismo são uma via potencialmente frutífera para pesquisas subseqüentes.

PIERCE et al., ${ }^{121}$ em 1995, examinaram 1) os relacionamentos entre atividade eletromiográfica de BS, auto-relato de estresse e variáveis de personalidade e 2) o relacionamento entre a crença no relacionamento estresse-bruxismo e o auto-relato de estresse. Cem adultos completaram uma bateria de questionários de personalidade (instrumentos psicométricos padronizados: 1) Taylor Manifest Anxiety Scale e Profile of Mood State, 2) Pilowsky Depression Scale e Profile of Mood State; 3) Illness Behavior Questionnaire e 4) Multidimensional Health Lócus of Control Scales. Também indicaram se acreditavam no relacionamento estresse-bruxismo, foram submetidos a um exame odontológico e moldagens das arcadas dentárias. Subsequentemente, foram realizadas medições eletromiográficas $(\mathrm{EMF})$ da freqüência e duração do BS durante 15 noites consecutivas. Previamente ao registro de cada noite, os indivíduos indicavam seu nível de estresse durante as 24 horas precedentes em uma escala de Likert de 1 a 5 , onde 1 indicava nenhum estresse e 5 representava o maior nível de estresse possível. Os autores não encontraram nenhum relacionamento entre as medições EMG e as variáveis de personalidade, nem entre as medições EMG e o auto-relato de estresse. Houve correlação estatisticamente significativa entre as medições EMG e o auto-relato de estresse para oito indivíduos. Ainda, indivíduos com maiores níveis de estresse, relataram maior ansiedade, irritabilidade e depressão e menor comportamento de negação. Indivíduos que relataram acreditar no 
relacionamento estresse-bruxismo relataram maior estresse. Apesar disso houve relacionamento significativo entre diversas variáveis de personalidade e auto-relato de estresse. Ou seja, indivíduos com relato de autos níveis de estresse eram mais prováveis de relatar altos níveis de ansiedade, irritabilidade e depressão, enquanto aqueles que relatavam menores níveis de estresse eram mais prováveis de relatar altos índices de negação. Os autores discutem que altos níveis de atividade de bruxismo podem estar relacionados à menor consciência acerca dos eventos estressantes da vida (maior negação). Notou-se que os bruxômanos que indicaram menores níveis de estresse também eram mais propensos a relatar altos níveis de negação. Os autores lembram que dados independentes de outro estudo suportam a idéia de que os bruxômanos mais frequentemente negam sintomas do que a população geral. Os autores lembram que os resultados não significam que a atividade de BS não se relaciona ao estresse, mas que bruxômanos podem não ser muito conscientes da natureza estressante dos eventos diários e ou que eles minimizam o impacto pessoal desse eventos. Faz-se também referencia ao comportamento Tipo A (definido em termos gerais como um estilo de atitude (coping style) caracterizado pelo desejo extremo de controle dos eventos da vida). Daí, hipotetiza-se que uma vez que, em decorrência da impossibilidade de controle desses eventos pelo individuo, o mesmo passa por períodos de extremo estresse que, poderia manifestar-se como BS. Que, em sua constante busca por controle, os indivíduos Tipo A são evidentemente inconscientes, ignoram ou negam, seu estresse induzido pelo seu estilo de atitude. Os autores completam que, a existência do baixo nível de consciência do estresse dos bruxômanos Tipo A pode suportar os achados de que os mais altos índices de negação associaram-se, embora fracamente, com menores níveis de percepção de estresse.

Em 1996, LOBBEZOO et al. $^{92}$ investigaram o envolvimento do sistema dopaminérgico na patofisiologia do BS. Realizaram-se tomografias computadorizadas funcionais dos receptores dopaminérgicos D2 de 10 bruxômanos e 10 indivíduos controle (bruxismo verificado por PSG). A injeção intravenosa de um antagonista radioligante específico dos receptores D2 (iodine-123-iodobenzamine) foi realizadas 90 min antes da aquisição dos dados. Observou-se que o potencial de ligação aos receptores D2 estriatais (proporção gânglio basal/fundo) não diferiu significativamente entre os grupos. Entretanto houve maior diferença entre os hemisférios do potencial de ligação aos receptores D2 estriatais (valores resultados da diferença lado com maior ligação menos lado com menor 
ligação) no grupo de bruxômanos $(\mathrm{p}<0,001)$. Concluiu-se que um desequilíbrio anormal inter-hemisférios na expressão dos receptores D2 estriatais pode estar associado ao BS.

BADER; LAVIGNE, ${ }^{13}$ em 2000, lembram que devido à freqüente inconsciência do hábito de BS, a prevalência do mesmo é difícil de ser estimada. Relatam que sua prevalência não difere entre os sexos e que é mais freqüente entre os jovens e tende a reduzir com a idade. Os sintomas reconhecidos na infância podem persistir na idade adulta. Sobre sua etiopatogenia, lembram que o BS pode estar associado a interferências oclusais, fatores psicológicos e ambientais, neurotransmissores e disfunção dos gânglios basais. Relatam que o BS pode estar associado a traços de personalidade, como ansiedade ou vulnerabilidade ao estresse, embora esse assunto seja ainda controverso.

LAVIGNE et al., ${ }^{78}$ em 2001, verificaram a variabilidade do BS em 9 bruxômanos moderados e graves. Obtiveram-se os coeficientes de variação de 25,3\% para episódios/hora; $30,4 \%$ para bursts/hora e 53,5\% para episódios com sons de ranger. Com base nesses valores de variabilidade, concluiu-se que o diagnóstico de BS permanece relativamente constante com o tempo em indivíduos com bruxismo moderado a grave.

No mesmo ano, LOBBEZOO; NAEIJE ${ }^{91}$ revisaram os fatores periféricos e centrais possivelmente envolvidos na etiologia do BS. Observam que, a despeito do importante papel atribuído no passado a fatores periféricos, tais como características morfológicas, discrepâncias oclusais e anatomia das estruturas ósseas da região orofacial, atualmente os mesmos assumem apenas um papel secundário. Relatam as evidências de que o BS faça parte de uma resposta de despertar do sono. Além disso, o BS parece ser modulado por vários neurotransmissores centrais, relacionados mais especificamente ao sistema dopaminérgico. Acrescentam que outros fatores como fumo, álcool, drogas, doenças e trauma podem estar envolvidos na etiologia do bruxismo. Apesar da freqüente menção feita aos fatores psicológicos em relação ao $\mathrm{BS}$, as pesquisas recentes trazem resultados conflitantes e indicam a realização de mais estudos sobre esse assunto. Concluem que o bruxismo parece ser regulado principalmente por fatores centrais, e não periféricos.

Em 2002, LAVIGNE et al. ${ }^{81}$ observaram, por meio de PSG, que bruxômanos apresentaram $42,7 \%$ menos complexos $\mathrm{K}$ por hora no estágio 2 do sono que não-bruxômanos. 
A ausência de outras diferenças na microestrutura do sono e nas variáveis do sono delta suporta a noção de que os bruxômanos possuem boa qualidade de sono. Os autores não encontraram maior incidência de microdespertares entre os bruxômanos.

Em 2003, CARLSSON; EGERMARK; MAGNUSSON ${ }^{22}$ publicaram os resultados de um estudo longitudinal de 20 anos sobre fatores de predição de bruxismo. Originalmente 402 indivíduos de 7, 11 e 15 anos de idade foram examinados clinicamente (questionário e exame físico). Vinte anos depois do exame inicial, 85\% foram reavaliados. $\mathrm{O}$ hábito de bruxismo foi definido pelos relatos das crianças de apertar de dentes durante o dia ou ranger à noite. Os relatos de apertamento, ranger à noite, roer unhas e/ou outra parafunção foram fatores de predição da mesma parafunção 20 anos depois. O relato de bruxismo e sintomas de DTM no exame inicial foram fatores de predição estatisticamente significante. $\mathrm{O}$ odds ratio de 3,1 sugere que houve aproximadamente 3 vezes mais chance e uma pessoa que relatou bruxismo no primeiro exame fazê-lo 20 anos depois. Todos os indivíduos que relataram bruxismo freqüente e $75 \%$ dos que relataram bruxismo ocasional no primeiro exame o fizeram novamente 20 anos depois. Os fatores de predição do ranger de dentes à noite foram 5: Dentre os quais, 2 foram estatisticamente significativos: apertamento (o mais forte) e índice de disfunção. Para o ranger de dentes à noite, foram encontrados 2 fatores de predição significativos: apertamento à noite e índice de desgaste dentário. Os autores concluíram o fato de o apertamento diurno e o ranger de dentes à noite apresentar diferentes fatores de predição reforçam a evidência de os mesmos sejam entidades distintas.

Em uma revisão sobre aspectos neurobiológicos do BS, LAVIGNE et al. ${ }^{79}$ (2003) discutiram os mecanismos envolvidos na gênese dos movimentos rítmicos dos músculos mastigatórios (MRMM) e suas interações com a fisiologia do sono. O estudo revisa os seguintes aspectos: A prevalência do bruxismo diurno (BD) e do sono na população geral é de $60 \%$ e $80 \%$, respectivamente). As queixas de ranger de dentes durante o sono reduzem-se com o tempo, de $14 \%$ nas crianças para $8 \%$ nos adultos e 3\% em indivíduos acima de 60 anos de idade. Em casos de BS freqüente e severo, a variação do número de epi/h é $25 \%$ e a variação da freqüência de ranger de dentes é de 53,5\%. Sobre o diagnóstico, desgaste dentário e auto-relato de rigidez ou desconforto e dor muscular são considerados menos confiáveis e, para finalidade de pesquisa, indica-se o registro poligráfico e audiovisual em ambiente 
laboratorial (a polissonografia - PSG). Mais de 88\% dos episódios de BS são do tipo fásico ou misto. A atividade muscular de BS ocorre principalmente durante o sono leve (60-80\%) a uma freqüência média de 5,4 a 5,8 epi/h. Sessenta por cento dos não bruxômanos apresentam alguma ARMM, com freqüência de 1,8 epi/h. Com relação ao sono, explicam que o termo "fragmentação do sono" é usado quando ocorre uma elevada freqüência de despertares, microdespertares ou mudanças de fase de sono (do profundo para o leve) e movimentos, em relação aos parâmetros considerados normais. Por exemplo, um índice abaixo de 15 microdespertares por hora é considerado uma faixa normal para adultos jovens. Foi recentemente notado que bruxômanos apresentam número significativamente menor de complexos $K$ que não-bruxômanos. Consideram que, embora a incidência de microdespertares seja moderadamente correlacionada com a alta freqüência de ARMM, é sua magnitude (início mais rápido do aumento da freqüência cardíaca, maior amplitude da atividade EMG e um contato dentário forçado com ranger) que parece distinguir bruxômanos de não-bruxômanos. Finalmente, abordam a questão da razão fisiológica pela qual a ARMM ou o BS ocorre. As duas hipóteses principais são: 1) papel na lubrificação do trato digestivo superior durante o sono, pois a maioria dos episódios de BS parecem estar associados com a degluticao e 2) o a melhora do fluxo de ar nas vias superiores durante o sono, pois durante o sono, a ativação repentina dos músculos mandibulares é freqüentemente associada com ARMM ou BS, e com o retorno do fluxo aéreo depois de um evento de apnéia.

Em 2004, AHLBERG et al. ${ }^{1}$ observaram que o relato de bruxismo estava significativamente associado ao fumo. E que relato de bruxismo freqüente associou-se com sintomas de dor relacionados à DTM, distúrbios afetivos e insônia. Participaram do estudo 1339 indivíduos ( $46 \pm 6$ anos de idade), por meio de questionário.

DUBÉ et al., ${ }^{42}$ em 2004, compararam a eficácia e a segurança das placas oclusais a dispositivos controle (que recobriam apenas o palato), em nove bruxômanos, por meio de PSG durante duas noites e após o uso de cada uma das placas durante 15 dias. Ambos os dispositivos reduziram o tempo de sono profundo, sendo a redução significativa apenas para o dispositivo oclusal. Apesar dessa redução, nenhuma outra variável do sono alterou-se pelo uso dos dispositivos. Houve redução no número de episódios/hora de SB e no número de episódios com sons de ranger de dentes para ambos os dispositivos (sem diferenças entre 
eles). Apesar de não ter havido alteração na amplitude dos bursts, nem na duração dos episódios, houve ainda redução no número de bursts/hora, de bursts/episódios e no intervalo entre os bursts para ambos os dispositivos. Como possível explicação, os autores relatam que tem sido sugerido que o BS possa contribuir para a recuperação da abertura das vias aéreas superiores durante o sono, ${ }^{79}$ conjeturando a possibilidade de que a espessura palatina dos dispositivos orais modificaria a posição da língua durante o sono. Ao mesmo tempo, sugerem atenção, visto que, durante o sono leve, o posicionamento posterior da língua e do palato mole contribui para a redução do espaço das vias aéreas. Finalmente, os autores sugerem maiores investigações sobre o mecanismo de ação dos dispositivos, visto que o senso comum para o uso das placas oclusais é prevenir o dano dentário pelo BS.

Em 2005, LAVIGNE; KATO $^{76}$ reconheceram o problema da carência de respostas acerca dos fatores associados às parafunções relacionadas ao desgaste dentário. Sugerindo a realização de estudos epidemiológicos por meio dos quais se estude a prevalência do desgaste dentário e os fatores psicosociais relacionados em populações reabilitadas e não reabilitadas, em indivíduos com e sem DTM e bruxômanos e não-bruxômanos. Propõem a validação de ferramentas para a quantificação de parafunções e ainda a verificação de associações de causa-e-efeito por meio de estudos desenhados de forma apropriada a explorar essas relações. ${ }^{76}$

MANFREDINI et al., ${ }^{100}$ em 2005, aplicaram o MOODS-SR (Mood Spectrum Self-report) um instrumento psicométrico validado, para verificar o espectro dos distúrbios de humor em uma população de 105 indivíduos livres de DTM, com idade entre 20 e 30 anos. A amostra foi composta por $38(36,2 \%)$ bruxômanos diagnosticados pelo critério da ASDA. ${ }^{8}$ e $67(63,6 \%)$ não-bruxômanos. O questionário MOODS-SR é composto por 161 itens que fornecem uma avaliação separada para cada um dos principais sintomas de desordens de humor (sintomas depressivos e maníacos), identificando também manifestações atípicas e sub-limiares do espectro de humor. É dividido em quatro domínios: Humor (que explora a fenomenologia de humor desde sintomas depressivos unipolares e bipolares sub-clínicos até sintomas maníacos e mistos severos); energia (devotado aos níveis de energia e mudanças nas atividades diárias, em particular, o trabalho, hobbies e vida social); cognição (explora as alterações cognitivas que frequentemente relacionam-se a irregularidades da energia e do 
humor) e ritmo e funções vegetativas (as quais consideram distúrbios e mudanças rítmicas nos sentimentos e no comportamento associadas com experiências físicas tais como alimentação, atividade sexual e sono, incluindo variações nos sintomas afetivos e sub-afetivos). Observouse maior prevalência de psicopatologias entre os bruxômanos tanto para mania quanto depressão, nos parâmetros humor, energia,cognição e funções vegetativas. Os autores discutem que uma quantidade consistente de literatura sugere que as influencias periféricas exercem um papel menor na etiopatogênese do bruxismo, enquanto fatores relacionados ao SNC parecem ter maior importância. Dentre os fatores centrais, os autores apontam o estudo do componente psíquico, cujas anormalidades podem contribuir para pobre qualidade de sono e maior tensão emocional, os quais são fatores de risco chave para o BS e diurno, respectivamente. A maioria das anormalidades no espectro de humor foram subclínicas, embora as diferenças entre bruxômanos e não-bruxômanos tenham sido significativas como para a prevalência das psicopatologias clínicas. Os autores comentam que é difícil determinar a importância clínica desse estudo, por não se conhecer ainda a importância de sintomas subclínicos em uma população não psiquiátrica. Como sugestão para pesquisas futuras, os autores citam que a literatura psiquiátrica parece sugerir que pacientes bipolares apresentam desordens nos mesmos neurotransmissores centrais envolvidos na etiologia do bruxismo.

CAMPARIS; SIQUEIRA, ${ }^{20}$ em 2006, realizaram um estudo descritivo de 100 bruxômanos ( 80 mulheres e 20 homens) com relação à presença ou ausência de características clínicas de DTM, por meio do RDC/TMD e um questionário de dor (EDOF-HC). Trinta por cento dos bruxômanos não apresentavam dor orofacial (Grupo A) e 70\% apresentava dor orofacial (Grupo B). Oitenta e nove por cento do Grupo B apresentava rigidez muscular em comparação com 36,4\% do grupo A. A duração média da dor foi de 6,92 anos; a intensidade média da dor foi de 4,33 na EAV numérica; a qualidade da dor era do tipo apertada/pressão em $84,3 \%$ e 95,7\% do grupo B apresentava DMF. Os níveis de depressão e somatização foram diferentes entre os grupos $(p=0,001)$. Os autores concluíram que há diferenças estatisticamente significativas entre os bruxômanos com e sem dor facial crônica; que ambos questionários permitiram interação entre a queixa principal e os achados clínicos e que os níveis de depressão aumentaram com a dor em muitas regiões do corpo. 
CAMPARIS et al., ${ }^{19}$ em 2006, verificaram, por meio de um estudo polissonográfico, que bruxômanos com e sem DMF (grupos correspondentes em número, gênero e idade) não apresentavam diferenças significativas quanto às variáveis do sono (número de bursts e episódios de bruxismo por hora, amplitude e duração dos episódios de bruxismo, eficiência e latência do sono, percentagem de sono REM e NREM, eventos respiratórios, movimentos periódicos dos membros e micro despertares). 


\subsection{SONO}

\subsubsection{Fisiopatologia}

Em 1999, a ACADEMIA AMERICANA DE MEDICINA DO SONO (American Academy of Sleep Medicine $)^{5}$ desenvolveu definições padronizadas dos eventos respiratórios anormais durante o sono em adultos e as síndromes associadas que poderiam facilitar relatos mais confiáveis e precisos em pesquisas científicas e na prática clínica. A apnéia/hipopnéia obstrutiva foi caracterizada como uma redução transitória ou a cessação completa da respiração. O diagnóstico é dado com base no preenchimento dos critérios 1 ou 2 mais o critério 3: 1) Clara redução ( $>50 \%)$ da amplitude de uma medica válida da respiração durante o sono. Essa redução é considerada a partir do baseline. O baseline é definido como a amplitude média da respiração e oxigenação estáveis nos dois minutos que precedem o início do evento; 2) uma clara redução na amplitude de uma medida válida da respiração durante o sono que não atinja o critério anterior, mas que esteja associada à dessaturação de oxigênio superior a 3\% ou a um despertar; 3) que o evento dure no mínimo 10 segundos. O critério de severidade emprega a sonolência diurna e o índice de apnéia/hipopnéia (IAH): entre 5 e 15 eventos por hora (Leve); entre 15 e 30 eventos por hora (Moderada) e mais que 30 eventos por hora (Severa).

Em 2004, MONTAGNA ${ }^{112}$ publicou uma revisão sobre desordens motoras nãoepitéticas relacionadas ao sono. Dentre elas, os movimentos periódicos dos membros durante o sono, caracterizados por movimentos dos membros inferiores e, mais raramente, inferiores, e por flexões repetitivas nos dedos, tornozelos, quadris e ombros, durando entre 0,5 e 5 segundos e recorrendo quase periodicamente em intervalos de 5 a 90 segundos durantes o sono. O autor cita que, por convenção, pelo menos 4 movimentos devem ser observados para o diagnóstico de MPM durante o sono ou "periodic limb movement in sleep". A desordem dos movimentos periódicos dos membros (DMPM) (é considerada uma dissonia, ou seja, desordem que causa excessiva sonolência ou queixas de insônia. Os movimentos ocorrem especialmente durante os estágios 1 e 2 no sono NREM, mas também podem ocorrer durante a vigília relaxada que precede o início do sono e, mais raramente, pode persistir no sono REM. A MPM é vista em 5\% da população normal com idade entre 30 e 49 anos e em 30\% 
ou mais entre aqueles com mais de 50 anos de idade. Quando os MPM ocorrem de forma particularmente freqüente, acima de 5 eventos por hora, é considerado patológico (DMPM). 


\subsubsection{Sono e Dor}

MOLDOFSKY ${ }^{109}$ apresentou, em 2001, uma revisão sobre os diversos aspectos que evidenciam a relação, muitas vezes recíproca, entre desordens do sono e dor. Apontou as evidências de que o tratamento das desordens do sono melhora tanto as cefaléias quanto as migraines. Observou que estímulos dolorosos aplicados nos músculos durante as fases 3 e 4 do sono NREM resultou em redução das ondas delta e no aumento das freqüências alfa e beta no EEG durante o sono. Estímulos auditivos que interrompiam o sono de ondas lentas resultaram em sono não restaurador, dor musculoesqueletal difusa, sensibilidade à palpação e fadiga em indivíduos saudáveis. Tais sintomas acompanham os padrões eletromiográficos alfa que ocorrem frequentemente em pacientes com fibromialgia. Concluiu que o reconhecimento de um sono fragmentado ou não restaurador influencia a terapêutica das desordens dolorosas.

Devido à freqüente queixa de pobre qualidade de sono entre pacientes de dor crônica, YATANI et al., ${ }^{174}$ em 2002, estudaram as relações entre qualidade de sono, percepção da dor e estresse psicológico entre pacientes com DTM. Um total de 137 pacientes com queixas de DTM foram examinados com Pittsburgh Sleep Quality Index (MSQI) para a avaliação da qualidade do sono e com o Multidimensional Pain Inventory (MPI) para a análise das dimensões da dor e do sofrimento. O Revised Symptom Checklist-90 (SCL-90R) foi usado para a avaliação psicológica. Os pacientes foram divididos em dois grupos de acordo com a qualidade de sono: (boa e má qualidade), de acordo com o MSQI (mediana escore total: 10). Não houve diferenças quanto à distribuição de sexo e idade entre os grupos. O grupo com sono de má qualidade relatou escores mais altos que o grupo de sono de boa qualidade em todas as 14 escalas do SCL-90R e em 7 das 13 escalas do MPI. A análise de regressão logística demonstrou que o sono de má qualidade poderia ser previsto por maior severidade da dor, maior estresse psicológico e menor percepção de controle.

LINDROTH; SCHMIDT; CARLSON, ${ }^{86}$ em 2002, compararam 435 pacientes com dor nos músculos mastigatórios (DM) e 139 pacientes com dor intracapsular (ICP) com relação aos domínios psicológicos e comportamentais. Observou-se que não houve diferenças singnificativas na severidade ou duração da dor entre os grupos. Entretanto, o grupo ICP relatou menos sintomas afetivos relacionados à dor que o grupo DM. O grupo DM é composto por uma proporção significativamente maior de indivíduos disfuncionais e 
estressados do que o grupo ICP (segundo o Multidimensional Pain Inventory), bem como maior proporção de relato de pobre qualidade de sono e sintomas de desordem do estresse pós-traumático. Não houve diferenças significativas entre as medidas fisiológicas de pressão sangüínea sistólica e freqüência cardíaca entre os grupos.

BROUSSEAU et al. ${ }^{16}$ (2003) lembram que a dor é a integração de experiências sensoriais, emocionais e motivacionais e que a dor musculoesqueletal crônica está frequentemente associada a queixas de sono ruim e fadiga. Remetem ainda às evidências de que pacientes com dor severa podem apresentar menor número de sítios de ligação centrais de opióides, o que pode contribuir para a alta variabilidade na medição da percepção da dor e na eficácia dos analgésicos. Os autores relatam que na maioria dos pacientes com dor aguda (50 a 90\%), a ocorrência da dor geralmente precede queixas de sono pobre, ao mesmo tempo em que, pacientes com síndrome da boca ardente e dor crônica têm indicado influências bidirecionais: uma noite de sono pobre pode seguir-se de maior dor no dia seguinte e, um dia com níveis mais elevados de dor muitas vezes são seguidos de sono ruim. Referenciam um relato de que pacientes fibromiálgicos não apresentam a redução na freqüência cardíaca normalmente observada durante os estágios profundos do sono. Daí, os autores ponderam que, se um cérebro mantém hiperativo durante o sono (i.e. freqüência excessiva de padrões alternantes cíclicos - PAC), com a freqüência cardíaca permanecendo nos níveis de vigília, o sono pode não ser restaurador. Esses achados podem explicar a relação entre sono pobre e outras manifestações de dor, como fadiga e irritabilidade. Os autores, propõem um protocolo de 4 passos a ser aplicado aos pacientes com dor crônica: 1) Avaliação da desordem primária do sono para verificação da necessidade de tratamento médico; 2) Higiene do sono e estratégias comportamentais e cognitivas caso não se suspeite de desordens do sono; 3 ) Encaminhamento do paciente a fisioterapeutas e psicólogos, caso necessário e 4) Intervenções farmacológicas, quando necessárias.

Em 2004, VAZQUEZ-DELGADO et al. ${ }^{164}$ investigaram se havia diferenças psicológicas e de qualidade do sono entre pacientes com cefaléia diária crônica (CDC) e DTM. Sessenta e sete pacientes com CDC; 67 com diagnóstico primário de DMF e 67 pacientes com diagnóstico primário de dor intracapsular na ATM (IC) (de acordo com $\mathrm{RDC} / \mathrm{TMD}$ ) foram examinados. $\mathrm{O}$ grupo $\mathrm{CDC}$ foi composto por subgrupos mutuamente 
exclusivos de diagnóstico: migraine crônica $(n=35)$, cefaléia tensional $(n=26)$, outras CDC $(n=6)$. Todos os pacientes completaram uma bateria de questionários psicológicos e de qualidade do sono. Todos os subgrupos de CDC tiveram perfis psicológicos e de qualidade de sono semelhantes. Os grupos CDC e DMF revelaram níveis mais altos de estresse psicológico do que o grupo IC na maioria dos domínios psicológicos. O grupo DMF também revelou níveis mais elevados de estresse psicológico, na maioria dos domínios psicológicos que o grupo CDC, embora essas diferenças tenham sido, em geral, não significativas. Não foram encontradas diferenças entre os três grupos quanto a sintomas de estresse pós-traumáticos. A qualidade do sono foi significativamente pior no grupo DMF que nos grupos CDC e IC. 


\subsection{Disfunç̃̃o TEMPOROMANDIBULAR}

\subsubsection{Epidemiologia}

GREENE; MARBACH, ${ }^{55}$ em 1982, em uma revisão sobre estudos epidemiológicos, sugeriram que o fato de alguns indivíduos procurarem ajuda profissional para a resolução de seus problemas os distingue dos demais. Quando se realiza um estudo epidemiológico baseado apenas nas características da doença obtidas por meio de anamnese, exame clínico e/ou exames adicionais sem se considerar a queixa principal do paciente como fator de motivação a procurar tratamento, pode-se obter como resultado não a prevalência de pessoas realmente doentes e sim, a prevalência de pessoas com características fora do padrão tido como normal.

LOCKER; SLADE, ${ }^{93}$ em 1988, realizaram um estudo de prevalência e distribuição dos sintomas comumente associados à DTM em uma amostra de adultos em Toronto, Canadá. De 1002 indivíduos com idades acima de 18 anos, 67,7\% preencheram um questionário sobre sua sintomatologia. Do total, $48,8 \%$ responderam positivamente a uma ou mais das nove questões sobre os sintomas. Sons articulares, cansaço ou rigidez dos músculos mandibulares e mordida desconfortável foram os sintomas mais freqüentemente relatados $(25,4 \% ; 21,4 \%$ e $20,4 \%$, respectivamente). Dor funcional ou em repouso foi relatada por $12,9 \%$ dos indivíduos. As diferenças em sexo e idade foram pequenas, mas significativas, sendo que, o grupo de mulheres mais jovens relatou um ou mais sintomas mais freqüentemente do que o grupo de homens mais velhos. Os autores encontraram uma correlação positiva entre "fatores de risco hipotéticos", tais como relato de ranger os dentes à noite; apertamento diurno e estresse freqüente com sinais e sintomas de DTM. Entretanto, os próprios autores advertem que esses achados precisam ser interpretados com cuidado. Pois em um estudo transversal como esse não é possível estabelecer uma seqüência temporal de causae-efeito. Além do mais, esse modelo de estudo não permitiu estimar o poder da relação entre os fatores de risco e os sintomas por meio de medidas tais como relação das probabilidades (odds ratio). Consequentemente, o estudo fornece fraca evidência da implicação desses fatores na causa das DTMs, havendo a necessidade de estudos de avaliação longitudinal para estabelecer seu exato papel etiológico. 
DWORKIN et al., ${ }^{43}$ em 1990 encontraram que a média de abertura mandibular máxima não-assistida (sem dor) e assistida (com dor) nos pacientes com DTM foi significativamente menor do que nos indivíduos sem qualquer sinal ou sintoma de DTM.

Em 1991, CLARK; ADLER; LEE ${ }^{27}$ sugeriram que a preexistência de uma condição patológica nos músculos mastigatórios pode ser necessária para o desenvolvimento da dor muscular persistente.

Em 1995, GOULET; LAVIGNE; LUND ${ }^{51}$ obtiveram, por meio de questionário, uma taxa de aproximadamente 5\% para dor mandibular freqüente de intensidade moderada a severa; $4 \%$ de ruídos articulares e 9\% de dificuldade durante a abertura da boca entre a população adulta de Quebec, Canadá. Os autores verificaram ainda que a prevalência dos sintomas de DTM era duas vezes maior nas mulheres do que nos homens.

FRICTON; OLSEN, ${ }^{45}$ em 1996, identificaram os seguintes itens como preditores do resultado do tratamento de pacientes de DTM: (1) sucesso de tratamentos prévios; (2) baixa auto-estima; (3) baixa energia; (4) sentimentos de preocupação; (5) nível de atividade sexual; (6) hábitos de alimentação; (7) nível de sono; (8) sentimento de confusão; (9) quanto tempo o indivíduo pensa que seu tratamento irá demorar e (10) quão freqüentemente o seu problema é uma desculpa para não fazer algo. Quando foi realizada uma segunda regressão múltipla sobre esses 10 fatores, os seguintes 4 fatores emergiram (listados em ordem de valor preditor): baixa auto-estima, sentimentos de preocupação, de falta de energia e atividades durante o sono. Cada um desses fatores estava correlacionado à depressão. A análise discrimitativa empregando esses 4 itens considerando-os para $49 \%$ da variação no resultado do tratamento, foi estatisticamente significativa $(\mathrm{p}<0,0001)$ e predisse corretamente a resposta ao tratamento para $87 \%$ dos indivíduos analisados. Os achados desse estudo sugerem que é importante tomar informações psicosociais do paciente na fase pré-tratamento a fim de melhor prever o resultado do tratamento das desordens temporomandibulares crônicas e que os sintomas de depressão mediam a resposta ao tratamento dos pacientes com dor crônica.

Em 2000, MAGNUSSON, EGERMARK; CARLSSON publicaram os resultados parciais de um acompanhamento de 20 anos de uma amostra epidemiológica. Cento e trinta e cinco indivíduos de 15 anos de idade selecionados aleatoriamente e analisados após 5, 10 e 15 
anos por meio de questionário e exame físico de DTM. Após 20 anos, quando os indivíduos haviam atingido a idade de 35 anos, 92\% responderam o questionário e $80 \%$ puderam ser avaliados clinicamente. Os autores verificaram que os sintomas de DTM (tanto relatados quanto avaliados clinicamente) flutuaram substancialmente ao longo do período de 20 anos, mas com rara progressão para DTM severa. Dentre todas as variáveis estudadas e avaliadas quanto ao valor de predição de sinais e sintomas de DTM (relato de sintomas de DTM, parafunções orais, cefaléia, fatores oclusais, desgaste dentário, função mandibular, mobilidade mandibular, índice de disfunção, dor muscular e articular à palpação, dor durante o movimento mandibular e gênero) o relato de apertamento diurno e noturno apresentaram as mais altas correlações $(r=0,4)$ com ruídos e cansaço articular.

Em 2001, CIANCAGLINI et al. ${ }^{26}$ estudaram a associação entre relato de ranger ou apertar os dentes (não especificamente BS) e sinais e sintomas de DTM em uma população geral composta por 483 indivíduos (18 a 75 anos de idade). Após ajuste estatístico, o relato de bruxismo associou-se fortemente com dificuldade de fechar a boca (OR 2,84); e mais fracamente com dor craniofacial (OR 1,84), ruídos articulares (OR 1,64).

CARLSSON; EGERMARK; MAGNUSSON, ${ }^{21}$ em 2002, após acompanhamento de 20 anos, observaram que três variáveis do exame inicial foram preditoras significantes do relato de estalido na ATM; o índice de desgaste dentário foi o fator de risco mais forte (OR 4,3). O relato de estalido articular no início foi o único fator de previsibilidade para sintomas de DTM sem estalido 20 anos depois (odds ratio = 2,3). Um terceiro modelo de regressão logística, usando o Escore de Disfunção Clínica de Helkimo como variável dependente, resultou em 4 fatores de previsibilidade do exame inicial: bruxismo, parafunção oral, estalido da ATM e sobremordida. Os resultados indicaram que alguns sinais e sintomas podem predizer sinais e sintomas de DTM em uma perspectiva de longo prazo. Entretanto, não se pode concluir que esses sinais registrados na infância (parafunção oral, desgaste dentário, estalido na ATM e mordida profunda) podem ser usados para predizer DTM manifesta na idade adulta.

MACFARLANE et al., ${ }^{96}$ em 2003, pesquisaram o relacionamento entre dor orofacial (DOF) e fatores mecânicos locais em uma população geral não selecionada de 2504 participantes (com participação ajustada de 74\%), por meio de questionários enviados pelo 
correio. Os autores verificaram uma associação significativa entre DOF e história de ranger de dentes, trauma facial e rigidez ou travamento mandibular, ruídos articulares durante a abertura ou fechamento da boca, dificuldade de abertura ampla da boca e hábito de morder canetas ou roer unhas. A rigidez ou travamento articular apresentou o maior risco relativo: 2,7 (IC 95\%: 2,3-3,2). História de tratamento ortodôntico prévio, uso de qualquer tipo de prótese ou hábito de mascar chicletes não estavam associados com DOF. Os autores concluíram que os fatores locais exercem um importante papel na etiologia da DOF.

MANFREDINI et al., ${ }^{99}$ em 2003, pesquisaram a prevalência de bruxismo em subtipos de diagnósticos de DTM (RDC/TMD) em uma população de 289 indivíduos (93 homens e 196 mulheres, com idade média de 34,4 \pm 13,8 anos). Dentre os 289 indivíduos, 220 apresentavam sinais e/ou sintomas de DTM. Cada participante passou por um exame clínico detalhado e padronizado (RDC/TMD - Eixo 1). A presença do bruxismo foi verificada clinicamente, de acordo com as diretrizes da Academia Americana de Dor Orofacial. ${ }^{4} \mathrm{O}$ exame clínico de bruxismo constava da verificação da presença de facetas de desgaste; do relato de ruídos associados ao ranger de dentes noturno, relatado por um terceiro; relato de apertamento diurno dos dentes; relato de acordar à noite enquanto range ou aperta os dentes; sensação de tensão/rigidez muscular durante o dia e/ou ao acordar; dor nos músculos temporais e/ou masseteres durante o dia ou ao acordar. Considerou-se o diagnóstico positivo de bruxismo quando os indicadores clínicos e pelo menos um indicador anamnésico foi positivo. Quarenta e quatro por cento dos indivíduos sem DTM foram diagnosticados como bruxômanos e 55,9\%, como não bruxômanos. A população com DTM foi dividida em três subgrupos de diagnóstico (segundo o RDC), grupo I: DMF ( $\mathrm{n}=29)$; grupo II: deslocamento de disco $(n=57)$; grupo III: outras condições articulares $(n=20)$; grupos I e II combinados $(n=16)$; grupos I e III combinados $(\mathrm{n}=30)$ e grupos I, II e III combinados $(\mathrm{n}=30)$. A prevalência do bruxismo no grupo com DTM foi de 58\% (123 de 212). No grupo I (isolado ou combinado), a prevalência do bruxismo foi de 71,4\% (75 de 105); no grupo II (isolado ou combinado), foi de $53,3 \%$ (71 de 133) e no grupo III (isolado ou combinado), de 60.9\% (67 de 110). Sendo que, nos grupos I, II e III o bruxismo esteve presente em 68,9\%, 38,5\% e 65\% da população, respectivamente. Os testes de Qui-quadrado e o teste exato de Fisher detectaram diferença significativa entre os grupos com e sem DTM quanto à prevalência de bruxômanos $(p<0,05)$. Houve diferenças estatisticamente significativas na prevalência de bruxismo entre os 
seguintes grupos: (a) sem DTM e I, combinação I e II e combinação I, II e III; (b) entre os grupos I e II; (c) entre os grupos II e combinações I e II, I e III e I, II e III; (d) entre a combinação I e II e a combinação II e III e (e) entre a combinação II e III e a combinação I, II e III. Os autores reconhecem as limitações do estudo referentes à subjetividade do diagnóstico de bruxismo e ao design transversal do mesmo, lembrando que, apesar desse estudo ter mostrado que o bruxismo e a DMF parecem ser condições associadas, não se podem tecer conclusões sobre um possível efeito causal do bruxismo na ocorrência dos sintomas de DTM, e da DMF em particular.

ALHLBERG et al. $^{2}$ (2005) verificaram que o relato de bruxismo freqüente e os sintomas de insônia eram significativamente mais prevalentes em indivíduos com dor crônica grau II (RDC/TMD Eixo II) do que em graus mais leves, em uma população de 750 pessoas empregadas com horários regulares e irregulares de trabalho. De acordo com o teste de regressão logística, dor orofacial presente estava positivamente associada com bruxismo freqüente $(\mathrm{p}<0,001)$, sexo feminino $(\mathrm{p}<0,001)$ e sono fragmentado $(\mathrm{p}<0,01)$; e estava negativamente associado com idade acima de 45 anos. Baseando-se na análise de multivariância, os autores concluíram que a fragmentação do sono e o bruxismo podem estar concomitantemente envolvidos no desenvolvimento da dor orofacial.

Um dos estudos mais bem conduzidos sobre a epidemiologia dos sinais e sintomas de DTM foi realizado por MAGNUSSON; EGERMARK; CARLSSON. ${ }^{98}$ Os autores conduziram um estudo longitudinal de mais de 20 anos sobre a prevalência de sinais e sintomas de DTM, bem como de outras variáveis com as quais correlacionou-se. Inicialmente 402 crianças e adolescentes de 7,11 e 15 anos de idade foram examinadas e re-examinadas após 10 e 20 anos. Apesar de leves, sinais e sintomas de DTM eram comuns já na infância. Mas raramente ocorreu progressão para DTM severa, como também foi rara a remissão espontânea de sintomas mais pronunciados. Encontrou-se correlação significante entre relato de bruxismo e sintomas de DTM. O relato de ranger de dentes no exame inicial foi um fator de predição de tratamento para DTM durante os 20 anos de acompanhamento; sinais clínicos de DTM (OR 5,3, $\mathrm{p}=0,016)$. Três variáveis foram preditores significativos para estalido articular 20 anos depois: índice de desgaste dentário (OR 4,3, p=0,014); estalido articular registrado clinicamente $(\mathrm{OR} 3,3, \mathrm{p}<0,0001)$ e relato de ranger de dentes à noite $(\mathrm{OR} 2,2, \mathrm{p}=$ 
0,023). Em um segundo modelo de regressão logística para sintomas articulares (excluindo estalido articular), apenas o relato de estalido articular no exame inicial foi um preditor significativo (OR 2,3, $\mathrm{p}=0,011)$. Os autores concluíram que os sinais e sintomas de DTM flutuam substancialmente da infância à idade adulta. 


\subsubsection{Diagnóstico}

Em 1992, RAPHAEL; MARBACH ${ }^{128}$ compararam a intensidade de dor e a duração da desordem de 136 mulheres com DTM a seus sinais e sintomas, a fim de estudar alguns fatores de risco para a intensidade da dor, bem como esclarecer dados sobre a história natural das DTMs. Ao longo de 1 ano, foram realizadas 12 entrevistas em que as voluntárias eram questionadas sobre a intensidade da dor no momento e sobre a pior dor experimentada no mês anterior. Para essa análise, empregou-se uma escala em que se combinaram a estimativa da magnitude e um descritor da dor. O exame clínico foi realizado por 3 examinadores experientes. Observou-se que a abertura bucal média foi de 32, $64 \pm 8,84 \mathrm{~mm}$, o que não se correlacionou com a dor média durante as 12 entrevistas $(\mathrm{p}>0,10)$. A dor média relacionou-se de forma significativa com a duração da DTM quando os indivíduos iniciaram o estudo $(\mathrm{r}=0,21, \mathrm{p}<0,001)$. O relacionamento entre $\mathrm{o}$ autor relato de limitação de movimentação mandibular não se correlacionou coma movimentação mandibular verificada clinicamente $(\mathrm{p}>0,10)$. Os autores sugeriram que é mais provável que o bruxismo seja mais facilmente detectável pelo auto-relato do que pela análise das facetas de desgaste visualmente detectáveis $(\mathrm{p}<0,0001)$.

Em 1995, LOBBEZOO-SCHOLTE et al. ${ }^{88}$ compararam o auto-relato e dados clínicos de DTM em uma população de 533 pacientes. Os autores encontraram que há pobre concordância (Kappa $<4,0$ ) entre o auto-relato e os achados clínicos para os seguintes parâmetros: dor nos masseteres $(0,10)$; dor nos temporais $(0,18)$, dor articular $(0,13)$; dor no sistema mastigatório $(0,21)$; crepitação $(0,08)$; restrição de movimento $(0,30)$; apertamento $(0,12)$; ranger $(0,06)$, dor no pescoço $(0,34)$ e restrição de movimentos do pescoço $(0,37)$. Apenas para estalidos obteve-se uma concordância moderada (kappa $=0,49)$. Relativamente mais pacientes do subgrupo de DTM miogênica relataram apertamento e ranger do que os demais subgrupos (deslocamento de disco com e sem redução e osteoartrose). Enquanto o percentual de ranger e apertamento encontrado pelo exame clínico distribuiu-se equitativamente entre os grupos. Em geral, os grupos de DTM miogênica e de osteoartrose relataram maiores percentuais de problemas gerais de saúde.

No mesmo ano, LOBBEZOO-SCHOLTE et al. ${ }^{89}$ publicaram a segunda parte do estudo anterior, onde os autores discutem alguns fatores associados aos subgrupos de DTMs. 
Com relação ao grupo miogênico, os autores descrevem a maior prevalência de fatores associados, fatores psicosociais, queixas musculoesqueletais em outras partes do corpo, o que pode contribuir para a os mais baixos índices de percepção de boa saúde geral. Acrescentam que o grupo miogênico é frequentemente conceitualizado como uma condição psicofisiológica provavelmente responsiva ao estresse. Como tal, os autores teorizam que a dor supostamente resulta de hiperatividade muscular induzida pelo estresse (conceito introduzido por YEMM $^{175}$ ). Discutem também o modelo de TRAVELL ${ }^{145}$, sobre a DMF causada por pontos-gatilho, os quais se originam de dano direto ou microtrauma (hábitos parafuncionais). Ao final, resumem que a mais alta incidência de hábitos parafuncionais e fatores psicológicos no grupo miogênico, em relação aos demais subgrupos, pode suportar os modelos acima mencionados. Sugerem cautela em tecer conclusões sobre causa-e-efeito por que os fatores relacionados podem funcionar na direção oposta: a dor per se pode ser considerada um importante agente estressante e, como tal, pode influenciar os fatores psicosociais. Relatando a descrição de maiores limitações psicosociais em pacientes com dor mais intensa e lembrando o modelo de adaptação à dor de LUND et al. ${ }^{94}$

Em 1996, CURRAN et al. ${ }^{35}$ exploraram os fatores psicológicos e fisiológicos (temperatura da pele, atividade EMG, freqüência cardíaca e pressão sanguínea e freqüência respiratória) que poderiam diferenciar pacientes com DTM miogênica $(\mathrm{n}=23)$ de indivíduos controle assintomáticos correspondentes em sexo, idade e peso. Cada indivíduo respondeu a vários questionários psicológicos padronizados e, em seguida, submeteram-se a dois testes laboratoriais de estresse (aritmética mental e estímulo pressão-dor). Os pacientes com DTM apresentaram maiores taxas de respiração em repouso e relataram maior ansiedade, tristeza e culpa em relação ao grupo controle. Em resposta ao fator estressante aritmética, pacientes com DTM reagiram com maiores níveis de raiva do que o grupo controle. Não houve diferenças entre os grupos quanto às medidas de dor ou qualquer outra variável medida para o teste de estímulo pressão-dor (no dedo médio da mão não dominante). Não houve diferença entre os grupos nos níveis eletromiográficos dos músculos masseteres e temporais em repouso. Os autores consideraram que a ansiedade tem sido um fator que, consistentemente, diferencia pacientes de dor facial crônica de indivíduos assintomáticos. Sugerem que a verificação do status psicológico do paciente deve ser realizada na avaliação inicial de pacientes com dor facial crônica. Relatam que a reatividade emocional aumentada a fatores 
estressantes do ambiente pode contribuir para os maiores níveis de estresse, ansiedade e depressão frequentemente encontrados em pacientes de dor facial. Os autores concluem que a atividade EMG não é uma medida adequada para diferenciar pacientes de dor facial de indivíduos controle durante a aplicação de protocolos de reatividade envolvendo fatores estressantes padronizados. A grande variabilidade individual e a habilidade de controle voluntário dos músculos mastigatórios durante as sessões experimentais podem ter complicado o uso do monitoramento EMG. Com relação à maior freqüência respiratória em repouso dos pacientes em relação ao grupo controle, os autores discutem que, o aumento crônico da freqüência respiratória pode levar a alterações no $\mathrm{pH}$ sangüíneo, o que está associado com o aumento da excitabilidade neuronal, menor fluxo sangüíneo periférico e hiper-irritabilidade. Os autores atribuem a ausência de diferenças no limiar de dor entre os grupos ao estímulo experimental empregado, bem como ao sitio anatômico, os quais diferiram de outros estudos.

GOULET et al., ${ }^{50}$ em 1998, avaliaram a reprodutibilidade de dos métodos de detecção de sensibilidade à palpação na ATM e nos músculos mastigatórios (LDP e palpação digital). Com aplicação de uma pressão padronizada por $2 \mathrm{~s}$ sobre sítios musculares anatomicamente definidos, 1 sítio controle e 1 sítio articular. Foram analisados 76 indivíduos (36 pacientes DTM crônica articular e/ou muscular e 36 indivíduos assintomáticos). Cada indivíduo foi analisados duas vezes por cada um dos métodos em uma seqüência aleatória por examinadores calibrados. A algometria obteve coeficiente de correlação intraclasse de 0,39 a 0,88 e a palpação digital de 0,22 a 0,74. Esses resultados indicam uma concordância entre boa e excelente entre examinadores calibrados. Verificou-se ainda que, a segunda medição do LDP, realizada $30 \mathrm{~s}$ depois da primeira, apresentava valores de LDP significativamente menores, provavelmente devido à sensibilização periférica dos nociceptores, causada pela primeira medida. Após o intervalo de 5 minutos, quando era realizada a medição pelo segundo examinador os níveis de LDP tendiam a se elevar e voltar aos níveis iniciais. 


\subsubsection{Etiopatogenia}

Embora os mecanismos da dor muscular crônica fossem pobremente compreendidos, em 1996, DELCANHO; KIM; CLARK $^{40}$ investigaram uma das teorias predominantes sobre essa questão: a hipóxia localizada. Realizou-se o monitoramento das mudanças relativas na concentração de hemoglobina $(\mathrm{Hb})$ intramuscular e nos níveis de saturação de oxigênio. Os dados foram coletados do masseter humano durante e após três sessões de 30s de contração isométrica com 50\% da FOVM. Participaram do estudo 10 mulheres com história de dor muscular crônica na região mandibular e 8 mulheres saudáveis sem dor muscular. Ao início da contração do músculo masseter, ocorreu uma rápida redução na concentração intramuscular de $\mathrm{Hb}$, concomitantemente à redução dos níveis de saturação de oxigênio. Após o término da contração, a concentração de $\mathrm{Hb}$ aumentou rapidamente até voltar ao nível inicial. Houve diferenças significativas no perfil de recuperação da saturação de oxigênio entre a primeira e as duas sessões seguintes no grupo com dor crônica, com relação ao grupo controle. Olhando apenas para a primeira sessão, ajustando-se as covariáveis altura, peso e força de mordida na análise, verificaram-se valores significativamente menores de saturação de oxigênio durante a recuperação no grupo com dor muscular crônica. Houve diferenças significativas nas concentrações de $\mathrm{Hb}$ entres os grupos, sem nenhum efeito da sessão. As bem conhecidas alterações no fluxo sangüíneo intramuscular durante e após a contração em músculos humanos refletiram-se nessas concentrações de $\mathrm{Hb}$ relativamente alteradas. $\mathrm{O}$ grupo com dor muscular crônica apresentou uma clara redução na recuperação da concentração de $\mathrm{Hb}$ durante o período pós-contração. Os resultados suportam o conceito de que os pacientes com dor muscular crônica possuem uma reperfusão mais lenta durante a fase de recuperação pós contrações isométricas sustentadas.

Em 1999, STOHLER ${ }^{149}$ relatou que apenas uma pequena percentagem de casos continua a ser diagnostica como condições musculares, segundo o RDC/TMD após 1 ano (23\%), 3 anos (13.3\%), e 5 anos (6.7\%) de acompanhamento. A parte do fato de que mais da metade dos casos são resolvidos com o tempo, apenas raramente a DTM miogênica parece persistir por um período superior a 5 anos sem o surgimento de indicadores clínicos sugestivos do envolvimento da ATM. As condições de dor muscular frequentemente não se limitam a um único domínio topográfico, experimentando dor em partes do corpo não 
exclusivas ao sistema trigeminal. O autor explicou a conceitualização de neuroplasticidade e sensibilização. Explicou a distinção entre plasticidade neural e comportamental. Segundo o autor, neuroplasticidade refere-se à reorganização do sistema nervoso com base nos mecanismos que influenciam a eficiência sináptica e a conectividade em todos os níveis cerebrais. Tanto as mudanças de curto (com duração de minutos) quanto as de longo prazo (com duração de horas ou mais) são distinguidas. Cita como exemplos de neuroplasticidade a sensibilização, a habituação e a reabilitação. Explica que a sensibilização é o fenômeno de exacerbação de uma resposta comportamental; habituação, por outro lado, refere-se à redução da resposta comportamental com a aplicação de estímulos repetidos. Em nível celular, a base da habituação está na perda da força sináptica, enquanto a sensibilização envolve o aumento na disponibilidade de neurotransmissores na fenda sináptica. Neuroplasticidade e sensibilização parecem estar envolvidas na geração dos sinais e sintomas que dominam o cenário clínico das DTMs miogênicas. O autor explica ainda os mecanismos de dor referida e difusa. Os aferentes nociceptivos da musculatura mandibular e do pescoço conectam-se, por meio da primeira sinapse, a neurônios que se projetam ao SNC, e a interneurônios inibitórios e excitatórios. A significativa convergência do impulso aferente que ascendem do impulso aferente nesse nível explica a dor difusa e a dor referida. Além dos impulsos nociceptivos, os aferentes não-nociceptivos e o sistema anti-nociceptivo descendente podem influenciar a excitabilidade desses neurônios. Diferentes neurotransmissores (ex.: glutamato, aspartato e substância P) estão implicados no surgimento dos potenciais sinápticos lentos e rápidos por atuarem sobre os receptores NMDA, AMPA e neurocinina-1. A alodinia, que é a característica chave das DTMs miogênicas, está associada ao aumento da excitabilidade de neurônios dorsais em ratos durante a infusão medular de substância P. O aumento da excitabilidade paralelo ao aumento dos campos receptores dos neurônios de segunda ordem é uma expressão de neuroplasticidade induzida por inflamação

Em 2003, RAPHAEL et al. ${ }^{131}$ verificaram a eficiência da terapia com placas intraorais em pacientes com DMF com e sem relato de bruxismo. Testou-se a hipótese de que os dispositivos seriam mais eficientes em reduzir a sintomatologia dolorosa no grupo de pacientes bruxômanos. Realizou-se um estudo randomizado controlado de 6 semanas, no qual 52 mulheres com DMF eram randomicamente distribuídas para receber o dispositivo rígido de acrílico de cobertura total ou um dispositivo que recobria apenas o palato. O bruxismo foi 
diagnosticado por meio do auto-relato e a medição objetiva do desgaste microscópicas na superfície do molar ao longo de 2 semanas prévias ao início do estudo.Os resultados demonstraram que o grupo que recebeu o dispositivo de cobertura total apresentou uma melhora marginal em relação ao outro grupo nas medidas relacionadas à dor. Mas a severidade do bruxismo não influenciou a eficácia terapêutica do dispositivo de cobertura total. Esses achados questionam fortemente a crença de que as placas intraorais reduzem a DMF por meio da redução do bruxismo e levanta questões sobre a importância do bruxismo na manutenção da DMF. Entretanto, os autores reportam a possibilidade de erro estatístico tipo II. Pois o erro tipo II torna-se mais provável à medida que se admitem erros na medição do bruxismo. 


\subsection{INTEGRAÇ̃̃o SENSORIaL-MOTORA NA DOR Muscular e ARTICULAR}

\subsubsection{Teorias sobre atividade muscular como fator etiológico da DTM}

TRAVELL; RINZLER; HERMAN, ${ }^{159}$ em 1942, hipotetizaram a existência de um ciclo vicioso relacionando dor e tônus muscular. Nesse modelo, acreditava-se na ação excitatória dos aferentes musculares do grupo III e IV sobre os neurônios fusomotores, aumentando, portanto a atividade subjacente dos fusos musculares e/ou a sensibilidade dos mesmos ao estiramento. Via excitação autogenética, isso poderia levar a um nível de ativação aumentado nos motoneurônios alfa e ao acúmulo de metabólitos. Se a produção de metabólitos fosse alta o suficiente ou se os impulsos das articulações e ligamentos fossem combinados a impulsos musculares nociceptivos, isso poderia iniciar o "ciclo vicioso" e levar a uma rigidez muscular aumentada.

Em 1969, LASKIN $^{74}$ elaborou uma discussão acerca das teorias existentes sobre a etiologia do que se chamava na época síndrome dor-disfunção da articulação temporomandibular (originalmente descrita por COSTEN, ${ }^{34}$ em 1934). Em sua revisão, o autor explica que a base da maioria dessas teorias era formada por conceitos sobre discrepâncias oclusais, relacionamento maxilo-mandibular ou ambos. As teorias "oclusionistas" propunham que, quando os dentes entrassem em contato durante a mastigação ou a deglutição, as discrepâncias oclusais produziriam um deslocamento da mandíbula, usualmente em uma direção posterior, resultando na compressão dos tecidos retrodiscais densamente inervados e vascularizados. Sua contínua compressão resultaria não apenas em dor, mas impedimento do suprimento sangüíneo às estruturas articulares, levando a alterações degenerativas. $\mathrm{O}$ autor descreve a evolução das teorias exclusivamente oclusionistas para as que incorporavam a influência muscular. Essas últimas não propunham um deslocamento mandibular diretamente causado por discrepâncias oclusais, mas sim, que as interferências oclusais levariam a um inadequado feedback proprioceptivo, causando espasmos e incoordenação de alguns músculos da mastigação. Em seguida, o autor cita SCHWARTZ, ${ }^{138}$ 1959, e o papel dos distúrbios funcionais da musculatura mastigatória na etiologia da disfunção da ATM. Baseando-se nessa teoria, o autor desenvolveu a teoria psicofisiológica, a 
qual atribui aos espasmos musculares o posto de fator primariamente responsável pelos sinais e sintomas da síndrome dor-disfunção da ATM. E, uma vez que o envolvimento patológico das estruturas articulares ocorreriam apenas em estágios mais avançados, o autor sugere a mudança do termo para "síndrome dor-disfunção miofascial". O autor explica que restaurações inadequadas levariam à sobreextensão ou sobrecontração muscular, bem como hábitos parafuncionais como apertamento e ranger de dentes (em geral decorrentes de estresse emocional), os quais levariam à fadiga muscular. Tanto a fadiga, quanto a sobreextensão ou a sobrecontração levariam aos espasmos musculares. Esses últimos, levariam não apenas à dor e à limitação, mas ainda produziriam uma alteração na posição mandibular de maneira que os dentes não ocluiriam de forma apropriada. Se esse relacionamento mandibular anormal persistisse por vários dias, os dentes gradualmente se alterariam para acomodar-se a essa nova posição. A persistência do mio-espasmo também poderia levar a alterações degenerativas (devido à função da articulação em posição inadequada) e à contratura muscular (alteração degenerativa no músculo decorrente de espasmo persistente). Assim, a condição se tornaria auto-perpetuante, visto que todas essas alterações levariam a um padrão de mastigação alterado, reforçando o espasmo original e a dor.

Sobre a etiopatogenia da DTM, em 1985, YEMM ${ }^{175}$ relata que a hipótese de que alguns músculos do sistema mastigatório estariam continuamente ativos, devido a espasmos, gerando dor isquêmica, não encontra suporte científico em estudos eletromiográficos. $\mathrm{O}$ autor cita estudos que demonstraram aumento da atividade muscular dos músculos elevadores da mandíbula durante a abertura em pacientes com DTM, e que essa atividade é máxima quando o paciente alcança o grau de abertura em que a dor se inicia, sugerindo que essa seria uma forma de reação protetora. Acrescenta que isso ocorre bilateralmente nos músculos masseter e temporal, mesmo quando apenas um músculo (geralmente o masseter) de um dos lados está clinicamente afetado. $\mathrm{O}$ autor conclui que os componentes do sistema mastigatório, em particular os músculos e aqueles associados à ATM são susceptíveis a cargas excessivas provenientes de um padrão mastigatório alterado pela oclusão e/ou de hábitos parafuncionais (devido ao estresse emocional).

LUND et al., ${ }^{94}$ em 1991, questionaram a hipótese de que a disfunção (hiperatividade ou espasmos musculares) característica nos vários quadros de dores 
musculares crônicas (por exemplo, a DTM) seja a causa da dor; propondo tratar-se a disfunção de um mecanismo adaptativo normal de proteção. Os autores discutem a relação dor-hiperatividade muscular em 5 condições: fibromialgia, dor miofascial, dor crônica na região lombar e cefaléia tensional. Atribui-se essa hiperatividade a várias causas, sendo as mais comuns, a fadiga ou a sobrecarga funcional, anormalidades estruturais e estresse emocional. Os autores expõem a teoria de TRAVELL, ${ }^{159}$ sobre a conversão de uma condição aguda em crônica, a qual hipotetiza que a dor e a hiperatividade estão reciprocamente ligadas: os espasmos musculares causando dor, que por sua vez, reforça a disfunção, compondo um "ciclo vicioso" auto perpetuante. Os autores apresentam evidências de que, embora a dor provoque pequenas mudanças na atividade postural dos músculos, ela modifica a performance muscular reduzindo a ação dos músculos agonistas e aumentando o nível de contrações dos antagonistas. Os autores criticam a parcela de estudos que vinculam a dor à hiperatividade muscular após análises de grupos de pacientes sem correspondência quanto ao sexo e à idade, lembrando que esses dois aspectos exercem efeito significativo sobre os níveis da atividade eletromiográfica de repouso. Acrescentou-se que, embora eventualmente tenha sido provado que pacientes com cefaléia apresentam pequenos aumentos nos níveis eletromiográficos dos músculos da cabeça e do pescoço, isso não é evidência suficiente de que a "hiperatividade" seja a causa da dor. Os autores atribuem, mais provavelmente, a uma resposta geral do paciente à dor, parte da responsabilidade pela hiperatividade muscular, o que inclui mudanças na expressão facial e na postura da cabeça. Há evidências de que se pode distinguir um paciente com dor crônica pela postura de seu corpo, gestos e expressões faciais. E ainda, indivíduos com dor lombar crônica, apresentaram maiores níveis de "comportamentos de dor" durante o caminhar do que o grupo controle, incluindo contrações dos músculos faciais. Também se encontrou evidência de que esses pacientes apresentam níveis eletromiográficos dos músculos anteriores significativamente maiores, tanto no repouso quanto durante o movimento, do que o grupo controle com correspondência de idade. No mesmo artigo, os autores explicam que a dor associada a condições como bruxismo e síndrome das pernas inquietas possa ser tipos de fadiga pós-exercício. A natureza crônica dessas dores pode ser devido à repetição periódica do trauma, visto que a dor e o cansaço que ocorrem, um ou dois dias após uma única sessão de novos exercícios, raramente permanecem por mais do que poucos dias. Os autores concluem que há evidências de que a dor não causa hiperatividade muscular e de que sua capacidade de contração máxima é reduzida, e não aumentada pela dor. 
A única situação em que a atividade EMG parece estar mais alta do que o normal, na presença de dor crônica, é quando um músculo age como antagonista. Os autores propõem a hipótese de que isso trate-se de um reflexo adaptativo útil na limitação da amplitude e velocidade do movimento, o que, provavelmente, reduz dano e dor adicionais.

MENSE, ${ }^{104}$ no mesmo ano, explica os mecanismos envolvidos na neurobiologia da dor muscular crônica. Dentre esses mecanismos o autor cita alguns ciclos viciosos, os quais exercem um importante papel na perpetuação da transmissão de mensagens nociceptivas. Ressalta, entretanto, que os mecanismos exatos pelos quais esses ciclos operam não são totalmente conhecidos, podendo ocorrer tanto nos tecidos periféricos quanto no sistema nervoso central. Sabe-se que um importante aspecto desse conceito é que o SNC é capaz de influenciar o comportamento de resposta dos nociceptores periféricos, por meio da alteração das condições sob as quais estes operam. O autor explica como se dá um dos ciclos viciosos mais debatidos na literatura: o que se origina nos nociceptores da musculatura (ou das articulações e mecanoceptores) e que, supostamente, levaria a espasmos musculares crônicos. Uma lesão dolorosa excitaria as fibras aferentes nociceptivas (fibras III e IV) do músculo, essas fibras ativam os motoneurônios- $\gamma$, os quais aumentam a taxa de descarga elétrica nos fusos musculares. Isso leva ao estímulo das fibras aferentes primárias dos fusos musculares (fibras Ia), as quais estabelecem conexão monosináptica com os motoneurônios$\alpha$, estimulando-os, o que leva à contração muscular. Portanto, uma lesão dolorosa do músculo, supostamente induziria a um mioespasmo no músculo afetado, o que por sua vez, levaria à isquemia devido à compressão dos vasos sangüíneos. Sabe-se que contrações isquêmicas são dolorosas e ativam nociceptores musculares, fechando, dessa forma, o mecanismo de ciclo vicioso. Nessa revisão de literatura, em seguida a essa explicação, o autor cita um experimento em que se testou esse conceito em animais experimentais. Utilizaram-se gatos anestesiados e, por meio da infiltração de carragina no músculo gastrocnemius-soleus (GS) dos mesmos, provocou-se inflamação. Registrou-se a atividade dos motoneurônios- $\gamma$ que inervavam o músculo inflamado. Em contraste com o conceito acima descrito, observou-se menor atividade $\gamma$ nos músculos inflamados do que nos músculos que não sofreram a inflamação experimental. Concluiu-se que a miosite inibiu a atividade $\gamma$ nos músculos inflamados e que, se os motoneurônios- $\gamma$ comportarem-se de maneira similar nos pacientes com dor, esses resultados podem oferecer uma explicação para a fraqueza sentida em 
músculos inflamados e, possivelmente, para os fracos reflexos e a atrofia dos músculos que agem sobre uma articulação com artrite. Logo, os espasmos musculares presentes nos pacientes que sofrem de dor profunda não puderam ser explicados de forma inequívoca pelos mecanismos neurofisiológicos.

Em uma análise dos conhecimentos acerca da etiologia da DTM, GREENE, ${ }^{54} \mathrm{em}$ 2001 após revisar a história do pensamento nessa área, concluiu que não apenas estavam os velhos conceitos mecanicistas incorretos, como dois dos mais populares conceitos atuais (biopsicosocial e multifatorial) apresentavam sérias falhas. Assim, o autor considerou que, o que realmente se observa no paciente de DTM é, quase sempre, uma condição idiopática sobre a qual não se sabe o suficiente, nem se pode medir de forma satisfatória, não se podendo determinar por que um paciente desenvolve aquela condição. Acrescenta ainda a falta de entendimento dos fatores de resistência individual, os quais, em última instância, realmente determinam por que uma pessoa fica doente e outra não. 


\subsubsection{Atividade Muscular e Alterações Somato-Motora}

\section{a) Atividade Muscular Experimental e Alteração Somato-Motora}

Em 1979, CHRISTENSEN ${ }^{23}$ realizou, com 10 adultos e 10 crianças, um estudo sobre limiar e tolerância à dor provocada pelo apertamento dental experimental. Os participantes eram instruídos a apertar seus dentes até que a dor intolerável e a exaustão dos músculos elevadores da mandíbula os forçassem a parar. Durante essas sessões determinavase o limiar de dor (momento de início da dor) e a tolerância à dor (período do início da dor até a cessação do apertamento devido à mesma ter se tornado insuportável). Verificou-se correlação entre limiar e tolerância à dor, ou seja, aparentemente, quanto mais baixo foi o limiar, menor a tolerância._Os indivíduos com alguma história de dor apresentaram níveis de limiar e tolerância à dor menores do que a média. $\mathrm{O}$ autor considerou que o metabolismo

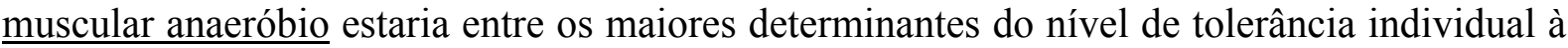
dor muscular decorrente de apertamento dental.

Em 1981, o mesmo autor ${ }^{23}$ realizou uma revisão de literatura sobre dor e fadiga muscular e concluiu que, após aproximadamente $0,5 \mathrm{~min}$ de apertamento dos dentes, ocorre a sensação de fadiga muscular. O autor sugeriu que o início da fadiga seria determinada, em grande parte, pela quantidade de contração isométrica e, talvez pela resistência original do músculo, admitindo a possibilidade de alguma influência dos fatores psicológicos individuais. Ou seja, que a ocorrência precoce da sensação de fadiga muscular deve estar associada a baixos níveis de contração voluntária ou a músculos relativamente fracos - com relação à produção de força. Do mesmo modo, uma percepção tardia do início da fadiga deve estar associada a altos níveis de atividade muscular voluntária ou a músculos relativamente fortes na geração de altos níveis de tensão. Nem o limiar de fadiga ao apertamento dental, nem a atividade elétrica muscular decorrente apresentaram variações intra-individuais significativas estatisticamente; o contrário ocorreu nas análises inter-individuais. Definiu-se como tolerância muscular à dor por apertamento dental como o momento após o início do apertamento em que ocorreu desconforto muscular severo e intolerável, com aumento gradual da sensação subjetiva de exaustão de um ou mais músculos mandibulares, que forçasse o indivíduo a cessar a atividade. A tolerância à dor foi medida em segundos. Definiu-se limiar de dor como o momento em que surgiu a sensação de desconforto intenso em um ou mais 
músculos mandibulares após o início do apertamento. O autor relatou uma relação linear positiva entre os limiares de fadiga e dor muscular ao apertamento dental, sugerindo que o limiar de fadiga pode ser um dos determinantes do limiar de dor, ou que esses dois parâmetros subjetivos podem ser influenciados pelos mesmos determinantes. A atividade elétrica muscular no limiar de dor (70\% da FOVM) é significativamente menor do que no limiar de fadiga muscular $(90 \%$ da FOVM). O autor explica a redução na atividade contrátil como provavelmente uma expressão da fadiga muscular fisiológica progressiva. A dor nos músculos elevadores surgiu após 1 min de apertamento. No mesmo artigo o autor afirma que o nível de atividade mio-elétrica no limiar de dor varia significativamente tanto intra como interindividualmente e que não houve nenhum relacionamento linear entre limiar de dor muscular e sua atividade elétrica. $\mathrm{O}$ autor menciona ainda a possível influência da isquemia decorrente da contração muscular isométrica no início da dor. Entretanto, não forneceu nenhuma explicação conclusiva sobre os mecanismos pelos quais a supressão total ou parcial do fluxo sangüíneo possa ser relacionada à dor dos músculos mastigatórios. A tolerância à dor muscular decorrente do apertamento dental foi de aproximadamente $2 \mathrm{~min}$. Esse resultado não apresentou variações intra-individuais, mas inter-individuais. Os valores de tolerância à dor diferiram significativamente dos valores de limiar de fadiga e dor. Entretanto, houve uma correlação positiva entre o primeiro e os dois últimos, sugerindo que os limiares de dor e fadiga podem estar entre os determinantes da tolerância à dor ou que esses três parâmetros são afetados pelos mesmos determinantes. $\mathrm{O}$ autor sugeriu que a tolerância muscular à dor estaria relacionada aos parâmetros fisiológicos da contração isométrica (isquemia e metabolismo muscular) e também seria influenciada por fatores psicológicos individuais.

Em 1982, CHRISTENSEN; MOHAMED; HARRISON ${ }^{24}$ verificaram os efeitos de diferentes níveis de contração isométrica voluntária dos músculos masseteres sobre o limiar e a tolerância à dor em indivíduos saudáveis. Seis voluntários do sexo masculino, com idade média de 35 anos foram primeiro instruídos a exercitar apertamento dental $(100 \%$ FOVM) durante 10s. Após um intervalo de 5min, o exercício muscular isométrico era repetido (100\% FOVM) até que a dor se iniciasse no músculo masseter direito ou esquerdo (definindo assim o limiar de dor, em segundos). Após outro intervalo de $5 \mathrm{~min}$, realizava-se novamente apertamento dental $(50 \%$ FOVM). Nas três fases do teste foi realizado o monitoramento eletromiográfico dos músculos masseteres. Houve uma correlação positiva 
linear significativa entre a atividade elétrica média da sessão de apertamento a 100\% FOVM $(195,3 \mu \mathrm{V})$ e a atividade elétrica média da sessão de apertamento a 50\% FOVM $(47,4 \mu \mathrm{V})$. Houve também uma correlação positiva linear significativa entre o nível de atividade elétrica no teste de limiar de dor a 100\% FOVM $(209,5 \mu \mathrm{V})$ e a 50\% FOVM $(47,4 \mu \mathrm{V})$. Segundo os autores, o início e o atraso no início da dor após apertamento dental não podem ser totalmente explicados por uma isquemia mais ou menos pronunciada do tecido muscular. Os autores consideram que o início da dor deve relacionar-se ao aparecimento de alguns metabólitos químicos, cujo acúmulo depende da quantidade de tensão isométrica.

SVENSSON; ARENDT-NIELSEN, ${ }^{153}$ em 1996 estudaram o limiar de percepção da dor (LPD) e o limiar de tolerância à dor (LTD) provocada por estímulo de pressão percutânea (palpação), durante 5 dias em que 10 mulheres sem dor, com idade média de 24,2 anos, durante sessões de apertamento dental de baixa intensidade (25\% FOVM) durante 45min. As dez participantes apresentaram níveis moderados de dor $(53,0 \mathrm{~mm} \pm 1,0-$ em EAV $100 \mathrm{~mm})$, sensibilidade $(52,0 \mathrm{~mm} \pm 1,0)$ e desconforto $(56,0 \mathrm{~mm} \pm 0,8)$ e níveis moderados de escore no questionário de dor de McGill - QDM (16,4 \pm 4,9) imediatamente após a sessão de apertamento de baixo nível no primeiro dia. Nos dias seguintes, as sessões de apertamento não aumentaram esses escores. Pelo contrário, ocorreu uma redução significativa no quinto dia de apertamento para intensidade de dor $(-48,9 \% \pm 14,6 \%)$, sensibilidade $(-46,1 \% \pm$ $14,2 \%)$, desconforto $(-50,4 \% \pm 8,5 \%)$ e escores do QDM $(-45,8 \% \pm 13,3 \%)(\mathrm{P}<0,05)$, em comparação ao primeiro dia. O procedimento de apertamento falhou em induzir um aumento progressivo da dor e da sensibilidade nos músculos mastigatórios durante 5 dias. Concluiu-se que nenhum dos parâmetros avaliados levou ao início de um ciclo vicioso em uma população saudável.

Apesar da fraca evidência de que hábitos parafuncionais ou de apertar de dentes não induzidos experimentalmente possam causar sintomas, em 1998, GLAROS; TABACCHI; GLASS, ${ }^{48}$ examinaram o papel do apertamento parafuncional experimental sobre várias medidas de dor e DTM. Cinco indivíduos (3 homens e 2 mulheres, com idades entre 23 e 29 anos) participaram de sessões de treinamento de biofeedback (com 17 minutos de duração cada). As sessões foram organizadas em três fases. Na primeira fase, denominada fase de relaxamento, os indivíduos eram instruídos a realizar a atividade dos músculos temporal e 
masseter abaixo de $2 \mu \mathrm{V}$ durante 10 sessões. Na segunda e terceira fases, os indivíduos eram instruídos a manter a atividade do músculo masseter acima de $10 \mu \mathrm{V}$ (fase de contração, composta por 1 a 8 sessões) e abaixo de $2 \mu \mathrm{V}$ (fase de relaxamento, composta por 10 a 15 sessões) respectivamente. Verificou-se previamente que nenhum dos indivíduos apresentava sintomatologia de DTM, entretanto duas mulheres relataram dor intolerável durante a segunda fase (de contração), e ambas foram diagnosticadas com sintomatologia de DTM durante essa fase, entretanto, a dor tendia a se resolver nas 24 horas seguintes. Era dada aos participantes a opção de parar o treinamento de contração e passar para a fase de relaxamento se a dor fosse intolerável. A decisão de terminar a fase de contração prematuramente não esteve em função dos níveis de atividade eletromiográfica apenas, visto que uma das participantes que o fizeram apresentou a menor atividade EMG média, enquanto a outra apresentou um nível mediano de atividade. Nenhum indivíduo apresentou sintomatologia de DTM durante as fases de relaxamento. Os autores demonstraram que atividade parafuncional crônica, de baixo nível, pode causar dor semelhante à de DTM.

Devido à crescente sugestão de que a dor em alguns bruxômanos representaria um estado de mialgia pós-exercício (MPE), ARIMA; SVENSSON; ARENDT-NIELSEN, ${ }^{10}$ em 1999, examinaram o efeito de movimentos voluntários e controlados de ranger de dentes sobre o desenvolvimento da dor e da sensibilidade no sistema mastigatório. Doze homens saudáveis, com idades entre 21 e 42 anos, sem qualquer sinal ou sintoma de DTM participaram do estudo. No primeiro dia, foram realizadas 9 sessões, com 5 minutos de duração cada, de movimentos repetidos de ranger de dentes, da posição de intercuspidação até a posição de topo-a-topo no canino direito, a uma freqüência de meio ciclo por segundo. A atividade eletromiográfica (EMG) do músculo masseter direito foi mantida em aproximadamente $50 \%$ de sua CVM, por meio do biofeedback. Foram registrados a intensidade de dor, o desconforto e a sensibilidade por meio de EAV de $100 \mathrm{~mm}$ e outras medidas de dor foram registradas pelo QDM. Antes e após cada sessão, era determinada a FOVM e o limiar de dor à pressão (LDP) em 9 diferentes sítios dos músculos masseteres. Os indivíduos retornaram ao laboratório por 3 dias consecutivos, onde novamente eram registrados o LDP, a EAV e a FOVM. Os resultados mostraram que, imediatamente após a

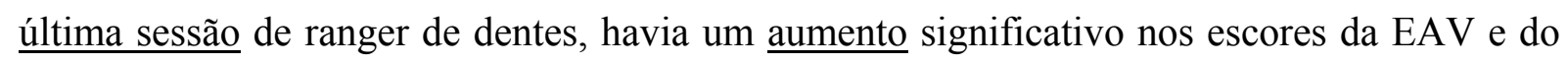
QDM para intensidade de dor, desconforto e sensibilidade, quando comparados aos valores 
iniciais (ANOVA, $\mathrm{p}<0,001)$. Houve ainda um efeito significativo do ranger de dentes nos escores de EAV e sensibilidade muscular nos dias seguintes, com o pico no primeiro dia depois do exercício (teste Tukey, $\mathrm{p}<0,023$ ). A dor foi freqüentemente relatada (em 7 de 12 indivíduos) na ATM ou em sua proximidade. Houve um efeito significativo do ranger de dentes sobre o LDP em ambos os músculos masseteres (ANOVA, p < 0,043) com LDP significativamente inferior (redução de 15 a 20\%) no primeiro dia após o exercício (teste de Tukey, $\mathrm{p}<0$,046). Não houve efeito do ranger de dentes sobre a FOVM. Os autores concluíram que 45 minutos de forte atividade experimental de ranger de dentes padronizada pode evocar mialgia pós-exercício; sintomatologia marginal e auto-limitante, de valores significativos, porém baixos na ATM e músculos mastigatórios de indivíduos saudáveis, nos dias que se seguem ao exercício.

A fim de elucidar se a atividade de ranger de dentes estaria associada à maior sensibilidade a um estímulo intramuscular, ARIMA; SVENSSON; ARENDT-NIELSEN ${ }^{11}$ (2000) compararam os efeitos hiperalgésicos de uma injeção intramuscular de capsaicina no músculo masseter direito com e sem atividade prévia de ranger de dentes. Dez homens saudáveis participaram de duas sessões aleatórias (exercício, não-exercício) separadas pelo intervalo de 1 semana. Imediatamente após a sessão de exercício (quarenta e cinco minutos de atividade de ranger de dentes - similar ao estudo anterior, com 50\% da FOVM), injetou-se $0,1 \mathrm{ml}$ de capsaicina $(100 \mu \mathrm{g} / \mathrm{ml})$ no interior do músculo masseter direito. Na sessão de não exercício, a capsaicina foi injetada, só que o indivíduo não realizou atividade de ranger de dentes. Registrou-se a intensidade de dor provocada pela injeção de capsaicina por meio de uma EAV de $100 \mathrm{~mm}$. As medidas foram tomadas 8 vezes: inicialmente, antes da injeção, cinco, 15 e 45 minutos depois da injeção e uma vez por dia durante os próximos 3 dias. Foram registrados o limiar de dor por estímulo de pressão (LDP), a contração voluntária máxima $(\mathrm{CVM})$ e a dor na EAV. Os resultados demonstraram que a injeção de capsaicina no interior do músculo masseter, exercitado ou não, não causa picos de intensidade de dor significativamente diferentes (valores de EAV: 57,0 \pm 6,0mm, no masseter exercitado e 53,0 $\pm 6,0 \mathrm{~mm}$ e no masseter não exercitado; $\mathrm{p}=0,464$ ). O limiar de dor à pressão (LDP) no

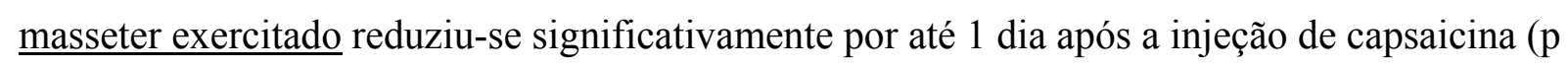
$\leq 0,038$ ), enquanto para o músculo masseter não exercitado, o LDP reduziu-se por apenas 5 min $(\mathrm{p}=0,017)$. A CVM do lado direito estava reduzida 15 minutos após a injeção de 
capsaicina após a sessão de exercício $(\mathrm{p}<0,010)$ e até 5 min após a injeção, na sessão sem exercício. A CVM no lado esquerdo foi significativamente reduzida por 15 minutos após a injeção de capsaicina, apenas na sessão de exercício $(\mathrm{p}<0,019)$. Os autores concluíram que o aumento da sensibilidade à pressão provavelmente reflete uma mialgia pós-exercício conseqüente do ranger de dentes, enquanto a sensibilidade intramuscular a estímulos químicos nocivos imediatamente após o exercício não parece ser alterada, visto que não houve diferenças na intensidade da dor evocada por capsaicina entre os musculares mandibulares exercitados ou não.

SVENSSON; BURGAAD; SCHLOSSER, ${ }^{156}$ em 2001, verificaram os efeitos fisiológicos decorrentes do apertamento leve (10\% da CVM) durante $60 \mathrm{~min}$ em homens assintomáticos. Os autores constataram que todos os participantes relataram sensação de fadiga aumentada nos músculos elevadores da mandíbula durante o exercício (média \pm desvio padrão da $\mathrm{EAV}=7,5 \pm 2,0 \mathrm{~cm}$ ), mas todos foram capazes de manter a força requerida. A maioria também relatou sensação dolorosa $(\mathrm{EAV}=2,7 \pm 2,8 \mathrm{~cm})$. Houve pequena, mas significativa redução da abertura bucal $(59,5 \pm 7,4$ vx 58,3 $\pm 6,5 \mathrm{~mm}, \mathrm{p}=0,031)$ e da CVM $(777 \pm 73$ vs $652 \pm 115 \mathrm{~N}, \mathrm{p}=0,002)$ imediatamente após o exercício, enquanto os LDPs permaneceram inalterados (ANOVA: $\mathrm{p}=0,612$ ). A freqüência média da atividade EMG diminuiu em todos os músculos durante o exercício $(95,7 \mathrm{vx} 46,6 \mathrm{~Hz} ; \mathrm{p}<0,001)$, e o RMS aumentou $(53,2$ vs $154 \mu \mathrm{V}, \mathrm{p}<0,001)$. As alterações na atividade EMG correlacionaram-se mais fortemente com a sensação de fadiga do que com a de dor. Esses achados demonstram que uma sessão de apertamento sustentado de baixa intensidade pode induzir a indicações subjetivas e eletrofisiológicas de fadiga.

CHUNG; KIM; McCALL, ${ }^{25}$ em 2002, investigando as seqüelas do apertamento sustentado, realizaram um experimento que registrou e comparou a duração, a amplitude, o número de fases e a área do potencial de ação de uma unidade motora antes e após o apertamento sustentado e a freqüência média do espectro de força eletromiográfica em 41 indivíduos (29 homens com média de 26,6 anos de idade e 12 mulheres com média de 23,6 anos de idade). Após o apertamento a freqüência média do espectro de força foi menor; a duração e a área do potencial de ação foram maiores. Entretanto a amplitude não diferiu entre os grupos. Também não houve diferença entre o grupo do sexo masculino e feminino. Os 
autores concluíram que os resultados desse estudo eram consistentes com uma redução na velocidade de condução do potencial de ação dos músculos, provavelmente decorrente de fadiga, como uma explicação para a alteração espectral observada.

Em 2004, SVENSSON et al. ${ }^{158}$ testaram os efeitos da dor muscular, no pescoço ou na mandíbula, evocada por injeção de glutamato, sobre a atividade EMG dos músculos mandibulares e do pescoço em 19 homens assintomáticos. Realizaram-se registros da atividade EMG dos músculos masséteres esquerdo (ME) e direito (MD), esternocleidomastóideo direito(ECM) e esplênio da cabeça (SP), em três diferentes posições da cabeça: repouso, extensão para trás, rotação para direita e durante apertamento voluntário máximo. Foi injetado glutamato (1 M) ou salina isotônica no MD ou SP, e a dor induzida foi registrada em escalas analógicas visuais. A atividade EMG no ME e MD aumentou significativamente na posição de extensão para trás, em comparação com o repouso e com a rotação para a direita. A atividade EMG no ECM e SP aumentou progressivamente à medida que a cabeça movia-se da posição de repouso para extensão para trás e rotação para direita. A dor no MD evocada pelo glutamato associou-se com os aumentos na atividade EMG no MD, ECM e SP em repouso, mas não nas posições de extensão e rotação. A dor evocada pelo glutamato no SP associou-se com o aumento na atividade EMG de repouso no SP, e com a redução da atividade no ECM na posicao de rotação parra direita. Reduções na atividade EMG relacionada ao apertamento mandibular foram observadas no ME, MD e ECM, apenas durante a dor evocada pelo glutamato no MD. As injeçoes de salina isotônica não induziram nenhuma dor ou alterações EMG. Os autores concluíram que a dor experimental no pescoço não está associada com aumentos tônicos na atividade EMG mandibular, embora a dor nos músculos mandibulares possa estar ligada a aumentos da atividade EMG no pescoço durante o repouso da cabeça e da mandíbula. 


\section{b) Atividade Muscular Clínica e Alteração Somato-Motora}

DROUKAS; LINDEE; CARLSSON, ${ }^{41}$ em 1985, realizaram uma avaliação clínica (questionário de sintomas subjetivos de DTM, índice de disfunção; consciência de bruxismo; tipo, localização e severidade dos sintomas e características oclusais) de DTM e verificaram que o índice de bruxismo relatado foi positivamente correlacionado com cefaléia e atrição e negativamente correlacionado com sinais de disfunção articular e sobremordida vertical.

Em 1993, GOULET et al. ${ }^{52}$ avaliaram, por meio de entrevista, a influência de fatores psicofisiológicos (auto-relato de níveis de estresse) e comportamentais (auto-relato de apertamento diurno ou bruxismo noturno) na etiologia da DTM. Estimou-se a prevalência do apertamento dental diurno (20\%), ranger de dentes noturno $(6 \%)$ e altos níveis de estresse emocional $(38 \%)$ na população geral $(n=897)$. Aproximadamente um quinto dos indivíduos que relataram hábitos parafuncionais experimentavam dor mandibular e a mesma proporção relatou barulhos articulares. Observou-se uma forte associação entre apertamento diurno e sintomas de DTM. Essa tendência foi moderada para o ranger de dentes noturno e baixa para os altos níveis de estresse. Ocorreu substancial associação dos sintomas de DTM com ambos os hábitos parafuncionais, e essa associação aumentou quando combinava-se aos hábitos parafuncionais, altos níveis de estresse. As medidas de risco relativo, relação das probabilidades "odds ratio" e fração etiológica foram bem mais elevadas entre os sintomas de DTM e o apertamento diurno. Os autores concluíram que comportamentos parafuncionais devem exercer um importante papel na ocorrência dos sintomas da DTM.

JUNGE; CLARK, ${ }^{66}$ em 1993 relataram que apertar os dentes não causa fadiga muscular, pois os músculos compensam a manutenção da atividade muscular por meio do não recrutamento dos neurônios motores ou através de "freqüências de disparo" mais lentas.

Não obstante tenha-se sugerido que o bruxismo é uma causa ou um fator de risco para a DMF, DAO; LUND; LAVIGNE, ${ }^{36}$ em 1994, argumentam que a prevalência de dor e suas características em bruxômanos ainda não haviam sido verificadas ou comparadas àquelas dos pacientes de DMF em geral. Os autores registraram auto-relatos de dor (em escala de análise visual de $100 \mathrm{~mm}$ ) e qualidade de vida (em escala com categorias em cinco pontos) em 
duas populações: 1)19 bruxômanos que participaram de um estudo polissonográfico e 2)61 pacientes com DMF nos músculos mastigatórios sem evidência de bruxismo, que participaram de um estudo clínico controlado da eficácia de placas intra-orais. Os resultados mostraram que a dor era mais intensa nos bruxômanos que relatavam dor do que nos pacientes com DMF, apesar da dor não ser a queixa principal dos bruxômanos. É interessante notar que a análise geral dos níveis de dor de todos os bruxômanos mascararam o fato de alguns indivíduos terem apresentado níveis mais altos de dor $(58 \mathrm{~mm}$ - média dentre os bruxômanos com dor) do que os indivíduos com DMF (20 a 48,6mm). Sendo que a maioria dos bruxômanos era livre de dor. Ambas as condições (bruxismo e dor) reduziam a qualidade de vida dos pacientes, embora os pacientes com dor (em ambos os grupos) parecessem muito mais afetados do que os bruxômanos livres de dor. $\mathrm{O}$ fato de a dor decorrente do bruxismo ter sido pior pela manhã sugere uma possível forma de mialgia pós exercício. A dor dos pacientes com DMF era pior ao anoitecer, sugerindo uma etiologia diferente.

DAO; LUND; LAVIGNE, ${ }^{38}$ em 1994, testaram a dor antes e depois da mastigação em 20 indivíduos assintomáticos (6 homens e 14 mulheres, com idade média de $28,6 \pm 7,8$ anos) e em 61 pacientes (10 homens e 51 mulheres, com idade média de 30,7 \pm 7,5 anos) com dor muscular. Primeiro, foram obtidos auto-relatos de dor por meio de um questionário e de uma escala dividida em cinco categorias (CAT), na sessão de triagem. Nenhum dos indivíduos assintomáticos relatou que a mastigação ou qualquer outro movimento causou dor. Antes do exercício, 80,3\% dos pacientes reportaram ao questionário, dor durante os movimentos mastigatórios. Mais especificamente $67,2 \%$ associaram dor à mastigação, enquanto alguns reportaram dor durante outros movimentos, tais como abertura e fechamento mandibular e bocejo. De forma similar, 78,7\% dos pacientes reportaram que sua dor dificultava a mastigação. Depois de tudo, registrou-se a intensidade da dor em repouso e após a mastigação de cera por $3 \mathrm{~min}$, em uma EAV de 100mm. Nenhum indivíduo assintomático sentiu dor antes ou depois do teste de mastigação, enquanto cerca de $50 \%$ dos pacientes reportaram um aumento na dor após a mastigação. Após o exercício, os escores de dor aumentaram em 48,3\%, mas diminuíram em 31,7\% dos pacientes. Nenhuma alteração foi encontrada em $20 \%$ dos pacientes. No primeiro subgrupo de pacientes, a intensidade média de dor aumentou até $28,3 \mathrm{~mm}$ (um aumento de $102,9 \%$ ), enquanto diminuiu no segundo subgrupo até $26,8 \mathrm{~mm}$ (uma redução de 56,5\%). Quando foram comparados os níveis de dor desses dois 
subgrupos antes do exercício (em repouso), verificou-se que os níveis de dor eram significativamente maiores no subgrupo que apresentou redução da dor com o exercício (47,4 $\pm 5,1 \mathrm{~mm})$, do que no que apresentou aumento da dor com o exercício $(27,5 \mathrm{~mm} \pm 3,1)$. Esses dados mostram que um teste de curto tempo de mastigação pode exacerbar a dor na maioria dos pacientes com DMF, mas não afeta os indivíduos assintomáticos. Surpreendentemente, o exercício reduziu a dor em um importante subgrupo de pacientes. Esses resultados sugerem que pode haver dois subgrupos de pacientes com DMF com reações opostas ao exercício. Resta saber se essas reações se devem a diferentes patologias ou à diferença nos níveis de dor pré-exercício, os quais foram significativamente diferentes nos dois grupos.

DE LEEUW et al., ${ }^{39}$ em 1994, verificaram que a hiperatividade muscular não parece estar associada com desordens da ATM.

Em 1998, KIESER; GROENEVELD ${ }^{70}$ examinaram dados longitudinais de 150 crianças sul africanas (de 6 a 9 anos de idade, com média de 7 anos), durante 5 anos, para verificar a existência de associação entre bruxismo juvenil e desordens temporomandibulares. Dessas, 126 foram reexaminadas 5 anos depois pelo mesmo examinador. O critério de inclusão foi a presença de bruxismo diagnosticado pelo relato de excessivo ranger de dentes e a presença de facetas de desgaste ou abrasão patológica nos dentes. Verificou-se que dentre as 126 crianças com bruxismo, apenas 17 persistiram com o hábito após 5 anos, concordando com outros dados da literatura. Os autores discutem ainda que, apesar de a literatura apontar correlação estatística entre bruxismo, dor articular e muscular, tal correlação não implica em causalidade. Acrescentam que o fato de apenas 30,15\% dos indivíduos desse estudo tenham experimentado dor articular deve-se questionar sobre o papel do bruxismo na geração da disfunção da ATM. Observou-se ainda uma correlação entre os hábitos parafuncionais de bruxismo, onicofagia e sucção do dedo na população estudado. O estudo sugeriu que o bruxismo juvenil é uma condição auto-limitante que não progride para o bruxismo do adulto e que não parece ser uma causa necessária para a DTM.

MOLINA et al., ${ }^{111}$ em 1999, avaliaram 276 pacientes encaminhados ao Centro de Estudo de DTM e Dor Facial para diagnóstico e tratamento e, utilizando-se de questionário, análise da história de sinais e sintomas e exame físico que incluiu palpação dos músculos e das articulações, avaliação dos movimentos mandibulares, busca de pontos- 
gatilho e padrão de dor referida, associados a modelos de estudo, radiografias panorâmica e transcraniana e tomografias quando necessário. Os autores definiam se os pacientes eram ou não portadores de DTM e, em seguida, parte do questionário era utilizado para diagnosticar se o paciente apresentava ou não bruxismo (noturno ou diurno). Em seguida, aqueles pacientes onde era constatada a presença do bruxismo, preenchiam um segundo questionário a fim de alocá-lo em uma das três categorias de severidade de bruxismo. Os critérios utilizados pelos autores para alocar os pacientes com DTM e bruxismo em uma categoria específica incluíam a análise das seguintes características: 1) presença de facetas de desgaste nos dentes; 2) história recente (nos últimos seis meses) de ruídos associados a ranger de dentes noturno, segundo relato de amigo, parente ou cônjuge; 3) relato anamnésico de apertamento diurno; 4) informação anamnésica de tensão ou cansaço durante o dia ou ao acordar; 5) informação anamnésica de despertar a noite apertando ou rangendo os dentes; 6) hipertrofia do músculo masseter e/ou temporal; 7) informação anamnésica de cansaço, dor ou tensão no músculo masseter e/ou temporal ao acordar e/ou durante o dia; 8) relato de travamento das ATM ao acordar; 9) relato de dor cervical ao acordar; 10) relato de fadiga ao acordar ou de sono de baixa qualidade; 11) relato de sensação de desconforto nos dentes ao acordar e 12) história recente de deslocamento crônico de restaurações provisórias ou definitivas. De acordo com o número de itens positivos os pacientes eram então alocados a uma das três categorias específicas de severidade de bruxismo. Ao analisarem os resultados, os autores sugerem que os pacientes portadores de bruxismo severo apresentam também mais desordens musculares e articulares, levando-os a indicar uma modificação na terapia para DTM no sentido de proteger, por períodos de tempo mais longos, as articulações e os músculos de pacientes portadores de bruxismo severo.

PERGAMALIAN et al., ${ }^{119}$ em 2003, buscaram determinar se havia associação entre desgaste dentário, bruxismo, dor na ATM e severidade de dor muscular em uma população com DTM. 84 pacientes de DTM (RDC/TMD) participaram do estudo. As medidas das facetas de desgaste foram feitas nos modelos por meio de uma escala de 4 pontos. $\mathrm{O}$ bruxismo foi diagnosticado por meio de um questionário (RDC/TMD) que indicava quão freqüentemente os indivíduos realizavam uma lista de hábitos orais, dentre eles, bruxismo $(0=$ nunca até $3=$ muito freqüentemente). Era questionado aos indivíduos sobre a freqüência de apertamento; de acordar com a sensação de que rangeu ou apertou os dentes durante o sono; 
de ter os músculos sensíveis devido ao apertamento e de ranger os dentes à noite. A dor muscular foi uma medida da soma dos achados do exame odontológico (variando de 0 a 20), calculada a partir da presença ou ausência de dor em 20 sítios musculares pré-determinados) De forma similar, a dor articular foi uma medida da soma da presença ou ausência de dor nas ATMs induzida por palpação nas articulações na superfície externa e no canal auditivo externo em 5 diferentes posições mandibulares. Na população testada, o desgaste dentário correlacionou-se modestamente com a idade $(\mathrm{r}=0,40, \mathrm{p}<0,001)$. Dentre os 84 indivíduos estudados, 11,9\% não relataram qualquer atividade de bruxismo, 32,1\% relataram atividade ocasional e 47,6\% relataram atividade freqüente de bruxismo. Os 8,4\% remanescentes foram eliminados da análise por fornecerem respostas inconsistentes. A atividade de bruxismo não se correlacionou significativamente com desgaste dentário, dor articular ou muscular. Os autores concluíram que, o desgaste dentário não diferenciou pacientes com e sem bruxismo. A intensidade do bruxismo não esteve associada com maior severidade de dor muscular e associou-se com menos dor articular à palpação.

BABA et al. ${ }^{12}$ (2005) realizaram EMG do masseter durante 6 noites consecutivas em 103 indivíduos sem queixa de DTM a fim de verificar a presença de associação entre sinais e sintomas de DTM e os níveis de atividade do músculo masseter. Todos os participantes realizaram um exame físico de DTM padronizado por examinadores calibrados. Verificou-se a presença de associação entre o gênero masculino e sons articulares e a duração da atividade EMG. Nenhuma das demais variáveis independentes (sinais e/ou sintomas de DTM) apresentaram qualquer relação significativa com a duração da atividade EMG do masseter durante o sono.

GLAROS; WILLIAMS; LAUSTEN, ${ }^{49}$ em 2005, examinaram o grau em que parafunções e estados emocionais poderiam predizer dor mandibular em indivíduos com DTM (DMF, DMF e artralgia ou deslocamento de disco) e em indivíduos controle. Verificouse que os pacientes de DMF apresentaram medidas mais elevadas do que os demais para dor, tensão nos músculos mastigatórios, tempo e intensidade do contato dentário, humor e estresse.Os autores usaram a tensão nos músculos mastigatórios, e a variável composta (humor e estresse) para predizer a dor mandibular por meio do teste de regressão linear. $\mathrm{O}$ modelo foi significativo e respondeu por 69 por cento da variação na dor muscular. Devido à 
alta correlação de tensão com dor mandibular, os autores removeram essa variável e refizeram a análise. O segundo modelo foi significativo e respondeu por 46 por cento da variação na dor mandibular. Desse modo, concluiu-se que parafunções, especialmente aquelas relacionadas ao aumento da tensão muscular e aos estados emocionais são bons preditores dos níveis de dor mandibular em pacientes com DTM e em indivíduos controle.

No mesmo ano, RAPHAEL; SIROIS, ${ }^{127}$ em carta enviada ao periódico The Journal of American Dental Association, criticaram o artigo previamente citado $^{49}$ pelo emprego do método de coleta de dados sobre as parafunções diurnas: verificação lógica momentânea ("logical momentary assessment - EMA"). Segundo os autores, o auto-relato de bruxismo tem validade questionável e sugerem o emprego de estudo EMG com monitoramento audiovisual. Os autores consideram que, embora o método EMA possa ser adequado na verificação da dor, o mesmo ainda necessita ser validado como método de diagnóstico do bruxismo, reiterando que, se há métodos EMG validados como adequados a essa finalidade, não haveria razão para o emprego do auto-relato para o diagnóstico do bruxismo diurno.

VAN DER MEULEN et al ${ }^{162}$ (2006) examinaram a relação entre diferentes tipos de parafunções (auto-relato) e a intensidade de queixas de dor de DTM em uma população de pacientes de DTM. Foi realizada uma avaliação de "freqüência" e outra de "estresse" das atividades parafuncionais. A análise das respostas gerou três escalas para cada avaliação: (1) BRUX: para atividades de bruxismo; (2) BITE: para atividades de mordida (ex. goma de mascar, onicofagia); e (3) SOFT: para atividades relacionadas aos tecidos moles (ex: língua, lábios). Os autores não encontraram qualquer relacionamento clinicamente relevante entre o auto-relato dos diferentes tipos de parafunções orais e queixas dolorosas de DTM. 


\subsubsection{Dor e Alterações Motoras}

\section{a) Dor Experimental e Atividade EMG Durante Condições Estáticas}

STOHLER; ZHANG; LUND, ${ }^{151}$ em 1996, examinaram, por meio de EMG, a atividade postural dos músculos temporal, masseter, de ambos os lados, em quatro situações experimentais: 1) ausência de dor; 2) dor tônica: provocada pela infiltração de solução salina hipertônica no corpo do músculo masseter - dor tônica; 3) dor simulada: lembrar e reviver experiência passada de dor e 4) ausência de dor. Quando da situação 2, à medida que era infiltrada a solução salina, o nível de dor do paciente era monitorado por meio de EAV eletrônica e coletavam-se os dados eletromiográficos quando o nível de dor estivesse relativamente estável entre 40 a $60 \mathrm{~mm}$. Após esse procedimento, cessava-se a infusão e a dor diminuía para 0 , dentro de $5 \mathrm{~min}$. Para a situação 3 , do mesmo modo, a coleta dos dados eletromiográficos era realizada quando o nível de dor situava-se entre 40 a $60 \mathrm{~mm}$. Para as situações 1 e 4, era requerido o nível de dor entre 0 e $2 \mathrm{~mm}$. Como resultados, as situações 1 , 2, 3 e 4 exerceram um efeito significativo sobre a atividade eletromiográfica nos 4 sítios de registro (músculos temporais e masseteres, de ambos os lados). A atividade postural nos quatro sítios de registro foi maior durante a dor tônica e simulada em comparação à situação 1. Ou seja, o aumento significativo da atividade eletromiográfica integrada (RMS) durante a dor tônica foi quase o mesmo daquele durante a dor simulada. Tanto que essas duas situações não poderiam ser distinguidas uma da outra, quando comparadas às situações de atividade EMG de repouso. Os autores atribuíram o aumento da atividade EMG durante as situações de dor tônica e simulada à atividade modificada por programas motores e acompanhada de expressões faciais e gestos relacionados à dor, não exercendo o papel de fator patogênico responsável pela dor. Concluiu-se que os dados não deram suporte ao modelo de ciclo vicioso entre dor e hiperatividade muscular.

GRAVEN-NIELSEN et al., ${ }^{53}$ em 2002, investigando se a fraqueza muscular, que freqüentemente acompanha as condições de dor musculoesqueletal deve-se a processos periféricos ou centrais, verificaram o efeito da dor muscular experimental induzida por injeção de salina hipertônica, sobre o torque de contração voluntária máxima e as propriedades contráteis periféricas do mesmo. A dor muscular experimental reduziu o torque produzido pela extensão isométrica do joelho durante a injeção de salina hipertônica, mas as 
propriedades contráteis verificadas por interpolação twich não foram afetadas. Isso indica que a inibição da força muscular pela dor é mediada centralmente. Esse achado tem implicação clínica na reabilitação e treinamento de pacientes com dor musculoesqueletal, em que não é evidente o dano muscular.

RO; SVENSSON; CAPRA, ${ }^{135}$ em 2002, realizaram um estudo cujo objetivo era investigar os efeitos do estímulo químico nocivo dos músculos mandibulares sobre a atividade eletromiográfica (EMG) postural. Foram estudados os músculos masseter, temporal e digástrico de ratos levemente anestesiados. Realizou-se injeção unilateral de uma substância que, sabidamente, induz à dor muscular aguda $(\mathrm{NaCl} 5 \%)$ ou à dor de maior duração com inflamação (óleo mostarda) no interior do músculo masseter. Registrou-se a atividade EMG após a injeção nos músculos masseteres (ipsi e contralateral) e digástrico ipsilateral. Todas as substâncias químicas algogênicas produziram um aumento significativo da atividade EMG, embora de curta duração. Os dados do presente estudo e observações similares de estudos clínicos e experimentais em humanos sugerem que o aumento da atividade EMG dos nociceptores musculares não foi suficiente para produzir um aumento prolongado da atividade EMG postural. Portanto, o desenvolvimento e manutenção de dor crônica dos músculos mandibulares não parecem resultar de um mecanismo cíclico de feedback.

\section{b) Dor Clínica e Atividade EMG Durante Condições Estáticas}

Em 1982, SHEIKHOLESLAM; MÖLLER; LOUS $^{141}$ realizaram um estudo longitudinal em que foram comparados os dados clínicos de dor e desconforto com registros eletromiográficos durante a atividade máxima e postural dos músculos temporal (porções anterior e posterior) e masseter de 37 pacientes antes e depois do tratamento de desordens funcionais do sistema mastigatório (placas oclusais, ajuste oclusal e combinação de ambos). Quarenta e três estudantes serviram como controle. O tratamento seguiu-se de concomitante redução da dor, do desconforto e da atividade postural relativa. Em valores absolutos, houve uma redução de 1,5 a $2,0 \mu \mathrm{V}(\mathrm{p}<0,01)$ na atividade do músculo temporal anterior; de cerca de $2 \mu \mathrm{V}(\mathrm{p}<0,01)$ na atividade do músculo temporal posterior e de 0,5 a $1 \mu \mathrm{V}(\mathrm{p}<0,001)$ na atividade do músculo masseter. Após o tratamento, a atividade postural relativa nos pacientes 
diminuiu de forma significativa e tornou-se mais simétrica nos músculos temporais anteriores, enquanto houve uma tendência de redução nos músculos temporal posterior e masseter embora ainda excedesse, de forma significativa, a atividade postural relativa do grupo controle. A atividade durante a CVM na posição de intercuspidação, não foi alterada pelo tratamento e foi significativamente inferior à do grupo controle. Entretanto, em contraste com a atividade postural relativa, não foi alterada com a redução da dor e do desconforto. Ocorreram alterações quanto à simetria da ação entre os lados direito e esquerdo, principalmente para o temporal posterior e o masseter. Uma vez que o tratamento envolveu a correção da oclusão, os autores concluíram que as condições intermaxilares dos contatos dentários durante a função exercem um papel na etiologia das desordens funcionais e que a redução do carregamento postural relativo dos músculos elevadores dos pacientes pelo tratamento contribui para o alívio das desordens funcionais. $\mathrm{O}$ valor relativamente alto de atividade postural relativa mostrado pelos pacientes, mesmo após o tratamento, pode explicar, segundo os autores, a flutuação dos sinais e sintomas das desordens funcionais do sistema mastigatório, o que enfatiza a necessidade de melhores métodos de tratamento para reduzir a probabilidade de recorrência.

Em 1984, CLARK; BEEMSTERMOER; JACOBSON ${ }^{28}$ estudaram os efeitos de uma sessão de apertamento isométrico sustentado (30\% CVM) sobre o nível da força oclusal voluntária máxima (FOVM) em pacientes com DTM e em indivíduos controle. Os resultados indicaram que os pacientes apresentavam menores FOVM e tempo de desempenho do que os indivíduos controle. Nenhum dos indivíduos da amostra apresentou mudança na FOVM breve após a sessão de fadiga induzida. Esses resultados sugerem uma falha nos elementos contráteis dos músculos de fechamento mandibular após apertamento isométrico sustentado abaixo do nível máximo.

SHERMAN, ${ }^{142}$ em 1985, não encontrou diferenças na atividade EMG de repouso entre bruxômanos, com e sem DTM, e não-bruxômanos, com e sem DTM, mas verificou que os bruxômanos, apresentavam níveis eletromiográficos de repouso maiores do que os não bruxômanos. Ou seja, os bruxômanos exercitam seus músculos mais do que o normal e apresentam níveis eletromiográficos de repouso mais elevados do que os indivíduos controle, independentemente da presença de dor. 
HIGH; MACGREGOR; TOMLINSON, ${ }^{60}$ em 1988, mediram níveis subjetivos de dor e níveis de CVM antes e após a exodontia de terceiros molares, e verificaram redução significativa da CVM de quase todos os indivíduos no período pós-operatório.

Em 1994, PAESANI et al. ${ }^{118}$ analisaram a atividade EMG de repouso em 10 indivíduos assintomáticos (5 homens e 5 mulheres) e 5 mulheres com desarranjos internos da ATM (diagnosticados por meio de ressonância magnética de alta resolução). Não foram verificadas diferenças estatisticamente significativas entre a atividade EMG de repouso dos músculos masseter e temporal entre os grupos assintomáticos e com desarranjos articulares.

Em 1997, GLAROS; GLASS ${ }^{47}$ testaram a hipótese de que a atividade eletromiográfica de repouso deveria ser significativamente maior nos pacientes com DMF do que em indivíduos controle e que poder-se-ia estabelecer um escore limítrofe, baseado nos valores EMG, para distinguir os dois grupos. Foram examinados 54 pacientes de com dor miofascial e 54 indivíduos controle, compatíveis em idade e sexo. Ambos os grupos participaram de um procedimento de leitura EMG dos músculos frontais, temporais e masseteres. O grupo com DTM apresentou atividade EMG de repouso significativamente maior, para 3 dos 6 sítios examinados. Entretanto a aplicação de um valor de corte que produziu o menor erro de classificação resultou em classificação inadequada de aproximadamente um terço dos indivíduos.

PINHO et al., ${ }^{123}$ em 2000, realizaram EMG de superfície nos músculos mastigatórios de 40 pacientes com DTM. Esses pacientes apresentavam queixas de dor temporomandibular e estalidos articulares. Na maioria dos casos $(75 \%)$ os sintomas afetavam o lado esquerdo da face. A média geral da atividade EMG de repouso foi de 2,52 $\pm 1,25 \mu \mathrm{V}$, levemente superior à média dos indivíduos controle $(1,92 \pm 1,20 \mu \mathrm{V})$. A atividade média de repouso mais alta ocorreu no músculo digástrico $(3,49 \mu \mathrm{V})$ do lado esquerdo. A média geral de atividade durante o apertamento foi de $66,77 \pm 35,22 \mu \mathrm{V}$, aproximadamente metade daquela observada nos indivíduos controle $(110,30 \mu \mathrm{V} \pm 82,97)$. Durante o movimento da mandíbula em direção ao lado esquerdo, a maior média de atividade ocorreu no músculo digástrico do lado esquerdo, enquanto, durante o movimento para a direita, a maior média de atividade ocorreu na porção anterior do músculo temporal direito. Os resultados indicaram que os pacientes com desordens na ATM apresentam: 1) um leve aumento no tônus basal; 2) uma 
significativa redução da capacidade de apertamento e 3) uma inibição aparentemente paradoxal do músculo temporal anterior no lado mais afetado durante os movimentos em direção a este lado.

BODERÉ et al., ${ }^{15}$ em 2005, mediram a atividade EMG dos músculos mastigatórios de pacientes com diferentes condições de dor orofacial (33 pacientes com DMF e 20 com dor neuropática), 27 não pacientes com desordens de desarranjo de disco e 32 indivíduos controle (assintomáticos). A atividade EMG dos músculos masseter e temporal durante o repouso foi significativamente maior nos grupos de pacientes com dor (DMF e dor neuropática) do que no grupo controle e no grupo com desarranjos internos (exceto pelo masseter direito do grupo de dor neuropática). Não houve diferença na atividade EMG de repouso entre os grupos controle e com desarranjos internos. A amplitude do reflexo massetérico estava reduzida em todos os grupos de pacientes em relação ao grupo controle. Nos grupos de pacientes com dor, o aumento da atividade EMG de repouso e a redução da amplitude do reflexo massetérico estavam homogeneamente distribuídas nos lados com e sem dor. Além disso, indivíduos com dor bilateral apresentaram maior atividade EMG durante o repouso do que os aqueles com dor unilateral. Esses resultados sugerem que a modulação da atividade muscular não foi uma conseqüência direta dos mecanismos nociceptivos periféricos e parecem indicar a atuação de um mecanismo central. $O$ contraste entre o aumento da atividade EMG de repouso e a redução da amplitude do reflexo massetérico pode significar que a modulação dos motoneurônios difere nas condições tônicas e fásicas em pacientes de dor crônica.

\section{c) Dor Experimental e Atividade EMG durante o Movimento}

Em 1995, SVENSSON; ARENDT-NIELSEN; HOUE ${ }^{154}$ realizaram dois experimentos. No primeiro, estudaram-se os efeitos sensoriais da dor. Provocou-se dor experimental por meio da injeção de $0,15 \mathrm{ml}$ de solução salina hipertônica (5\%) no interior do músculo masseter de 10 indivíduos do sexo masculino sem DTM. A experiência sensorial foi descrita por meio de uma EAV de 100mm e pelo questionário de dor de McGill (QDM). No segundo experimento, estudaram-se as interações entre dor nos músculos mandibulares e 
mastigação, em 13 indivíduos sem DTM, do sexo masculino, distintos do primeiro grupo. Verificaram-se quantitativamente os efeitos da dor sobre a mastigação deliberada unilateral, por meio de registros cinemáticos da mandíbula e EMG dos músculos mandibulares. A injeção de salina 5\% levou a perfis de EAV e características do QDM similares. O deslocamento da mandíbula durante a mastigação dolorosa foi significativamente menor no eixo vertical $(10,0 \pm 11,5 \%, \mathrm{p}<0,05 \%)$ e no eixo lateral $(22,6 \pm 20,9 \%, \mathrm{p}<0,05)$ quando comparada aos valores da mastigação não dolorosa. A abertura média e as velocidades de fechamento da mandíbula foram significativamente reduzidas $(10,5 \pm 16,3 \%$ e 15,3 $\pm 21,2$, $\mathrm{p}<0,05)$; as distâncias acumuladas do movimento mandibular também foram significativamente menores durante $a$ dor $(10,4 \pm 11,8 \%, \quad \mathrm{p}<0,05)$. A atividade eletromiográfica dos músculos agonistas durante a dor foi significativamente inferior no músculo masseter ipsilateral $(20,3 \pm 25,4 \%, \mathrm{p}<0,05)$ quando comparada aos valores pré-dor. Os autores concluíram que as interações sensoriais-motoras podem ser explicadas por um efeito facilitatório da atividade dos aferentes nociceptivos musculares sobre os interneurônios inibitórios do tronco encefálico durante a ação agonista. Assim, são gerados movimentos $\underline{\text { menos amplos e mais lentos, }}$ o que mais provavelmente representa uma adaptação funcional à dor muscular mandibular experimental.

O estudo de MATRE et al., ${ }^{102}$ em 1998, investigou o efeito da dor muscular experimental em humanos sobre o reflexo-H (Hoffman) e de estiramento como indicadores de alterações na sensibilidade dos fusos musculares. Participaram do estudo 14 voluntários do sexo masculino, sem dor. A dor muscular foi produzida por meio de infusão de salina hipertônica durante o período de 10-15 minutos no músculo sóleo e no músculo tibial anterior. Os reflexos foram evocados no músculo sóleo relaxado e ativo (torque no tornozelo de 10 a $15 \mathrm{Nm}$ ) antes, durante e depois da dor muscular. As mensurações controle foram feitas com infusões de salina fisiológica $(0,9 \%)$. Mediu-se a atividade eletromiográfica de superfície do músculo sóleo e o torque da articulação do tornozelo, para averiguar o reflexo de estiramento. Na presença de dor no músculo sóleo, a resposta reflexa de estiramento (torque no tornozelo) aumentou significativamente $(\mathrm{p}=0,0007)$, em comparação ao período pré-dor. Com dor no músculo tibial anterior, tanto a resposta mecânica quanto a resposta EMG aumentaram significativamente no músculo sóleo $(p=0,001 ; p=0,0003)$ em comparação ao período pré-dor. O reflexo-H não apresentou quaisquer alterações significativas durante as 
infusões em ambos os músculos. Esse estudo demonstrou um aumento relacionado à dor na amplitude dos reflexos de estiramento sem um aumento correspondente na amplitude do reflexo-H. Uma explicação pode ser um aumento na sensibilidade dinâmica dos fusos musculares durante a dor muscular causada por um aumento na taxa de disparo dos motoneurônios- $\gamma$ dinâmicos, evidenciado pelo aumento na resposta do reflexo de estiramento. Entretanto os dados podem não suportar o modelo do ciclo vicioso porque a excitabilidade dos motoneurônios alfa não foi alterada, evidenciado pela não alteração do reflexo-H.

Visando ampliar a compreensão acerca da influência da dor muscular sobre a atividade motora, SVENSSON; ARENDT-NIELSEN; HOUE, ${ }^{155}$ em 1998, realizaram um estudo com os objetivos de determinar o efeito da dor muscular experimental constante sobre a função motora mandibular, especificamente a mastigação ipsi e contralateral frente à infusão de solução salina hipertônica (5\%); analisar o padrão mastigatório ciclo-a-ciclo e estudar a influência da dor muscular sobre a função motora isométrica dos músculos mastigatórios. Nesse estudo, a dor foi induzida no músculo masseter por meio da infusão tônica da solução salina em 12 homens sem DTM. Antes, durante e após os períodos de dor muscular constante, analisou-se quantitativamente a mastigação por meio de traçado do movimento mandibular e de registros eletromiográficos dos músculos elevadores da mandíbula. Também foi monitorada a força oclusal voluntária máxima (FOVM). Em todos os indivíduos, a infusão tônica causou uma dor profunda localizada de intensidade clínica relevante (EAV média \pm $\mathrm{DP}, 46,00 \pm 3 \mathrm{~mm})$. A FOVM foi afetada de forma significativa pela dor muscular $(\mathrm{p}<$ 0,0005), com valores significativamente inferiores durante a dor em comparação aos períodos pré e pós-dor $(\mathrm{p}<0,05)$. Em um número significativo de ciclos mastigatórios, a atividade eletromiográfica média de todos os músculos elevadores da mandíbula diminuiu durante sua função agonista ipsi e contralateral à dor $(\mathrm{p}<0,05)$. Essas mudanças eletromiográficas são provavelmente um reflexo do padrão natural de recrutamento bilateral dos músculos elevadores da mandíbula durante a mastigação. Não foram detectadas alterações significativas nos movimentos mandibulares durante a mastigação dolorosa por meio do dispositivo de traçado mandibular. Os autores concluíram que a dor experimental nos músculos $\underline{\text { mandibulares levou à redução de sua capacidade de trabalho contra carga, o que está de }}$ acordo com uma adaptação funcional à dor muscular. Provavelmente, a finalidade biológica dessa adaptação é permitir o reparo da área traumatizada. 
Em 2002, TURP et a. ${ }^{161}$ investigaram se a dor discreta evocada pela injeção de solução salina poderia modificar a reação sensorial-motora (EMG) do músculo masseter, em 20 homens assintomáticos, durante a mastigação unilateral. Observou-se uma redução no músculo masseter ipsilateral à injeção no sentido antero-posterior. À medida que a distância do local da injeção aumentava, reduzia-se também a inibição da atividade. Os resultados suportam a idéia de que uma estratégia de ativação diferencial protege o músculo afetado ao mesmo tempo em que mantém a função em ótimo estado.

\section{d) Dor Clínica e Atividade EMG Durante o Movimento}

Em 1986, CLARK; LYNN ${ }^{30}$ registraram e compararam três parâmetros do movimento mandibular (magnitude, reprodutibilidade e velocidade) no plano horizontal de 20 indivíduos controle e 20 pacientes que procuraram tratamento para DTM. Na primeira parte do estudo observou-se a extensão do movimento mandibular no plano horizontal por meio de um dispositivo de traçado do movimento mandibular. Executaram-se os movimentos lateral direito completo, lateral esquerdo completo e protrusivo completo, três vezes cada. Foi realizada, previamente ao registro, uma sessão de treino de reprodutibilidade dos movimentos com feedback visual da trajetória do movimento. A sessão de registro foi então realizada sem o feedback visual. O grupo controle e o grupo com DTM não diferiram de maneira significativa com relação à magnitude dos movimentos Laterais ou protrusivos. Mas os indivíduos controle apresentaram uma velocidade retrusiva maior do que os pacientes com DTM. A habilidade dos pacientes com DTM em realizar com precisão os movimentos laterais direito e esquerdo foi marcadamente reduzida.

STOHLER; ASHTOWN-MILLER; CARLSON,${ }^{150} \mathrm{em} 1988$, estudaram o padrão de mastigação habitual de 12 indivíduos dentados com sintomatologia de dor e disfunção articular e muscular e 12 indivíduos saudáveis controle. Executou-se o registro eletromiográfico bilateral dos músculos elevadores e dos movimentos mandibulares durante três seqüências mastigatórias completas. Utilizou-se análise computadorizada para classificar os movimentos mastigatórios como contínuos ou descontínuos. Embora ciclos mastigatórios descontínuos tenham sido significativamente mais freqüentes durante a função dolorosa $(\mathrm{p}=$ 0,001), eles também ocorreram durante a função livre de dor, o que reduz seu valor de diagnóstico. Quando usados como antagonistas, como durante a abertura mandibular, os 
músculos elevadores apresentaram atividade com maior pico médio durante a função dolorosa do que não dolorosa $(\mathrm{p}=0,0001)$.

WARE; RUGH, ${ }^{169}$ em 1988, procuraram correlacionar a severidade do quadro clínico de pacientes com queixas de dor relacionada à DTM à peculiaridades do bruxismo noturno, tais como o estagiamento. Os autores selecionaram três grupos de pacientes: Grupo 1) chamado de grupo destrutivo, consistia de cinco pacientes do sexo feminino, com idade entre 24 e 33 anos. Os pacientes apresentavam queixas de severa dor na ATM e músculos mastigatórios, provavelmente causadas por bruxismo crônico relacionado ao sono. Todas as pacientes exibiam excessivo desgaste dentário e dor. A presença do bruxismo nesse grupo foi confirmada por meio de monitoramento eletromiográfico do músculo masseter por meio de unidade eletromiográfica portátil. Todas as pacientes também apresentavam sinais de depressão. Duas pacientes estavam livres de medicação e as demais tomaram alguma medicação apenas na manhã antes da avaliação. Grupo 2) constituído de pacientes portadores de bruxismo (diagnosticado por meio da unidade eletromiográfica portátil), porém sem sinais ou sintomas de DTM. Os pacientes apresentavam queixa de insônia e excessiva sonolência diurna e seis estavam livres de medicação. A maioria apresentava diagnóstico de insônia psicosocial ou apnéia. Com idades entre 21 e 55 anos. Grupo 3) Grupo controle, constituído de 35 pacientes do sexo feminino com depressão, porém livres de medicação e sem queixas de bruxismo. A idade das pacientes variava de 25 a 38 anos. Apenas a primeira noite de exame foi analisada e a atividade de bruxismo foi medida por um técnico experiente como parte dos registros de rotina da polissonografia. Como resultados, os autores verificaram a baixa ocorrência de bruxismo no grupo 3 (com depressão) em comparação aos demais grupos. O grupo 1 (bruxismo destrutivo) e o grupo 2 (bruxismo não destrutivo) não diferiram, exceto quanto à quantidade de eventos de bruxismo na fase REM do sono. $\mathrm{O}$ grupo 1 apresentou o número e a duração dos episódios de bruxismo significativamente maior durante o estágio REM do sono do que o grupo 2. Os grupos 2 (bruxismo não destrutivo) e 3 (com depressão) não diferiram quanto aos episódios de bruxismo na fase REM do sono. O número de bursts fásicos por episódio não variou significativamente entre os grupos em qualquer estágio do sono, nem o padrão de bruxismo (fásico, tônico-fásico e fásico-tônico) variou entre os grupos. O padrão fásico foi o predominante entre os grupos. 
NIELSON et al., ${ }^{113}$ em 1990, observaram que indivíduos com desordens temporomandibulares (dor nos músculos mandibulares e do pescoço; dor nesses mesmos músculos associada a degerenaracão articular e dor apenas nos músculos mandibulares) usaram os temporais anteriores em menor intensidade e freqüência do que indivíduos assintomáticos durante várias respostas. Essas respostas incluíam movimentos de fechamento vertical rápido, retrusão, laterotrusão ipsilateral e mastigação natural e contralateral. Os músculos masseteres também foram menos recrutados, embora com menor intensidade que os temporais e o recrutamento $\mathrm{s}$ músculos supra-hioídeos não foram afetados Durante $\mathrm{o}$ apertamento, os indivíduos com DTM apresentavam recrutamento severamente assimétrico desses músculos.

SPILKER, ${ }^{146}$ em 1991, explica que muitos tipos de relação podem ser observados entre duas condições. Por exemplo, quando se trata de um relacionamento de causa-e-efeito direto ou indireto, na verdade, devido à presença de subjetividade, tal relação pode não existir efetivamente, até o ponto em que pode ser possível a não existência de nenhum tipo de relação entre ambas, sendo estas, portanto, completamente independentes. Logo, a fim de perscrutar o tipo de relacionamento existente entre BS e DTM, dever-se-ia eliminar toda subjetividade, erro e influências que possam confundir a análise.

Devido às recentes evidências experimentais sugerindo que dor muscular nem sempre causa hiperatividade no ser humano, LAVIGNE et al., ${ }^{82}$ em 1997, investigaram a influência da dor sobre a atividade de BS. As medidas das variáveis oromotoras (burst/episódio; episódio/hora) foram comparadas entre dois subgrupos de bruxômanos: 1) 6 pacientes (3 homens e 3 mulheres, com idade média de 25,3 anos $\pm 3,6$ ), cuja queixa principal era BS e relatos de dor (não miofascial) nos músculos mastigatórios; 2) 7 indivíduos (5 homens e 2 mulheres, com idade média de 27,3 \pm 4,8) com bruxismo sem nenhuma dor. Todos os participantes passaram por duas noites consecutivas de exame polissonográfico, sendo a primeira para o condicionamento do paciente ao ambiente e para a coleta de dados que pudessem excluí-lo. Antes e após da segunda noite, na qual seria realizada a coleta de dados para análise, os pacientes registravam seus índices de dor em uma EAV de 100mm. Enquanto os indivíduos sem dor registraram valores de EAV iguais a zero, os indivíduos com dor marcaram índices médios de 36,7 $\pm 28,2 \mathrm{~mm}$, antes de dormirem e 44,0 $\pm 28,3 \mathrm{~mm}$ ao 
amanhecer. A fim de evitar que fatores como dor crônica pudessem afetar os resultados, foram excluídos pacientes com dor miofascial, fibromialgia ou qualquer desordem temporomandibular artrogênica. Os resultados mostraram que, na presença de dor (nãomiofascial) encontrou-se um número de episódios/hora 40\% menor, do que nos indivíduos sem queixa de dor. Os autores, entretanto, recomendaram cautela na interpretação desses resultados devido ao reduzido tamanho da amostra e sugeriram ainda investigações sobre a natureza do relacionamento entre bruxismo (e suas características, episódios fásicos ou tônicos) e a dor muscular, incluindo estudos com dor experimental ou experiências de multicentros colaboradores.

Não obstante a literatura científica apresente sérias críticas e contestações ao relacionamento direto entre bruxismo e DTM. LOBBEZZO; LAVIGNE, ${ }^{82,} 90$ em 1997, enfatizam que, quando da avaliação da existência de relação de causa-e-efeito entre duas entidades biológicas, os fatores de subjetividade deveriam ser diminuídos até o ponto de não serem percebidas, embora admitam a impossibilidade de sua completa eliminação (ou seja, $100 \%$ de certeza), sugerindo que se busque a maior probabilidade de segurança possível. Os autores indicam portanto, a adoção de um modelo de estudo duplo-cego, a fim de minimizar o erro e a tendência. Indicam também que, deve-se buscar estabelecer uma associação consistente, ou seja, o maior grau de reprodutibilidade possível entre os experimentos, bem como uma relação temporal onde a causa preceda o efeito. Sugerem ainda, a observação de um gradiente dose-resposta positivo, no qual, quanto mais intensa ou presente for a causa, mais forte será o efeito. E, por fim, acrescentam que a associação deve apresentar concordância com os achados epidemiológicos e especificidade, ou seja, o efeito não poderá ocorrer sem que a causa tenha acontecido previamente. Os autores resumiram os critérios de estabelecimento de relação causa-e-efeito (modificados de SPILKER, ${ }^{146}$ 1991) em: 1) ausência de subjetividade, erro ou influências que possam confundir a análise; 2) estabelecimento de uma associação consistente; 3) relação temporal onde a causa preceda o efeito; 4) presença de gradiente dose-resposta; 5) concordância com achados epidemiológicos e 6) especificidade da associação.

Em 2001, ARIMA; ARENDT-NIELSEN; SVENSSON ${ }^{9}$ realizaram um estudo com o objetivo específico de avaliar o efeito da dor e do desconforto (clínicos e 
experimentais) dos músculos mandibulares sobre a atividade motora orofacial do sono. Doze indivíduos saudáveis, com idades entre 21 e 31 anos, participaram desse estudo. Todos tinham ciência de seus sinais e sintomas de atividade motora orofacial durante o sono e foram subdivididos em um grupo com queixas de dor clínica $(n=5)$ e um grupo sem dor $(n=7)$. Todos os indivíduos dormiram em um laboratório por 3 noites consecutivas, incluindo uma noite de adaptação, uma noite de registro inicial e uma noite experimental. Foram realizados durante o sono, o EEG e a EMG dos músculos masseteres. Na noite experimental, antes de dormir, todos os indivíduos receberam uma injeção de capsaicina $(0,1 \mathrm{ml}, 100 \mu \mathrm{g} / \mathrm{ml})$ no músculo masseter que apresentou maior atividade EMG durante os registros prévios. Os eventos de atividade motora orofacial e os episódios foram quantificados e comparados entre as noites de registro inicial e experimental. A cada noite e manhã durante o período de estudo, os indivíduos atribuíram valores de intensidade de dor, desconforto e sensibilidade em escalas de análise visual. Também foram medidos o limiar de dor nos músculos masseteres e a força oclusal voluntária máxima (FOVM). Os resultados demonstraram que a injeção de capsaicina antes do sono não causou diferenças significativas entre os grupos na intensidade do pico de dor na escala de análise visual (EAV). Nem o limiar de dor, nem a FOVM apresentaram quaisquer diferenças significativas entre os grupos, entre o lado que recebeu e o que não recebeu a injeção ou entre as noites e as manhãs dos registros inicial e experimental. $\mathrm{O}$ número de episódios EMG por hora de sono, o número de bursts por hora de sono e a área total de todos os bursts e episódios durante a noite de registro foram significativamente maiores nos indivíduos sem dor do que nos indivíduos com dor. Entretanto, a injeção de capsaicina não causou qualquer alteração significativa nesses parâmetros. Os autores concluíram que um estímulo doloroso agudo antes de dormir não exerce qualquer efeito sobre a atividade motora orofacial do sono, mas esse estudo confirmou achados prévios de que a dor e o desconforto estão associados a uma menor atividade EMG dos músculos mastigatórios.

SVENSSON; GRAVEN-NIELSEN, ${ }^{157}$ em 2001, revisaram a literatura em que a dor muscular craniofacial era induzida por técnicas experimentais em animais e em voluntários humanos, e os efeitos somato-sensoriais e motores da dor eram verificados sob condições padronizadas. Os autores comparavam essas situações às situações de dor clínica, descritas e avaliadas em vários estudos transversais de pacientes com dor muscular craniofacial. Os estímulos de dor foram classificados em endógenos (tais como atividade 
parafuncional ou exercício) e exógenos (por exemplo, infusão de salina hipertônica) e foram descritos, além dos efeitos somato-sensoriais, os efeitos motores em diferentes modalidades: a atividade motora postural ou de repouso, a contração muscular estática (CVM) e a atividade muscular dinâmica (mastigação) Verifica-se, claramente, que a dor muscular induz a significativos efeitos tanto na função motora craniofacial quanto na função somato-sensorial. Primeiro, com relação ao estímulo endógeno, verificou-se que condições de carregamento mecânico pesado, com insuficientes períodos de relaxamento, produzem dor muscular, provavelmente por isquemia; que sessões de apertamento dental sustentado ou estático repetido em diferentes posições mandibulares podem levar à intensa dor nos músculos mandibulares com um rápido início, mas, cessado o apertamento, a dor logo desaparece. Depois, avaliando-se as interações somato-motoras de pacientes com dor experimental e clínica, os autores concluíram que a dor dos músculos mandibulares de um nível clinicamente relevante tem pouco ou nenhum efeito sobre a atividade EMG postural dos músculos elevadores da mandíbula; que a atividade EMG máxima e a força oclusal voluntária máxima (FOVM) em pacientes com dor muscular craniofacial são reduzidas em comparação a indivíduos controle; que a função motora dinâmica é alterada pela presença de dor e ainda, que o principal efeito da dor muscular seria a redução dos bursts EMG agonistas e a facilitação dos bursts EMG antagonistas, o que poderia levar a movimentos mais lentos e menos amplos. Isso poderia levar a um reparo mais rápido e à minimização do dano ao sistema. Finalmente, a literatura revisada demonstrou que a função motora craniofacial é principalmente inibida durante a dor muscular experimental, mas com excitação fasedependente durante a mastigação, redução da amplitude dos movimentos mandibulares. Os mecanismos neurobiológicos subjacentes provavelmente envolvem combinações variadas de sensibilização dos aferentes periféricos, hiperexcitabilidade dos neurônios centrais e desequilíbrio dos sistemas de modulação de dor. Acrescentando-se que os circuitos reflexos no mesencéfalo parecem importantes para o ajuste das funções sensoriais-motoras na presença da dor craniofacial, devendo, portanto a função motora e somato-sensorial serem vistas como conseqüências da dor e não como fatores que levam à dor.

Em 2002, baseando-se na premissa de que o espasmo dos elevadores da mandíbula é uma das causas da limitação de abertura mandibular, YAMAGUCHI et al. ${ }^{172}$ examinaram se havia diferenças entre a atividade EMG dos músculos de fechamento da 
mandíbula durante a abertura mandibular em pessoas saudáveis e em pacientes com espasmos do músculo masseter, sem história de trauma ou infecção. O grupo de pacientes consistiu de 11 mulheres (18-62 anos de idade) sem nenhuma história de trauma ou infecção, com limitação de abertura de boca devido a espasmo no músculo masseter. O grupo controle incluiu 11 mulheres saudáveis (23-50 anos de idade). A atividade EMG foi registrada bilateralmente na porção central do músculo masseter, porção anterior do músculo temporal e no ventre anterior do músculo digástrico. Nove das 11 pacientes apresentaram atividade EMG óbvia no músculo masseter durante a abertura da boca, o que foi tipicamente diferentes dos padrões EMG exibidos durante a abertura da boca de até $40 \mathrm{~mm}$ do grupo controle. Dentre as 9 pacientes 8 apresentaram contrações dos músculos temporal e masseter, quando atuando como antagonistas. $\mathrm{O}$ valor da média integral da atividade dos músculos masseter e temporal durante a abertura da boca dos pacientes foi significativamente superior ao do grupo controle $(p<0,01)$. Esses resultados sugerem que a atividade EMG dos músculos elevadores da mandíbula, durante a abertura, em pacientes com espasmos musculares, sem história de trauma ou infecção, é diferente da atividade de pacientes saudáveis.

SHIAU et al., ${ }^{143}$ em 2003, avaliaram a performance de mastigação com um alimento teste de consistência padronizada - duro $(20 \mathrm{~kg})$ e extra-duro $(60 \mathrm{~kg})$ - em 20 mulheres com dor muscular à palpação e em um grupo de 20 mulheres livres de dor. Os autores verificaram que o grupo com dor apresentava um LDP significativamente menor e que a mastigação do alimento teste extra-duro requisitou maior atividade do músculo masseter e mais movimento mandibular do lado de trabalho em ambos os grupos. Durante a mastigação do alimento teste duro e extra-duro, o grupo com dor apresentou a atividade do músculo masseter com duração significativamente maior em relação ao grupo sem dor. Foi encontrada forte correlação entre a atividade EMG dos músculos masseter e ECM durante os dois testes de mastigação no grupo com dor, enquanto essa correlação foi muito fraca no grupo sem dor. Os autores concluíram que a dor no músculo masseter e/ou ECM levaram a uma redução da força muscular e que é necessário um maior tempo de contração em vez da execução de maior força de contração. Verificaram ainda que a co-ativação dos músculos masseter e ECM é mais evidente quando a dureza do alimento aumenta ou quando a dor é mais severa. 
PROPOSIÇÃO 


\section{3 - PROPOSIÇÃO}

O presente estudo visa a:

1) Verificar a associação entre a ocorrência de BS e DMF.

2) Verificar a presença de correlação entre a atividade parafuncional realizada durante uma noite de exame polissonográfico e o limiar de dor à pressão na manhã seguinte (LDP pós-PSG).

3) Verificar presença do mecanismo de adaptação à dor exercido pelos níveis de sensibilidade à palpação (LDP pré-PSG) sobre a intensidade da atividade rítmica dos músculos mastigatórios durante a noite.

4) Verificar a sensibilidade e a especificidade (confiabilidade) do exame clínico de bruxismo $(\mathrm{ECB})$ com relação à polissonografia. 


\section{4 - MATERIAL E MÉTODOS}

\section{1 EstabeleCimento dos Grupos}

Todos os participantes assinaram o termo de consentimento livre e esclarecido (Anexo 3), após a leitura da carta de informação ao paciente sobre todos os procedimentos a serem realizados (Anexo 3). Este estudo recebeu a aprovação do Comitê de Ética em Pesquisa da Faculdade de Odontologia de Bauru, Universidade de São Paulo, e encontra-se protocolado pelo número 021/2002 (Anexos 1 e 2)

O grupo experimental (GE) foi composto por 30 pacientes voluntários (6 homens e 24 mulheres) com DMF, indicados para a Clínica de Tratamento de Disfunção Temporomandibular da Faculdade de Odontologia de Bauru, Universidade de São Paulo e para o Instituto de Ensino Odontológico - IEO, Bauru, SP. Os pacientes foram selecionados por meio de um questionário e um exame físico.

O grupo controle (GC) foi composto por 30 indivíduos voluntários (6 homens e 24 mulheres) saudáveis, sem sinais e/ou sintomas DTM. Foi utilizada a participação voluntária de estudantes de odontologia da Faculdade de Odontologia de Bauru Universidade de São Paulo. O mesmo exame clínico realizado para a seleção dos pacientes com DFM (GE) foi empregado na seleção dos indivíduos assintomáticos. 


\subsection{CRTtÉrIOS de InCLuSÃo e EXCLUSÃo}

\subsubsection{Critérios de exclusão iniciais}

Foram utilizados os seguintes critérios de exclusão para todos os participantes da pesquisa (baseados nos critérios sugeridos por LAVIGNE; ROMPRÉ; MONTPLAISIR: ${ }^{83}$ apresentação de dois ou mais dentes perdidos (excluindo-se os terceiros molares); utilização de prótese dental removível; presença de má-oclusão grosseira, especificamente, mordida aberta anterior, mordida cruzada unilateral, sobrepasse horizontal (overjet) maior que $6 \mathrm{~mm}$ e interferência no arco de fechamento que provocasse um deslize de RC para MIH maior do que $5 \mathrm{~mm}$ (características oclusais de risco ${ }^{125}$ ). Esses critérios visaram à exclusão de fatores que pudessem predispor o paciente à DTM. Também eram excluídos os indivíduos que relatassem odontalgias, doença periodontal ativa; nevralgias, sensibilidade dentária generalizada ou intensa, história de trauma na região de cabeça e pescoço e doenças sistêmicas que interferissem com o bem estar ou limiar de dor dos participantes (ex: neuropatias e doenças articulares inflamatórias). Eram critérios de exclusão: a utilização de medicação e/ou dispositivos com possíveis efeitos sobre a atividade motora durante o sono, tais como benzodiazepínicos, L-dopa, neurolépticos e antidepressivos-tricíclicos; abuso de álcool ou drogas; ou utilização de placa intermaxilar; ${ }^{69}$ apresentação de grandes desordens neurológicas, psiquiátricas ou de movimento, ${ }^{69}$ por ex.: atividade indicadora de epilepsia (epileptiforme) no EEG ou mal de Parkinson; relato de mioclonia cervical, narcolepsia, insônia, movimentos periódicos das pernas ou apnéia do sono. ${ }^{85}$

Com relação às desordens de sono ou desordens motoras menos evidentes, os pacientes foram selecionados inicialmente por meio do questionário e entrevista iniciais. Entretanto, se qualquer dos eventos descritos acima ocorresse durante a primeira noite de PSG, o indivíduo era excluído da pesquisa. Indivíduos com mais de 10 eventos de movimentos periódicos dos membros por hora e/ou mais de 5 eventos de apnéia/hipopnéia por hora de sono foram excluídos do estudo. (Anexo 25 e Anexo 26).

Após o preenchimento do questionário e a realização da entrevista, se os indivíduos não relatassem qualquer das desordens acima, era realizado o exame clínico específico de DTM. 


\subsubsection{Critérios de inclusão e exclusão específicos}

Os pacientes com DMF deveriam apresentar, como queixa principal, dor na mandíbula, têmporas, face ou área pré-auricular em repouso ou durante a função, associada à sensibilidade ou dor à palpação em pelo menos três dentre os dezoito sítios musculares palpados (os lados esquerdo e direito foram contados separadamente para cada sítio): temporal anterior, médio e posterior, origem, corpo e inserção do masseter, masseter profundo, ventre posterior do músculo digástrico e inserção do pterigóideo medial. Esse critério deriva do critério para o diagnóstico de DMF do Research Diagnostic Criteria for Temporomandibular Disorders (RDC/TMD). ${ }^{44}$

Substituiu-se a palpação da "área do músculo pterigóideo lateral” (recomendada pelo $\mathrm{RDC} / \mathrm{TMD}^{44}$ ) pela palpação da porção profunda do masseter devido às evidências clínicas e anatômicas da impossibilidade de palpação do músculo pterigóideo lateral. ${ }^{65,152,160}$ A palpação da porção profunda do masseter tem sido incluída em diversos estudos de análise da DMF. ${ }^{15,167}$

A palpação do tendão do músculo temporal não foi incluída porque o critério de diagnóstico inicialmente proposto não o incluía. Nos 15 primeiros participantes não foi realizada a palpação desse sítio muscular, mas de todos os demais. A fim de preservar a homogeneidade do critério, optou-se por manter o tendão do temporal fora do critério. Essa exclusão beneficiaria o diagnóstico de DMF, por que foi mantido o critério de pelo menos três pontos sensíveis, dentre um total de apenas 18 sítios, em vez de 20.

Pacientes com quadros concomitantes de DMF e dor e disfunção da ATM eram excluídos, entretanto, caso a queixa do pacientes se referisse à DMF e, durante o exame físico, se detectasse leve sensibilidade articular à palpação, o mesmo não era excluído. Pois a presença de leve sensibilidade articular à palpação per se não é critério de diagnóstico de artralgia (sinovite/capsulite). ${ }^{44}$

O mesmo protocolo de exame clínico de DTM foi realizado para os indivíduos assintomáticos (GC). Os critérios de inclusão específicos do grupo controle incluíram: ausência de queixa de dor ou desconforto na mandíbula, face, têmporas ou área pré-auricular. A presença de três ou mais sítios musculares sensíveis à palpação (dentre os 18 palpados) era 
critério de exclusão. Ainda, os indivíduos não deveriam apresentar queixa de dor ou disfunção articular, tais como: dor ou travamento articular, luxações mandibulares, limitação de abertura bucal ou edema. Sinais clínicos de deslocamentos de disco assintomáticos e estalidos assintomáticos não fizeram parte dos critérios de exclusão. 


\subsection{EXame Qínico de Dor Mofascial}

Inicialmente, todos os participantes da pesquisa foram submetidos a duas etapas de uma consulta inicial:

\subsubsection{Diagnóstico de dor miofascial (Examinador 1)}

Direcionada à investigação e diagnóstico de Dor Miofascial (para o grupo experimental), bem como de sua ausência (para o grupo controle).

\section{a) O questionário de DTM:}

Foram coletados os dados pessoais do paciente; histórico (queixa principal, histórico da condição atual, histórico médico e odontológico); descrição da intensidade, frequência qualidade e local da dor, ruídos articulares ou limitação da abertura bucal (Anexo $5)$.

Os participantes marcaram a intensidade da dor na face em uma escala de análise visual (EAV). A EAV consistia em uma linha horizontal de $100 \mathrm{~mm}$ de comprimento, com as seguintes expressões em suas extremidades: "nenhuma dor" e "a pior dor imaginável". O voluntário era instruído a indicar o ponto na reta que melhor representasse a intensidade de sua dor (valor médio nos últimos seis meses).

Preencheram um questionário para determinação do índice de DTM, ${ }^{32}$ composto por 10 perguntas, que permitiu a determinação da intensidade do quadro de DTM (Anexo 5):

1. Você sente dificuldade de abrir a boca?

2. Você sente dificuldade de movimentar sua mandíbula para os lados?

3. Você sente desconforto ou dor muscular quando mastiga?

4. Você sente dores de cabeça com freqüência?

5. Você sente dores no pescoço e/ou ombros?

6. Você sente dores de ouvido ou próximo a ele?

7. Você percebe algum ruído na ATM? 

8. Você considera sua mordida "anormal"?
9. Você usa apenas um lado de sua boca para mastigar?
10. Você sente dores na face ao acordar?

Havia três possibilidades de resposta: SIM, NÃO e ÀS VEZES. Cada "sim" recebeu o valor 2, cada "às vezes" recebeu o valor 1 e cada "não" recebeu o valor 0 . As questões 4, 6 e 7 receberam valor 3 para cada resposta "sim" se correspondessem a sintomas bilaterais ou intensos e valor 2 se correspondessem a sintomas unilaterais ou leves; receberam valor 1 para a resposta "às vezes" e valor 0 para a resposta "não".

O somatório dos valores obtidos fornecia a classificação da DTM em intensidade:

Valores de 0 a 3: não portador de DTM

Valores de 4 a 8: portador de DTM leve

Valores de 9 a 14: portador de DTM moderada

Valores de 15 a 23: portador de DTM severa.

Em seguida, foi preenchida uma ficha de exame físico de DTM.

\section{b) O exame físico de DTM:}

1) Inspeção intra e extra-oral incluindo hábitos posturais e assimetrias;

2) Exame funcional do sistema mastigatório:

a) Abertura bucal (extensão e trajetória).

b) Palpação dos músculos temporal (porções anterior, média e posterior), músculo masseter (origem, corpo e inserção da porção superficial e porção profunda), pterigóideo medial (inserção) e ventre posterior do digástrico. Utilizaram-se os escores: "0" para ausência de dor; "1" para relato de dor leve (o paciente relata que doeu um pouco); "2" para dor moderada (paciente responde com reflexo palpebral) e "3" para dor intensa, (o paciente reage afastando o rosto). Foi aplicada, durante a palpação, pressão digital aproximada de $1,5 \mathrm{~kg} .{ }^{56,144}$

c) Inspeção de ruídos articulares (estalido e crepitação) (Anexo 5) por meio de palpação digital. Dworkin et al., ${ }^{43}$ (1990) demonstraram que o uso do estetoscópio em detectar 
ruídos articulares específicos resultou em reprodutibilidade inaceitável $(\mathrm{k}=0,26)$. Em situações em que havia dúvida, questionava-se o paciente quanto à percepção do ruído durante o exame.

O examinador 1 (o qual realizou a primeira etapa do exame inicial em todos os participantes da pesquisa) calibrava a pressão exercida durante a palpação, por meio de um algômetro ${ }^{\dagger}$.

\subsubsection{Diagnóstico Clínico de Bruxismo do Sono (Examinadores 1 e} 2)

O exame clínico de bruxismo do sono (ECB) consistiu em um questionário de 6 perguntas e a avaliação de facetas de desgaste na região anterior. A sua realização por dois examinadores calibrados visou à verificação da reprodutibilidade do mesmo.

\section{a) Questionário de bruxismo}

O questionário era composto por 6 perguntas referentes a: 1) auto-relato de bruxismo do sono (consciência do hábito); 2) cansaço ou dor nos músculos da face ao acordar; 3) rigidez ou travamento articular matinal; 4) desconforto nos dentes ao acordar, 5) restaurações ou cúspides fraturadas e 6) relato de terceiro (companheiro de quarto ou parente) de ruídos de ranger os dentes durante o sono (Anexo 6).

\section{b) Exame físico de bruxismo}

Verificação da presença de facetas de desgaste coincidentes, segundo o critério de JOHANSSON ${ }^{64}$ na região anterior (Anexo 6). Considerava-se a presença de facetas a partir do escore 1:

Escore 0 : nenhuma faceta visível no esmalte

Escore 1: facetas de desgaste no esmalte. Modificação incisal alterada.

\footnotetext{
${ }^{\dagger}$ Kratos - Brasil
} 
Escore 2: Desgaste atingindo a dentina. Exposição da dentina incisal ou de superfície adjacente.

Escore 3: Extenso desgaste na dentina. Área de dentina exposta maior ou igual a $2 \mathrm{~mm}^{2}$.

Escore 4: Desgaste atingindo dentina secundária. 


\subsection{POLSSONOGRAFIA}

Em seguida, todos os voluntários foram encaminhados à realização do exame de Polissonografia (PSG), no Instituto de Medicina do Sono ou na Clínica de Distúrbios do Sono (ambos situados em Bauru) a fim se verificar a ocorrência do hábito do bruxismo do sono (BS) e suas características.

Realizou-se o exame polissonográfico (PSG) em duas noites, para cada paciente, em um quarto com temperatura controlada e sons atenuados (Figura 1). A primeira noite teve por finalidade a adaptação do paciente e a verificação de eventos que pudessem excluí-lo da pesquisa. Caso o participante preenchesse os critérios de inclusão, era realizada a segunda noite de exame, da qual eram coletados os dados experimentais.

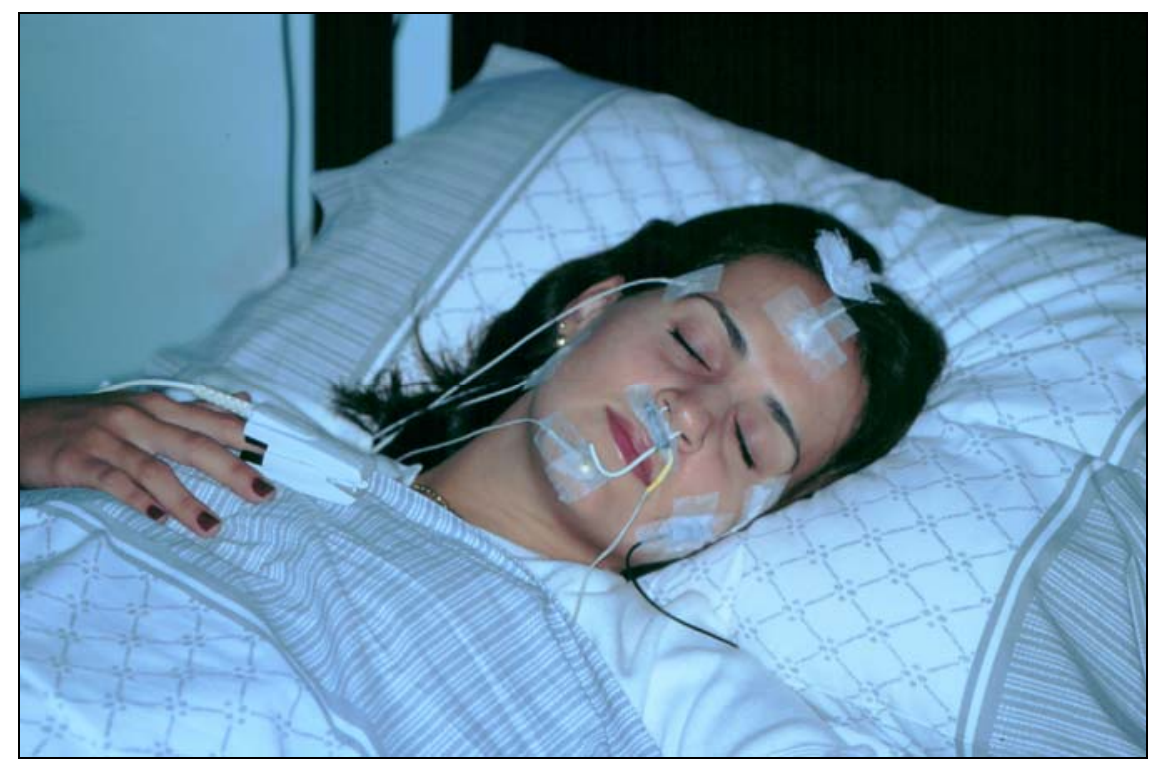

Figura 1 Representação de como o registro foi realizado durante o sono

Foram registrados os seguintes parâmetros (Figura 2): pletismografia de esforço respiratório torácico e abdominal; captação de sons de ranger de dentes por meio de microfone fixado na região do músculo bucinador; eletroencefalograma (EEG; $\mathrm{C}_{3} \mathrm{~A}_{2}, \mathrm{O}_{2} \mathrm{~A}_{1}$ ), eletro-oculagramas bilaterais (EOG), eletrocardiograma (ECG), eletromiografia (EMG) do músculo masseter esquerdo e mentoniano, registro de fluxo aéreo nasal/oral por termistor; 
oximetria e análise visual por meio de câmera de vídeo, ${ }^{132}$ simultaneamente a todo o registro polissonográfico para a identificação das atividades motoras orofaciais distintas do bruxismo.

A pele do paciente foi limpa com água e sabão. Foram utilizados eletrodos de superfície de ouro cônicos. Os eletrodos foram embebidos em um creme eletrólito ${ }^{\ddagger}$ e afixados à pele do paciente por meio de gaze ou micropore.

Para o EEG, utilizaram-se as posições O1, OZ e O2 e C3, CZ e C4. Os eletrodos de referência foram colocados em A2 (referência auricular). ${ }^{132}$ Para cada eletrodo, havia uma entrada individual e um canal de visualização no monitor.

Para o EOC, foi obedecida a recomendação, com uma referência auricular (A1). As entradas foram Fp1 e Fp2, bem como um canal para o olho esquerdo e outro para o olho direito (Figura 2B e C).

Foi realizada eletromiografia dos músculos mentoniano, masseter (esquerdo) (Figura 2) e tibiais anteriores (um em cada perna), com entradas individuais e um canal de visualização para os músculos mentoniano e masseter e outro para os músculos tibiais anteriores

Antes dos registros do sono, cada paciente realizou uma série de testes de calibração fisiológica, a fim de permitir o reconhecimento do sinal voluntário de apertamento máximo (CVM), movimentos mandibulares (lateral e protrusivo), contrações rítmicas, deglutição e tosse (Anexo 8).

\footnotetext{
${ }^{\ddagger}$ NEUROFIX - SAN TEK Eletromedicina (Embu Guaçu- São Paulo)
} 


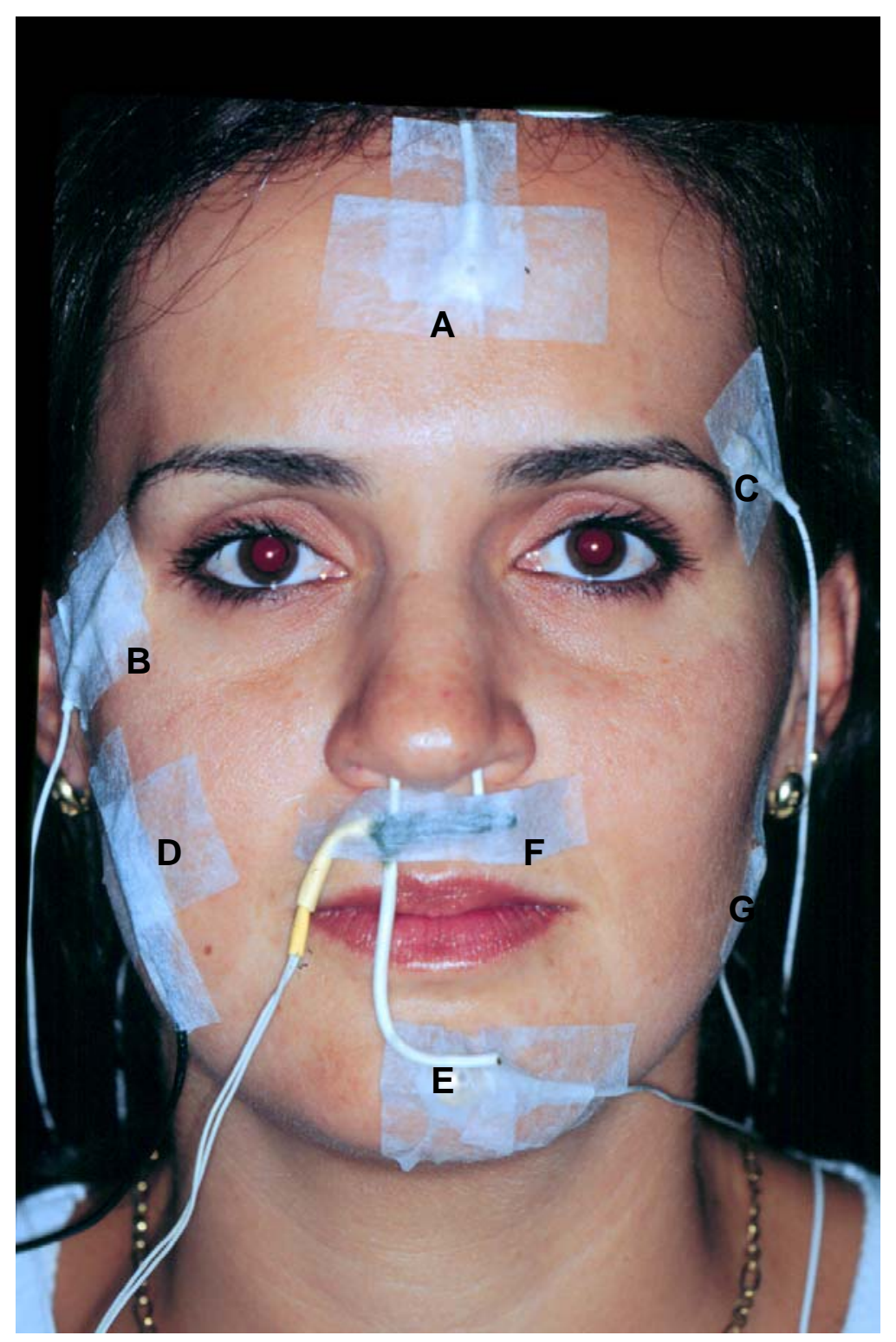

Figura 2 Posicionamento do fio terra (A); EOG (B e C); microfone (D); EMG do músculo mentoniano (E); registro de fluxo aéreo oral/nasal $(F)$ e eletromiografia do músculo masseter (G). 


\subsubsection{Dados técnicos}

Os eletrodos da eletromiografia estavam calibrados e apresentavam impedância menor que $5 \mathrm{k} \Omega$. O sinal eletromiográfico foi amplificado com um ganho de 2000 vezes, sensibilidade de $150 \mu \mathrm{V} / \mathrm{cm}$, impedância de $10 \mathrm{M} \Omega$. Foram utilizados filtros de baixa freqüência de $30 \mathrm{~Hz}$ e de alta freqüência de $128 \mathrm{~Hz}$. Após amplificados e filtrados, o sinal foi digitalizado por meio de um conversor analógico digital (A/D). ${ }^{\S} \mathrm{O}$ sinal eletroencefalográfico foi registrado com uma sensibilidade de $75 \mu \mathrm{V} / \mathrm{cm}$. O eletrooculograma com $150 \mu \mathrm{V} / \mathrm{cm}$. O registro foi feito em épocas de 30 s com uma freqüência de amostragem de $256 \mathrm{~Hz}$

\footnotetext{
${ }^{\S}$ Meditron Eletromedicina (Santo Amaro São Paulo)
} 


\subsection{AVAliação Pré-Polissonográfica (Examinador 1)}

Após a realização da primeira noite de PSG (noite de adaptação), o registro poligráfico era avaliado para que se pudesse confirmar a segunda noite de exame.

À noite, previamente ao início do exame (entre 21:00h e 22:00h), foi coletada a intensidade de dor (EAV - $100 \mathrm{~mm}$ ), em repouso, daquele momento. Realizou-se avaliação de ruídos articulares e palpação articular (aspectos lateral e posterior), palpação da inserção do pterigóideo medial e ventre posterior do digástrico.

Previamente ao teste de algometria, explicou-se aos participantes como o mesmo era realizado, demonstrando-se a utilização do algômetro na região dorsal do antebraço. $\mathrm{O}$ algômetro utilizado possui um dispositivo acoplado que permite ao paciente fixar o pico de pressão no momento que a mesma foi percebida como dolorosa.

Com uma caneta para retroprojetor, marcaram-se na face do paciente os pontos a serem avaliados para o registro do limiar de dor à pressão (LDP): origem, corpo e inserção do masseter, porção anterior do temporal. As porções média e posterior do temporal não foram marcadas devido à impossibilidade de visualização, pelos cabelos. Por essa razão, tomaram-se pontos de referência para a realização da algometria. Para o temporal médio: considerava-se 2 cm em direção posterior e horizontal em relação à marcação feita na região do temporal anterior. Para o temporal posterior, considerou-se a região imediatamente acima de uma linha longitudinal ao pavilhão auditivo. Além disso, pedia-se ao indivíduo que apertasse os dentes, para os músculos pudessem ser palpados e, ao mesmo tempo, marcados.

O algômetro foi posicionado perpendicularmente à superfície a ser testada, enquanto o examinador apoiava a cabeça do indivíduo no lado contralateral. Era pedido ao indivíduo que relaxasse a musculatura, mantendo-os lábios em leve toque, com os dentes afastados. Então era exercida pressão, a partir do zero, a uma velocidade aproximada de 0,5 kgf/seg até que o indivíduo pressionasse o dispositivo em sua mão, fixando a pressão exercida naquele momento. 
A ponta ativa do algômetro (1 cm de diâmetro) foi coberta com um dispositivo anti-impacto a fim de eliminar o desconforto decorrente do contato de uma ponta metálica de ângulos retos. 


\section{6 Avaliação Pós-Polissonográfica (EXAMINADOR 2)}

$\mathrm{Na}$ manhã seguinte à segunda noite do exame de Polissonografia (aproximadamente às 7:00h) os participantes preencheram uma nova EAV, sobre a dor facial daquele momento e foi realizado um novo exame físico similar ao exame pré-PSG.

O exame pós-PSG foi realizado por um segundo examinador calibrado, mascarado em relação ao diagnóstico clínico de DMF dos indivíduos. A pressão de palpação era periodicamente calibrada. E, a algometria foi realizada tomando-se como referência as marcações presentes na pele do paciente na porção anterior do temporal e na origem, corpo, inserção e porção profunda do masseter. Para a algometria das porções média e posterior do temporal, foram usadas as mesmas referências.

O teste foi realizado da mesma forma, explicando-se ao paciente previamente sobre o momento em que o mesmo deveria indicar que a pressão se tornou dolorosa; empregando-se a mesma velocidade de aplicação, posicionamento e apoio da cabeça dos indivíduos.

A reavaliação por um segundo examinador, mascarado quanto ao diagnóstico de DMF, visou à minimização dos vieses que eventualmente pudessem surgir por tendência do examinador. 


\subsection{ANÁLISE dOS DADOS POUSSONOGRÁFICOS}

Um único observador realizou a contagem visual dos eventos eletromiográficos, por meio do software, MEDITRON - SONOLAB. ${ }^{* *}$ O burst era contado se o mesmo apresentasse pelo menos 20\% da amplitude da CVM com o indivíduo acordado (LAVIGNE; ROMPRÉ; MONTPLAISIR, ${ }^{83}$ 1996). Esse valor era calculado com base no registro de calibração realizado pelo paciente ao início do exame polissonográfico (Anexo 8). Os eventos eletromiográficos de atividade rítmica dos músculos mastigatórios foram definidos e classificados em três diferentes tipos: fásico (rítmico); tônico (sustentado) ou misto (tanto fásico quanto misto em um mesmo episódio). Um episódio fásico correspondia a pelo menos três bursts eletromiográficos de 0,25s a 2,0s de duração, separados por intervalos interburst. Um episódio tônico correspondia a um burst eletromiográfico com duração maior do que $2 \mathrm{~s}$. Considerava-se um episódio isolado, se o mesmo apresentasse um intervalo inter-episódio de pelo menos 3s de duração (Figura 3).

Realizou-se a contagem das variáveis oromotoras de corte: número de episódios de bruxismo por noite (epi/noite), episódios por hora (epi/hora); bursts por hora (b/hora) e bursts por episódios (b/epi). As variáveis oromotoras de corte correspondem à atividade rítmica dos músculos mastigatórios (ARMM) tanto nos bruxômanos, quanto nos nãobruxômanos. Os voluntários que apresentassem valores de ARMM acima dos valores de corte indicados por LAVIGNE; ROMPRÉ; MONTPLAISIR ${ }^{83}$ seriam considerados bruxômanos.

Contabilizou-se também o número e a classe de episódios por fase do sono, a eficiência do sono, o número de episódios associados a microdespertar e a atividade motora das pernas.

Após a contagem, considerou-se o diagnóstico de bruxismo, por meio da polissonografia, como positivo se o número de eventos atingisse os valores de corte de 4 ou mais epi/hora ou 25 ou mais b/hora definidos por LAVIGNE; ROMPRÉ; MONTPLAISIR, ${ }^{83}$ 1996. O valor de episódios com ranger de dentes não foi utilizado no diagnóstico devido a sua variabilidade. Mesmo no estudo original de LAVIGNE; ROMPRÉ; MONTPLAISIR, ${ }^{83}$

\footnotetext{
${ }^{* *}$ Meditron Eletromedicina (Santo Amaro São Paulo)
} 
alguns indivíduos controle apresentaram sons de ranger de dentes e 4 dos bruxômanos não o fizeram. Os autores atribuíram ainda a essa variabilidade, a sensibilidade do microfone, a qual poderia não se suficiente para captar sons muito suaves de ranger e que portanto, não poderiam ser contados. Além do mais, a utilização dos sons de ranger de dentes como critério de diagnóstico excluiria indivíduos com um número suficiente de ARMM mas que, naquela noite do exame, sua atividade tenha sido de apertamento e não de ranger de dentes.

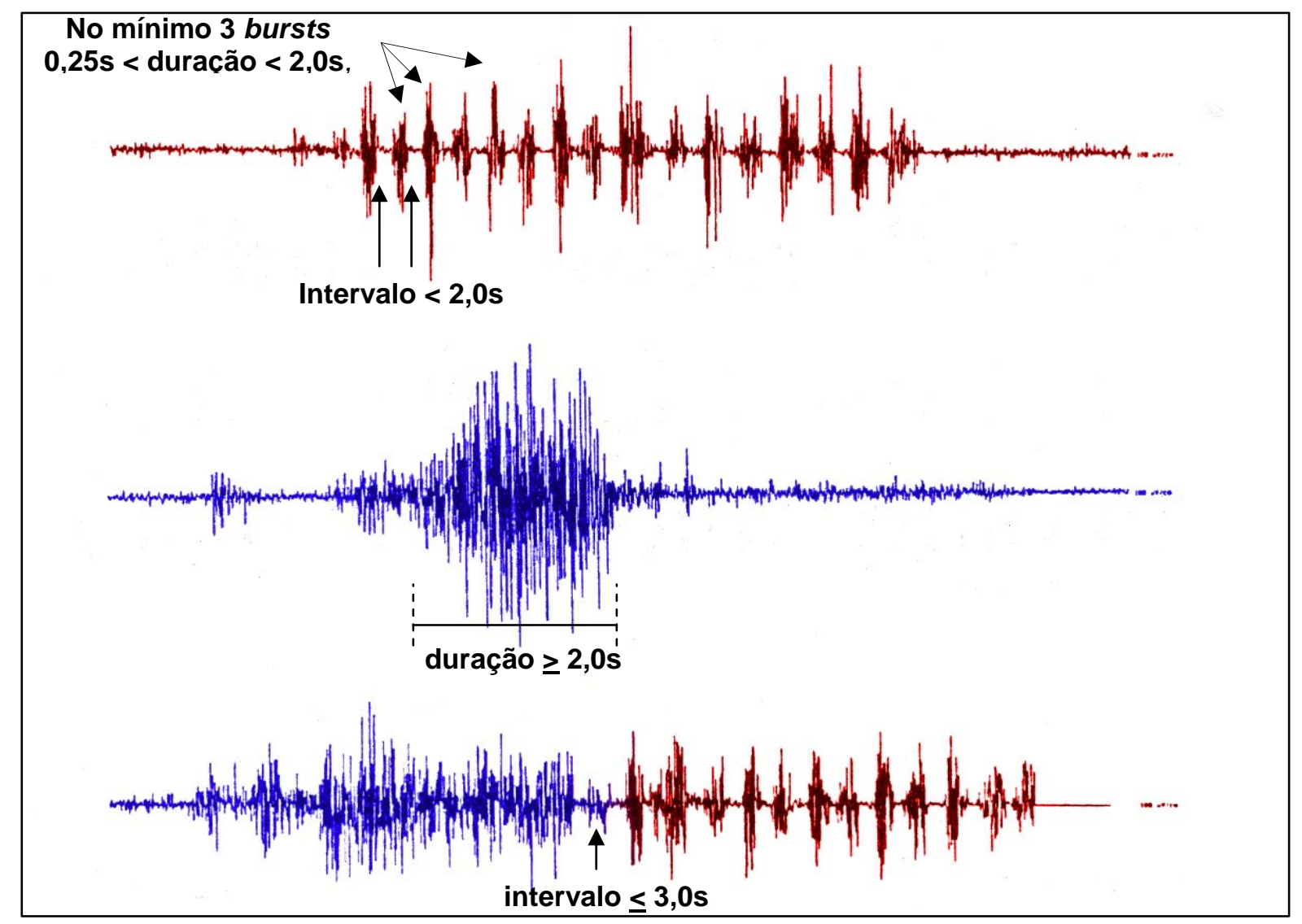

Figura 3 Exemplos de episódios de bruxismo fásico (A), tônico (B) e misto (C), registrado de um músculo masseter direito. Modificado de LAVIGNE; ROMPRÉ; MONTPLAISIR, ${ }^{83} 1996$. 


\subsection{ANÁUSE EstATÍSTICA}

Inicialmente, foram descritas as variáveis do sono (latência do sono; eficiência do sono; tempo de sono nos estágios 1, 2, 3/4 e REM e número de microdespertares por hora) de todos os participantes.

Em seguida, foram realizados os seguintes testes e cálculos:

Prevalência de bruxômanos dentre a população com e sem Dor Miofascial, além da realização do teste Qui-quadrado, para verificar a presença de associação entre bruxismo e Dor Miofascial. (Cumprimento Proposição 1)

Teste de distribuição de freqüência para a escolha dos testes: se paramétricos ou não-paramétricos mais adequados parra cada caso.

Correlação de Pearson, para verificar a presença de correlação entre as variáveis oromotoras de corte (ARMM) e os valores da EAV e limiar de dor à pressão (LDP) pós-PSG (Cumprimento da Proposição 2).

Correlação de Pearson entre LDP pré-PSG e ARMM durante a noite, para verificar a presença de algum efeito da sensibilidade prévia sobre a intensidade da parafunção noturna, em bruxômanos e não bruxômanos com e sem DMF. (Cumprimento da Proposição 3)

Cálculo da confiabilidade (sensibilidade, especificidade e acuidade) do exame clínico de bruxismo (ECB), como um todo e de cada item que o compõe. Determinação da combinação de itens mais apropriada ao diagnóstico clínico de BS. (Cumprimento da Proposição 4)

Foi adotado o nível de significância de 5\% para todos os testes. 
RESULTADOS 


\section{5 - RESULTADOS}

Durante o processo de triagem, foram avaliados 142 indivíduos, dos quais, 78 foram excluídos por não atenderem aos critérios de inclusão. Desses 78 indivíduos, 42 apresentavam queixas de dor e/ou disfunção articular (dor articular acompanhada de desvios e ruídos articulares), 6 não preenchiam o critério de idade, 3 apresentavam dores de origem odontogênica, 4 não aceitaram participar do estudo, 2 apresentavam apenas queixa de zumbido, 5 apresentavam desordens do sono (como insônia ou suspeitas de apnéia), 10 não preenchiam os critérios relacionados à oclusão (má-oclusão grosseira ou número de ausências dentárias superior ao permitido), 5 indivíduos inicialmente indicados para o grupo controle não preenchiam aos requisitos, por apresentarem algum sinal de desordem articular, apesar da ausência de queixa e de sintomatologia, 1 utilizava um dispositivo ortodôntico extra-oral para dormir, o qual poderia interferir com a função de bruxismo.

Sessenta e quatro indivíduos realizaram o exame polissonográfico, dos quais, 4 foram excluídos após a realização da primeira noite de exame devido à presença de PLM, ou episódios de apnéia/hipopnéia acima do permitido pelos critérios de inclusão. A amostra final destinada à análise estatística compôs-se (como previsto) de 60 indivíduos, 30 do grupo controle (27 mulheres e 3 homens, com idade média de 25,967 $\pm 4,499$ ) e 30 do grupo experimental (27 mulheres e 3 homens, com idade média de 26,633 $\pm 4,972$ ) 


\subsection{TRIAGEM}

Como se observa na Tabela 1 , nenhum dos indivíduos do grupo controle apresentou queixa de dor muscular na região orofacial, bem como na ATM. A média da intensidade de dor, EAV (mm), desse grupo foi de $0,0 \pm 0,0$. Quanto ao índice de DTM ${ }^{32} \mathrm{o}$ grupo apresentou média de $1,867 \pm 1,697$, sendo, 26 diagnosticados como sem DTM (ausente) e 4, como DTM leve. A Tabela 2 mostra a distribuição das respostas dadas pelos indivíduos do grupo controle diagnosticados como portadores de DTM leve pelo índice de DTM. ${ }^{32}$ Todos os indivíduos controle apresentaram amplitude de abertura dentro da faixa de normalidade $(50,43 \pm 6,47 \mathrm{~mm})$. Dentre os 18 sítios musculares palpados, 16 (53,33\%) indivíduos não apresentavam qualquer ponto sensível à palpação, 7 (23,33\%) apresentavam 2 sítios sensíveis e 7 (23,33\%) apresentavam 1 sítio sensível (Anexos 9 a 12). Nove relataram ruídos articulares assintomáticos e 3 apresentaram sensibilidade leve à palpação articular, não representando justificativa para exclusão dos mesmos.

Como o grupo experimental restringiu-se a pacientes do grupo de diagnóstico de Dor Miofascial, segundo o $\mathrm{RDC} / \mathrm{TMD}^{44}$ (Diagnóstico Ia), verifica-se que os mesmos apresentaram-se livres de sinais e sintomas na ATM. E todos os participantes da pesquisa apresentam abertura bucal dentro da faixa de normalidade (Tabela 3 ). 
Tabela 1 Características clínicas (triagem) do grupo CONTROLE

\begin{tabular}{|c|c|c|c|c|c|c|c|c|c|c|c|}
\hline & PACIENTE & SEXO & Grupo & Idade & QUEIXA & $\begin{array}{c}\text { EAV } \\
\text { média }^{\dagger}\end{array}$ & \multicolumn{2}{|c|}{ iDTM $^{\ddagger}$} & Abertura & $\begin{array}{c}\text { Ruídos articulares } \\
\text { (exame físico) }\end{array}$ & $\begin{array}{c}\text { DorATM } \\
\text { (palpação) }\end{array}$ \\
\hline 1 & APAM & $\mathrm{F}$ & C & 25 & - & 0,0 & 1 & ausente & 40 & 1 & 0 \\
\hline 2 & CSP & $\mathrm{F}$ & C & 22 & - & 0,0 & 1 & ausente & 54 & 1 & 0 \\
\hline 3 & CFEC & $\mathrm{F}$ & C & 26 & - & 0,0 & 3 & ausente & 63 & 0 & 0 \\
\hline 4 & DED & $\mathrm{F}$ & C & 24 & - & 0,0 & 2 & ausente & 45 & 0 & 0 \\
\hline 5 & DJ $M$ & $\mathrm{~F}$ & C & 25 & - & 0,0 & 2 & ausente & 51 & 1 & 0 \\
\hline 6 & $\mathrm{EO}$ & $\mathrm{F}$ & C & 24 & - & 0,0 & 4 & leve & 60 & 0 & 0 \\
\hline 7 & FFAF & $M$ & C & 25 & - & 0,0 & 5 & leve & 45 & 0 & 0 \\
\hline 8 & $\mathrm{FYI}$ & $\mathrm{F}$ & C & 20 & - & 0,0 & 7 & leve & 44 & 0 & 1 \\
\hline 9 & FFFT & $\mathrm{F}$ & C & 24 & - & 0,0 & 2 & ausente & 58 & 0 & 1 \\
\hline 10 & GB & $\mathrm{F}$ & C & 36 & - & 0,0 & 0 & ausente & 36 & 0 & 0 \\
\hline 11 & $\mathrm{HJF}$ & $\mathrm{F}$ & C & 24 & - & 0,0 & 2 & ausente & 50 & 1 & 0 \\
\hline 12 & J AO & $M$ & C & 24 & - & 0,0 & 2 & ausente & 45 & 0 & 0 \\
\hline 13 & KVC & $\mathrm{F}$ & C & 30 & - & 0,0 & 1 & ausente & 57 & 0 & 0 \\
\hline 14 & LP & $\mathrm{F}$ & C & 24 & - & 0,0 & 1 & ausente & 45 & 0 & 0 \\
\hline 15 & LC & $\mathrm{F}$ & C & 27 & - & 0,0 & 2 & ausente & 56 & 0 & 0 \\
\hline 16 & LVZ & $M$ & C & 25 & - & 0,0 & 1 & ausente & 48 & 0 & 0 \\
\hline 17 & LP & $\mathrm{F}$ & C & 21 & - & 0,0 & 0 & ausente & 47 & 0 & 0 \\
\hline 18 & MFAF & $\mathrm{F}$ & C & 27 & - & 0,0 & 2 & ausente & 54 & 1 & 0 \\
\hline 19 & MG & $\mathrm{F}$ & C & 24 & - & 0,0 & 0 & ausente & 45 & 0 & 0 \\
\hline 20 & MR & $\mathrm{F}$ & C & 26 & - & 0,0 & 2 & ausente & 62 & 0 & 0 \\
\hline 21 & $M C$ & $\mathrm{~F}$ & C & 27 & - & 0,0 & 2 & ausente & 53 & 0 & 0 \\
\hline 22 & MPF & $\mathrm{F}$ & C & 42 & - & 0,0 & 5 & leve & 49 & 0 & 1 \\
\hline 23 & MTK & $\mathrm{F}$ & C & 26 & - & 0,0 & 0 & ausente & 52 & 1 & 0 \\
\hline 24 & MAM & $M$ & C & 27 & - & 0,0 & 0 & ausente & 54 & 0 & 0 \\
\hline 25 & PSC & $\mathrm{F}$ & C & 23 & - & 0,0 & 1 & ausente & 55 & 0 & 0 \\
\hline 26 & RSS & $M$ & C & 26 & - & 0,0 & 2 & ausente & 55 & 0 & 0 \\
\hline 27 & $\mathrm{~S}$ & $\mathrm{~F}$ & C & 21 & - & 0,0 & 3 & ausente & 45 & 1 & 0 \\
\hline 28 & SG & $\mathrm{F}$ & C & 26 & - & 0,0 & 3 & ausente & 51 & 1 & 0 \\
\hline 29 & SG & $\mathrm{F}$ & C & 34 & - & 0,0 & 0 & ausente & 43 & 1 & 0 \\
\hline 30 & TP & $M$ & C & 24 & - & 0,0 & 0 & ausente & 51 & 0 & 0 \\
\hline & MÉDIA & & & $25,967 \pm 4,49$ & & $0,0 \pm 0,0$ & $3,3 \pm 2,628$ & & $50,43 \pm 6,47$ & & \\
\hline
\end{tabular}

$\mathrm{C}=$ Grupo Controle

${ }^{\dagger}$ Valor obtido na Escala de Análise Visual (EAV), em mm, durante a triagem. Representa a intensidade média de dor nos últimos 6 meses.

* Valor obtido no questionário de avaliação objetiva de $\mathrm{DTM}^{33}$, durante a triagem 
Tabela 2 Freqüência das respostas ao questionário de índice de $\mathrm{DTM}^{32}$ no grupo CONTROLE

\begin{tabular}{|c|c|c|c|}
\hline Perguntas & SIM & ÀS VEZES & BILATERAL \\
\hline \multicolumn{4}{|l|}{ 1) Você sente dificuldade de abrir a boca? } \\
\hline \multicolumn{4}{|l|}{$\begin{array}{l}\text { 2) Você sente dificuldade de movimentar sua mandíbula para } \\
\text { os lados? }\end{array}$} \\
\hline 3) Você sente dores de cabeça com freqüência? & & 1 & 1 \\
\hline 4) Você sente desconforto ou dor muscular quando mastiga? & & 1 & \\
\hline 5) Você sente dores no pescoço e/ou ombros? & 2 & 1 & \\
\hline \multicolumn{4}{|l|}{ 6) Você sente dores de ouvido ou próximo a ele? } \\
\hline 7) Você percebe algum ruído na ATM? & 2 & 2 & 1 \\
\hline 8) Você considera sua mordida "anormal"? & 1 & & \\
\hline 9) Você usa apenas um lado de sua boca para mastigar? & 2 & & \\
\hline 10) Você sente dores na face ao acordar? & & & \\
\hline
\end{tabular}


Tabela 3 Características clínicas (triagem) do grupo EXPERIMENTAL

$$
\text { PACIENTE }
$$

SEXO

Grupo

1 AOL

$2 A B$

3 CTBS

4 DV

5 EC

6 EPM

7 FGM

8 IE

9 J GRR

$10 \mathrm{~J} M B B$

$1 \mathrm{KCN}$

12 KCSG

13 LM

14 LSC

15 LEB

16 LGCB

$17 \mathrm{MP}$

$18 \mathrm{MRC}$

19 MP

20 NB

21 PDR

22 MK

23 PB

24 RAB

$25 \mathrm{RC}$

26 RDBG

27 SRC

$28 \mathrm{~S}$

29 SHS

30 TAM

MÉDIA
Idade

DM

$D M$

DM

DM

DM

DM

DM

DM

DM

DM

DM

DM

DM

DM

DM

DM

DM

DM

DM

DM

DM

DM

DM

DM

DM

DM

DM

DM

DM

DM
22

22
25
39

39

31

29

22

26

24

21

19

23

25

24

26

25

27

28

30

23

27

26

24

32

28

38

38

26

25

20

26
Dor nos masseteres bilatera

Dor nos masseteres e temporais bilateral

Dor cervical e dor na região temporal bilateral

Dor na região frontal e nos masseteres bilateral

Dor nos músculos da mastigação bilateral

Dor no masseter bilateral

Dor no masseter bilateral

Desconforto na face ao acordar (músculos) bilateral

Dor temporal bilateral

Dor no temporal e masseter no lado direito

Dor no masseter bilateral, quando acorda

Dor no masseter bilateral

Dor na região temporal ao acordar

Dores nos músculos da face

Dor na região do temporal bilateral

Dor no masseter bilateral (esporádica)

Dores nos músculos da face

Dor temporal bilateral (dor de cabeça), origem masseter

Dor no masseter bilateral

Dor no masseter direito e região cervical bilateral

Dor no masseter bilateral, ao mastigar alimento duros

Dor temporal bilateral

Dor no masseter bilateral

Dor no masseter direito

Dor no masseter e temporal bilateral (referida do ECM)

Dor no masseter bilateral

Dor no masseter esquerdo

Dor no masseter e temporal bilateral

Dor temporal bilateral

Dor temporal bilateral (dor de cabeça ao acordar)
INTENSIDADE*

$$
\text { LEVE }
$$

MODERADA

SEVERA

MODERADA

MODERADA

LEVE

LEVE

LEVE

LEVE

MODERADA

SEVERA

MODERADA

MODERADA

LEVE

LEVE

LEVE

MODERADA

LEVE

LEVE

MODERADA

MODERADA

MODERADA

LEVE

LEVE

MODERADA

MODERADA

MODERADA

SEVERA

LEVE

LEVE

(Dor miofascial)

* Intensidade da dor relatada pelo paciente 
Tabela 4 Características clínicas (triagem) do grupo EXPERIMENTAL

\begin{tabular}{|c|c|c|c|c|c|c|c|c|c|}
\hline & PACIENTE & $\begin{array}{c}\text { Tempo Início } \\
\text { (meses) }\end{array}$ & $\begin{array}{c}\text { Horário da } \\
\text { pior dor }\end{array}$ & EAV dor média & & & Abertura (mm) & $\begin{array}{l}\text { Relato de } \\
\text { Ruídos }\end{array}$ & $\begin{array}{l}\text { Relato de dor } \\
\text { na ATM }\end{array}$ \\
\hline 1 & $\mathrm{AOL}$ & 12 & $\mathrm{~N}$ & 20,0 & 10 & MODERADA & 60 & 0 & 1 \\
\hline 2 & $A B$ & 120 & $\mathrm{~T}$ & 30,0 & 8 & LEVE & 55 & 1 & 1 \\
\hline 3 & CTBS & 120 & $\mathrm{~N}$ & 84,0 & 10 & MODERADA & 46 & 0 & 0 \\
\hline 4 & DV & 120 & $M$ & 64,0 & 16 & SEVERA & 45 & 0 & 1 \\
\hline 5 & EC & 36 & $\mathrm{M}$ & 30,0 & 5 & LEVE & 53 & 0 & 0 \\
\hline 6 & EPM & 54 & $M$ & 19,0 & 6 & LEVE & 40 & 0 & 1 \\
\hline 7 & FGM & 84 & $\mathrm{~N}$ & 15,0 & 9 & MODERADA & 43 & 0 & 0 \\
\hline 8 & IE & 12 & $M$ & 25,0 & 6 & LEVE & 47 & 1 & 0 \\
\hline 9 & J GRR & 12 & $\mathrm{~S}$ & 15,0 & 4 & LEVE & 45 & 0 & 0 \\
\hline 10 & $\mathrm{~J}$ MBB & 9 & $M$ & 10,0 & 4 & LEVE & 51 & 0 & 0 \\
\hline 11 & $\mathrm{KCN}$ & 12 & $\mathrm{M}$ & 74,0 & 19 & SEVERA & 40 & 0 & 1 \\
\hline 12 & KCSG & 11 & $\mathrm{M}$ & 63,0 & 11 & MODERADA & 45 & 0 & 0 \\
\hline 13 & LM & 6 & $\mathrm{M}$ & 40,0 & 8 & LEVE & 44 & 1 & 0 \\
\hline 14 & LSC & 12 & $\mathrm{~T}$ & 20,0 & 5 & LEVE & 46 & 0 & 0 \\
\hline 15 & LEB & 12 & $S$ & 60,0 & 5 & LEVE & 56 & 1 & 1 \\
\hline 16 & LGCB & 60 & $\mathrm{M}$ & 16,0 & 4 & LEVE & 52 & 0 & 0 \\
\hline 17 & MP & 84 & $\mathrm{M}$ & 20,0 & 8 & LEVE & 51 & 0 & 1 \\
\hline 18 & MRC & 48 & A & 12,0 & 9 & MODERADA & 35 & 0 & 0 \\
\hline 19 & $\mathrm{MP}$ & 18 & $\mathrm{~T}$ & 69,9 & 5 & LEVE & 41 & 0 & 0 \\
\hline 20 & NB & 48 & $M$ & 50,0 & 17 & SEVERA & 49 & 1 & 0 \\
\hline 21 & PDR & 24 & $\mathrm{M}$ & 31,7 & 12 & MODERADA & 49 & 0 & 0 \\
\hline 22 & MK & 6 & A & 80,0 & 2 & AUSENTE & 53 & 0 & 0 \\
\hline 23 & PB & 2 & $\mathrm{M}$ & 10,0 & 9 & MODERADA & 56 & 1 & 1 \\
\hline 24 & $\mathrm{RAB}$ & 2 & $\mathrm{~N}$ & 85,5 & 10 & MODERADA & 45 & 0 & 0 \\
\hline 25 & $\mathrm{RC}$ & 9 & $\mathrm{~T}$ & 72,7 & 15 & SEVERA & 37 & 1 & 0 \\
\hline 26 & RDBG & 36 & $\mathrm{~T}$ & 45,8 & 8 & LEVE & 51 & 0 & 1 \\
\hline 27 & SRC & 48 & $S$ & 32,6 & 10 & MODERADA & 44 & 0 & 1 \\
\hline 28 & $\mathrm{~S}$ & 5 & $\mathrm{~T}$ & 28,4 & 12 & MODERADA & 55 & 0 & 1 \\
\hline 29 & SHS & 12 & $\mathrm{~N}$ & 26,0 & 7 & LEVE & 40 & 0 & 0 \\
\hline 30 & TAM & 48 & $\mathrm{M}$ & 19,0 & 11 & MODERADA & 35 & 0 & 1 \\
\hline
\end{tabular}

* Período do dia de ocorrência da pior dor, onde $\mathrm{A}=$ ao acordar, $\mathrm{M}=$ manhã, $\mathrm{T}=$ tarde, $\mathrm{N}=$ noite e $\mathrm{S}=$ sem período específico.

† Valor obtido na Escala de Análise Visual (EAV), em mm

*Valor obtido no questionário de avaliação objetiva de DTM ${ }^{33}$ 
Tabela 5 Freqüência das respostas ao questionário de índice de $\mathrm{DTM}^{32}$ no grupo EXPERIMENTAL

\section{Perguntas}

Freqüência (\%)

1) Você sente dificuldade de abrir a boca?

$24,14(7)$

2) Você sente dificuldade de movimentar sua mandíbula para os lados?

$17,24(5)$

3) Você sente dores de cabeça com freqüência?

$86,21(25)$

4) Você sente desconforto ou dor muscular quando mastiga?

$55,17(16)$

5) Você sente dores no pescoço e/ ou ombros?

$93,10(27)$

6) Você sente dores de ouvido ou próximo a ele?

$48,28(14)$

7) Você percebe algum ruído na ATM?

$48,28(14)$

8) Você considera sua mordida "anormal"?

$27,59(8)$

9) Você usa apenas um lado de sua boca para mastigar?

$48,28(14)$

10) Você sente dores na face ao acordar? 
Tabela 6 Características Gerais (triagem) dos Grupos CONTROLE e EXPERIMENTAL

\begin{tabular}{|c|c|c|c|}
\hline & $\begin{array}{l}\text { Grupo Controle } \\
(\mathrm{n}=\mathbf{3 0})\end{array}$ & $\begin{array}{l}\text { Grupo Experimental } \\
(n=30)\end{array}$ & $\begin{array}{l}\text { P (teste t ou } \\
* \text { Mann Whitney) }\end{array}$ \\
\hline \multirow[t]{2}{*}{ Distribuição por sexo } & 24 mulheres & 24 mulheres & \\
\hline & 6 homens & 6 homens & \\
\hline Idade & $25,97 \pm 4,49$ & $26,63 \pm 4,97$ & 0,29 \\
\hline EAV média & $0,0 \pm 0,0$ & $39,00 \pm 27,70$ & $\varangle 0,001$ \\
\hline $\begin{array}{l}\text { Presença de queixa de dor } \\
\text { muscular }\end{array}$ & Não (100\%) & $\operatorname{Sim}(100 \%)$ & \\
\hline \multirow[t]{3}{*}{ Intensidade da dor } & & $14-$ leve $(46,67 \%)$ & \\
\hline & & 13 - moderada $(43,33 \%)$ & \\
\hline & & 3 - severa $(10,0 \%)$ & \\
\hline Índice de DTM (escore) & $1,867 \pm 1,697$ & $8,800 \pm 4,164$ & $\varangle 0,001$ \\
\hline Índice de DTM & 26 - ausente $(86,67 \%)$ & 1 - ausente $(3,33 \%)$ & \\
\hline \multirow[t]{3}{*}{ (interpretação) } & 4 - leve $(13,33 \%)$ & 14 - leve $(46,66 \%)$ & \\
\hline & & 11 - moderada $(36,67 \%)$ & \\
\hline & & 4 - severa $(13,33 \%)$ & \\
\hline Abertura Máxima (mm) & $50,43 \pm 6,47$ & $46,97 \pm 6,53$ & 0,043 \\
\hline $\begin{array}{l}\text { Tempo de início da dor } \\
\text { (meses) }\end{array}$ & $0,0 \pm 0,0$ & $34,67 \pm 36,96(2-120)$ & \\
\hline \multirow[t]{5}{*}{ Horário de piora da dor } & - & 2 - ao acordar $(6,67 \%)$ & \\
\hline & & 15 - manhã $(50,00 \%)$ & \\
\hline & & 6 - tarde $(20,0 \%)$ & \\
\hline & & 4 - noite $(13,33 \%)$ & \\
\hline & & 3 - não sabiam (10,0\%) & \\
\hline $\begin{array}{l}\text { Relato de estalidos } \\
\text { articulares }\end{array}$ & $9(30,0 \%)$ & $7(23,33 \%)$ & $0,662^{*}$ \\
\hline
\end{tabular}


Tabela 7 Distribuição dos horários de piora da dor no grupo EXPERIMENTAL

\begin{tabular}{ccc}
\hline & \multicolumn{2}{c}{ GRUPO EXPERIMENTAL $(\mathbf{n}=\mathbf{3 0})$} \\
\cline { 2 - 3 } Horário da pior dor & Bruxômanos $(\mathbf{n}=\mathbf{1 9})$ & Não-bruxômanos $(\mathbf{n = 1 1})$ \\
\hline Ao acordar & $1(5,26 \%)$ & $1(9,10 \%)$ \\
Manhã & $10(52,63 \%)$ & $4(36,36 \%)$ \\
Tarde & $3(15,79 \%)$ & $2(18,18 \%)$ \\
Noite & $4(21,05 \%)$ & $2(18,18 \%)$ \\
Não sabe & $1(5,26 \%)$ & $2(18,18 \%)$ \\
\hline TOTAL & $100 \%$ & $100 \%$ \\
\hline
\end{tabular}

O teste Exato de Fisher não detectou associação estatisticamente significativa entre BS e qualquer dos horários de pior dor, no grupo experimental $(p=0,706)$ - Tabela 7.

A fim de avaliar se os cinco não-bruxômanos que relataram o período da manhã como sendo o de piora da dor apresentaram mais ARMM durante a noite, verificaram-se as diferenças entre as variáveis oromotoras destes e dos não-bruxômanos que relataram outros horários como os de piora da dor (Tabela 8).

Tabela 8 Variáveis oromotoras dos NÃO-BRUXÔMANOS do grupo EXPERIMENTAL com e sem piora da dor pela manhã

\begin{tabular}{|c|c|c|c|}
\hline \multirow[b]{2}{*}{$\begin{array}{l}\text { Variáveis } \\
\text { oromotoras }\end{array}$} & \multicolumn{3}{|c|}{ NÃO-BRUXÔMANOS - GRUPO EXPERIMENTAL } \\
\hline & $\begin{array}{c}\text { manhã (n= } \mathbf{5}) \\
\text { Média } \pm d p(\operatorname{máx}-\min )\end{array}$ & $\begin{array}{l}\text { outros horários }(\mathbf{n}=\mathbf{6}) \\
\text { Média } \pm d p \text { (máx-min) }\end{array}$ & P (teste-t) \\
\hline Episódios/noite & $13,20 \pm 5,17(19,0-6,0)$ & $13,33 \pm 7,69(23,0-4,0)$ & 0,974 \\
\hline Episódios/hora & $2,24 \pm 0,85(2,9-0,9)$ & $2,12 \pm 1,09(3,5-0,7)$ & 0,832 \\
\hline Bursts/hora & $10,26 \pm 6,02(19,2-2,6)$ & $8,55 \pm 5,12(15,2-2,7)$ & 0,625 \\
\hline Bursts/epi & $4,51 \pm 2,18(7,3-2,7)$ & $3,95 \pm 0,51(4,5-3,1)$ & 0,558 \\
\hline
\end{tabular}

Tabela 9 Variáveis oromotoras dos Bruxômanos com e sem piora da dor pela manhã

\begin{tabular}{lccc}
\hline & \multicolumn{4}{c}{ BRUXÔMANOS - GRUPO EXPERIMENTAL } \\
\cline { 2 - 5 } Variáveis & manhã(n = 11) & outros horários (n = 8) & P (teste-t) \\
oromotoras & Média $\pm \mathrm{dp}(\operatorname{máx}$-min) & Média $\pm \mathrm{dp}($ máx-min) & \\
\hline Episódios/noite & $40,27 \pm 14,88(78,0-25,0)$ & $36,13 \pm 10,90(52,0-25,0)$ & 0,514 \\
Episódios/hora & $6,67 \pm 2,59(13,7-4,4)$ & $6,26 \pm 1,67(8,9-4,2)$ & 0,703 \\
Bursts/hora & $30,39 \pm 7,98(49,3-20,6)$ & $29,47 \pm 6,35(36,8-21,6)$ & 0,790 \\
Bursts/ epi & $4,81 \pm 0,96(6,3-2,6)$ & $4,81 \pm 0,99(7,04-4,09)$ & 0,988 \\
\hline
\end{tabular}


Também não houve diferenças estatisticamente significativas entre as variáveis oromotoras dos bruxômanos cujo horário de piora da dor foi a manhã versus aqueles que relataram outros horários (Tabela 9). Isso indica que o período da manhã como o de piora da dor não se relacionou a maior intensidade da ARMM.

Não houve diferenças estatísticas entre os valores de EAV $(\mathrm{mm})$ dos bruxômanos e não-bruxômanos com DMF em qualquer das escalas (triagem, pré ou pós-PSG) - Tabela 10.

Tabela 10 Valores das EAVs do grupo EXPERIMENTAL

\begin{tabular}{cccc}
\hline \multirow{2}{*}{ EAV } & \multicolumn{3}{c}{ GRUPO EXPERIMENTAL $(\mathbf{n}=\mathbf{3 0})$} \\
\cline { 2 - 4 } & $\begin{array}{c}\text { Bruxômanos }(\mathbf{n}=\mathbf{1 9}) \\
\operatorname{EAV}(\mathrm{mm})\end{array}$ & $\begin{array}{c}\text { Não-bruxômanos }(\mathbf{n}=\mathbf{1 1} \\
\mathrm{EAV}(\mathrm{mm})\end{array}$ & $\mathbf{p}$ \\
\hline Média & $43,02 \pm 26,19$ & $31,93 \pm 21,22$ & $0,243^{*}$ \\
Pré-PSG & $12,95 \pm 17,17$ & $17,18 \pm 13,22$ & $0,487^{*}$ \\
Pós-PSG & $12,19 \pm 18,12[4(0,0-52)]$ & $9,22 \pm 8,43[10(0,0-20,0)]$ & $0,813^{\#}$ \\
\hline
\end{tabular}

* Teste $\mathrm{t}$

\# Mann-Whitney 
Tabela 11 Características clínicas dos Bruxômanos e Não-Bruxômanos do GRUPO EXPERIMENTAL

\begin{tabular}{|c|c|c|c|}
\hline & $\begin{array}{l}\text { BRUXÔMANOS GE } \\
(n=19)\end{array}$ & $\begin{array}{c}\text { NÃO BRUXÔMANOS GE } \\
(n=11)\end{array}$ & $\mathbf{P}$ \\
\hline \multirow[t]{2}{*}{ Distribuição por sexo } & 16 mulheres & 8 mulheres & \\
\hline & 3 homens & 3 homens & \\
\hline Idade & $27,26 \pm 5,07(26,00)$ & $25,54 \pm 4,82(24,00)$ & 0,149 \\
\hline Índice de DTM (escore) & $9,21 \pm 4,67$ & $8,18 \pm 3,03$ & $0,519 *$ \\
\hline \multirow[t]{3}{*}{ Intensidade da dor (descrição) } & 7 - LEVE $(36,8 \%)$ & 7 - LEVE $(63,6 \%)$ & \\
\hline & 9 - MODERADA $(47,4 \%)$ & 4 - MODERADA $(36,4 \%)$ & \\
\hline & 3 - SEVERA (15,8\%) & & \\
\hline Abertura Máxima (mm) & $48,32 \pm 5,78$ & $44,64 \pm 7,34$ & $0,139 *$ \\
\hline Tempo de início da dor (meses) & $34,63 \pm 37,48(12,000)$ & $34,64 \pm 37,93(12,000)$ & $0,863^{\#}$ \\
\hline Ruídos articulares & $3(15,79 \%)$ & $4(36,36 \%)$ & $0,371^{* *}$ \\
\hline $\begin{array}{l}\mathrm{N}^{0} \text { de pontos musculares sensíveis } \\
\text { (total) }\end{array}$ & $10,11 \pm 5,02$ & $10,46 \pm 5,03$ & $0,856^{*}$ \\
\hline $\begin{array}{l}N^{0} \text { de pontos musculares sensíveis } \\
\text { (músculos mastigatórios) }\end{array}$ & $7,63 \pm 4,04$ & $8,18 \pm 4,51$ & $0,733^{*}$ \\
\hline $\begin{array}{l}\text { Escore de sensibilidade muscular } \\
\text { (total) }\end{array}$ & $0,63 \pm 0,40$ & $0,69 \pm 0,50$ & $0,722^{*}$ \\
\hline $\begin{array}{l}\text { Escore de sensibilidade muscular } \\
\text { (músculos mastigatórios) }\end{array}$ & $0,594 \pm 0,38$ & $0,652 \pm 0,498$ & $0,722^{*}$ \\
\hline $\begin{array}{l}\mathbf{N}^{0} \text { de pontos sensíveis (Masseter e } \\
\text { Temporal) }\end{array}$ & $6,47 \pm 3,20(6,00)$ & $6,63 \pm 4,15(6,00)$ & $0,949^{\#}$ \\
\hline $\begin{array}{l}\text { Escore de Sensibilidade } \\
\text { (Masseter e Temporal) }\end{array}$ & $0,64 \pm 0,40(0,43)$ & $0,69 \pm 0,58(0,43)$ & $0,731^{\#}$ \\
\hline
\end{tabular}

Os bruxômanos e não-bruxômanos com DMF não diferiram quanto às características clínicas (Tabela 11) 


\section{2 avaliação Prévia ao Exame Polissonográfico (PSG)}

Previamente à segunda noite de PSG, cada participante foi reavaliado, visando ao registro inicial dos pontos sensíveis à palpação, para que esses fossem tomados como parâmetro de comparação para a análise da sensibilidade à palpação na manhã do dia seguinte.

Alguns indivíduos apresentaram alguma sintomatologia articular à palpação, entretanto, essa sintomatologia não era espontânea, não se tratava da queixa dos pacientes, nem vinha acompanhada de qualquer outro sinal como ruído (estalido ou crepitação), limitação ou deflexão da abertura ou edema. Portanto, essa sintomatologia à palpação esporádica, visto que não se manifestou no exame inicial, não foi suficiente para completar o diagnóstico de uma desordem articular inflamatória, como artralgia ou artrite, segundo o RDC/TMD. ${ }^{44}$

Tabela 12 Limiares de Dor à Pressão pré-PSG (LDP pré-PSG) dos grupos CONTROLE E EXPERIMENTAL

\begin{tabular}{lccc}
\hline \multicolumn{1}{c}{ sítIO MUSCULAR } & $\begin{array}{c}\text { GRUPO CONTROLE } \\
(\mathbf{n}=\mathbf{3 0})\end{array}$ & $\begin{array}{c}\text { GRUPO EXPERIMENTAL } \\
(\mathbf{n}=\mathbf{3 0})\end{array}$ & $\begin{array}{c}\mathbf{P} \\
\text { (*teste t ou } \\
\text { "Mann-Whitney) }\end{array}$ \\
\hline Temporal Anterior & $2,556 \pm 0,665$ & $1,900 \pm 0,549$ & $<0,001^{*}$ \\
Temporal Médio & $2,833 \pm 0,635$ & $2,226 \pm 0,723$ & $0,001^{*}$ \\
Temporal Posterior & $3,088 \pm 0,798$ & $2,505 \pm 0,814$ & $0,007^{*}$ \\
Masseter (origem) & $2,011 \pm 0,519$ & $1,414 \pm 0,436$ & $<0,001^{*}$ \\
Masseter (corpo) & $1,73 \pm 0,43[1,590]$ & $1,36 \pm 0,35[1,390]$ & $0,001^{\#}$ \\
Masseter (inserção) & $2,064 \pm 0,523$ & $1,442 \pm 0,365$ & $<0,001^{*}$ \\
Masseter (profundo) & $2,10 \pm 0,48[2,050]$ & $1,53 \pm 0,39[1,465]$ & $<0,001^{\#}$ \\
\hline
\end{tabular}

* Teste $\mathrm{t}$

\# Mann-Whitney

Observa-se que os grupos controle e experimental diferiram estatisticamente quanto aos LDPs pré-PSG em todos os sítios musculares avaliados (Tabela 12). 


\subsection{DADOS POLISSONOGRÁFICOS}

O Anexo 25 mostra que, em nenhum dos exames polissonográficos levados em consideração para a análise, a freqüência de apnéia/hipopnéia foi superior a 5 eventos por hora de sono, nem a freqüência de movimentos periódicos dos membros (MPP) foi superior a 10 eventos por hora de sono. Ainda, apenas 3 indivíduos do grupo controle apresentaram número de microdespertares por hora levemente superior a 15, em ambas as noites de estudo.

Tabela 13 Índice Apnéia/Hipopnéia, microdespertares/hora e índice de movimentos periódicos dos membros nas duas noites de PSG

\begin{tabular}{lcc}
\hline Variável & $\begin{array}{c}\text { GRUPO CONTROLE } \\
(\mathbf{n}=\mathbf{3 0})\end{array}$ & $\begin{array}{c}\text { GRUPO EXPERIMENTAL } \\
(\mathbf{n}=\mathbf{3 0})\end{array}$ \\
& Média $\pm \mathbf{d p}($ Max - Min) & Média $\pm \mathbf{d p}($ Max - Min) \\
\hline IAH noite 1 & $0,52 \pm 0,69(2,2-0,0)$ & $0,30 \pm 0,62(2,5-0,0)$ \\
MD/h noite 1 & $7,51 \pm 4,34(16,7-0,0)$ & $5,95 \pm 3,76(14,7-0,0)$ \\
MPM noite 1 & $0,56 \pm 2,06(10,0-0,0)$ & $0,66 \pm 1,78(8,5-0,0)$ \\
IAH noite 2 & $0,39 \pm 0,611(2,7-0,0)$ & $0,47 \pm 0,83(3,5-0,0)$ \\
MD/h noite 2 & $7,49 \pm 4,09(17,3-1,1)$ & $5,64 \pm 3,09(14,9-1,4)$ \\
MPM noite 2 & $0,5 \pm 1,64(7,7-0,0)$ & $0,37 \pm 0,85(2,8-0,0)$ \\
\hline
\end{tabular}

A Tabela 13 apresenta os índices de apnéia/hipopnéia (IAH), de movimentos periódicos dos membros durante o sono (MPM/h) e o número de microdespertares por hora de sono $(\mathrm{MD} / \mathrm{h})$ nas duas noites de exame polissonográfico. 


\subsubsection{Variáveis do Sono}

Não houve diferença estatisticamente significativas entre quaisquer das variáveis de sono entre os grupos controle e experimental (Tabela 14), nem entre os bruxômanos e nãobruxômanos (Tabela 15).

Tabela 14 Variáveis gerais do sono nos grupos CONTROLE e EXPERIMENTAL

\begin{tabular}{llll}
\hline & \multicolumn{1}{c}{$\begin{array}{c}\text { GRUPO CONTROLE } \\
\text { (média } \pm \mathrm{dp} / \text { mediana) }\end{array}$} & $\begin{array}{c}\text { GRUPO EXPERIMENTAL } \\
\text { (média } \pm \mathrm{dp} / \text { mediana) }\end{array}$ & \multicolumn{1}{c}{ P } \\
\hline Latência do sono (h) & 0,229 & 0,169 & $0,214^{\#}$ \\
Tempo de Registro (h) & $6,431 \pm 0,584$ & $6,539 \pm 0,715$ & $0,524^{*}$ \\
Eficiência do sono (\%) & 92,400 & 92,350 & $0,762^{\#}$ \\
Tempo de sono (h) & $5,824 \pm 0,568$ & $5,969 \pm 0,609$ & $0,345^{*}$ \\
MD/hora & 5,750 & 5,500 & $0,337^{\#}$ \\
Tempo/Fase 1 (\%) & 9,150 & 8,950 & $0,877^{\#}$ \\
Tempo Fase 2(\%) & $50,897 \pm 7,169$ & $51,980 \pm 8,783$ & $0,603^{*}$ \\
Tempo Fase 3/4 (\%) & $19,183 \pm 5,315 a$ & $19,230 \pm 7,394 a$ & $0,978^{*}$ \\
Tempo Fase REM (\%) & $19,883 \pm 4,624 a$ & $18,437 \pm 6,632 \mathrm{a}$ & $0,331^{*}$ \\
\hline Ans &
\end{tabular}

Análise intra-grupo Tempo Fases do Sono: Kruskal-Wallis Multiple-Comparison Z Value Test Letras iguais representam valores estatisticamente semelhantes

* Teste $\mathrm{t}$

\# Mann-Whitney 
Tabela 15 Variáveis gerais do sono nos BRUXÔMANOS e NÃO-BRUXÔMANOS

\begin{tabular}{llll}
\hline & \multicolumn{1}{c}{$\begin{array}{c}\text { BRUXÔMANOS } \\
(\text { média } \pm d p / \text { mediana })\end{array}$} & \multicolumn{1}{c}{$\begin{array}{c}\text { NÃO-BRUXÔMANOS } \\
\text { (média } \pm d p / \text { mediana) }\end{array}$} & \multicolumn{1}{c}{ P } \\
\hline Latência do sono (h) & 0,175 & 0,200 & $0,383^{\#}$ \\
Tempo de Registro (h) & $6,426 \pm 0,669$ & $6,539 \pm 0,638$ & 0,505 \\
Eficiência do sono (\%) & 93,700 & 91,800 & $0,107^{\#}$ \\
Tempo de sono (h) & $5,903 \pm 0,591$ & $5,891 \pm 0,596$ & $0,936^{*}$ \\
MD/hora & 5,900 & 4,800 & $0,280^{\#}$ \\
Tempo/Fase 1 (\%) & 9,600 & 8,600 & $0,178^{\#}$ \\
Tempo Fase 2(\%) & $51,755 \pm 7,248$ & $51,142 \pm 8,695$ & $0,769^{*}$ \\
Tempo Fase 3/4 (\%) & $17,893 \pm 6,799$ & $20,177 \pm 5,871$ & $0,172^{*}$ \\
Tempo Fase 5 (\%) & $19,035 \pm 5,457$ & $19,277 \pm 6,035$ & $0,870^{*}$ \\
\hline
\end{tabular}

* Teste $\mathrm{t}$

\# Mann-Whitney

Os grupos controle e experimental não diferiram quanto à distribuição das variáveis oromotoras de bruxismo nas fases do sono (Tabela 16), o mesmo ocorrendo entre os bruxômanos e não-bruxômanos dos grupos controle (Tabela 17) e experimental (Tabela 18).

Tabela 16 Distribuição dos episódios e bursts nas diferentes fases do sono nos Grupos CONTROLE e EXPERIMENTAL

\begin{tabular}{|c|c|c|c|}
\hline & $\begin{array}{l}\text { CONTROLE }(\mathbf{n}=\mathbf{3 0}) \\
\text { (média } \pm d p / \text { mediana) }\end{array}$ & $\begin{array}{l}\text { EXPERIMENTAL }(n=30) \\
\text { (média } \pm d p / \text { mediana) }\end{array}$ & $\begin{array}{l}\mathrm{P} \\
\text { (*Teste t / \#ann } \\
\text { Whitney) }\end{array}$ \\
\hline Episódios/Fase 1 (\%) & 32,840 & 33,975 & $0,953^{\#}$ \\
\hline Episódios / Fase 2 (\%) & $29,621 \pm 17,321$ & $35,862 \pm 13,752$ & $0,128 *$ \\
\hline Episódios / Fase 3/4 (\%) & 8,575 & 8,520 & $0,773^{\#}$ \\
\hline Episódios / Fase 5 (\%) & $22,228 \pm 15,891$ & $19,407 \pm 13,616$ & $0,463 *$ \\
\hline Bursts / Fase 1 (\%) & 35,655 & 34,865 & $0,647^{\#}$ \\
\hline Bursts / Fase 2 (\%) & $28,627 \pm 18,858$ & $36,049 \pm 15,551$ & $0,102 *$ \\
\hline Bursts / Fase $3 / 4(\%)$ & 9,700 & 10,750 & $0,641^{\#}$ \\
\hline Bursts / Fase REM (\%) & 20,830 & 13,240 & $0,631^{\#}$ \\
\hline Episódios Fásicos (\%) & $65,552 \pm 25,623$ & $70,380 \pm 16,670$ & $0,391 *$ \\
\hline Episódios Tônicos (\%) & 17,440 & 12,075 & $0,104^{\#}$ \\
\hline Episódios Mistos (\%) & $12,647 \pm 14,480$ & $16,665 \pm 10,087$ & $0,217 *$ \\
\hline Burst fásicos (\%) & 91,320 & 92,580 & $0,695^{\#}$ \\
\hline Bursts tônicos (\%) & 8,680 & 7,260 & $0,520^{\#}$ \\
\hline
\end{tabular}


Tabela 17 Distribuição dos episódios e bursts nas diferentes fases do sono no grupo CONTROLE

\begin{tabular}{llll}
\hline & \multicolumn{2}{c}{ GRUPO CONTROLE } & P \\
\cline { 2 - 3 } & $\begin{array}{l}\text { BRUXÔMANOS (n = 10) } \\
\text { (média } \pm \mathrm{dp} / \text { mediana) }\end{array}$ & $\begin{array}{l}\text { NÃO-BRUXÔMANOS (n = 20) } \\
\text { (média } \pm \mathrm{dp} / \text { mediana) }\end{array}$ & \\
\hline Episódios/Fase 1 (\%) & $32,840 \mathrm{a}, \mathrm{b}$ & $35,710 \mathrm{a}$ & $0,947^{\#}$ \\
Episódios / Fase 2 (\%) & $34,865 \pm 12,274 \mathrm{a}, \mathrm{c}$ & $34,102 \pm 12,936 \mathrm{a}, \mathrm{b}$ & $0,878^{*}$ \\
Episódios / Fase 3/4 (\%) & 7,400 & $11,805 \mathrm{~b}$ & $0,545^{\#}$ \\
Episódios / Fase 5 (\%) & $25,139 \mathrm{~b}, \mathrm{c}$ & $20,773 \mathrm{a}, \mathrm{b}$ & $0,488^{\#}$ \\
Bursts / Fase 1 (\%) & 33,715 & 42,090 & $0,912^{\#}$ \\
Bursts / Fase 2 (\%) & $32,247 \pm 13,487$ & $26,817 \pm 21,125$ & $0,467^{*}$ \\
Bursts / Fase 3/4 (\%) & 10,950 & 8,330 & $0,676^{\#}$ \\
Bursts / Fase 5 (\%) & 21,567 & 20,836 & $0,914^{\#}$ \\
Episódios Fásicos (\%) & 62,585 & 81,305 & $0,312^{\#}$ \\
Episódios Tônicos (\%) & 20,325 & 12,770 & $0,301^{\#}$ \\
Episódios Mistos (\%) & 16,955 & 4,450 & $0,075^{\#}$ \\
Burst fásicos (\%) & 89,780 & 94,820 & $0,180^{\#}$ \\
Bursts tônicos (\%) & 12,220 & 5,180 & $0,180^{\#}$ \\
Episódios com MD (\%) & $73,21 \pm 6,14$ & $81,67 \pm 14,09$ & $0,082^{*}$ \\
\hline
\end{tabular}

Letras iguais representam valores semelhantes entre si, em cada subgrupo.

Análise intra-grupo (Episódios / Fase): Teste ANOVA a um critério, seguido do teste de Tukey

*Teste $\mathrm{t}$

${ }^{*}$ Mann Whitney

Tabela 18 Distribuição dos episódios e bursts nas diferentes fases do sono no grupo EXPERIMENTAL

\begin{tabular}{llll}
\hline & \multicolumn{2}{c}{ GRUPO EXPERIMENTAL } & \\
\cline { 2 - 3 } & $\begin{array}{l}\text { BRUXÔMANOS (N = 19) } \\
\text { (média } \pm \mathrm{dp} / \text { (mediana) }\end{array}$ & $\begin{array}{l}\text { NÃO-BRUXÔMANOS (N = 11) } \\
\text { (média } \pm \mathrm{dp} / \text { (mediana) }\end{array}$ & P \\
\hline Episódios/Fase 1 (\%) & $34,712 \pm 12,741 \mathrm{a}$ & $33,744 \pm 12,692 \mathrm{a}$ & $0,842^{*}$ \\
Episódios / Fase 2 (\%) & $30,928 \pm 19,094 \mathrm{a}$ & $27,365 \pm 14,316 \mathrm{a}, \mathrm{b}$ & $0,596^{*}$ \\
Episódios / Fase 3/4 (\%) & $8,340 \mathrm{~b}$ & $8,700, \mathrm{~b}$ & $0,983^{\#}$ \\
Episódios / Fase 5 (\%) & $13,950 \mathrm{~b}$ & $29,410 \mathrm{a}, \mathrm{b}$ & $0,078^{\#}$ \\
Bursts / Fase 1 (\%) & $34,353 \pm 13,525$ & $32,629 \pm 13,299$ & $0,738^{*}$ \\
Bursts / Fase 2 (\%) & $41,595 \pm 12,345$ & $26,471 \pm 16,362$ & $0,008^{*}$ \\
Bursts / Fase 3/4 (\%) & $10,562 \pm 8,041$ & $12,664 \pm 10,337$ & $0,539^{*}$ \\
Bursts / Fase 5 (\%) & 10,560 & 20,300 & $0,093^{\#}$ \\
Episódios Fásicos (\%) & $70,029 \pm 16,447$ & $70,986 \pm 17,841$ & $0,883^{*}$ \\
Episódios Tônicos (\%) & 11,110 & 13,040 & $0,780^{\#}$ \\
Episódios Mistos (\%) & $17,094 \pm 10,913$ & $15,925 \pm 8,930$ & $0,766^{*}$ \\
Burst fásicos (\%) & $91,321 \pm 5,943$ & $90,480 \pm 10,051$ & $0,774^{*}$ \\
Bursts tônicos (\%) & $7,732 \pm 4,912$ & $9,522 \pm 10,051$ & $0,516^{*}$ \\
Episódios com MD (\%) & $78,22 \pm 7,257$ & $75,65 \pm 9,107$ & $0,401^{*}$ \\
\hline
\end{tabular}

Letras iguais representam valores semelhantes entre si, em cada subgrupo.

Análise intra-grupo (Episódios / Fase): Teste ANOVA a um critério, seguido do teste de Tukey

*Teste $\mathrm{t}$

${ }^{\#}$ Mann Whitney 
Verificou-se a confiabilidade intra-examinador quanto à contagem dos eventos de bruxismo por meio do teste Kappa entre 2 leituras de uma amostra de 87 episódios de bruxismo selecionados de forma cega ${ }^{6}$ dentre a população estudada. Obteve-se um valor de Kappa de 0,7247 para a detecção de eventos do tipo fásico, de 0,5859 para a detecção de eventos do tipo tônico e de 0,704 para a detecção de eventos do tipo misto, representando concordância entre boa e moderada. ${ }^{17}$

A Tabela 19 mostra os valores médios das variáveis oromotoras obtidas pelos bruxômanos e não-bruxômanos da amostra total. Como esperado todas as variáveis oromotoras de BS foram estatisticamente mais elevadas entre os bruxômanos.

Tabela 19 Variáveis oromotoras de corte na amostra total

\begin{tabular}{lccc}
\hline & $\begin{array}{c}\text { BRUXÔMANOS }(\mathbf{N}=\mathbf{2 9}) \\
\text { média } \pm \mathrm{dp} \\
{[\text { mediana }(\text { máx-min) }}\end{array}$ & $\begin{array}{c}\text { NÃO-BRUXÔMANOS (N = 31) } \\
\text { média } \pm \mathrm{dp}\end{array}$ & $\begin{array}{c}\mathbf{P} \\
\text { (teste t) }\end{array}$ \\
\cline { 2 - 4 } Episódios/noite & $37,72 \pm 11,54$ & $12,90 \pm 6,48$ & \\
& {$[36,00(78,0-25,0)]$} & {$[11,00(24,0-3,0)]$} & $<0,001$ \\
Episódios/hora & $6,40 \pm 1,91$ & $2,14 \pm 0,99$ & \\
Bursts/hora & {$[7,78(13,7-4,2)]$} & {$[2,08(3,8-0,5)]$} & $<0,001$ \\
& $28,39 \pm 7,28$ & $8,91 \pm 5,33$ & \\
Bursts/episódio & {$[28,12(49,3-12,2)]$} & {$[8,56(19,4-1,2)]$} & $<0,001$ \\
\hline
\end{tabular}

Não houve diferenças estatisticamente significativas entre a atividade oromotora dos bruxômanos com e sem DMF (Tabela 38), bem como entre os não bruxômanos com e sem DMF (Tabela 20).

\footnotetext{
${ }^{6}$ Seleção realizada por uma funcionária da Clínica do Sono que não conhecia os diagnósticos dos
} indivíduos 
Tabela 20 Variáveis oromotoras de corte dos não-bruxômanos

\section{NÃO-BRUXÔMANOS}

EXPERIMENTAL $(\mathbf{N}=\mathbf{1 1})$

CONTROLE $(\mathrm{N}=\mathbf{2 0})$

média $\pm d p$ (máx-min)

média \pm dp (máx-min)

Teste $\mathrm{t}$

Episódios/noite

$13,27 \pm 6,34(23,0-4,0)$

$12,70 \pm 6,71(24,0-3,0)$

0,818

Episódios/hora

$2,18 \pm 0,94(3,5-0,7)$

$2,13 \pm 1,04(3,8-0,5)$

0,897

Bursts/hora

$9,33 \pm 5,36(19,2-2,6)$

$8,68 \pm 5,44(19,4-1,2)$

0,752

Bursts/episódio

$4,21 \pm 1,46(7,3-2,7)$

$3,84 \pm 1,12(5,3-1,3)$

0,437 
5.4 ASSOCIAÇÃO ENTRE BRUXISMO dO SONO E DOR MOFASCIAL

Tabela 21 Tabela de contingência do BS

\begin{tabular}{|c|c|c|c|c|c|c|}
\hline \multirow[b]{2}{*}{ EXPERIMENTAL } & \multicolumn{2}{|c|}{ BRUXISMO PSG (+) } & \multicolumn{2}{|c|}{ BRUXISMO PSG (-) } & \multicolumn{2}{|c|}{ TOTAL } \\
\hline & 19 & $63,33 \%$ & 11 & $36,67 \%$ & 30 & $50 \%$ \\
\hline & $65,52 \%$ & $31,67 \%$ & $c^{35,48 \%}$ & $18,33 \%$ & & \\
\hline \multirow[t]{2}{*}{ CONTROLE } & 10 & $33,33 \% b$ & d 20 & $66,67 \%$ & 30 & $50 \%$ \\
\hline & $34,48 \%$ & $16,67 \%$ & $64,52 \%$ & $33,33 \%$ & & \\
\hline \multirow[t]{2}{*}{ TOTAL } & \multicolumn{2}{|c|}{29} & \multicolumn{2}{|c|}{31} & \multicolumn{2}{|c|}{60} \\
\hline & \multicolumn{2}{|c|}{$48,33 \%$} & \multicolumn{2}{|c|}{51,67} & \multicolumn{2}{|c|}{$100 \%$} \\
\hline
\end{tabular}

Células em amarelo: valores absolutos

Células em verde: valores percentuais da linha

Células em laranja: valores percentuais da coluna

Células em azul: valores percentuais em relação ao total

O teste de Qui-quadrado demonstrou haver associação entre bruxismo e Dor miofascial na população estudada $\left(\chi^{2}=4,271\right) \operatorname{com} p=0,039$.

O Odds ratio (OR) (chance de um bruxômano desenvolver dor miofascial em relação a um não-bruxômano) é de 3,455 (IC 95\% 1,19 - 9,99), p = 0,039. O intervalo de confiança situou-se acima de 1, ratificando que há maiores chances de um bruxômano desenvolver dor miofascial do que um não-bruxômano.

O risco de um bruxômano desenvolver DMF (em relação à população geral) é de 0,66 (66\%) e o risco de um não-bruxômano desenvolver DMF (em relação à população geral) é de 0,36 (36\%). O Risco Relativo de DMF para os bruxômanos em relação aos nãobruxômanos (na população geral) é de $1,83(\mathrm{p}=0,039)$.

O Likelihood ratio positivo (LR+) foi de 1,90 [IC95: 1,07 - 3,38] e o Likelihood ratio negativo (LR-) foi de 0,55 [IC95: 0,32 - 0,94]. 
Considerando-se a probabilidade pré-teste igual à prevalência de DMF na população geral $(30 \%)^{124,126,173}$ [e não a prevalência da amostra deste estudo (50\%)], calculase o odds pré-teste.

Odds $=$ probabilidade $/ 1-$ probabilidade $=0,3 / 0,7=0,429$

Com base no valor de odds pré-teste, calcula-se o odds pós-teste para os bruxômanos (odds+) e não-bruxômanos (odds-).

Odds pós-teste $+=$ odds pré-teste $\mathrm{x}$ LR $+=0,429 \times 1,90=0,549$

Odds pós-teste- $=$ odds pré-teste $\mathrm{x}$ LR- $=0,429 \times 0,55=0,236$

Os valores de odds são convertidos em probabilidade, invertendo-se a fórmula:

Probabilidade $=$ odds $/$ odds +1

Probabilidade pós-teste $+=$ odds $+/$ odds $+1=0,55 / 2,55=0,61=61 \%$

Probabilidade pós-teste- $=$ odds- $/$ odds- $+1=0,236 / 1,236=0,191=19 \%$.

Com base na prevalência de DMF na população geral (30\%), considera-se esse valor a probabilidade pré-teste (geral) de um indivíduo desenvolver DMF. Mas, após o diagnóstico de bruxismo, essa probabilidade aumenta 1,9 vezes e passa a ser de $61 \%$. Do mesmo modo, após o diagnóstico de ausência de bruxismo, essa probabilidade "geral" cai para $19 \%$. 


\subsection{Reavalação de DTMApós o Exame Polissonográfico}

Após o exame polissonográfico, logo pela manhã (aproximadamente às 7:00h), todos os indivíduos foram reavaliados, aferindo-se a dor à palpação na ATM (Anexos 19 e 20); LDPs nos músculos temporal e masseter (mesmos sítios previamente descritos (Anexos 21 e 22) e escores de dor à palpação dos músculos esternocleidomastóideo, trapézio superior, pterigóideo medial e ventre posterior do músculo digástrico (Anexos 23 e 24).

A Tabela 22 mostra que os grupos diferiram estatisticamente quanto aos valores dos LDPs pós-PSG em todos os sítios musculares avaliados, excetuando-se o temporal posterior, $(\mathrm{p}=0,05)$.

Tabela 22 Limiares de Dor à Pressão pós-PSG (LDP pós) dos grupos CONTROLE e EXPERIMENTAL

\begin{tabular}{|c|c|c|c|}
\hline SÍTIO MUSCULAR & $\begin{array}{c}\text { GRUPO CONTROLE } \\
(\mathrm{n}=30) \\
\text { Média } \pm \mathrm{dp} \text { [mediana] }\end{array}$ & $\begin{array}{l}\text { GRUPO EXPERIMENTAL } \\
\text { ( } \mathrm{n}=30) \\
\text { Média } \pm \mathrm{dp} \text { [mediana] }\end{array}$ & $\begin{array}{c}\mathbf{P} \\
\text { (teste } t \text { ou }{ }^{\# M a n n-} \\
\text { Whitney) }\end{array}$ \\
\hline Temporal Anterior & $2,516 \pm 0,551$ & $1,918 \pm 0,417$ & $\varangle 0,001$ \\
\hline Temporal Médio & $2,66 \pm 0,69[2,430]$ & $2,17 \pm 0,56[2,160]$ & $0,005 \#$ \\
\hline Temporal Posterior & $2,726 \pm 0,615$ & $2,417 \pm 0,583$ & 0,050 \\
\hline Masseter (origem) & $2,000 \pm 0,483$ & $1,588 \pm 0,317$ & $\varangle 0,001$ \\
\hline Masseter (corpo) & $1,77 \pm 0,41[1,770]$ & $1,49 \pm 0,30[1,460]$ & $0,003 \#$ \\
\hline Masseter (inserção) & $1,78 \pm 0,43[1,785]$ & $1,46 \pm 0,33[1,445]$ & $\varangle 0,001$ \\
\hline Masseter (profundo) & $2,071 \pm 0,513$ & $1,566 \pm 0,377$ & $\varangle 0,001$ \\
\hline
\end{tabular}




\subsection{BRUXISMO do SONO E LIMAR DE DOR À PRESSÃo Pós-PSG}

\subsubsection{Grupo Controle}

O grupo controle apresentou redução significativa do LDP pós-PSG em relação ao LDP pré-PSG em 2 sítios musculares: temporal posterior e inserção do masseter (Tabela 23).

Tabela 23 Limiares de Dor à Pressão (LDP) pré e pós-PSG do grupo CONTROLE

\begin{tabular}{|c|c|c|c|}
\hline \multirow[b]{2}{*}{ Sítio Muscular } & \multicolumn{2}{|c|}{ GRUPO CONTROLE $(n=30)$} & \multirow{2}{*}{$\begin{array}{c}\text { P } \\
\text { (teste t Pareado ou } \\
{ }^{\# \text { Wilcoxon) }}\end{array}$} \\
\hline & $\begin{array}{c}\text { LDP pré }\left(\mathrm{kgf} / \mathrm{cm}^{2}\right) \\
\text { Média } \pm \mathrm{dp} \text { [mediana] }\end{array}$ & $\begin{array}{c}\text { LDP pós }\left(\mathrm{kgf} / \mathrm{cm}^{2}\right) \\
\text { Média } \pm \mathrm{dp}[\text { mediana] }\end{array}$ & \\
\hline Temporal Anterior & $2,556 \pm 0,665$ & $2,516 \pm 0,551$ & 0,742 \\
\hline Temporal Médio & $2,833 \pm 0,635$ & $2,663 \pm 0,686$ & 0,213 \\
\hline Temporal Posterior & $3,088 \pm 0,798[2,970]$ & $2,726 \pm 0,615[2,605]$ & $0,017 \#$ \\
\hline Masseter (origem) & $2,011 \pm 0,519[1,945]$ & $2,000 \pm 0,483[1,935]$ & $0,696 \#$ \\
\hline Masseter (corpo) & $1,734 \pm 0,434$ & $1,772 \pm 0,413$ & 0,609 \\
\hline Masseter (inserção) & $2,064 \pm 0,523$ & $1,781 \pm 0,429$ & 0,008 \\
\hline Masseter (profundo) & $2,104 \pm 0,483$ & $2,071 \pm 0,513$ & 0,581 \\
\hline
\end{tabular}

A fim de evidenciar a influência do BS sobre a redução no LDP vista no grupo controle, realizou-se o teste $\mathrm{t}$ pareado ou Wilcoxon entre os LDPs pré e pós-PSG separadamente para os subgrupos de bruxômanos (Tabela 24) e não-bruxômanos (Tabela 25). Confirmou-se a redução do LDP pós-PSG no temporal posterior e evidenciaram-se as reduções dos LDPs pós-PSG do temporal médio nos bruxômanos e da inserção do masseter nos não-bruxômanos. 
Tabela 24 Limiares de Dor à Pressão (LDP) pré e pós-PSG nos bruxômanos do grupo CONTROLE

\begin{tabular}{|c|c|c|c|}
\hline \multirow[b]{2}{*}{ Sítio Muscular } & \multicolumn{2}{|c|}{ BRUXÔMANOS GRUPO CONTROLE $(n=10)$} & \multirow{2}{*}{$\begin{array}{c}P \\
\text { (teste } t \text { pareado ou } \\
{ }^{\text {WWilcoxon) }}\end{array}$} \\
\hline & $\begin{array}{c}\text { LDP pré } \\
\text { Média } \pm \mathrm{dp} \text { [mediana] }\end{array}$ & $\begin{array}{c}\text { LDP pós } \\
\text { Média } \pm \mathrm{dp} \text { [mediana] }\end{array}$ & \\
\hline Temporal Anterior & $2,69 \pm 0,59$ & $2,46 \pm 0,386$ & 0,221 \\
\hline Temporal Médio & $2,97 \pm 0,46$ & $2,49 \pm 0,436$ & 0,033 \\
\hline Temporal Posterior & $3,09 \pm 0,69[2,970]$ & $2,57 \pm 0,49[2,520]$ & $0,020 \#$ \\
\hline Masseter (origem) & $1,99 \pm 0,409$ & $1,78 \pm 0,245$ & 0,127 \\
\hline Masseter (corpo) & $1,68 \pm 0,226$ & $1,62 \pm 0,226$ & 0,588 \\
\hline Masseter (inserção) & $1,95 \pm 0,26[2,000]$ & $1,76 \pm 0,57[1,785]$ & $0,129 \#$ \\
\hline Masseter (profundo) & $1,916 \pm 0,219$ & $1,873 \pm 0,340$ & 0,727 \\
\hline
\end{tabular}

Tabela 25 Limiares de Dor à Pressão (LDP) pré e pós-PSG nos não-bruxômanos do grupo CONTROLE

\begin{tabular}{|c|c|c|c|}
\hline \multirow{2}{*}{ Sítio Muscular } & \multicolumn{2}{|c|}{ NÃO-BRUXÔMANOS GRUPO CONTROLE $(n=20)$} & \multirow{2}{*}{$\begin{array}{c}P \\
\text { (teste } t \text { pareado ou } \\
{ }^{\# \text { Wilcoxon) }}\end{array}$} \\
\hline & $\begin{array}{c}\text { LDP pré } \\
\text { Média } \pm \mathrm{dp} \text { [mediana] }\end{array}$ & $\begin{array}{c}\text { LDP pós } \\
\text { Média } \pm \mathrm{dp} \text { [mediana] }\end{array}$ & \\
\hline Temporal Anterior & $2,490 \pm 0,703$ & $2,546 \pm 0,625$ & 0,721 \\
\hline Temporal Médio & $2,767 \pm 0,707$ & $2,749 \pm 0,778$ & 0,915 \\
\hline Temporal Posterior & $3,085 \pm 0,861$ & $2,803 \pm 0,666$ & 0,149 \\
\hline Masseter (origem) & $2,02 \pm 0,58[1,645]$ & $2,11 \pm 0,54[2,040]$ & $0,622^{\#}$ \\
\hline Masseter (corpo) & $1,763 \pm 0,510$ & $1,847 \pm 0,468$ & 0,400 \\
\hline Masseter (inserção) & $2,124 \pm 0,613$ & $1,791 \pm 0,357$ & 0,009 \\
\hline Masseter (profundo) & $2,198 \pm 0,533$ & $2,170 \pm 0,562$ & 0,685 \\
\hline
\end{tabular}

Os LDPs pós-PSG não diferiram entre bruxômanos e não-bruxômanos do grupo controle (Tabela 26).

Tabela 26 LDP pós-PSG dos bruxômanos e não-bruxômanos do grupo CONTROLE

\begin{tabular}{|c|c|c|c|}
\hline \multirow{2}{*}{ Sítio Muscular } & \multicolumn{2}{|c|}{ LDP pós-PSG $\left(\mathrm{kgf} / \mathrm{cm}^{2}\right)$ - GRUPO CONTROLE } & \multirow{2}{*}{$\begin{array}{c}\text { P } \\
\text { (teste t ou }{ }^{\# M a n n-} \\
\text { Whitney) }\end{array}$} \\
\hline & $\begin{array}{l}\text { Bruxômanos }(n=10) \\
\text { Média } \pm d p \text { [mediana] }\end{array}$ & $\begin{array}{l}\text { Não-bruxômanos }(n=20) \\
\text { Média } \pm d p \text { [mediana] }\end{array}$ & \\
\hline Temporal Anterior & $2,455 \pm 0,386$ & $2,546 \pm 0,625$ & 0,677 \\
\hline Temporal Médio & $2,491 \pm 0,436[2,400]$ & $2,749 \pm 0,778[2,490]$ & $0,455^{\#}$ \\
\hline Temporal Posterior & $2,57 \pm 0,49[2,520]$ & $2,803 \pm 0,666[2,630]$ & $0,391^{\#}$ \\
\hline Masseter (origem) & $1,778 \pm 0,245$ & $2,111 \pm 0,538$ & 0,075 \\
\hline Masseter (corpo) & $1,78 \pm 0,25[1,560]$ & $1,847 \pm 0,468[1,790]$ & $0,253^{\#}$ \\
\hline Masseter (inserção) & $1,62 \pm 0,23[1,785]$ & $1,791 \pm 0,357[1,785]$ & $0,725^{\#}$ \\
\hline Masseter (profundo) & $1,87 \pm 0,34$ & $2,170 \pm 0,562$ & 0,137 \\
\hline
\end{tabular}


Apenas entre os bruxômanos do grupo controle houve uma correlação positiva significativa entre uma das variáveis da ARMM (bursts/hora) e o LDP pós-PSG do masseter profundo (Tabelas 27 e 28).

\section{Tabela 27 Correlação de Pearson entre ARMM e LDP pós-PSG nos BRUXÔMANOS DO GRUPO CONTROLE}

\begin{tabular}{|c|c|c|c|c|}
\hline \multirow[b]{2}{*}{ Sítio Muscular } & Epi/noite & Epi/hora & B/hora & B/epi \\
\hline & \multicolumn{4}{|c|}{$\begin{array}{l}\text { Coeficiente de correlação - } r \text { (Bruxômanos - Grupo Controle } n=10 \text { ) } \\
\text { Valor de } p\end{array}$} \\
\hline \multirow[t]{2}{*}{ Temporal Anterior } & 0,176 & 0,951 & 0,225 & 0,263 \\
\hline & 0,627 & 0,794 & 0,533 & 0,463 \\
\hline \multirow[t]{2}{*}{ Temporal Médio } & 0,304 & 0,312 & 0,515 & 0,181 \\
\hline & 0,394 & 0,380 & 0,128 & 0,460 \\
\hline \multirow[t]{2}{*}{ Temporal Posterior } & 0,227 & 0,257 & 0,397 & 0,364 \\
\hline & 0,528 & 0,473 & 0,256 & 0,301 \\
\hline \multirow[t]{2}{*}{ Masseter (Origem) } & $-0,189$ & $-0,012$ & 0,211 & 0,394 \\
\hline & 0,600 & 0,973 & 0,558 & 0,260 \\
\hline \multirow[t]{2}{*}{ Masseter (Corpo) } & 0,0383 & 0,108 & 0,372 & 0,500 \\
\hline & 0,916 & 0,767 & 0,289 & 0,141 \\
\hline \multirow[t]{2}{*}{ Masseter (Inserção) } & 0,164 & 0,207 & 0,488 & 0,608 \\
\hline & 0,651 & 0,566 & 0,153 & 0,062 \\
\hline \multirow[t]{2}{*}{ Masseter (Profundo) } & 0,496 & 0,497 & 0,691 & 0,572 \\
\hline & 0,144 & 0,144 & 0,027 & 0,084 \\
\hline
\end{tabular}

Quando os testes de correlação foram realizados entre a ARMM e os LDPs pós PSG dos sítios musculares esquerdos e direitos separadamente, no subgrupo de bruxômanos controle, ocorreram seis correlações estatisticamente significativas. Temporal médio esquerdo e b/epi $\left(r^{2}=0,53, r=0,73, p=0,017\right)$; corpo do masseter direito e epi/noite $\left(r^{2}=0,49, r=\right.$ $0,70, p=0,024)$, epi/hora $\left(r^{2}=0,45, r=0,67, p=0,036\right)$ e $b /$ hora $\left(r^{2}=0,56, r=0,75, p=\right.$ 0,012); inserção do masseter esquerdo e b/epi $\left(r^{2}=0,38, r=0,62, p=0,035\right)$ e inserção do masseter esquerdo e $\mathrm{b} /$ hora $\left(\mathrm{r}^{2}=0,49, \mathrm{r}=0,7, \mathrm{p}=0,026\right)$. Todas, correlações positivas, confirmando a não redução do LDP pós-PSG, mesmo após BS mais intenso (Tabela 35). 
Tabela 28 Correlação de Pearson entre ARMM e LDP pós-PSG nos NÃOBRUXÔMANOS DO GRUPO CONTROLE

\begin{tabular}{|c|c|c|c|c|}
\hline \multirow[b]{2}{*}{ Sítio Muscular } & Epi/noite & Epi/hora & B/hora & B/epi \\
\hline & \multicolumn{4}{|c|}{$\begin{array}{l}\text { Coeficiente de correlação - } r \text { (Não-bruxômanos - Grupo Controle } n=20 \text { ) } \\
\text { Valor de } p\end{array}$} \\
\hline \multirow{2}{*}{ Temporal Anterior } & 0,29 & 0,31 & 0,25 & 0,10 \\
\hline & 0,215 & 0,190 & 0,288 & 0,677 \\
\hline \multirow{2}{*}{ Temporal Médio } & 0,13 & 0,13 & 0,16 & 0,14 \\
\hline & 0,595 & 0,584 & 0,492 & 0,561 \\
\hline \multirow{2}{*}{ Temporal Posterior } & 0,21 & 0,22 & 0,32 & 0,27 \\
\hline & 0,373 & 0,343 & 0,174 & 0,273 \\
\hline \multirow{2}{*}{ Masseter (Origem) } & 0,07 & 0,079 & 0,08 & 0,01 \\
\hline & 0,780 & 0,740 & 0,737 & 0,961 \\
\hline \multirow{2}{*}{ Masseter (Corpo) } & $-0,13$ & $-0,14$ & $-0,11$ & 0,05 \\
\hline & 0,491 & 0,546 & 0,656 & 0,821 \\
\hline \multirow{2}{*}{ Masseter (Inserção) } & $-0,05$ & $-0,07$ & 0,00 & 0,03 \\
\hline & 0,844 & 0,770 & 0,993 & 0,915 \\
\hline \multirow[b]{2}{*}{ Masseter (Profundo) } & $-0,04$ & $-0,01$ & 0,02 & 0,01 \\
\hline & 0,868 & 0,956 & 0,921 & 0,958 \\
\hline
\end{tabular}

Quando os testes de correlação foram refeitos considerando-se os LDPs pós-PSG dos lados esquerdo e direito separadamente, para o subgrupo de não-bruxômanos controle não foi encontrada nenhuma correlação entre ARRM e LDP pós-PSG. 


\subsubsection{Grupo Experimental}

No Grupo Experimental, ocorreu aumento significativo do LDP pós-PSG na origem e no corpo do masseter em relação ao LDP pré-PSG (Tabela 29).

Tabela 29 LDPs pré e pós-PSG do grupo EXPERIMENTAL

\begin{tabular}{lccc}
\hline \multirow{2}{*}{ Sítio Muscular } & \multicolumn{2}{c}{ GRUPO EXPERIMENTAL $(\mathbf{n}=\mathbf{3 0})$} & $\begin{array}{c}\text { P } \\
\text { LDP pré }\end{array}$ \\
\cline { 2 - 3 } & $\begin{array}{c}\text { LDP }- \text { pós } \\
\text { Média } \pm \text { desvio padrão }\end{array}$ & Média \pm desvio padrão & \\
\hline Temporal Anterior & $1,900 \pm 0,549$ & $1,912 \pm 0,417$ & 0,880 \\
Temporal Médio & $2,226 \pm 0,723$ & $2,173 \pm 0,555$ & 0,587 \\
Temporal Posterior & $2,505 \pm 0,814$ & $2,417 \pm 0,583$ & 0,503 \\
Masseter (origem) & $1,414 \pm 0,436$ & $1,588 \pm 0,317$ & 0,011 \\
Masseter (corpo) & $1,363 \pm 0,345$ & $1,489 \pm 0,301$ & 0,022 \\
Masseter (inserção) & $1,442 \pm 0,365$ & $1,461 \pm 0,333$ & 0,757 \\
Masseter (profundo) & $1,529 \pm 0,389$ & $1,566 \pm 0,377$ & 0,534 \\
\hline
\end{tabular}

A fim de evidenciar se esse aumento ocorreu de forma particular entre os bruxômanos, realizou-se o teste t pareado ou Wilcoxon separadamente. As Tabelas 30 e 31 mostram que o aumento visto no LDP pós-PSG no grupo experimental não se restringiu aos bruxômanos.

Tabela 30 LDPs pré e pós-PSG dos bruxômanos do grupo EXPERIMENTAL

\begin{tabular}{|c|c|c|c|}
\hline \multirow{2}{*}{ Sítio Muscular } & \multicolumn{2}{|c|}{ BRUXÔMANOS GRUPO EXPERIMENTAL $(n=19)$} & \multirow{2}{*}{$\begin{array}{c}\text { P } \\
\text { (teste t pareado ou } \\
\text { "Wilcoxon) }\end{array}$} \\
\hline & $\begin{array}{c}\text { LDP pré } \\
\text { Média } \pm \text { desvio padrão }\end{array}$ & $\begin{array}{c}\text { LDP pós } \\
\text { Média } \pm \text { desvio padrão }\end{array}$ & \\
\hline Temporal Anterior & $1,924 \pm 0,567$ & $1,874 \pm 0,423$ & 0,613 \\
\hline Temporal Médio & $2,245 \pm 0,734$ & $2,183 \pm 0,564$ & 0,578 \\
\hline Temporal Posterior & $2,479 \pm 0,893$ & $2,423 \pm 0,617$ & 0,736 \\
\hline Masseter (origem) & $1,364 \pm 0,461$ & $1,547 \pm 0,361$ & 0,035 \\
\hline Masseter (corpo) & $1,343 \pm 0,383$ & $1,479 \pm 0,323$ & 0,103 \\
\hline Masseter (inserção) & $1,420 \pm 0,421$ & $1,385 \pm 0,303$ & 0,632 \\
\hline Masseter (profundo) & $1,505 \pm 0,455$ & $1,535 \pm 0,421$ & 0,670 \\
\hline
\end{tabular}


Tabela 31 LDPs pré e pós-PSG dos não-bruxômanos do grupo EXPERIMENTAL

\begin{tabular}{|c|c|c|c|}
\hline \multirow{2}{*}{ Sítio Muscular } & \multicolumn{2}{|c|}{ NÃO-BRUXÔMANOS GRUPO EXPERIMENTAL $\quad(n=11)$} & \multirow{2}{*}{$\begin{array}{c}\text { P } \\
\text { (teste } t \text { pareado } \\
\text { ou "Wilcoxon) }\end{array}$} \\
\hline & $\begin{array}{c}\text { LDP pré } \\
\text { Média } \pm \mathrm{dp} \text { [mediana] }\end{array}$ & $\begin{array}{c}\text { LDP pós } \\
\text { Média } \pm \mathrm{dp} \text { [mediana] }\end{array}$ & \\
\hline Temporal Anterior & $1,852 \pm 0,541$ & $1,977 \pm 0,420$ & 0,298 \\
\hline Temporal Médio & $2,194 \pm 0,736$ & $2,156 \pm 0,567$ & 0,848 \\
\hline Temporal Posterior & $2,548 \pm 0,694$ & $2,406 \pm 0,550$ & 0,531 \\
\hline Masseter (origem) & $1,502 \pm 0,393$ & $1,659 \pm 0,218$ & 0,179 \\
\hline Masseter (corpo) & $1,397 \pm 0,278$ & $1,507 \pm 0,271$ & 0,032 \\
\hline Masseter (inserção) & $1,484 \pm 0,255[1,490]$ & $0,592 \pm 0,356[1,520]$ & $0,577^{\#}$ \\
\hline Masseter (profundo) & $1,571 \pm 0,248$ & $1,618 \pm 0,297$ & 0,669 \\
\hline
\end{tabular}

Os valores de LDP pós-PSG não diferiram entre os subrgrupos de bruxômanos e não-bruxômanos do grupo experimental (Tabela 32).

Tabela 32 LDPs pós-PSG do grupo EXPERIMENTAL (bruxômanos x nãobruxômanos)

\begin{tabular}{lccc}
\hline \multirow{2}{*}{ Sítio Muscular } & \multicolumn{2}{c}{ LDP pós-PSG - GRUPO EXPERIMENTAL } & \\
\cline { 2 - 3 } & $\begin{array}{c}\text { Bruxômanos (n= 19) } \\
\text { Média } \pm \mathbf{d p}\end{array}$ & $\begin{array}{c}\text { Não-bruxômanos } \\
\text { Média } \pm \mathbf{~ d p ~}\end{array}$ & $\begin{array}{c}\text { (n } \mathbf{~ 1 1 )} \\
\text { (teste t) }\end{array}$ \\
\hline Temporal Anterior & $1,874 \pm 0,423$ & $1,977 \pm 0,420$ & 0,524 \\
Temporal Médio & $2,183 \pm 0,564$ & $2,156 \pm 0,567$ & 0,901 \\
Temporal Posterior & $2,479 \pm 0,893$ & $0,548 \pm 0,694$ & 0,828 \\
Masseter (origem) & $1,547 \pm 0,361$ & $1,659 \pm 0,218$ & 0,361 \\
Masseter (corpo) & $1,479 \pm 0,323$ & $1,507 \pm 0,271$ & 0,808 \\
Masseter (inserção) & $1,385 \pm 0,303$ & $1,592 \pm 0,356$ & 0,102 \\
Masseter (profundo) & $1,535 \pm 0,421$ & $1,618 \pm 0,297$ & 0,570 \\
\hline
\end{tabular}


A Tabela 33 mostra que houve correlação negativa entre a ARMM (b/epi) e o LDP pós-PSG no corpo do masseter dos bruxômanos com DMF. O valor de "r" obtido para essa correlação foi de $-0,48$ e, o teste de regressão linear mostra que o número de bursts/episódio foi responsável por $23 \%$ da variabilidade do LDP pós-PSG no corpo do masseter, nesse subgrugo (Tabela 35).

Tabela 33 Correlação de Pearson ARMM e o LDP pós-PSG nos BRUXÔMANOS DO GRUPO EXPERIMENTAL

\begin{tabular}{|c|c|c|c|c|}
\hline \multirow[b]{2}{*}{ Sítio Muscular } & Epi/noite & Epi/hora & B/hora & B/epi \\
\hline & \multicolumn{4}{|c|}{$\begin{array}{l}\text { Coeficiente de correlação - } r \text { (Bruxômanos - Grupo Experimental }(\mathrm{n}= \\
\text { 19) } \\
\text { Valor de } p\end{array}$} \\
\hline \multirow[t]{2}{*}{ Temporal Anterior } & $-0,135$ & $-0,191$ & $-0,408$ & $-0,302$ \\
\hline & 0,582 & 0,434 & 0,083 & 0,209 \\
\hline \multirow[t]{2}{*}{ Temporal Médio } & $-0,143$ & $-0,173$ & $-0,342$ & $-0,195$ \\
\hline & 0,558 & 0,479 & 0,152 & 0,425 \\
\hline \multirow[t]{2}{*}{ Temporal Posterior } & 0,174 & 0,119 & $-0,358$ & $-0,214$ \\
\hline & 0,476 & 0,626 & 0,132 & 0,380 \\
\hline \multirow[t]{2}{*}{ Masseter (Origem) } & 0,186 & 0,119 & $-0,272$ & $-0,455$ \\
\hline & 0,445 & 0,627 & 0,259 & 0,0502 \\
\hline \multirow[t]{2}{*}{ Masseter (Corpo) } & 0,317 & 0,204 & $-0,125$ & $-0,477$ \\
\hline & 0,186 & 0,402 & 0,611 & 0,0390 \\
\hline \multirow[t]{2}{*}{ Masseter (Inserção) } & 0,0580 & 0,0109 & $-0,154$ & $-0,227$ \\
\hline & 0,814 & 0,965 & 0,529 & 0,350 \\
\hline \multirow[t]{2}{*}{ Masseter (Profundo) } & $-0,0969$ & $-0,218$ & $-0,297$ & $-0,0201$ \\
\hline & 0,693 & 0,369 & 0,217 & 0,935 \\
\hline
\end{tabular}

Quando o teste de correlação de Pearson foi repetido no subgrupo de bruxômanos com DMF, considerando-se os LDPs pós-PSG dos sítios musculares esquerdo e direito separadamente, manteve-se a correlação negativa entre o LDP pós-PSG do corpo do masseter (no lado esquerdo) e b/epi $\left(r^{2}=0,23, r=-0,48, p=0,037\right)$ e surgiu apenas mais uma correlação, entre o temporal anterior direito e b/hora $\left(r^{2}=0,26, r=-0,51, p=0,025\right)$. Mantendo a discreta tendência de redução do LDP pós-PSG com o aumento da ARMM (Tabela 35). 
Houve correlação negativa entre o ARMM (b/hora e b/epi) e os LDPs pós-PSG do temporal posterior, inserção do masseter e masseter profundo entre os NÃOBRUXÔMANOS com DMF (Tabela 34). Em todas as correlações significativas os valores de "r" foram superiores a -0,6. E o teste de regressão linear mostrou que o número de bursts/hora foi responsável por aproximadamente $40 \%$ da variabilidade do LDP pós-PSG do temporal posterior, inserção do masseter e masseter profundo. Mostra ainda que o número de bursts/episódio foi responsável por 19\% do LDP pós-PSG do temporal posterior (Tabela 35). O teste de regressão múltipla entre variáveis motoras (b/hora e b/epi) sobre o LDP pós-PSG do temporal posterior mostrou que, apesar de isoladas as variáveis motoras correlacionaremse com o LDP pós-PSG, quando colocadas em modelo único, não apresentam correlação significativa $(\mathrm{p}=0,09)$.

Tabela 34 Correlação de Pearson entre ARMM e LDP pós-PSG nos NÃOBRUXÔMANOS do grupo experimental

\begin{tabular}{|c|c|c|c|c|}
\hline \multirow{3}{*}{ Sítio Muscular } & Epi/noite & Epi/hora & B/hora & B/epi \\
\hline & \multicolumn{4}{|c|}{$\begin{array}{l}\text { Coeficiente de correlação - } r \text { (não-bruxômanos - grupo } \\
\text { Experimental) }(n=11)\end{array}$} \\
\hline & Valor de $p$ & & & \\
\hline \multirow[t]{2}{*}{ Temporal Anterior } & 0,0941 & 0,0821 & $-0,109$ & $-0,267$ \\
\hline & 0,783 & 0,810 & 0,750 & 0,427 \\
\hline \multirow[t]{2}{*}{ Temporal Médio } & 0,315 & $-0,295$ & $-0,537$ & $-0,519$ \\
\hline & 0,470 & 0,379 & 0,089 & 0,102 \\
\hline \multirow[t]{2}{*}{ Temporal Posterior } & 0,576 & $-0,256$ & $-0,611$ & $-0,635$ \\
\hline & 0,479 & 0,446 & 0,0459 & 0,0359 \\
\hline \multirow[t]{2}{*}{ Masseter (Origem) } & 0,00382 & $-0,0618$ & $-0,231$ & $-0,362$ \\
\hline & 0,991 & 0,857 & 0,495 & 0,274 \\
\hline \multirow[t]{2}{*}{ Masseter (Corpo) } & 0,337 & $-0,364$ & $-0,524$ & $-0,452$ \\
\hline & 0,229 & 0,270 & 0,0982 & 0,163 \\
\hline \multirow[t]{2}{*}{ Masseter (Inserção) } & $-0,484$ & $-0,512$ & $-0,631$ & $-0,463$ \\
\hline & 0,146 & 0,108 & 0,0374 & 0,151 \\
\hline \multirow[t]{2}{*}{ Masseter (Profundo) } & $-0,534$ & $-0,530$ & $-0,611$ & $-0,438$ \\
\hline & 0,091 & 0,094 & 0,0460 & 0,178 \\
\hline
\end{tabular}

Também entre os não-bruxômanos com DMF, ao se testarem as correlações entre ARMM e LDP pós-PSG dos sítios esquerdo e direito separadamente, o número de correlações significativas aumentou para cinco, mantendo-se o sinal negativo das mesmas: Entre b/hora e temporal posterior direito $\left(\mathrm{r}^{2}=0,38, \mathrm{r}=-0,62, \mathrm{p}=0,042\right)$, inserção do masseter direito $\left(\mathrm{r}^{2}=\right.$ $0,50, r=-0,71, p=0,014)$ e masseter profundo direito $\left(r^{2}=0,66, r=-0,81, p=0,003\right)$; entre 
epi/hora e masseter profundo direito $\left(r^{2}=0,55, r=-0,74, p=0,010\right)$ e entre epi/noite e masseter profundo direito $\left(r^{2}=0,50, r=-0,71, p=0,014\right)$ - Tabela 35

Tabela 35 Regressão Linear Simples entre ARMM e LDPs pós-PSG

\begin{tabular}{|c|c|c|c|c|c|c|c|c|c|c|c|c|}
\hline GRUPO & $\mathbf{x}$ & y & $\mathbf{P}$ & $\mathbf{R}$ & $\mathbf{R}^{2}$ & $\begin{array}{l}\text { ARMM } \\
x \text { LDP }\end{array}$ & $x$ & $\mathbf{y}$ & $\mathbf{p}$ & $r$ & $r^{2}$ & $\begin{array}{l}\text { ARMM } \\
x \text { LDP }\end{array}$ \\
\hline BS (GE) & b/epi & $\mathrm{MC}$ & 0,039 & $-0,48$ & 0,23 & Neg & b/epi & MCE & 0,037 & $-0,48$ & 0,23 & $\mathrm{Neg}$ \\
\hline$(n=19)$ & & & & & & & b/hora & TAD & 0,025 & $-0,51$ & 0,26 & $\mathrm{Neg}$ \\
\hline NBS (GE) & B/ hora & TP & 0,046 & $-0,61$ & 0,37 & Neg & b/hora & TPD & 0,042 & $-0,62$ & 0,38 & $\mathrm{Neg}$ \\
\hline \multirow[t]{4}{*}{$(n=11)$} & & $\mathrm{Ml}$ & 0,037 & $-0,63$ & 0,40 & Neg & & MID & 0,014 & $-0,71$ & 0,50 & $\mathrm{Neg}$ \\
\hline & & MP & 0,046 & $-0,61$. & 0,37 & Neg & & MPD & 0,030 & $-0,81$ & 0,66 & $\mathrm{Neg}$ \\
\hline & B/ epi & TP & 0,036 & $-0,64$ & 0,19 & Neg & Epi/ hora & MPD & 0,010 & $-0,74$ & 0,55 & $\mathrm{Neg}$ \\
\hline & & & & & & & Epi/ noite & MPD & 0,014 & $-0,71$ & 0,50 & Neg \\
\hline BS (GC) & B/ hora & $\mathrm{MP}$ & 0,027 & 0,69 & 0,48 & Pos & b/hora & MCD & 0,012 & 0,75 & 0,56 & Pos \\
\hline \multirow[t]{5}{*}{$(n=10)$} & & & & & & & & MIE & 0,026 & 0,70 & 0,49 & Pos \\
\hline & & & & & & & b/ epi & TME & 0,017 & 0,73 & 0,53 & Pos \\
\hline & & & & & & & & MIE & 0,035 & 0,62 & 0,38 & Pos \\
\hline & & & & & & & Epi/noite & MCD & 0,024 & 0,70 & 0,49 & Pos \\
\hline & & & & & & & Epi/ hora & MCD & 0,036 & 0,67 & 0,45 & Pos \\
\hline \multicolumn{13}{|c|}{$\begin{array}{l}\text { NBS (GC) s/ tendência } \\
(\mathbf{n}=\mathbf{2 0})\end{array}$} \\
\hline \multicolumn{13}{|c|}{$\begin{array}{l}\text { A metade esquerda da tabela fornece os dados da regressão linear entre ARMM e o LDP pós-PSG dos sítios musculares } \\
\text { (independente do lado - esquerdo ou direito) } \\
\text { A metade direita da tabela fornece os mesmos dados da regressão considerando os lados esquerdo e direito separadamente. } \\
\text { x: variáveis independentes (ARMM); y: variáveis dependentes (LDP pós-PSG dos diferentes sítios musculares) } \\
\text { BS: bruxismo do sono ou bruxômanos; NBS: sem bruxismo do sono ou não-bruxômanos } \\
\text { GE: grupo experimental; GC: grupo controle } \\
\text { Pos: positiva; Neg: negativa } \\
\text { MC: corpo do masseter, MI inserção do masseter; MP: masseter profundo; TA: temporal anterior; TP: temporal posterior } \\
\text { TAD: temporal anterior direito; TMD: temporal médio direito; TPD: temporal posterior direito; TPE: temporal posterior } \\
\text { esquerdo; MCD: corpo do masseter direito; MCE: corpo do masseter esquerdo; MIE: inserção do masseter esquerdo. }\end{array}$} \\
\hline
\end{tabular}

Não se observou qualquer correlação significativa entre ARMM e LDPpós-PSG no grupo de não-bruxômanos controle. 
Tomando-se o grupo experimental como um todo, independente da presença de bruxismo, houve 5 correlações negativas com $\mathrm{P}<0,05$ entre ARMM (b/hora e b/epi) e o LDP pós-PSG de quatro dos sete sítios musculares, com " $\mathrm{r}^{2}$ " variando de 0,15 a 0,23 . O teste de regressão linear múltipla verificou a influência dos diferentes parâmetros de ARMM (variáveis independentes), bem como a presença de bruxismo sobre o LDP pós-PSG (variável dependente) (Tabela 36).

Observou-se que, embora isoladamente os parâmetros de ARMM tenham exercido influência sobre o LDP pós-PSG, na maioria dos casos em que as variáveis independentes foram adicionadas aos modelos, o mesmo passava a não representar mais influência estatisticamente significativa.

O parâmetro b/hora sozinho exerceu uma influência de $17 \%$ e o parâmetro b/epi, de $15 \%$ sobre a variabilidade do LDP pós-PSG na inserção do masseter (MI), mas quando a variável BS foi adicionada a cada um dos modelos, os mesmos não foram significativos. Quando os parâmetros b/hora e b/epi foram colocados no mesmo modelo, observou-se uma influência de 23\% na variabilidade do LDP pós-PSG da inserção do masseter (MI).

A variável b/epi, isolada, exerceu influência sobre a variabilidade do LDP pósPSG do temporal posterior (TP), origem e corpo do masseter (MO e MC) em 20\%, 17\% e $20 \%$, respectivamente. Sobre o LDP pós-PSG do temporal posterior (TP) e corpo do masseter (MC), ao se adicionar a variável BS aos modelos, os mesmos permaneceram significativos, embora a influência dos mesmos pouco tenha se alterado para $21 \%$ no temporal posterior (TP) e $20 \%$ no o corpo do masseter (MC). Sobre o LDP pós-PSG da origem do masseter (MO), a incorporação da variável BS ao modelo levou à não significância do mesmo.

A incorporação da variável BS aos diferentes modelos manteve a significância dos mesmos em apenas 2 dentre os 6 modelos testados. Nos demais modelos, a incorporação da variável BS tornou o modelo estatisticamente não significativo. Isso reflete o menor número de correlações significativas encontrado entre os pacientes bruxômanos (duas correlações negativas), em relação aos pacientes não-bruxômanos (cinco correlações negativas). Aparentemente os pacientes não bruxômanos foram mais afetados pela ARMM que os bruxômanos (Tabela 35). 
Tabela 36 Regressão Linear Simples e Múltipla entre ARMM e LDPs pós-PSG nos grupOs EXPERIMENTAL e CONTROLE

\begin{tabular}{|c|c|c|c|c|c|c|c|c|}
\hline GRUPO & $\begin{array}{l}\text { Variável Indep } \\
\mathbf{x}_{1} \text { (Coeficiente) } \\
\mathbf{p}\end{array}$ & $\begin{array}{l}\text { Variável Indep } \\
x_{2} \text { (Coeficiente) } \\
\text { p }\end{array}$ & & y & $\mathbf{r}$ & $r^{2}$ & $\mathbf{P}$ & \\
\hline GE & $\begin{array}{l}\mathrm{b} / \text { hora }(-0.011) \\
0,024\end{array}$ & & & \multirow{6}{*}{ MI } & 0,41 & 0,17 & 0,024 & NEGATIVA \\
\hline & $\begin{array}{l}\mathrm{b} / \text { hora }(-0,0149) \\
0,110\end{array}$ & $\begin{array}{l}\text { BRU }(0,100) \\
0,653\end{array}$ & & & 0,42 & 0,18 & 0,073 & \multirow{5}{*}{ NEGATIVA } \\
\hline & $\begin{array}{l}\text { b/ epi }(-0,112) \\
0,032\end{array}$ & & & & 0,39 & 0,15 & 0,032 & \\
\hline & $\begin{array}{l}\text { b/ epi }(-0,096) \\
0,069\end{array}$ & $\begin{array}{l}\text { BS }(-0,149) \\
0.229\end{array}$ & & & 0,45 & 0,20 & 0,050 & \\
\hline & $\begin{array}{l}\text { b/ hora }(-0,008) \\
0,118\end{array}$ & $\begin{array}{l}\text { b/ epi }(0,189) \\
0,163\end{array}$ & & & 0,48 & 0,23 & 0,030 & \\
\hline & $\begin{array}{l}\mathrm{b} / \text { hora }(-0,009) \\
0,318\end{array}$ & $\begin{array}{l}\text { b/ epi }(-0,074) \\
0,191\end{array}$ & $\begin{array}{l}\operatorname{BRU}(0,041) \\
0,857\end{array}$ & & 0,48 & 0,23 & 0,075 & \\
\hline & $\begin{array}{l}\text { b/ epi }(-0,220) \\
0,014\end{array}$ & & & \multirow{2}{*}{ TP } & 0,44 & 0,20 & 0,014 & NEGATIVA \\
\hline & $\begin{array}{l}\text { b/ epi }(-0,237) \\
0,012\end{array}$ & $\begin{array}{l}\mathrm{BS}(0,161) \\
0,451\end{array}$ & & & 0,46 & 0,21 & 0,040 & NEGATIVA \\
\hline & $\begin{array}{l}\text { b/ epi }(-0,111) \\
0,024\end{array}$ & & & \multirow{2}{*}{ MO } & 0,41 & 0,17 & 0,024 & \multirow[t]{2}{*}{ NEGATIVA } \\
\hline & $\begin{array}{l}\text { b/ epi }(-0,106) \\
0,039\end{array}$ & $\begin{array}{l}\mathrm{BS}(-0,0475) \\
0,688\end{array}$ & & & 0,42 & 0,17 & 0,077 & \\
\hline & $\begin{array}{l}\text { B/ epi }(-0,114) \\
0,014\end{array}$ & & & \multirow{2}{*}{ MC } & 0,44 & 0,20 & 0,014 & NEGATIVA \\
\hline & $\begin{array}{l}\text { B/ epi }(-0,118) \\
0,015\end{array}$ & $\begin{array}{l}\mathrm{BS}(0,043) \\
0,694\end{array}$ & & & 0,45 & 0,20 & 0,049 & NEGATIVA \\
\hline GC & s/ correlações & & & & & & & \\
\hline
\end{tabular}




\subsection{EFETTO INIBITÓRIO DA DOR SOBRE ARMM}

Tabela 37 Características clínicas dos Bruxômanos com e sem DMF

\begin{tabular}{|c|c|c|c|}
\hline \multirow[b]{3}{*}{ Idade } & \multicolumn{2}{|c|}{ BRUXÔMANOS } & \multirow[b]{2}{*}{$p$} \\
\hline & $\begin{array}{l}\text { s/ DMF } \\
(n=10)\end{array}$ & $\begin{array}{l}\text { c/ DMF } \\
(n=19)\end{array}$ & \\
\hline & $25,6 \pm 2,633$ & $27,26 \pm 5,08$ & $0,255^{*}$ \\
\hline Sexo & $\begin{array}{c}9 \text { mulheres } \\
1 \text { homem }\end{array}$ & $\begin{array}{c}16 \text { mulheres } \\
3 \text { homens }\end{array}$ & \\
\hline $\begin{array}{l}\text { Intensidade da } \\
\text { queixa }\end{array}$ & - & $\begin{array}{c}7 \text { (leve) } 36,84 \% \\
9 \text { (moderada) } 47,37 \% \\
3 \text { (severa) } 15,79 \%\end{array}$ & \\
\hline iDTM (escore) & 1 & 9 & $0,001^{\#}$ \\
\hline iDTM (interpretação) & $\begin{array}{c}9 \text { (ausente) } 90 \% \\
1 \text { (leve) } 10 \%\end{array}$ & $\begin{array}{c}1 \text { (ausente) 5,26\% } \\
8 \text { (leve) } 42,11 \% \\
7 \text { (moderada) } 36,84 \% \\
3 \text { (severa) } 15,79 \%\end{array}$ & \\
\hline EAV (média) mm & 0 & 31,7 & \\
\hline Abertura & $50,80 \pm 6,973$ & $48,316 \pm 5,784$ & $0,314^{*}$ \\
\hline
\end{tabular}


Os bruxômanos com DMF (grupo experimental) apresentaram o número de bursts por episódio (b/epi) estatisticamente superior ao dos bruxômanos do grupo controle. Não houve diferenças estatisticamente significativas entre os grupos quanto aos demais parâmetros de ARMM (Tabela 38).

Tabela 38 ARMM entre BRUXÔMANOS dos grupos CONTROLE e EXPERIMENTAL

\begin{tabular}{|c|c|c|c|c|}
\hline & $\begin{array}{c}\text { BRU s/ DMF (GC) } \\
\mathbf{n}=\mathbf{1 0} \\
\text { Média } \pm \text { dp } \\
\text { Mediana [min-max] }\end{array}$ & $\begin{array}{c}\text { BRU c/ DMF (GE) } \\
\mathbf{n}=\mathbf{1 9} \\
\text { Média } \pm \mathrm{dp} \\
\text { Mediana [min-max] }\end{array}$ & $\mathbf{P}$ & Poder \\
\hline Epi/noite & $\begin{array}{c}36,20 \pm 7,78 \\
35,00[26-51]\end{array}$ & $\begin{array}{c}38,53 \pm 13,18 \\
36,00[25-78]\end{array}$ & $0,927 \#$ & \\
\hline Epi/hora & $\begin{array}{c}6,22 \pm 1,26 \\
5,85[4,3-8,6]\end{array}$ & $\begin{array}{c}6,50 \pm 2,20 \\
5,78[4,2-13,7]\end{array}$ & $1,000 \#$ & \\
\hline Bursts/hora & $\begin{array}{c}25,360 \pm 6,786 \\
25,43[12,23-33,71]\end{array}$ & $\begin{array}{c}30,00 \pm 7,162 \\
29,09[20,63-49,26]\end{array}$ & $0,103^{*}$ & $57 \%$ \\
\hline Burst/epi & $\begin{array}{c}4,052 \pm 0,669 \\
4,2[2,85-4,84]\end{array}$ & $\begin{array}{c}4,809 \pm 0,947 \\
4,7[2,59-7,04]\end{array}$ & 0,033* & $68 \%$ \\
\hline
\end{tabular}

Os bruxômanos dos grupos controle e experimental não diferiram quanto às variáveis do sono (Tabela 39).

Tabela 39 Variáveis do sono dos BRUXÔMANOS dos grupos CONTROLE e EXPERIMENTAL

\begin{tabular}{lcccc}
\hline & \multicolumn{2}{c}{ BRUXÔMANOS } & & \\
\cline { 2 - 3 } & $\begin{array}{c}\text { s/ DMF } \\
(\mathbf{n}=\mathbf{1 0})\end{array}$ & $\begin{array}{c}\mathbf{c} / \mathbf{D M F} \\
(\mathbf{n = 1 9 )}\end{array}$ & \multirow{2}{*}{ Referência } & $\mathbf{p}$ \\
\hline Latência do sono (h) & 0,225 & 0,158 & & $0,347 \#$ \\
Tempo de registro (h) & $6,480 \pm 0,498$ & $6,398 \pm 0,755$ & & $0,759^{*}$ \\
Eficiência do sono (\%) & $90,262 \pm 6,451$ & $92,984 \pm 4,171$ & & $0,248 *$ \\
Tempo de sono (h) & $5,834 \pm 0,415$ & $5,939 \pm 0,673$ & & $0,654^{*}$ \\
MD/hora & 5,9 & 5,9 & & $0,459 \#$ \\
Tempo/Fase 1 (\%) & $11,00 \pm 3,526$ & $9,974 \pm 3,177$ & $2-5$ & $0,433 *$ \\
Tempo/Fase 2 (\%) & $50,59 \pm 4,889$ & $52,368 \pm 8,284$ & $45-55$ & $0,539 *$ \\
Tempo/Fase 3/4 (\%) & $17,56 \pm 5,301$ & $18,489 \pm 7,642$ & $13-23$ & $0,735 *$ \\
Tempo/Fase REM (\%) & $20,66 \pm 4,222$ & $18,179 \pm 5,931$ & $20-25$ & $0,252 *$ \\
\hline$\#$ Mann-Whitney & & & &
\end{tabular}

"Mann-Whitney

* Teste $\mathrm{t}$ 


\subsubsection{Modelo de Adaptação à Dor}

As Tabela 40 a 44 mostram as correlações encontradas entre LDP pré-PSG e ARMM dos bruxômanos e não bruxômanos dos grupos controle e experimental. Encontramse sombreadas as correlações com $\mathrm{p}<0,05$.

Tabela 40 Correlação de Pearson entre LDP pré-PSG e ARMM nos BRUXÔMANOS DO GRUPO CONTROLE

\begin{tabular}{|c|c|c|c|c|}
\hline \multirow[b]{2}{*}{ Sítio Muscular } & Epi/noite & Epi/hora & B/hora & B/epi \\
\hline & \multicolumn{4}{|c|}{$\begin{array}{l}\text { Coeficiente de correlação - } r(\text { Bruxômanos - Grupo Controle } n=10) \\
\text { Valor de } p\end{array}$} \\
\hline \multirow[t]{2}{*}{ Temporal Anterior } & 0,752 & 0,671 & 0,471 & 0,0436 \\
\hline & 0,012 & 0,034 & 0,169 & 0,905 \\
\hline \multirow[t]{2}{*}{ Temporal Médio } & 0,411 & 0,403 & 0,158 & $-0,205$ \\
\hline & 0,238 & 0,248 & 0,663 & 0,570 \\
\hline \multirow[t]{2}{*}{ Temporal Posterior } & 0,285 & 0,227 & 0,414 & 0,426 \\
\hline & 0,424 & 0,592 & 0,234 & 0,220 \\
\hline \multirow[t]{2}{*}{ Masseter (Origem) } & 0,250 & 0,410 & 0,362 & 0,113 \\
\hline & 0,486 & 0,239 & 0,304 & 0,755 \\
\hline \multirow[t]{2}{*}{ Masseter (Corpo) } & 0,575 & 0,625 & 0,317 & $-0,231$ \\
\hline & 0,0819 & 0,0534 & 0,372 & 0,521 \\
\hline \multirow[t]{2}{*}{ Masseter (Inserção) } & 0,651 & 0,674 & 0,445 & 0,00251 \\
\hline & 0,042 & 0,033 & 0,197 & 0,995 \\
\hline \multirow[t]{2}{*}{ Masseter (Profundo) } & 0,217 & 0,192 & $-0,0149$ & $-0,226$ \\
\hline & 0,548 & 0,595 & 0,967 & 0,529 \\
\hline
\end{tabular}

Em relação aos sítios musculares dos lados esquerdo e direito desse subgrupo, houve três correlações significativas, também positivas, entre o LDP pré-PSG do temporal anterior direito e $\mathrm{b} /$ hora $\left(\mathrm{r}^{2}=0,40, \mathrm{r}=0,63, \mathrm{p}=0,049\right)$ e entre o temporal anterior esquerdo e epi/noite $\left(r^{2}=0,49, r=0,70, p=0,023\right)$ e epi/hora $\left(r^{2}=0,53, r=0,73, p=0,016\right)$ - Tabela 44 . 
Os não-bruxômanos do grupo controle (Tabela 41) não apresentaram quaisquer correlações significativas $(\mathrm{p}<0,05)$. Foram sombreadas as correlações com $\mathrm{p}<0,10$ com a finalidade apenas de observar o sentido (ou a tendência) das mesmas.

\section{Tabela 41 Correlação de Pearson entre LDP pré-PSG e ARMM nos NÃO- BRUXÔMANOS DO GRUPO CONTROLE}

\begin{tabular}{|c|c|c|c|c|}
\hline \multirow[b]{2}{*}{ Sítio Muscular } & Epi/noite & Epi/hora & B/hora & B/epi \\
\hline & \multicolumn{4}{|c|}{$\begin{array}{l}\text { Coeficiente de correlação - } r \text { (Não-bruxômanos - Grupo Controle } \\
n=20 \text { ) } \\
\text { Valor de } p\end{array}$} \\
\hline \multirow[t]{2}{*}{ Temporal Anterior } & $-0,199$ & $-0,219$ & $-0,182$ & $-0,0575$ \\
\hline & 0,399 & 0,354 & 0,441 & 0,810 \\
\hline \multirow[t]{2}{*}{ Temporal Médio } & $-0,0259$ & $-0,0723$ & $-0,00278$ & 0,0292 \\
\hline & 0,914 & 0,762 & 0,991 & 0,903 \\
\hline \multirow[t]{2}{*}{ Temporal Posterior } & 0,0270 & 0,0390 & 0,0796 & 0,147 \\
\hline & 0,910 & 0,870 & 0,739 & 0,536 \\
\hline \multirow[t]{2}{*}{ Masseter (Origem) } & $-0,0416$ & $-0,366$ & $-0,310$ & $-0,0995$ \\
\hline & 0,0682 & 0,112 & 0,183 & 0,676 \\
\hline \multirow[t]{2}{*}{ Masseter (Corpo) } & $-0,272$ & $-0,249$ & $-0,176$ & $-0,0519$ \\
\hline & 0,246 & 0,289 & 0,457 & 0,828 \\
\hline \multirow[t]{2}{*}{ Masseter (Inserção) } & $-0,408$ & $-0,388$ & $-0,295$ & $-0,167$ \\
\hline & 0,0738 & 0,0911 & 0,207 & 0,480 \\
\hline \multirow[t]{2}{*}{ Masseter (Profundo) } & $-0,0323$ & 0,0124 & 0,0596 & 0,0309 \\
\hline & 0,893 & 0,959 & 0,803 & 0,897 \\
\hline
\end{tabular}

Quando foram testadas as correlações entre LDP pré-PSG e ARMM nos não bruxômanos do grupo controle, considerando-se os lados esquerdo e direito, observaram-se três correlações significativas (negativas) entre: o LDP pré-PSG do temporal médio direito e epi/noite $\left(r^{2}=0,22, r=-0,47, p=0,038\right)$ e epi/hora $\left(r^{2}=0,25, r=-0,50, p=0,026\right)$, e entre a origem do masseter esquerdo e epi/noite $\left(r^{2}=0,20, r=-0,45, p=0,047\right)$ - Tabela 44. 
Tabela 42 Correlação de Pearson entre o LDP pré-PSG e ARMM nos BRUXÔMANOS DO GRUPO EXPERIMENTAL

\begin{tabular}{|c|c|c|c|c|}
\hline \multirow[b]{2}{*}{ Sítio Muscular } & Epi/noite & Epi/hora & B/hora & B/epi \\
\hline & \multicolumn{4}{|c|}{$\begin{array}{l}\text { Coeficiente de correlação - r (Bruxômanos - Grupo Experimental } n= \\
\text { 19) }\end{array}$} \\
\hline \multirow[t]{2}{*}{ Temporal Anterior } & -0301 & $-0,341$ & $-0,452$ & $-0,161$ \\
\hline & 0,211 & 0,153 & 0,0521 & 0,509 \\
\hline \multirow[t]{2}{*}{ Temporal Médio } & 0,0788 & 0,0256 & $-0,253$ & $-0,443$ \\
\hline & 0,749 & 0,917 & 0,295 & 0,0573 \\
\hline \multirow{2}{*}{ Temporal Posterior } & 0,137 & $-0,0317$ & $-0,316$ & $-0,187$ \\
\hline & 0,575 & 0,897 & 0,187 & 0,443 \\
\hline \multirow[t]{2}{*}{ Masseter (Origem) } & $-0,0227$ & $-0,0268$ & $-0,175$ & $-0,266$ \\
\hline & 0,926 & 0,913 & 0,474 & 0,271 \\
\hline \multirow[t]{2}{*}{ Masseter (Corpo) } & $-0,0765$ & $-0,0642$ & $-0,293$ & $-0,287$ \\
\hline & 0,755 & 0,794 & 0,223 & 0,233 \\
\hline \multirow[t]{2}{*}{ Masseter (Inserção) } & 0,0435 & $-0,0126$ & $-0,687$ & $-0,0859$ \\
\hline & 0,860 & 0,959 & 0,780 & 0,727 \\
\hline \multirow[t]{2}{*}{ Masseter (Profundo) } & 0,0276 & $-0,0943$ & $-0,157$ & $-0,0942$ \\
\hline & 0,911 & 0,701 & 0,520 & 0,701 \\
\hline
\end{tabular}

Surgiram três correlações significativas e negativas entre o LDP pré-PSG do temporal anterior direito e temporal médio esquerdo e a ARMM (b/hora): $\mathrm{r}^{2}=0,26, \mathrm{r}=-0,51$, $p=0,024$ e $r^{2}=0,22, r=-0,47, p=0,043$, respectivamente - Tabela 44 .

Tabela 43 Correlação de Pearson entre LDP pré-PSG e ARMM nos NÃOBRUXÔMANOS DO GRUPO EXPERIMENTAL

\begin{tabular}{|c|c|c|c|c|}
\hline \multirow{3}{*}{ Sítio Muscular } & Epi/pré-PSG & Epi/hora & B/hora & B/epi \\
\hline & \multicolumn{4}{|c|}{$\begin{array}{l}\text { Coeficiente de correlação - } r \text { (Não-bruxômanos - Grupo } \\
\text { Experimental - } n=11 \text { ) }\end{array}$} \\
\hline & Valor de $p$ & & & \\
\hline \multirow[t]{2}{*}{ Temporal Anterior } & 0,0398 & 0,0571 & $-0,0696$ & $-0,221$ \\
\hline & 0,908 & 0,867 & 0,839 & 0,514 \\
\hline \multirow[t]{2}{*}{ Temporal Médio } & 0,106 & $-0,00783$ & $-0,254$ & $-0,411$ \\
\hline & 0,973 & 0,982 & 0,451 & 0,209 \\
\hline \multirow[t]{2}{*}{ Temporal Posterior } & 0,261 & 0,234 & 0,0747 & $-0,380$ \\
\hline & 0,470 & 0,489 & 0,827 & 0,249 \\
\hline \multirow[t]{2}{*}{ Masseter (Origem) } & 0,242 & $-0,0202$ & $-0,270$ & $-0,415$ \\
\hline & 0,907 & 0,953 & 0,422 & 0,204 \\
\hline \multirow[t]{2}{*}{ Masseter (Corpo) } & 0,268 & $-0,353$ & $-0,628$ & $-0,639$ \\
\hline & 0,287 & 0,286 & 0,0384 & 0,0343 \\
\hline \multirow[t]{2}{*}{ Masseter (Inserção) } & 0,174 & $-0,379$ & $-0,711$ & $-0,669$ \\
\hline & 0,289 & 0,251 & 0,0142 & 0,0245 \\
\hline \multirow{2}{*}{ Masseter (Profundo) } & 0,158 & $-0,193$ & $-0,556$ & $-0,673$ \\
\hline & 0,613 & 0,570 & 0,0755 & 0,0232 \\
\hline
\end{tabular}


No subgrupo de não-bruxômanos com DMF (Tabela 43), o número de correlações significativas caiu para três, (negativas) quando se compararam os lados esquerdo e direito separadamente: entre inserção do masseter esquerdo e $b /$ hora $\left(r^{2}=0,53, r=-0,73, p\right.$ $=0,010)$ e $\mathrm{b} /$ epi $\left(\mathrm{r}^{2}=0,66, \mathrm{r}=-0,81, \mathrm{p}=0,003\right)$; e entre corpo do masseter esquerdo e $\mathrm{b} /$ epi $\left(r^{2}=0,44, r=-0,66, p=0,026\right)$ - Tabela 44 .

A Tabela 44 mostra o resultado do teste de regressão linear entre os LDPs préPSG que correlacionaram-se mais fortemente com a ARMM $(\mathrm{p}<0,05)$.

Tabela 44 Regressão Linear entre os LDPs pré-PSG e variáveis oromotoras dentre as quais houve correlação

\begin{tabular}{|c|c|c|c|c|c|c|c|c|c|c|c|c|}
\hline GRUPO & $\mathbf{x}$ & $y$ & $\mathbf{P}$ & $r$ & $\mathbf{r}^{2}$ & Rel & $\mathbf{x}$ & y & $\mathbf{p}$ & $\mathbf{r}$ & $\mathbf{r}^{2}$ & Rel \\
\hline BS (GE) & \multirow{2}{*}{\multicolumn{5}{|c|}{ correlações não-significativas }} & \multirow[t]{2}{*}{ Neg } & TAD & \multirow{2}{*}{ b/ hora } & 0,024 & $-0,51$ & 0,26 & $\mathrm{Neg}$ \\
\hline$(n=19)$ & & & & & & & TME & & 0,043 & $-0,47$ & 0,22 & Neg \\
\hline \multirow{5}{*}{$\begin{array}{l}\text { NBS (GE) } \\
(n=11)\end{array}$} & MC & & 0,038 & $-0,63$ & 0,40 & $\mathrm{Neg}$ & MCE & b/ epi & 0,026 & $-0,66$ & 0,44 & $\mathrm{Neg}$ \\
\hline & $\mathrm{MI}$ & - B/ hora & 0,014 & $-0,71$ & 0,51 & Neg & \multirow{2}{*}{ MIE } & b/hora & 0,010 & $-0,73$ & 0,53 & Neg \\
\hline & $M C$ & & 0,034 & $-0,64$ & 0,41 & Neg & & b/epi & 0,026 & $-0,66$ & 0,44 & Neg \\
\hline & $\mathrm{Ml}$ & \multirow[t]{2}{*}{ B/ epi } & 0,024 & $-0,67$ & 0,45 & $\mathrm{Neg}$ & & & & & & \\
\hline & $\mathrm{MP}$ & & 0,023 & $-0,67$ & 0,45 & Neg & & & & & & \\
\hline \multirow{4}{*}{$\begin{array}{l}\text { BS (GC) } \\
(n=10)\end{array}$} & TA & \multirow{2}{*}{ Epi/ noite } & 0,012 & 0,75 & 0,57 & Pos & TAD & b/ hora & 0,049 & 0,63 & 0,40 & Pos \\
\hline & Ml & & 0,042 & 0,65 & 0,42 & Pos & \multirow{3}{*}{ TAE } & Epi/noite & 0,023 & 0,70 & 0,49 & Pos \\
\hline & TA & \multirow{2}{*}{ Epi/hora } & 0,034 & 0,67 & 0,45 & Pos & & \multirow[t]{2}{*}{ Epi/ hora } & \multirow[t]{2}{*}{0,016} & \multirow[t]{2}{*}{0,73} & \multirow[t]{2}{*}{0,53} & \multirow[t]{2}{*}{ Pos } \\
\hline & $\mathrm{Ml}$ & & 0,033 & 0,67 & 0,45 & Pos & & & & & & \\
\hline \multirow{3}{*}{$\begin{array}{l}\text { NBS (GC) } \\
(n=20)\end{array}$} & \multirow{3}{*}{\multicolumn{5}{|c|}{ correlações não-significativas }} & \multirow[t]{3}{*}{ Neg } & \multirow{2}{*}{ TMD } & Epi/noite & 0,038 & $-0,47$ & 0,22 & Neg \\
\hline & & & & & & & & Epi/ hora & 0,026 & $-0,50$ & 0,25 & Neg \\
\hline & & & & & & & TME & b/hora & 0,047 & $-0,45$ & 0,20 & $\mathrm{Neg}$ \\
\hline \multicolumn{13}{|c|}{$\begin{array}{l}\text { x: variáveis independentes (LDP pré-PSG nos diferentes sítios musculares); y: variáveis dependentes: (parâmetros de } \\
\text { ARMM) } \\
\text { BS: bruxismo do sono ou bruxômanos; NBS: sem bruxismo do sono ou não-bruxômanos } \\
\text { GE: grupo experimental; GC: grupo controle } \\
\text { Rel: Relação entre LDP pré-PSG e ARMM; Pos: positiva; Neg: negativa } \\
\text { MC: corpo do masseter, MI inserção do masseter; MP: masseter profundo; TA: temporal anterior. } \\
\text { TAD: temporal anterior direito; TME: temporal médio esquerdo; TMD: temporal médio direito; MCE: corpo do masseter } \\
\text { esquerdo; MIE: inserção do masseter esquerdo. } \\
\text { r: coeficiente de correlação; } \mathrm{r}^{2}: \text { quadrado do coeficiente de correlação }\end{array}$} \\
\hline
\end{tabular}


A Figura 4 mostra as relações de correlação e o $r^{2}$ entre o LDP prévio e a ARMM nos bruxômanos do Grupo Controle.

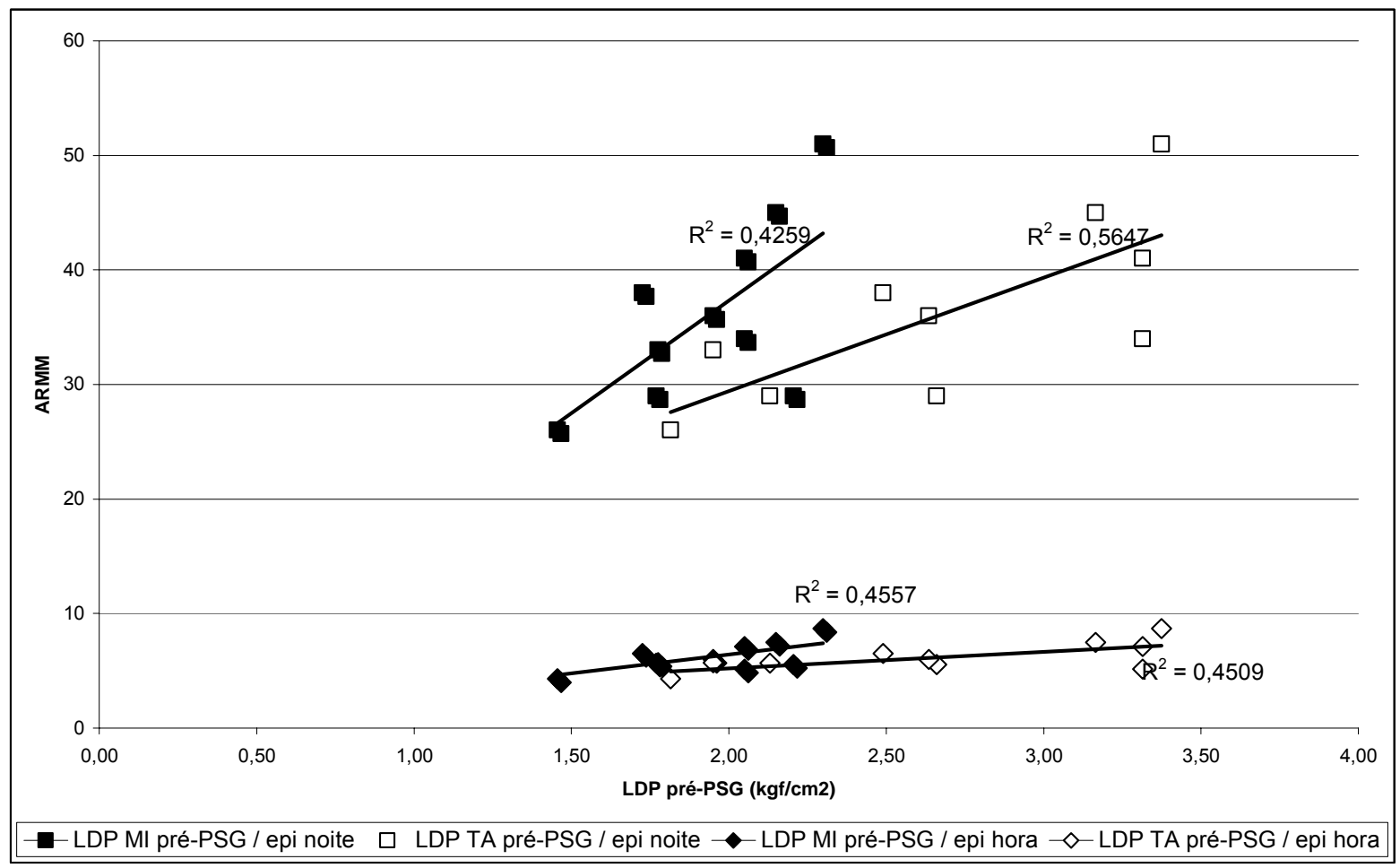

MI: inserção do masseter; TA: temporal anterior

Figura 4 Relações entre LDP pré-PSG e ARMM nos bruxômanos do Grupo Controle 
A Figura 5 mostra as correlações entre o LDP pré-PSG e a ARMM nos nãobruxômanos do Grupo Experimental.

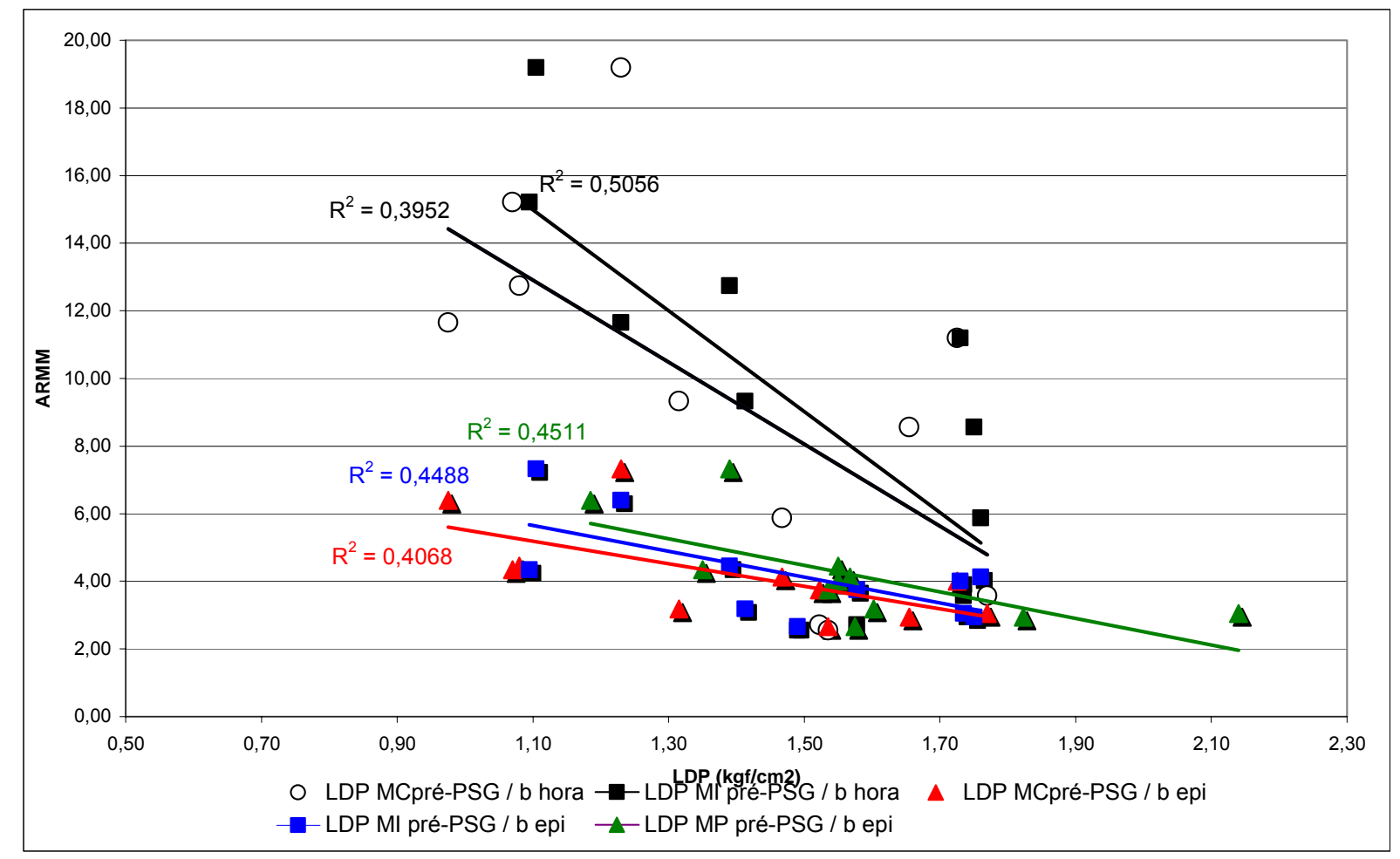

MC: corpo do masseter; MI: inserção do masseter; MP: masseter profundo

\section{Figura 5 Relações entre LDP pré-PSG e ARMM nos NÃO BRUXÔMANOS do Grupo Experimental}

Tabela 45 Variáveis oromotoras nos bruxômanos do grupo controle (s/DMF) e do grupo experimental com relato de intensidade de dor leve (c/DMF leve)

\begin{tabular}{lccc}
\hline & \multicolumn{2}{c}{ BRUXÔMANOS } & \\
\cline { 2 - 3 } & s/ DMF $(\mathbf{n}=\mathbf{1 0})$ & c/ DMF leve $(\mathbf{n}=\mathbf{7})$ & $\begin{array}{c}\mathbf{P} \\
\text { (teste } \mathbf{t})\end{array}$ \\
\hline Epi/noite & $36,2 \pm 7,79$ & $35,7 \pm 71$ & 0,908 \\
Epi/hora & $6,216 \pm 1,26$ & $5,87 \pm 1,68$ & 0,638 \\
b/hora & $25,36 \pm 6,79$ & $26,13 \pm 5,73$ & 0,810 \\
b/epi & $4,05 \pm 0,67$ & $4,52 \pm 0,44$ & 0,124 \\
\hline
\end{tabular}

Houve apenas uma correlação com $\mathrm{p}<0,05$ entre o LDP pré-PSG da origem do masseter e b/hora $(r=0,77, p=0,042)$ no subgrupo de 7 bruxômanos com DMF leve. 
As Tabelas 49 e 50 mostram as correlações encontradas entre os LDPs pré-PSG e ARMM nos grupos controle e experimental, independente do bruxismo.

Tabela 46 Correlação de Pearson entre LDP pré-PSG e ARMM e do Grupo CONTROLE

\begin{tabular}{|c|c|c|c|c|}
\hline \multirow[b]{2}{*}{$\begin{array}{l}\text { Sítio Muscular (LDP pré- } \\
\text { PSG) }\end{array}$} & Epi/noite & Epi/hora & B/hora & B/epi \\
\hline & \multicolumn{4}{|c|}{$\begin{array}{l}\text { Coeficiente de correlação }-r \text { (Grupo Controle } n=30 \text { ) } \\
\text { Valor de } p\end{array}$} \\
\hline \multirow[t]{2}{*}{ Temporal Anterior } & 0,174 & 0,159 & 0,136 & $-0,0220$ \\
\hline & 0,357 & 0,402 & 0,474 & 0,908 \\
\hline \multirow[t]{2}{*}{ Temporal Médio } & 0,172 & 0,157 & 0,144 & 0,00843 \\
\hline & 0,364 & 0,408 & 0,448 & 0,956 \\
\hline \multirow[t]{2}{*}{ Temporal Posterior } & 0,0605 & 0,0528 & 0,113 & 0,197 \\
\hline & 0,751 & 0,782 & 0,552 & 0,296 \\
\hline \multirow[t]{2}{*}{ Masseter (Origem) } & $-0,140$ & $-0,0910$ & $-0,0854$ & $-0,0661$ \\
\hline & 0,459 & 0,632 & 0,654 & 0,729 \\
\hline \multirow[t]{2}{*}{ Masseter (Corpo) } & $-0,132$ & $-0,116$ & $-0,117$ & $-0,0807$ \\
\hline & 0,486 & 0,543 & 0,540 & 0,672 \\
\hline \multirow[t]{2}{*}{ Masseter (Inserção) } & $-0,239$ & $-0,223$ & $-0,210$ & $-0,163$ \\
\hline & 0,203 & 0,237 & 0,266 & 0,390 \\
\hline \multirow[t]{2}{*}{ Masseter (Profundo) } & $-0,233$ & $-0,225$ & $-0,203$ & $-0,0247$ \\
\hline & 0,216 & 0,233 & 0,281 & 0,897 \\
\hline
\end{tabular}

Tabela 47 Correlação de Pearson entre LDP pré-PSG e ARMM do Grupo EXPERIMENTAL

\begin{tabular}{|c|c|c|c|c|}
\hline & Epi/noite & Epi/hora & B/hora & B/epi \\
\hline Sítio Muscular (LDP pré-PSG) & \multicolumn{4}{|c|}{$\begin{array}{l}\text { Coeficiente de correlação - r (Grupo Experimental } n=30 \text { ) } \\
\text { Valor de } p\end{array}$} \\
\hline Temporal Anterior & $\begin{array}{l}-0,0972 \\
0,609\end{array}$ & $\begin{array}{l}-0,114 \\
0,547\end{array}$ & $\begin{array}{l}-0,126 \\
0,506\end{array}$ & $\begin{array}{l}-0,159 \\
0,401\end{array}$ \\
\hline Temporal Médio & $\begin{array}{l}0,0641 \\
0,737\end{array}$ & $\begin{array}{l}0,0383 \\
0,841\end{array}$ & $\begin{array}{l}-0,106 \\
0,578\end{array}$ & $\begin{array}{l}-0,396 \\
0,0303\end{array}$ \\
\hline Temporal Posterior & $\begin{array}{l}0,0728 \\
0,702\end{array}$ & $\begin{array}{l}-0,0253 \\
0,895\end{array}$ & $\begin{array}{l}-0,121 \\
0,525\end{array}$ & $\begin{array}{l}-0,323 \\
0,0818\end{array}$ \\
\hline Masseter (Origem) & $\begin{array}{l}-0,133 \\
0,485\end{array}$ & $\begin{array}{l}-0,134 \\
0,481\end{array}$ & $\begin{array}{l}-0,237 \\
0,208\end{array}$ & $\begin{array}{l}-0,341 \\
0,0653\end{array}$ \\
\hline Masseter (Corpo) & $\begin{array}{l}-0,137 \\
0,470\end{array}$ & $\begin{array}{l}-0,126 \\
0,505\end{array}$ & $\begin{array}{l}-0,264 \\
0,159\end{array}$ & $\begin{array}{l}-0,401 \\
0,0282\end{array}$ \\
\hline Masseter (Inserção) & $\begin{array}{l}-0,0687 \\
0,708\end{array}$ & $\begin{array}{l}-0,0998 \\
0,600\end{array}$ & $\begin{array}{l}-0,175 \\
0,356\end{array}$ & $\begin{array}{l}-0,270 \\
0,149\end{array}$ \\
\hline Masseter (Profundo) & $\begin{array}{l}-0,0604 \\
0,751\end{array}$ & $\begin{array}{l}-0,131 \\
0,490\end{array}$ & $\begin{array}{l}-0,193 \\
0,307\end{array}$ & $\begin{array}{l}-0,260 \\
0,165\end{array}$ \\
\hline
\end{tabular}


O teste de regressão linear revelou que os LDPs pré-PSG do temporal médio e do corpo do masseter influenciou entre $16 \%$ e $20 \%$ a variabilidade da ARMM no grupo experimental,

Tabela 48 Regressão Linear Simples e Múltipla entre LDP pré-PSG e ARMM

\begin{tabular}{|c|c|c|c|c|c|c|c|}
\hline GRUPO & $\begin{array}{l}\text { Variável Indep } \\
\mathrm{x}_{1} \text { (Coef) } \\
\mathrm{p}\end{array}$ & $\begin{array}{l}\text { Variável Indep } \\
x_{2} \text { (Coef) } \\
\text { p }\end{array}$ & $\mathbf{y}$ & $r$ & $r^{2}$ & $\mathbf{P}$ & \\
\hline \multirow[t]{3}{*}{ GE } & $\begin{array}{l}\text { TM pré }(-0,642) \\
0,030\end{array}$ & & \multirow{3}{*}{ b/ epi } & 0,40 & 0,16 & 0,030 & \multirow{3}{*}{ NEGATIVA } \\
\hline & $\begin{array}{l}\text { MC pré }(-0,114) \\
0,014\end{array}$ & & & 0,44 & 0,20 & 0,014 & \\
\hline & $\begin{array}{l}\text { TM pré }(-0,865) \\
0,250\end{array}$ & $\begin{array}{l}\text { MC pré }(-0,393) \\
0,272\end{array}$ & & 0,45 & 0,20 & 0,051 & \\
\hline GC & s/ correlações & & & & & & \\
\hline
\end{tabular}




\subsection{BRUXISMO DO SONO E EAV}

A Tabela 49 mostra a relação entre a intensidade da dor (EAV) média, antes e depois da PSG e ARMM no grupo experimental. Não se observaram correlações significativas entre quaisquer EAVs e ARMM nos pacientes com DMF.

Tabela 49 Correlação de Pearson entre ARMM e EAV no grupo EXPERIMENTAL

\begin{tabular}{|c|c|c|c|c|}
\hline \multirow[b]{2}{*}{ EAV } & Epi/noite & Epi/hora & B/hora & B/epi \\
\hline & \multicolumn{4}{|c|}{$\begin{array}{l}\text { Coeficiente de correlação - } r \text { (Grupo Experimental } n=30 \text { ) } \\
\text { Valor de } p\end{array}$} \\
\hline & 0,185 & 0,232 & 0,279 & 0,347 \\
\hline EAV (meala) & 0,328 & 0,216 & 0,136 & 0,060 \\
\hline EAV (pré-PSG) & $\begin{array}{l}-0,244 \\
0,194\end{array}$ & $\begin{array}{l}-0,145 \\
0,446\end{array}$ & $\begin{array}{l}-0,092 \\
0.627\end{array}$ & $\begin{array}{l}-0,052 \\
0,785\end{array}$ \\
\hline EAV (pós-PSG) & $\begin{array}{l}0,067 \\
0,726\end{array}$ & $\begin{array}{l}0,078 \\
0,682\end{array}$ & $\begin{array}{l}0,153 \\
0,421\end{array}$ & $\begin{array}{l}0,056 \\
0,766\end{array}$ \\
\hline
\end{tabular}

Tabela 50 Correlação de Pearson entre ARMM e EAV nos não-bruxômanos do grupo EXPERIMENTAL

\begin{tabular}{lllll}
\hline \multirow{2}{*}{ EAV } & \multicolumn{1}{l}{ Epi/noite } & Epi/hora & B/hora & B/epi \\
\cline { 2 - 5 } & $\begin{array}{l}\text { Coeficiente de correlação - } \mathbf{r} \text { (Não-bruxômanos Grupo Experimental } \\
\mathbf{n}=\mathbf{1 1} \text { ) } \\
\text { Valor de } \mathbf{p}\end{array}$ & & & \\
\hline \multirow{2}{*}{ EAV (média) } & 0,250 & 0,265 & 0,604 & 0,618 \\
& 0,459 & 0,431 & 0,049 & 0,043 \\
\hline \multirow{2}{*}{ EAV (pré-PSG) } & 0,189 & 0,128 & 0,006 & $-0,220$ \\
& 0,578 & 0,709 & 0,987 & 0,515 \\
\hline \multirow{2}{*}{ EAV (pós-PSG) } & 0,056 & 0,095 & 0,118 & 0,013 \\
& 0,868 & 0,781 & 0,729 & 0,971 \\
\hline
\end{tabular}


Tabela 51 Correlação de Pearson entre ARMM e EAV nos bruxômanos do grupo EXPERIMENTAL

\begin{tabular}{lllll}
\hline \multirow{2}{*}{ EAV } & \multicolumn{1}{l}{ Epi/noite } & Epi/hora & B/hora & B/epi \\
\cline { 2 - 5 } & $\begin{array}{l}\text { Coeficiente de correlação - } \mathbf{r} \text { (Bruxômanos Grupo Experimental } \\
\mathbf{n}=\mathbf{1 9} \text { ) } \\
\text { Valor de } \mathbf{p}\end{array}$ & & & \\
\hline \multirow{2}{*}{ EAV (média) } & $-0,014$ & 0,076 & 0,034 & 0,120 \\
EAV (pré-PSG) & 0,953 & 0,758 & 0,888 & 0,625 \\
\cline { 2 - 5 } & $-0,318$ & $-0,116$ & 0,031 & 0,109 \\
EAV (pós-PSG) & 0,185 & 0,637 & 0,899 & 0,657 \\
\hline & $-0,005$ & 0,009 & 0,154 & 0,052 \\
& 0,982 & 0,971 & 0,528 & 0.831 \\
\hline
\end{tabular}

Tabela 52 EAVs pré e pós PSG do grupo EXPERIMENTAL

\begin{tabular}{llll}
\hline GRUPO EXPERIMENTAL & \multicolumn{1}{c}{ EAV pré-PSG } & \multicolumn{1}{c}{ EAV pós-PSG } & p \\
& Média $\pm d p$ [mediana (min-máx) & Média $\pm d p$ [mediana (min-máx) & \\
\hline Bruxômanos $(\mathbf{n}=\mathbf{1 9})$ & $12,94 \pm 17,15[8(0-65)]$ & $12,19 \pm 18,12[4(0-52)]$ & $0,50^{\#}$ \\
Não-Bruxômanos $(\mathbf{n}=\mathbf{1 1})$ & $17,18 \pm 13,23[15(0-47)]$ & $9,22 \pm 8,43[0-20)]$ & $0,04^{*}$
\end{tabular}

* teste $\mathrm{t}$

${ }^{\text {\# }}$ Mann-Whitney 


\subsection{BRUXISMO CúNICO}

Os Anexos 28 e 29 apresentam as respostas dos indivíduos ao questionário de bruxismo, bem como os resultados dos exames de facetas de desgastes e os diagnósticos clínicos finais dos dois examinadores.

Tabela 53 Distribuição das concordâncias entre os examinadores 1 e 2 na realização do Exame Clínico de Bruxismo (ECB)

\begin{tabular}{llll}
\hline & Exa $\mathbf{1}(+)$ & Exa $\mathbf{1}(-)$ & TOTAL \\
\hline Exa $2(+)$ & 28 & 5 & 33 \\
Exa 2 $(-)$ & 6 & 20 & 26 \\
TOTAL & 34 & 25 & 59 \\
\hline
\end{tabular}

Exa $1=$ Examinador 1

Exa 2 = Examinador 2

O teste Kappa mostrou uma concordância inter-examinadores de 0,68 (p< 0,0001 ) representando uma boa concordância, por situar-se entre os valores de 0,4 e 0,75.

A amostra submetida ao exame clínico de bruxismo (ECB) foi composta por 59 indivíduos (havendo apenas 29 no grupo controle) devido à não realização do exame clínico em 1 indivíduo durante a vigência da pesquisa.

A realização do ECB por um segundo examinador teve por finalidade a análise da concordância inter-examinadores visando à análise de sua reprodutibilidade. Entretanto, para fins de comparação do diagnóstico final do exame clínico e obtenção dos valores de sensibilidade e especificidade em relação à PSG, foram considerados os resultados do Examinador 1. A Tabela 54 apresenta a distribuição da concordância entre os diagnósticos clínico (BS ECB) e polissonográficos (BS PSG) na amostra total: sensibilidade de $60 \%$ e especificidade de $71 \%$. 
Tabela 54 Distribuição dos diagnósticos clínicos e polissonográficos na amostra total

\begin{tabular}{llll}
\hline & BS PSG (+) & BS PSG (-) & TOTAL \\
\hline BS ECB (+) & $21 \quad(75 \%)$ & $7 \quad(25 \%)$ & $28(100 \%)$ \\
& $(60 \%)$ & $(29 \%)$ & $31(100 \%)$ \\
BS ECB $(-)$ & $14 \quad(45 \%)$ & $17 \quad(55 \%)$ & \\
& $(40 \%)$ & $(71 \%)$ & 59 \\
\hline TOTAL & $35(100 \%)$ & $24(100 \%)$ & \\
\hline
\end{tabular}

BS ECB = Diagnóstico de bruxismo do sono por meio do exame clínico de bruxismo

BS PSG = Diagnóstico de bruxismo do sono por meio da polissonografia

Já na população sem DMF (grupo controle), a Tabela 55 mostra sensibilidade de $36 \%$ e especificidade de $72 \%$.

Tabela 55 Distribuição dos diagnósticos clínicos e polissonográficos no grupo CONTROLE

\begin{tabular}{llll}
\hline & BS PSG (+) & BS PSG (-) & TOTAL \\
\hline BS ECB $(+)$ & 4 & 5 & 9 \\
& $(36 \%)$ & $(28 \%)$ & \\
BS ECB $(-)$ & 7 & 13 & 20 \\
TOTAL & $(64 \%)$ & $(72 \%)$ & 29 \\
\hline
\end{tabular}

BS ECB = Diagnóstico de bruxismo do sono por meio do exame clínico de bruxismo

BS PSG = Diagnóstico de bruxismo do sono por meio da polissonografia

Tabela 56 Distribuição dos diagnósticos clínicos e polissonográficos no grupo EXPERIMENTAL

\begin{tabular}{llll}
\hline & BS PSG (+) & BS PSG (-) & TOTAL \\
\hline BS ECB (+) & 17 & 7 & 24 \\
& $(89 \%)$ & $(64 \%)$ & \\
BS ECB $(-)$ & 2 & 4 & 6 \\
& $(12 \%)$ & $(36 \%)$ & 30 \\
\hline TOTAL & $19(100 \%)$ & $11(100 \%)$ & 30 \\
\hline
\end{tabular}

BS ECB = Diagnóstico de bruxismo do sono por meio do exame clínico de bruxismo

BS PSG $=$ Diagnóstico de bruxismo do sono por meio da polissonografia

No grupo com DMF (experimental), o ECB alcançou sensibilidade de $89 \%$ e especificidade de $36 \%$. 
Assim, a Tabela 57 apresenta os valores de sensibilidade e especificidade do Exame Clinico de Bruxismo (ECB) na população geral, na população com DMF e na população controle.

Tabela 57 Sensibilidade e Especificidade do ECB

\begin{tabular}{lcc}
\hline Amostra & Sensibilidade (\%) & Especificidade (\%) \\
\hline Total & 60 & 71 \\
Controle & 36 & 72 \\
Com dor miofascial & 89 & 63 \\
\hline
\end{tabular}

Para fins comparativos, calculou-se a confiabilidade do critério clínico de diagnóstico de BS da ASDA: ${ }^{7}$ presença de auto-relato de BS seguido de um ou mais dos seguintes critérios: desgaste anormal dos dentes (item 7 do ECB - facetas de desgaste); ruídos de ranger de dentes (item 6 do ECB - relato de terceiros) e desconforto muscular (item 2 do ECB - cansaço).

Tabela 58 Confiabilidade do critério da ASDA em relação à PSG

\begin{tabular}{lccc}
\hline Amostra & Sensibilidade (\%) & Especificidade (\%) & P* \\
\hline Total & 64 & 61 & \\
Controle & 33 & 65 & 1,00 \\
Com dor miofascial & 79 & 55 & 0,12 \\
\hline
\end{tabular}

Teste Exato de Fisher 
A fim de evidenciar quais parâmetros clínicos (dentre as perguntas do questionário e a análise da presença de facetas na região anterior) foram mais confiáveis para o diagnóstico de BS, calculou-se a sensibilidade e a especificidade de cada uma das questões do ECB em relação à PSG.

Para facilitar a disposição dos dados, cada pergunta foi codificada da seguinte maneira:

1) Auto-relato:

2) Cansaço muscular:

3) Rigidez articular:

4) Desconforto dentário: Sente desconforto nos dentes ao acordar?

5) Restaurações deslocadas: Teve restaurações deslocadas recentemente?

6) Relato de $3^{\circ}$ :
Acorda durante a noite ou pela manhã apertando ou rangendo os dentes?

Sente cansaço nos músculos da face ao acordar?

Acorda pela manhã com as articulações um pouco rígidas?

Alguém já relatou que você range ou aperta os dentes?

Tabela 59 Valores de contingência, sensibilidade, especificidade, teste de associação*\# e de kappa de cada uma das questões do ECB

\begin{tabular}{lcccccc}
\hline & Sensibilidade & Especificidade & P & $\begin{array}{c}\text { R Falso } \\
\text { Negativo }\end{array}$ & $\begin{array}{c}\text { R Falso } \\
\text { Positivo }\end{array}$ & Kappa \\
\hline $\begin{array}{l}\text { 1. Auto-relato } \\
\begin{array}{l}\text { 2, Cansaço } \\
\text { muscular }\end{array}\end{array}$ & 79 & 55 & $0,018^{*}$ & $26 \%$ & $39 \%$ & 0,71 \\
$\begin{array}{l}\text { 3, Rigidez } \\
\text { articular }\end{array}$ & 54 & 74 & $0,055^{*}$ & $36 \%$ & $35 \%$ & 0,52 \\
$\begin{array}{l}\text { 4, Desconforto } \\
\text { dentário }\end{array}$ & 63 & 81 & $0,161^{*}$ & $40 \%$ & $35 \%$ & 0,49 \\
$\begin{array}{l}\text { 5, Restaurações } \\
\text { fraturadas }\end{array}$ & 29 & 66 & $0,054^{*}$ & $32 \%$ & $39 \%$ & 0,48 \\
$\begin{array}{l}\text { 6, Relato de } \\
\text { terceiros }\end{array}$ & 36 & 84 & $0,348^{\#}$ & $43 \%$ & $38 \%$ & 0,28 \\
$\begin{array}{l}\text { Facetas } \\
\text { Coincidentes }\end{array}$ & 53 & 84 & $0,153^{\#}$ & $40 \%$ & $33 \%$ & 0,56 \\
\hline $\begin{array}{l}* \text { Qui-quadrado } \\
\text { \#este exato de Fisher }\end{array}$ & 36 & $0,555^{*}$ & $54 \%$ & $57 \%$ & 0,24 \\
\hline
\end{tabular}


Apesar de nenhum dos parâmetros clínicos apresentar valores satisfatoriamente elevados de sensibilidade e especificidade. Cabe aqui a discussão sobre o que se deve priorizar no diagnóstico do BS, se a sensibilidade ou a especificidade. Visto que o a medida terapêutica mais difundida do BS é a placa lisa, e que a mesma oferece outros benefícios (inclusive o placebo), o sobretratamento com a mesma não traria qualquer dano ao paciente. Já a não detecção de uma parafunção existente e o seu não tratamento poderia comprometer a boa evolução terapêutica de um paciente com DTM. Logo, optou-se por priorizar a sensibilidade (menor número de falso-negativos) do exame de BS.

Como nenhum dos parâmetros isolados apresentou valores concomitantemente aceitáveis de sensibilidade e especificidade, os dois parâmetros com os valores mais elevados (auto relato, com a maior sensibilidade e relato de terceiros, com a maior especificidade) foram analisados separadamente:

A pergunta sobre restaurações fraturadas apresentou o mesmo valor de especificidade que o relato de terceiros, mas optou-se por realizar a segunda análise com esta última por ser esse último mais largamente empregado e aceito na literatura. ${ }^{7}$ Além disso, a resposta ao relato de restaurações fraturadas obteve um índice de condordância (kappa) intraindividual (reprodutibilidade de resposta dos indivíduos analisados) de 0,28.

Para testar a influência do quadro clínico da população sobre a resposta dos indivíduos, avaliou-se a confiabilidade do auto-relato e do relato de terceiros na amostra total e nos grupos com e sem DMF. A sensibilidade e a especificidade dos mesmos variaram sensivelmente com a amostra empregada (Tabela 60).

\section{Tabela 60 Confiabilidade do auto-relato e do relato de terceiros na amostra} total e nos grupos com e sem DMF

\begin{tabular}{lcc}
\hline & Sensibilidade (\%) & Especificidade (\%) \\
\hline Auto-relato TOTAL & 79 & 55 \\
Auto-relato GE & 76 & 66 \\
Auto-relato GC & 40 & 79 \\
Relato de terceiro TOTAL & 36 & 84 \\
Relato de terceiro GE & 42 & 82 \\
Relato de terceiro GC & 22 & 85 \\
\hline
\end{tabular}


Testou-se a confiabilidade de um segundo exame clínico com as seguintes hipóteses de respostas às perguntas de auto-relato e relato de terceiros: Observou-se que, no grupo controle (GC) - sem DMF - a sensibilidade de ambas as questões alcançou os níveis mais baixos, indicando maior número de diagnósticos falso-negativos.

Quando o auto-relato e o relato de terceiros foram considerados juntos, formularam-se duas hipóteses:

Hipótese 1: Para considerar que o paciente apresente BC, o mesmo deveria responder positivamente a uma das duas perguntas, ou seja, ou ao auto-relato ou ao relato de terceiros.

Hipótese 2: Para considerar que o paciente apresente BC, o mesmo deveria responder positivamente às ambas perguntas, ao auto-relato e ao relato de terceiros.

Tabela 61 Valores de contingência, sensibilidade e especificidade da Hipótese 1 e Hipótese 2 do ECB

\begin{tabular}{lllllcc}
\hline PARÂMETRO CLÍNICO & & PSG+ & PSG- & TOTAL & $\begin{array}{c}\text { SENSIBILIDADE } \\
\text { (\%) }\end{array}$ & $\begin{array}{c}\text { ESPECIFICIDADE } \\
\text { (\%) }\end{array}$ \\
\hline 1 ou 6 (ECB) & pos+ & 23 & 15 & 38 & & 82 \\
& neg- & 5 & 16 & 21 & & 52 \\
\cline { 2 - 5 } & TOTAL & 28 & 31 & 59 & & \\
\hline 1 e 6 (ECB) & pos+ & 9 & 4 & 13 & & 32 \\
& neg- & 19 & 27 & 46 & & \\
\cline { 2 - 5 } & TOTAL & 28 & 31 & 59 & & \\
\hline
\end{tabular}

A sensibilidade obtida pelo teste da hipótese 2 (32\%) é considerada inaceitável, pois sensibilidade inferior a 50\% gera tendência ao diagnóstico incorreto, com alto risco de diagnósticos falso-negativos (41\%). A especificidade do teste da hipótese 2 (52\%) indica que a chance de acerto de diagnóstico do teste é a mesma de um teste "cara-ou-coroa", ou seja, regida pelo acaso. A especificidade obtida pelo teste da hipótese 2, apesar de elevada (87\%) ainda foi inferior ao mínimo recomendado para um teste de diagnóstico (90\%). ${ }^{170}$ Assim, o teste indicado pela hipótese 2 (auto-relato ou relato de terceiros) apresentou sensibilidade acima do mínimo indicado $(75 \%),{ }^{170}$ a despeito da baixa especificidade. 
Testado separadamente nos grupos com e sem DMF, o teste da hipótese 2 apresentou $84 \%$ de sensibilidade e $55 \%$ de especificidade no grupo com DMF e $78 \%$ de sensibilidade e 50\% de especificidade no grupo sem DMF. Ou seja, sensibilidade aceitável em ambas as condições (com e sem DMF).

Buscando-se elevar a especificidade do teste, calculou-se a combinação mais apropriada de respostas testando-se a resposta positiva ao auto-relato ou relato de terceiros e o número de questões adicionais do questionário do ECB que deveria ser respondida positivamente pelo indivíduo em cada uma das populações (total, com e sem DMF) - Tabela 62. Excluiu-se da análise a presença de facetas de desgaste, a fim de simplificar o exame e passível de realização por meio de questionário. 
Tabela 62 Confiabilidade da resposta SIM ao ECB de 2 ou mais e 3 ou mais perguntas

\begin{tabular}{lcccccc}
\hline $\mathbf{N}^{\mathbf{0}}$ & \multicolumn{3}{c}{ SENSIBILIDADE (\%) } & \multicolumn{3}{c}{ ESPECIFICIDADE (\%) } \\
respostas SIM & Total & GC & GE & Total & GC & GE \\
\hline $\mathbf{2 +}$ & 86 & 67 & 95 & 39 & 60 & 0 \\
$\mathbf{3 +}$ & 57 & 22 & 73 & 74 & 85 & 54 \\
$\mathbf{4 +}$ & 35 & 0 & 53 & 90 & 95 & 82 \\
\hline
\end{tabular}

A análise da confiabilidade do número mínimo de perguntas a ser respondida mostrou alta sensibilidade $(86 \%)$ para o critério de pelo menos 2 respostas SIM na amostra total. Quanto à sensibilidade, pareceu o critério mais adequado, mas apresentou inaceitável especificidade na amostra total (39\%) e na população com DMF (0\%). Ademais, o mesmo critério apresentou baixa sensibilidade no grupo controle (67\%). 
Buscando-se combinações mais adequadas, associaram-se o número mínimo de respostas SIM à resposta SIM ao auto-relato e/ou ao relato de terceiros (Tabela 63).

\section{Tabela 63 Combinações de respostas ao ECB com maiores índices de confiabilidade nos grupos com e sem DMF}

\begin{tabular}{|c|c|c|c|c|c|}
\hline \multirow{2}{*}{$\begin{array}{l}\mathrm{N}^{0} \\
\text { respostas SIM }\end{array}$} & \multicolumn{2}{|c|}{ SENSIBILIDADE (\%) } & \multicolumn{2}{|c|}{ ESPECIFICIDADE (\%) } & \multirow{2}{*}{ P* } \\
\hline & GC & GE & GC & GE & \\
\hline $2+(1 \mathrm{e} / \mathrm{ou} 6)(\mathrm{GC})$ & 67 & & 60 & & 0,22 \\
\hline $3+(1 \mathrm{e} / \mathrm{ou} 6)$ (GE) & & 74 & & 73 & 0,023 \\
\hline
\end{tabular}

Como o quadro clínico dos indivíduos influenciou as respostas dos indivíduos, a confiabilidade do diagnóstico clínico variou com a população testada. Isso gerou a necessidade de diferentes critérios segundo o quadro clínico do indivíduo. A combinação de pelo menos 2 respostas SIM ao questionário do ECB, sendo que dentre as mesmas inclua-se resposta sim ao auto-relato e/ou relato de terceiros, deve ser utilizada na população sem DMF (controle) como critério de diagnóstico de BS, com sensibilidade de $71 \%$ e especificidade de $59 \%$, Já na população com DMF, o critério requerido é o de resposta SIM a pelo menos 3 perguntas do questionário do ECB, incluindo o auto-relato e/ou o relato de terceiros). Esse critério alcançou sensibilidade de $74 \%$ e especificidade de $73 \%$ na população com DMF (Tabela 63).

O critério de diagnóstico clínico de BS eleito para a população assintomática (1 ou $6+1)$ apresentou likelihood ratio positiva $(\mathrm{LR}+)$ de 1,67 e likelihood ratio negativa de (LR-) de 0,56. O teste exato de Fisher não indicou associação estatisticamente significativa entre o diagnóstico positivo de BS, segundo o critério eleito, e BS diagnosticado pela PSG em indivíduos assintomáticos $(\mathrm{p}=0,214)$.

O critério de diagnóstico clínico de BS eleito para a população com DMF (1 ou 6 +2) apresentou LR+ de 2,74 e LR- de 0,36. O teste exato de Fisher indicou associação estatisticamente significativa entre o diagnóstico positivo de BS, segundo o critério eleito, e BS diagnosticado pela PSG em indivíduos com DMF $(\mathrm{p}=0,023)$. 


\section{6 - DISCUSSÃO}

\section{1 AMOSTRA}

A homogeneidade do quadro clínico dos pacientes de DTM é um pré-requisito básico à realização de estudos sobre esse tema e já foi abordada por diversos autores. ${ }^{35,44,88}$

Apesar da ausência de queixas e de sinais de DTM no grupo controle (excluindose ruídos assintomáticos e leve sensibilidade articular à palpação), 4 indivíduos controle foram classificados como portadores de DTM leve, segundo o índice de DTM ${ }^{32}$ (escore de $4-$ 8). Isso ocorreu por que alguns itens do questionário relacionam-se a aspectos subjetivos da análise ou à presença de estalidos: Itens referentes a dores de cabeça (1 resposta às vezes); desconforto muscular quando mastiga (1 resposta às vezes); dores no pescoço e/ou ombros (2 respostas sim e 1 às vezes); ruídos articulares ( 2 respostas sim e 2 às vezes); relato de mordida "anormal" (1 resposta sim) e relato de usar apenas um lado da boca para mastigar (2 respostas sim). Por se tratarem de respostas isoladas a questões mais subjetivas ou a estalidos, optou-se pela não exclusão desses indivíduos assintomáticos (Tabelas 1 e 2). A prevalência de estalidos assintomáticos no grupo controle (23\%) está de acordo com os achados de DWORKIN et al., ${ }^{43}$ que encontraram estalidos assintomáticos em aproximadamente um quarto $(25 \%)$ da comunidade controle e em $43 \%$ entre os casos clínicos - não exclusivamente miogênicos. Concorda ainda com LOCKER; SLADE, ${ }^{93}$ os quais relataram uma prevalência de ruídos articulares de $25,4 \%$ na população geral.

O perfil de sintomas do grupo experimental vai ao encontro das descrições de subgrupos miogênicos de outros estudos $35,44,88,89$ em muitos aspectos. A média da intensidade de dor $(39 \mathrm{~mm})$, levemente abaixo da média do grupo de DTM miogênica do estudo de LOBBEZOO-SCHOLTE; ${ }^{89}$ baixa freqüência de estalidos articulares $(23,3 \%$ Tabela 6) - embora no questionário de índice de DTM - Tabela 5, 48,3\% dos pacientes tenham relatado que já perceberam algum ruído na ATM. Concordando com os achados de LOBBEZOO-SCHOLTE et al. ${ }^{88}$ que encontraram maiores índices de cefaléia recorrente (57\%) e de queixas relacionadas ao ouvido (às vezes) no grupo de DTM miogênica em 
comparação aos demais subgrupos, o presente estudo encontrou altos percentuais de relato de cefaléia freqüente $(86,2 \%)$ e dores no pescoço e/ou ombros $(93,1 \%)$ no grupo com DMF.

O grupo experimental foi composto, majoritariamente por pacientes com DMF (iDTM) leve e moderada (86,67\%). Isso ocorreu como conseqüência do cumprimento dos critérios de exclusão. Tais critérios exigiam a ausência de diagnóstico de DTM mista (miogênico e articular) e, sabe-se que, concomitantemente ao agravamento do quadro clínico dos pacientes, há a tendência de surgirem sintomas mais generalizados de dor (passando a incluir a $\mathrm{ATM}^{149}$ ). STOHLER ${ }^{149}$ (1999) relata que apenas uma pequena percentagem de casos continua a ser diagnosticada como condições musculares, após exames de acompanhamento de 1 ano (23\%), 3 anos (13,3\%) e 5 anos (6,7\%). Outra possível razão para a maioria dos pacientes apresentarem quadro clínico leve ou moderado foi a exclusão de indivíduos com desordens do sono e relato de depressão. Já é razoavelmente bem conhecida a relação entre desordens do sono e dor, ${ }^{16,109,174}$ particularmente as desordens miogênicas crônicas. ${ }^{86,164}$ Muitos estudos também já evidenciaram a estreita relação entre dor miofascial crônica e desordens psicológicas, particularmente, ansiedade e depressão, ${ }^{35,89}$ bem como somatização, comportamento obcessivo-compulsivo e hostilidade. ${ }^{86}$

As diferenças estatisticamente significativas entre os limiares de dor à pressão (LDP) pré-PSG dos grupos controle e experimental ratificam a adequada alocação dos participantes da pesquisa e, ainda, que a sensibilidade muscular (indicativa de sensibilização periférica) não se alterou entre o dia da triagem e a realização da PSG. SILVA et al. ${ }^{144}$ (2005) demonstraram os valores de corte do LDP para 4 dos 7 sítios musculares analisados neste estudo: 1,$5 ; 2,47 ; 2,75$ e $2,77 \mathrm{kgf} / \mathrm{cm}^{2}$ para o masseter superficial (corpo) e para as porções anterior, média e posterior do temporal, respectivamente, com especificidade de $90,8 \%$. No presente estudo, vê-se que todos os valores dos LDPs do grupo controle situaram-se acima dos valores de corte $\left(2,01 ; 2,56 ; 2,83\right.$ e $3,09 \mathrm{kgf} / \mathrm{cm}^{2}$, respectivamente). E que todos os valores dos LDPs do grupo experimental situaram-se abaixo dos valores de corte $(1,39 ; 1,90 ; 2,23$ e $2,51 \mathrm{kgf} / \mathrm{cm}^{2}$ respectivamente).

Apesar de alguns indivíduos terem apresentado MPM acima do nível considerado patológico (5 eventos/horas) ${ }^{112}$ (Tabela 13), o critério de exclusão deste estudo previu a exclusão de indivíduos com índice de MPM acima de 20 (baseado em LAVIGNE et al. ${ }^{83}$ 
Ainda, nenhum dos indivíduos que apresentou índices mais altos de MPM na primeira noite os manteve na segunda noite (Anexo 25). E, na segunda noite, apenas um indivíduo apresentou índice de MPM acima de 5 eventos/hora (7,7 MPM/h). MACALUSO et al., ${ }^{95} \mathrm{em}$ um estudo sobre a físiopatologia do BS não especificou limite do índice de MPM como critério de exclusão. LAVIGNE et al., ${ }^{85}$ em outro estudo sobre a físiologia do BS estabeleceu como um dos critérios de exclusão, o índice de MPM superior a 10. Observa-se, portanto, que a literatura não restringe a participação de indivíduos com índice MPM leve a moderada (5 a 10/h), encontrando-se em concordância com este trabalho. 


\subsection{Dagnóstico de BruXISMo do SONo e de Dor Mofascal}

O presente estudo realizou a análise polissonográfica em 2 noites de 60 indivíduos (bruxômanos e não-bruxômanos, com e sem DMF), buscando correlacionar parâmetros objetivos de atividade parafuncional (BS) com parâmetros objetivos de DTM (subgrupo Dor Miofascial - RDC/TMD).

A carência de evidência científica sobre a relação existente entre BS e DTM motivou a realização deste estudo, visando à minimização dos vieses inerentes ao diagnóstico do BS e à classificação das DTMs.

A literatura científica nos alerta para o risco de erro ao se confiar no auto-relato ${ }^{87}$ de uma forma geral, principalmente em se tratando de uma atividade realizada durante o sono. ${ }^{13}$ Também já nos mostrou que uma parte significativa do desgaste dentário observado nos indivíduos é atribuída a fatores tais como idade e geometria das relações de contatos oclusais, além da atividade parafuncional. ${ }^{139}$ LAVIGNE; ROMPRÉ; MONTPLAISIR ${ }^{83}$ validaram o exame PSG para o diagnóstico de bruxismo, buscando, a partir desse método, obter diagnósticos mais confiáveis e objetivos, bem como a possibilidade de quantificação e qualificação da ARMM realizada pelo paciente. Assim, o presente estudo, por meio do exame PSG realizado em 2 noites consecutivas, buscou minimizar o erro e os vieses do diagnóstico de BS.

Também é fartamente citada na literatura a dificuldade de se comparar estudos ou mesmo de tirar conclusões mais concretas acerca dos fatores etiológicos ou contribuintes das DTMs. Essa dificuldade se deve a fatores tais como:

A própria definição de DTM. A Academia Americana de Dor Orofacial $^{4}$ define DTM como um termo genérico empregado a um conjunto de problemas musculoesqueletais do sistema mastigatório. Assim, em se tratando de um termo abrangente, composto por distintos e variados quadros clínicos, não poderia ser abordado de maneira genérica. 
O método de diagnóstico. Os estudos de prevalência de DTM (sinais e sintomas) apresentam resultados muitas vezes discrepantes devido à forma pela qual a mesma é diagnosticada. Muitas vezes realiza-se o cruzamento de dados tais como: autorelato de bruxismo, limitação de abertura, dor na cabeça, do na ATM e estalidos baseando-se em auto-relatos. ${ }^{57,} 93$ Outros estudos ${ }^{134}$ realizam também o exame físico e verificam valores de prevalência distintos daqueles que realizaram apenas o questionário. Esses valores variam também com a população estudada.

Critérios de diagnóstico, para se compor um quadro clínico. Há que se estabelecer o conjunto de características que o defina. MAGNUSSON et al. ${ }^{97}$ relatam associação positiva entre sinais e sintomas específicos de DTM (cansaço na mandíbula e ruídos articulares) e bruxismo. Entretanto, sinais e/ou sintomas isolados não necessariamente compõem um quadro clínico de disfunção temporomandibular. GREENE; MARBACH, ${ }^{55}$ em uma análise crítica sobre estudos epidemiológicos, enfatizam a necessidade de se levar em conta a queixa principal do paciente bem como a sua motivação em procurar tratamento para caracterizar uma determinada doença. Lembram que a população geral pode apresentar alta prevalência de sinais e/ou sintomas isolados sem que a mesma represente, ou de fato pertença à população doente.

Pelas razões apresentadas e visando à objetividade e clareza nas conclusões optou-se por estudar apenas um subgrupo de DTM (Dor Miofascial), obedecendo ao critério de diagnóstico derivado do RDC/TMD. ${ }^{44}$

A objetividade do diagnóstico de DMF foi ratificada pelos valores de limiar de dor à pressão (LDP) significativamente diferentes em todos os sítios musculares aferidos previamente ao exame polissonográfico (PSG) (Tabela 12). Como variantes experimentais intra-grupo, os pacientes de DMF diferiram, principalmente quanto à intensidade da dor 
relatada e ao período de pior dor. A Tabela 6 mostra que apenas $3(10 \%)$ dos pacientes relatavam dor severa, ao passo que os demais dividiram-se em dor leve $(46,67 \%)$ e moderada $(43,33 \%)$.

Apesar da conhecida associação que a DTM (particularmente a DMF) apresenta com os distúrbios do sono, ${ }^{16,77,174}$ não ocorreram diferenças significativas entre o GC e o GE quanto às variáveis gerais do sono (latência, eficiência e tempo de sono, bem como a distribuição das fases do sono em termos percentuais). Isso se deveu à rígida observação dos critérios de inclusão, os quais previam a exclusão de indivíduos com relato de algum distúrbio do sono (Ver Critérios de Inclusão e Exclusão na sessão de Material e Métodos). A exclusão de pacientes com distúrbios do sono, por um lado, minimizou a ocorrência de fatores de confusão na análise dos dados, ao mesmo tempo em que, indiretamente, também excluiu a

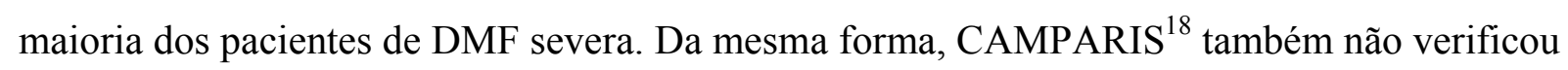
diferenças nessas mesmas variáveis do sono entre uma população de bruxômanos com e sem DMF. O presente estudo observou que os valores dessas variáveis encontram-se dentro dos padrões de normalidade ${ }^{132}$ e são semelhantes aos relatados na literatura. ${ }^{18,85,95}$

Quanto ao número de microdespertares/hora (MD/h), LAVIGNE et al. ${ }^{85}$ observaram maior freqüência de microdespertares (MD) entre os bruxômanos $(9,5 \mathrm{MD} / \mathrm{h}$ versus 5,7 MD/h nos não-bruxômanos $-\mathrm{p}=0,007)$, bem como MACALUSO et al. ${ }^{95}$ Outros autores $^{18,68,81}$ não verificaram tal diferença, concordando com o presente estudo. Embora a incidência de MD seja moderadamente correlacionada com alta freqüência de $\mathrm{ARMM}^{79}$, é sua magnitude (ex: início mais rápido do aumento na freqüência cardíaca, maior elevação EMG e contatos dentários com sons de ranger) que parece distinguir bruxômanos de nãobruxômanos. ${ }^{68,79}$ 


\subsection{VARIÁVEIS OROMOTORAS}

A literatura aponta a maior ocorrência dos episódios e bursts de ARMM durante a fase 2 (BADER et al.: ${ }^{14} 10,2 \%$ na fase 1 e $43 \%$ na fase 2 ; e MACALUSO: ${ }^{95} 15,32 \%$ na fase 1 e 55,47\% na fase 2), diferindo da distribuição por nós obtida, em que, apesar de mais prevalentes nas fases 1 e 2 (sono leve NREM), não houve maior prevalência na fase 2(Tabela 16) tanto para o GC quanto para o GE.

Com base em registros $\mathrm{EMG}^{85,95}$ mais de $88 \%$ dos episódios de BS são dos tipos fásico e misto, concordando com os achados do presente estudo, principalmente em relação aos bruxômanos do GE (87\% para os bruxômanos do GE e 79,54\% para os bruxômanos do $\mathrm{GC})$.

Entre os bruxômanos, a freqüência média de episódios de bruxismo por hora foi de 6,4 $\pm 1,91$ (Tabela 19). Valores próximos, embora ligeiramente acima dos relatados pela literatura $(5,4$ a 5,8$) .{ }^{83,85}$ Nos não-bruxômanos, a freqüência média dos episódios/hora foi de $2,14 \pm 0,99$, também próxima e ligeiramente acima do valor encontrado na literatura $(1,8) .{ }^{85}$ Essa pequena discrepância pode deve-ser à variabilidade entre os examinadores dos diferentes estudos, apesar da boa confiabilidade intra-examinador (Kappa 0,7 para eventos fásicos e mistos e 0,6 para eventos tônicos). Observa-se que, em concordância com a observação de que os bruxômanos apresentam freqüência de episódios/hora 3 vezes maior do que os nãobruxômanos, ${ }^{79,85}$ observou-se a mesma proporção entre esses grupos. 


\subsection{INFLUÊNCIA DA ATIVIDADE MUSCULAR SOBRE A DOR}

É vasta e controversa a literatura sobre esse tema, mas apenas recentemente têm se conduzido estudos mais bem desenhados e, muitos aspectos antes obscuros agora são mais bem compreendidos. Vários autores questionam a relação entre BS e DTM apontando falhas no preenchimento dos requisitos das relações de causalidade, ${ }^{90}$ ausência de associação entre número de sítios musculares ou articulares sensíveis e auto-relato de $\mathrm{BS},{ }^{119}$ bem como ausência de evidência de que o bruxismo module a eficácia de placas oclusais no tratamento da DMF. ${ }^{131}$

Acredita-se que as mais prováveis razões para as controvérsias sobre essa questão residam nas limitações metodológicas referentes ao diagnóstico de BS: auto-relato ou desgaste dentário, ${ }^{70,119,131}$ avaliação de uma amostra parcial, ${ }^{67,}$ 70, 111 heterogeneidade dos grupos de DTM e variabilidade do BS. A maioria dos estudos que verificou a associação entre bruxismo e DTM, nos quais o diagnóstico de bruxismo foi realizado por meio do auto-relato encontrou associação estatisticamente significativa entre ambos. ${ }^{21,26,89,96,98,99,111,2,97}$ Por outro lado, apenas 2 estudos ${ }^{70,119}$ que empregaram o mesmo método de diagnóstico do BS não encontraram associação com sinais ou sintomas de DTM 


\subsubsection{Associação entre Bruxismo do Sono e Dor Miofascial}

Em concordância com a literatura, 2, 21, 26, 57, 67, 88, 96-99 detectou-se associação significativa entre BS e DMF $\left(\chi^{2}=4,271\right)$ com $\mathrm{p}=0,039$; OR (odds ratio) de 3,455 (IC 95\% $1,1-11,2)$; RR (risco relativo) de 1,83; likelihood ratio positivo (LR+) de 1,9 e negativo (LR-) de 0,55. Todos os valores apontam para o BS como fator de risco para a ocorrência de DMF.

Os valores de OR (odds ratio) representam a chance que um bruxômano tem de apresentar DMF em relação a um não-bruxômano, enquanto o $\mathrm{R}$ (risco) representa a chance de um bruxômano apresentar DMF, em relação à população geral. Como, normalmente, a chance de quem é exposto a um determinado fator de risco é maior do que a de quem não é exposto, o OR, costuma apresenta valores maiores que o Risco. ALDERSON; GREEN; HIGGINS $^{3}$ explicam que essa diferença de valores não representa um erro, ambos são maneiras inteiramente válidas de descrever um efeito. O problema surge quando o odds ratio é interpretado como risco relativo. Devido à aplicabilidade direta dos valores de risco na clínica diária, em geral recomenda-se o uso do risco, ${ }^{3}$ a fim de evitar um erro na interpretação e superestimar um determinado fator. Nesse caso, o risco de um bruxômano apresentar DMF é quase duas vezes maior que o de um não-bruxômano, e não três vezes $(\mathrm{OR} 3,5)$, como indica o OR, se o mesmo for interpretado como risco.

Embora com metodologia diferente, os valores de $\mathrm{OR}$ e $\mathrm{R}$ encontrados no presente estudo aproximam-se dos relatados na literatura. Os estudos que abordam a prevalência do bruxismo em populações assintomáticas ou mistas (indivíduos com e sem DTM), ${ }^{19-21, ~ 26, ~ 29, ~ 37, ~ 52, ~ 96-98 ~}$ normalmente o diagnosticam por meio do auto-relato $^{2,21,26,52,96-98}$ e, algumas vezes não distingue o BS do bruxismo diurno. 2, 21, 26, 96-98 Em geral esses estudos verificam a presença de associação ou calculam a correlação entre o relato de apertamento ou ranger de dentes e a presença de sinais e sintomas de DTM. Todos os estudos mencionados reportaram associação estatisticamente significativa entre relato de bruxismo e algum sinal ou sintoma de DTM ${ }^{52}$ tais como [dificuldade de fechamento (OR 2,84) ${ }^{26}$ dor craniofacial (OR $1,84)^{26}$ ou orofacial $(\mathrm{p}<0,001){ }^{2}(\mathrm{RR} 1,6){ }^{96}$; ruídos articulares $(\mathrm{OR} 1,64),{ }^{26}(\mathrm{R}=0,4),{ }^{97}$ (OR $3,3) ;{ }^{98}$ rigidez, travamento (RR 2,7) ${ }^{96}$ ou cansaço articular $(\mathrm{r}=0,4)^{97}$ e sono fragmentado $(\mathrm{p}<$ $\left.0,001) .^{2}\right]$ 
Um estudo polissonográfico ${ }^{20}$ descritivo sobre as características de 100 bruxômanos relatou a prevalência de $30 \%$ de bruxômanos assintomáticos em uma amostra de bruxômanos, concordando com a prevalência de bruxômanos assintomáticos (34,5\%) na população de bruxômanos $(n=29)$ do presente estudo (Tabela 21). A proporção de bruxômanos assintomáticos na população sem DMF encontrada neste estudo $(33,3 \%)$ concorda com os achados de MANFREDINI et al., ${ }^{100}$ os quais encontraram $36,2 \%$ de bruxômanos (critérios ASDA) em uma população livre de DTM. Um percentual tão elevado de bruxômanos sem sinais ou sintomas de DTM per se contribui para o legítimo questionamento sobre a relação de causalidade entre BS e DTM e aponta a fragilidade de estudos que tentam investigar tal relação analisando apenas bruxômanos ${ }^{67,70}$ ou apenas pacientes de DTM. ${ }^{111}$

JAESCHKE; GUYATT; SACKETT ${ }^{63}$ explicam a importância clínica de um determinado fator de acordo com o likelihood ratio. Segundo os autores, baixos valores de $\mathrm{LR}+($ entre 1 e 2 ) e altos valores de LR- (entre 0,5 e 1) representam pequenas alterações (normalmente insignificantes clinicamente) na probabilidade pré-teste. Isso significa dizer que, apesar de estatisticamente associado à DMF, a importância do BS como fator etiológico ou predisponente da DMF é quase insignificante clinicamente. Pois, no outro extremo, tem-se que, para que um fator altere, de forma conclusiva, a probabilidade pré-teste de ocorrência de um evento, o LR+ deveria ser maior que 10 e o LR-, menor que 0,1 .

LOBBEZOO; LAVIGNE $^{90}$ descrevem os vários fatores que implicam em uma relação de causa-e-efeito nas ciências biomédicas, e abordam especificamente o BS. Os autores fazem referência aos critérios elaborados por SPILKER ${ }^{146}$ para o estabelecimento de uma relação de causalidade:

1) Ausência de vieses, acaso e fatores de confusão: os autores ${ }^{90}$ afirmam que é impossível estabelecer uma relação de causa-e-efeito com $100 \%$ de certeza, particularmente na área biomédica. Mas insistem que se deve buscar um alto grau de probabilidade. Assim, defendem que a probabilidade de uma relação causa-e-efeito depende fortemente do desenho do estudo, apontando os estudos randomizados e duplo-cego como os preferidos na eliminação da tendência e dos vieses. Apesar de não se tratar de um estudo randomizado, este estudo buscou eliminar os vieses por meio das seguintes medidas: 
a) mascaramento do examinador durante a alocação dos participantes quanto ao relato de bruxismo. A alocação dos indivíduos aos grupos controle e experimental dependeu apenas do quadro clínico de DMF, cujo diagnóstico obedeceu ao RDC/TMD. Durante a alocação dos indivíduos ao grupo controle, excluiu quaisquer indivíduos que, mesmo sem queixa, apresentassem três ou mais pontos de dor muscular nos sítios palpados;

b) diagnostico de BS por meio da polissonografia.

c) leitura dos registros polissonográficos de forma mascarada.

2) Associação consistente: obteve-se uma relação de associação consistente com as já apresentadas na literatura, ${ }^{26,57,67,88,96,99}$ a despeito das diferenças metodológicas entre este e os demais estudos.

3) Relação temporal (a causa deve preceder o efeito): não foi possível estabelecer uma relação temporal, sobre a qual seja possível afirmar que o bruxismo precedeu o desenvolvimento da DMF. Devido ao desenho transversal deste estudo não foi possível estabelecer uma relação de causalidade. O início do hábito de bruxismo não foi investigado na presente amostra, não nos possibilitando comparar o tempo de duração do hábito e o início do quadro de DMF. Entretanto a literatura relata que o hábito do bruxismo normalmente se inicia

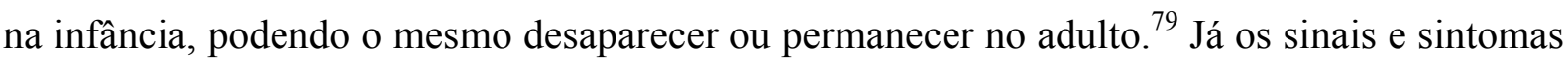
de DTM haviam se iniciado, na amostra deste estudo há, no máximo, 120 meses, em 2 pacientes com idades de 39 e 31 anos (Tabela 3) (média de 34,67 meses $\pm 36,96$ ) Assim, no máximo, pode-se fazer a inferência de que, provavelmente, o hábito de BS tenha se iniciado anteriormente ao quadro de DMF. Apesar da limitação de apenas 1 noite, por meio da comparação entre os LDPs pré e pós-PSG, buscou-se evidenciar se os bruxômanos apresentaram redução do LDP pós-PSG em relação ao LDP pré-PSG. Esse tópico será novamente discutido na sessão referente aos LDPs. Em um bem conduzido estudo longitudinal, único desenho capaz de verificar relações temporais entre fatores de risco e doença, MAGNUSSON et al. ${ }^{98}$ encontraram que o relato de bruxismo é um fator de previsibilidade de sinais clínicos de disfunção temporomandibular 20 anos depois (OR 5,3, p $=0,016)$. Isso indica que o bruxismo não pode ser descartado como um dos possíveis fatores etiológico do desenvolvimento das DTMs. O BS, especificamente, foi fator de previsibilidade 
para demanda por tratamento de DTM, suportando o conceito de um relacionamento positivo entre BS e DMF. Além disso, o valor preditivo negativo do relato de bruxismo no início do estudo foi de $90 \%$, ou seja, há uma alta probabilidade de não necessitar de tratamento para DTM ao longo da vida, quando não se relata essa parafunção na adolescência. Mesmo diante dessas evidências, os autores ${ }^{98}$ sensatamente, indicam cautela, pois as associações encontradas não informam sobre causalidade. Acrescentam ainda que: "muitos pacientes com sinais e sintomas de DTM relatam que tomaram conhecimento sobre seu hábito parafuncional por meio de seus dentistas, mesmo com evidência incerta. Hábitos parafuncionais ainda são considerados por muitos clínicos como importantes fatores de causa das DTMs, mas seu papel é confuso e não há evidência científica de um relacionamento próximo entre bruxismo de DTM." 98

4) Presença de um gradiente dose-resposta: buscou-se verificar a presença do gradiente dose-resposta por meio dos testes de correlação entre ARMM (epi/noite, epi/hora, b/hora e b/epi) e da dor pós-PSG (mensurada objetivamente por meio da EAV e do LDP pósPSG). Esse tópico será discutido pormenorizadamente na sessão referente aos LDPs.

5) A associação deve ser coerente com os dados epidemiológicos: é interessante notar que, ao mesmo tempo em que a literatura aponta insistentemente para a associação entre bruxismo e DTM, ${ }^{26,67,96,99,111}$ ressaltando, entretanto, a fraca evidência da mesma; também é conhecida a discrepância dos dados epidemiológicos ${ }^{90}$ entre BS e DTM. Com relação ao sexo, a DTM se apresenta em uma relação de $3: 1$ a $5: 1$ entre mulheres e homens, ao passo que o bruxismo apresenta-se comumente bem distribuído entre homens e mulheres, podendo, em alguns estudos, apresentar-se levemente mais prevalente nas mulheres. Com relação à idade, o pico da prevalência de sinais e sintomas de DTM ocorre na idade adulta jovem, ao passo que do bruxismo, na infância. ${ }^{70}$

6) A associação deve ser específica: quanto mais específica for uma associação, mais convincente será a evidencia da relação de causa-e-efeito (i.e. o efeito não ocorreria sem que a causa não tivesse ocorrido previamente). Embora faça sentido, esse tópico confundiria a interpretação das relações de causalidade nos casos de doenças multifatoriais. Ou seja, onde, o efeito estudado pudesse ocorrer em função de outros fatores, que não a causa estudada. Já foi exaustivamente citada na literatura a natureza multifatorial das DTMs ${ }^{54}$ e da DMF. ${ }^{89}$ 
Embora a maioria dos bruxômanos $(63,2 \%)$ tenha indicado o período da manhã como sendo o da pior dor, não houve associação estatística entre o horário e a presença de bruxismo. A ausência de associação entre dor ao acordar ou pela manhã e BS (Tabela 7) pode relacionar-se ao fato de a seleção dos pacientes ter sido realizada com base apenas no quadro clínico de DMF, buscando-se não questionar os indivíduos quanto ao BS. Intencionou-se com isso minimizar a tendência de selecionar mais pacientes de DMF conscientes do hábito de BS. É bem conhecida a associação entre auto-relato de BS e DTM. ${ }^{26,57,96,99}$ Como o objetivo principal deste estudo foi verificar a associação entre BS (independente da consciência dos indivíduos sobre seu hábito) e sinais e sintomas de DMF, realizou-se a seleção dos participantes independentemente da sua consciência do BS. Um estudo ${ }^{18}$ encontrou que 100 por cento dos bruxômanos com DMF relatavam o período da manhã como sendo o de piora da dor. O mesmo utilizou o auto-relato confirmado por uma terceira pessoa como critério inicial de seleção. Seu objetivo, entretanto não era verificar a associação entre BS e DMF e sim, avaliar as características clínicas e polissonográficas de pacientes com BS, não sendo, portanto, afetado negativamente pelo método de seleção.

A fim de esclarecer se o período da manhã como o de piora da dor poderia relacionar-se, de alguma forma, à intensidade da ARMM durante o sono, realizou-se o teste $\mathrm{t}$ para verificar se os pacientes com piora da dor pela manhã apresentaram maior atividade muscular durante o sono (Tabela 8 e Tabela 9). Essa hipótese não se confirmou no presente estudo. Indica-se, entretanto, cautela devido ao reduzido tamanho da amostra utilizada para essa análise, sendo necessária a repetição da mesma em uma amostra de tamanho mais apropriado.

A ausência de dor mais severa (EAV) entre os bruxômanos do que nos nãobruxômanos aponta para a etiologia multifatorial da DMF, ${ }^{54}$ onde o bruxismo, per se, não implicou em maior severidade da dor (Tabela 10). RAPHAEL; MARBACH ${ }^{128}$ encontraram que nem o auto-relato de ranger de dentes nem a evidência clínica de abrasão dentária correlacionaram-se significativamente com a intensidade de dor em uma população de 136 mulheres com DTM examinadas por questionário e exame clínico durante 12 meses. Além disso, houve uma tendência para menor duração da desordem entre aqueles com evidência de apertamento (auto-relato ranger e evidência clínica de abrasão). 


\subsection{LMMAR de DOR À Pressão e DISfunçÃo TeMPOROMANDibular}

O teste de algometria foi desenvolvido e aprimorado com a finalidade de melhor quantificar a sensibilidade muscular ${ }^{7}$ em indivíduos saudáveis e pacientes portadores de diferentes desordens musculoesqueletais. ${ }^{50}$

É possível averiguar, de forma confiável, o LDP por meio de um algômetro manual, desde que alguns fatores sejam observados: tamanho da ponta ativa, velocidade de aplicação da pressão, grau de contração muscular, ${ }^{103}$ tempo de reação do indivíduo e do examinador e subjetividade do relato de dor. ${ }^{50}$ Além disso, o LDP varia com o gênero, grupos musculares e interindividualmente. ${ }^{50}$ Apesar da suscetibilidade a variações da determinação do LDP, têm-se relatado índices de concordância intra e inter examinadores entre bons e excelentes. ${ }^{50} \mathrm{O}$ algômetro utilizado neste estudo possui ponta ativa com diâmetro de $1 \mathrm{~cm}^{2}$, ( similar aos estudos de VISSCHER et al. ${ }^{166}$ e SILVA et al. ${ }^{144}$ ). A velocidade de aplicação da força foi de aproximadamente $0,5 \mathrm{~kg} / \mathrm{cm}^{2} / \mathrm{s}$, aplicada com os músculos em repouso (com os dentes mantidos separados e lábios unidos). ${ }^{103}$ Uma das limitações do presente estudo foi a tomada do LDP apenas uma vez em cada sítio muscular (em vez de 2 ou mais tomadas e posterior cálculo da média). ISSELÉE et al. ${ }^{62}$ verificaram que, em uma seqüência de 4 medições do LDP em uma mesma sessão, a primeira medição foi significativamente superior à segunda (realizadas com $30 \mathrm{~s}$ de intervalo), a terceira foi significativamente superior à segunda (realizadas com $5 \mathrm{~min}$ de intervalo) e a quarta foi significativamente inferior à terceira medição (intervalo de $30 \mathrm{~s}$ ). As medições realizadas após $30 \mathrm{~s}$ de intervalo (segunda e quarta) sofreram a influência da sensibilização dos nociceptores devido à medida anterior (primeira e terceira). Enquanto a medição realizada após 5 minutos de intervalo em relação à anterior (terceira medição) tendeu a fornecer valores similares à primeira. ORBACH; GALE $^{116}$ verificaram que, empregando-se intervalos de 4 a 5 minutos entre as medições de LDP nos músculos mastigatórios, não se observou nenhuma tendência de alteração entre as mesmas. Mesmo assim, consideraram mais indicada a realização de duas medições com intervalo de 4-5 min e o cálculo da média entre elas. Entretanto, outros estudos têm utilizado a verificação do LDP por meio de algômetro manual digital em apenas uma medição. SILVA et

\footnotetext{
${ }^{7}$ Limiar de dor à pressão (LDP) e tolerância à dor
} 
al. ${ }^{144}$ calcularam valores de corte de LDP para 4 sítios musculares (masseter e temporal) empregando apenas uma medição.

Embora os valores de LDP geralmente sejam maiores na primeira medição (quando o intervalo entre as medições é inferior a $5 \mathrm{~min}$ ) ${ }^{35}$ os valores médios do LDP no grupo controle ainda foram inferiores aos apresentados por Visscher ${ }^{167}$, em apenas 1 medição para cada sítio muscular: temporal anterior $\left(4,0 \mathrm{~kg} / \mathrm{cm}^{2}\right)$; temporal médio $\left(5,0 \mathrm{~kg} / \mathrm{cm}^{2}\right)$; temporal posterior $\left(5,7 \mathrm{~kg} / \mathrm{cm}^{2}\right)$; origem do masseter $\left(2,9 \mathrm{~kg} / \mathrm{cm}^{2}\right)$; corpo do masseter $(2,6$ $\left.\mathrm{kg} / \mathrm{cm}^{2}\right)$; inserção do masseter $\left(2,7 \mathrm{~kg} / \mathrm{cm}^{2}\right)$ e masseter profundo $\left(3,4 \mathrm{~kg} / \mathrm{cm}^{2}\right)$ (Tabela 12). Se o presente estudo tivesse realizado duas medições do LDP em cada sítio muscular (com intervalo de até $5 \mathrm{~min}$ ), provavelmente os valores médios seriam inferiores aos obtidos e ainda mais discrepantes dos valores de $\operatorname{VISSCHER}^{167}$ no grupo controle (GC). Ainda, a coerência dos valores obtidos no presente estudo com os valores de corte já validados ${ }^{144}$ demonstra a adequação do procedimento e a validade dos valores de LDP apresentados. 


\subsubsection{Relação Temporal e Gradiente Dose-Resposta}

\subsubsection{Grupo Controle}

Os BRUXÔMANOS assintomáticos apresentaram redução do LDP pós-PSG em 2 dos sete sítios musculares em relação ao LDP pré-PSG (Tabela 24). O que poderia, a priori, ser interpretado como uma evidência de que a atividade parafuncional teria contribuído para essa redução. Entretanto, os NÃO-BRUXÔMANOS assintomáticos também apresentaram redução significativa do LDP em 1 sítio muscular, em relação ao LDP pré-PSG.. Visto que $60 \%$ dos não-bruxômanos podem apresentar ARMM durante a noite. ${ }^{85}$ Cabe aqui um questionamento oportuno: “A redução do LDP em um sítio muscular entre os nãobruxômanos assintomáticos poderia estar relacionada a uma maior intensidade da ARMM desses indivíduos?"

Os testes de correlação entre ARMM e LDP pós-PSG poderiam fornecer dados sobre essa questão, entretanto, não houve correlação entre quaisquer parâmetros de ARMM e o LDP pós-PSG de nenhum dos sítios musculares nos não-bruxômanos assintomáticos (Tabela 28). Tais resultados descartam a possibilidade de que a redução do LDP pós-PSG em um sítio muscular (inserção do masseter) nos não-bruxômanos assintomáticos possa dever-se à atividade parafuncional noturna. Contribui ainda para essa conclusão a ausência de uma tendência de redução, mesmo não significativa, dos LDPs dos demais sítios musculares do mesmo subgrupo (Tabela 25).

De forma semelhante, apesar da redução do LDP pós-PSG em relação ao préPSG nos BRUXÔMANOS ASSINTOMÁTICOS, os testes de correlação se opuseram à hipótese de que essa redução pudesse estar relacionada ao bruxismo. Pois, todas as correlações significativas entre ARMM e LDP pós-PSG, nesse subgrupo, foram positivas (seis, quando foram considerados os sítios musculares dos lados esquerdo e direito separadamente - Tabela 27). Esses dados negam a hipótese de que, em indivíduos assintomáticos, a ARMM caracterizada ou não por BS relacione-se à redução do LDP matinal. Indicando a aceitação da hipótese nula.

Em amostras relativamente pequenas, a não significância dos resultados correm alto risco de representarem um erro tipo II, ou seja, de não verificar uma diferença onde ela 
realmente exista. Porém, deve-se lembrar que, ao se realizarem numerosas comparações para a verificação de um mesmo resultado (por exemplo, para cada subgrupo, foram realizados 28 testes de correlação: entre 4 determinantes da ARMM e 7 sítios musculares). Ao se realizar essa quantidade de testes, o risco de que resultados "estatisticamente significativos" surjam por mero acaso também aumenta. Portanto, essa situação é mais propícia à ocorrência do erro tipo I do que tipo II, o que minimiza a possibilidade de erro na interpretação de que não há relação entre a ARMM e o LDP pós-PSG em não-bruxômanos assintomáticos.

Esses resultados sugerem que indivíduos sem DTM, parecem ser "refratários" à ação "danosa" do BS. Indicando a necessidade de uma condição predisponente como, por exemplo, a sensibilidade periférica tecidual para que a atividade parafuncional noturna passasse a exercer alguma influência sobre a mesma.

Interessante notar que houve seis correlações positivas (variando de média a forte $-\mathrm{r}$ entre 0,62 e 0,75$)$ com $\mathrm{p}<0,05$. A despeito do risco de erro tipo I, devido ao grande número de comparações (28), a tendência positiva e os coeficientes das correlações sugerem que o aumento da ARMM não contribui para a redução do LDP matinal nos bruxômanos assintomáticos. Essa observação se contrapõe aos relatos de que o bruxismo pode levar à mialgia pós-exercício em indivíduos assintomáticos. ${ }^{153}$ Encontra-se bem documentada a elevação dos LDP musculares após realização de exercícios aeróbicos ou isométricos em indivíduos assintomáticos. ${ }^{71-73,147,163}$ As correlações positivas entre ARMM e LDP pós-PSG entre bruxômanos assintomáticos concorda com esses achados.

Alguns estudos testaram os efeitos da parafunção experimental sobre a intensidade da dor (EAV), ${ }^{10,48,153}$ limiar de dor à pressão (LDP), ${ }^{10,156}$ força oclusal voluntária máxima (FOVM) ${ }^{10}$ atividade eletromiográfica $(\mathrm{EMG}),{ }^{156}$ contração voluntária máxima $(\mathrm{CVM})^{156}$ e abertura bucal ${ }^{156}$ de indivíduos assintomáticos. De maneira geral, a literatura relata que a parafunção experimental leva ao desenvolvimento de níveis moderados de dor, sensibilidade e desconforto no primeiro dia após o exercício, ocorrendo remissão nos dias seguintes. ${ }^{10,48,153}$ Logo, o quadro clínico que se apresenta sob tais condições parece marginal e auto-limitante na população assintomática. É possível que as diferenças entre este e os demais estudos quanto ao surgimento de sintomatologia, deva-se às diferenças metodológicas 
[parafunção experimental (com duração e intensidade controladas) e ao BS clinicamente manifesto (com toda sua variabilidade temporal e inter-individual)].

Apesar da potencial possibilidade de avaliação do bruxismo, os estudos clínicos não têm fornecido dados precisos sobre o BS e suas conseqüências na população assintomática. Dentre as limitações metodológicas do estudo do BS em grandes populações, acredita-se que a maior delas seja a inviabilidade financeira da realização do exame PSG em uma amostra de tamanho considerável. Essa limitação, per se, leva ao emprego do auto-relato como método de diagnóstico mais viável. Entretanto, LAVIGNE et al. ${ }^{83}$ utilizaram um critério clínico bastante confiável para o diagnóstico do BS, minimizando os erros potencias do simples auto-relato e não envolvendo o alto custo do exame PSG.

Alguns autores têm estudado o BS em indivíduos assintomáticos por meio de exame PSG. As características da ARMM nos bruxômanos assintomáticos (epi/noite, epi/hora, b/hora e b/epi; duração, distribuição e amplitude dos episódios) não são diferentes daquelas dos bruxômanos com DMF. ${ }^{18-20,115}$ A despeito da similaridade nas características do BS, uma parcela desses indivíduos $(30 \%),{ }^{19}(33,3 \%)^{115}$ não desenvolve DMF, concordando com o percentual de bruxômanos assintomáticos do presente estudo $(34,5 \%)$. CAMPARIS ${ }^{18}$ apresentou que, mesmo com pequenos percentuais de estalido (30\%), sensação de mordida desconfortável (25\%), dor ou rigidez matinal (30\%) e ruídos nos ouvidos, (45\%) tais características não compõem um quadro clínico de DMF ou DTM e, nem mesmo representam a queixa dos indivíduos (queixa relacionada à bruxismo, desgaste e fratura dental).

A ausência de correlação entre ARMM e LDP pós-PSG nos bruxômanos assintomáticos sugere a "refratariedade" desses indivíduos à ação potencialmente danosa do BS quanto ao desenvolvimento de sintomatologia dolorosa.

\subsubsection{Grupo Experimental}

Tanto os bruxômanos quanto os não-bruxômanos do GRUPO EXPERIMENTAL apresentaram aumento do LDP pós-PSG em relação ao pré-PSG, em um sítio muscular para cada subgrupo (origem e corpo do masseter, respectivamente) (Tabela 30 e Tabela 31). Resultados "contrários ao previsto pela hipótese da associação entre BS e DMF." Um estudo $^{131}$ avaliou a eficácia de placas oclusais em reduzir a intensidade da dor facial e sua 
correlação com a redução do BS, e encontrou que, após 6 semanas de utilização das placas oclusais, indivíduos que não relatavam BS foram os únicos a relatar redução significativa da intensidade da dor nas 2 semanas prévias e que os que relataram BS não apresentaram melhora significativa em nenhum dos parâmetros de intensidade da dor com o uso das placas oclusais. "...Se considerado isoladamente, esse resultado poderia indicar que o BS é uma contra-indicação às placas oclusais, em pacientes com DMF". ${ }^{131}$ Entretanto, os autores indicam cautela devido ao grande número de testes estatísticos realizados e ao fato de ser um resultado isolado. Similarmente, o aumento do LDP pós-PSG em 1 dentre 7 sítios musculares tanto entre bruxômanos quanto não-bruxômanos com DMF, deve ser interpretado com cautela devido ao grande número de testes realizados ( 7 comparações para cada subgrupo), podendo, portanto, terem surgido por acaso. Se se realiza o ajuste do valor de $\alpha$ para sete comparações, a margem de erro aceitável para as mesmas passa a ser de 0,007. E, se se considera tal nível de significância, os aumentos dos LDPs pós-PSG assumem valores não significativos.

O teste de correlação de Pearson mostrou que, apesar do aumento do LDP pósPSG em relação ao pré-PSG na origem do masseter nos BRUXÔMANOS com DMF, houve duas correlações negativas e moderadas ${ }^{31}$ entre ARMM e LDP pós-PSG. Portanto, não é possível traçar um paralelo entre esse achado e a elevação do LDP pós-PSG nos bruxômanos com DMF. Ainda, a presença de apenas duas correlações com $\mathrm{p}<0,05$ dentre 56 comparações realizadas não suporta a presença de uma relação temporal ou gradiente doseresposta entre os mesmos, indicando, pelo contrário, alta probabilidade de erro tipo I. Ou seja, de que essas correlações, sejam conseqüências casuais do alto número de testes e que, portanto, não representem correlações clinicamente significativas.

Nesses casos, um recurso do qual se pode dispor para minimizar o risco de erro tipo I, é a correção do nível de significância necessário para que não se corra um risco maior que $5 \%$ ao se afirmar que, dentre as 56 comparações, alguma delas realmente é significativa. Um cálculo que pode ser realizado como forma de ajuste é a divisão do valor de "p" desejável $(0,05)$ pelo número de comparações realizadas $(28) .^{75}$ Desse modo, para que, dentre 56 comparações, se tenha um nível de confiabilidade de 95\%, o valor necessário de $\alpha$ deveria ser 0,001. Nenhuma das comparações realizadas atingiu um valor de $\alpha$ "adequado". O cálculo do tamanho da amostra necessária para a obtenção de um valor de $r=0,6$, com poder de $80 \%$ e $\alpha$ 
$=0,001$ é de 39 indivíduos. Se se considera o ajuste de $\alpha$, as correlações verificadas passam a ser não-significativas estatisticamente.

A ausência de correlações em número e significância suficientes entre ARMM e LDP pós-PSG, além do “inexplicável” aumento do LDP pós-PSG em relação ao LDP préPSG, nos bruxômanos com DMF, vão de encontro à associação encontrada na literatura e comprovada no presente estudo de forma objetiva. Sugere-se, portanto, a realização de estudos com amostra mais representativa.

Entre os NÃO-BRUXÔMANOS com DMF, verificaram-se cinco correlações

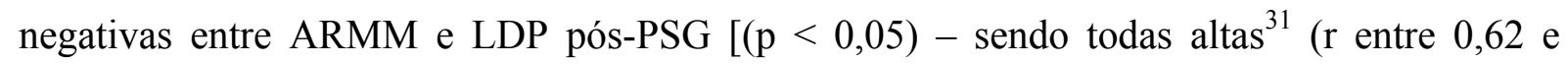
0,81)]. A despeito da elevação do LDP pós-PSG em relação ao LDP pré-PSG, as correlações encontradas entre a ARMM e os LDPs pós-PSG apontam para a possibilidade de relação temporal e gradiente dose-resposta entre ARMM e sensibilidade à palpação, nesse subgrupo (Tabela 34 e 35). O teste de regressão linear indicou que a ARMM exerceu influência entre $38 \%$ e $66 \%$ sobre a variabilidade dos LDPs pós-PSG.

Entretanto, caso se considere o valor de $\alpha$ ajustado para 56 comparações $(0,001)$, novamente, nenhuma das correlações atingiu tal nível de significância. Indicando que os achados dessa interação ARMM e LDP pós-PSG, bem como a comparação entre LDPs pré- e pós-PSG devem ser interpretados com cautela e que, estudos com uma amostra mais significativa e, se possível, com maior duração ainda precisam ser realizados.

Apesar da possibilidade de erro tipo I, os não-bruxômanos com DMF apresentaram indicativos mais consistentes de um aumento na sensibilidade muscular à palpação associada à ARMM (5 correlações negativas fortes, com influência entre 38 e 66\% $n=11)^{31}$, em comparação aos indivíduos assintomáticos (correlações positivas ou ausência de correlações significativas) - (Tabela 35). Ratificando que, na presença de um processo patológico muscular (características locais de sensibilização periférica e/ou central), a atividade parafuncional poderia (até certo ponto) exercer papel agravante.

Considerando-se o grupo experimental, independente do bruxismo, observou-se que, embora isoladamente, os parâmetros de ARMM tenham exercido influência sobre os LDPs pós-PSG, à medida que as variáveis independentes eram adicionadas aos modelos, o 
nível de significância dos mesmos reduzia-se (Tabela 36). Em geral os parâmetros de ARMM exerceram influência sobre a variabilidade do LDP pós-PSG (15\% a 23\%) no grupo experimental (Tabela 36). A incorporação da variável BS, predominantemente, levou à redução da significância dos modelos. Isso concorda com o fato de que tais correlações foram bem mais freqüentes entre os não-bruxômanos com DMF do que entre os bruxômanos (5 correlações negativas fortes : 2 correlações negativas moderadas e altas ). Clinicamente, os bruxômanos e não-bruxômanos com DMF não diferiram quanto à intensidade da dor (EAV) nos três momentos de avaliação (triagem, avaliações pré e pós-PSG - Tabela 10); idade, índice de DTM, abertura máxima, tempo do início da dor, presença de ruídos articulares, número de pontos sensíveis e escore de sensibilidade (Tabela 11) - características que, se distintas entre os grupos, poderiam atuar como fatores de confusão. É possível que os bruxomanos com DMF tenham a musculatura mais treinada do que os não-bruxômanos com DMF e que, portanto, reajam com menos sensibilidade às variações da ARMM.

A ausência de correlações significativas entre ARMM e LDP pós-PSG no grupo controle, suporta a idéia de que a influência da ARMM sobre a sensibilidade matinal à palpação pode estar associada à presença de uma condição de sensibilização, prévia ou concomitantemente, estabelecida (Tabela 36).

A sensibilização periférica na musculatura do sistema mastigatório é um dos mecanismos que, em última instância, promovem a sensação dolorosa frente a estímulos não nocivos (alodinia) ou a exacerbação da sensação dolorosa frente a estímulos potencialmente nocivos (hiperalgesia). STOHLER ${ }^{149}$ conceituou que "os mecanismos subjacentes à geração de sinais e sintomas incluem a sensibilização tecidual periférica, neuroplasticidade e sensibilização central dos sistemas anti- e pró-nociceptivos e neuroendócrino.”

De modo geral, esses achados precisam ser testados em uma amostra de tamanho mais significativo (única maneira de reduzir as possibilidades de erro tipo I e II simultaneamente $)^{17} \mathrm{e}$, preferencialmente, durante o maior número possível de noites. 


\section{6 INFLUÊNCIA DA DOR SOBRE A ARMM}

Em 1969, LASKIN $^{74}$ introduziu a teoria psicofisiológica da etiologia da DTM, segundo a qual hábitos parafuncionais decorrentes de tensão, fadiga muscular e mioespasmos gerariam a síndrome dor-disfunção miofascial, podendo levar a contraturas (por mioespasmos prolongados) ou degeneração articular (devido à função com o côndilo em posição anormal). Todas essas condições alterariam o padrão mastigatório que, por sua vez, reforçaria o espasmo original e a dor. A partir daí, surgiu um grande interesse em registrar a atividade EMG de músculos doloridos. O relato de atividade EMG aumentada passou a ser indicativo de contratura, espasmos ou contrações espásticas. TRAVELL; RINZLER; HERMAN ${ }^{159}$ explicaram a evolução da dor aguda para crônica com a hipótese de que a dor e a disfunção eram ligadas reciprocamente: disfunção causando dor que, por sua vez, reforçaria a disfunção, construindo um "ciclo vicioso" mantenedor dessa condição.

A sensibilidade muscular à palpação dos portadores de DTM tem sido relacionada ao aumento da atividade muscular postural. Entretanto, estudos recentes têm encontrado uma diferença de aproximadamente $2 \mu \mathrm{V}$ na atividade EMG de repouso entre pacientes com DTM e indivíduos controle, ${ }^{35,47}$ não sendo um aumento que justifique a condição dolorosa. Um estudo recente, ${ }^{15}$ entretanto, encontrou aumentos consideráveis na atividade EMG de repouso em uma população com DMF e dor neuropática em relação a indivíduos controle. Mas os autores atribuíram esse aumento a um mecanismo central e não ao ciclo vicioso. Em geral, esse aumento também ocorre nos músculos antagonistas, gerando um efeito "splint".

A hipótese de que a "disfunção" característica de diversos tipos de dor muscular crônica seja uma adaptação protetora normal, e não a causa da dor, foi proposta em 1991, por LUND et al. ${ }^{94}$ Os autores questionaram o efeito da dor sobre a manutenção ou aumento da atividade muscular fechando um "ciclo-vicioso". Esse questionamento baseia-se nas evidências de que a dor modifica a função por meio da redução do impulso agonista e aumento da co-contração antagonista. Ou seja, a dor promoveria um efeito inibitório sobre os músculos mastigatórios agonista como um mecanismo de proteção. 
Diante das evidências expostas por LUND et al., ${ }^{94}$ LAVIGNE et al. ${ }^{84}$ investigaram a influência da dor na musculatura mastigatória sobre o padrão EMG de BS e a hipótese de que ocorreria menor atividade de BS entre os indivíduos com dor nessa musculatura. Foram analisados treze bruxômanos [seis sem dor ou sensibilidade nos músculos mastigatórios e sete com relato de dor matinal ("não miofascial") nos músculos elevadores da mandíbula]. Observou-se que na presença de dor não-miofascial, o número de episódios/hora foi $40 \%$ menor que na ausência de dor. Esses achados concordam com a sugestão de que a dor muscular leva à redução da atividade muscular agonista. ${ }^{94}$

No presente estudo, a comparação das variáveis oromotoras entre os bruxômanos com e sem DMF contrariou a hipótese do mecanismo de adaptação à dor. Os bruxômanos com DMF apresentaram mais bursts/episódio do que os bruxômanos sem DMF ( $p=0,033)$. Caso se considere o ajuste do valor de $\alpha$, o mesmo passa a ser de 0,013 tornando a diferença não significativa. Apesar de não-significativo, ocorreram 16\% mais bursts/episódio e 15,5\% mais bursts/hora nos bruxômanos com DFM em relação aos sem DMF.

A discrepância entre esses achados e os de LAVIGNE et al. ${ }^{82}$ e ARIMA; ARENDT-NIELSEN; SVENSSON ${ }^{9}$ pode dever-se às diferentes populações estudadas. Ambos os estudos ${ }^{9,82}$ observaram redução na ARMM durante o sono em bruxômanos com relato de dor/desconforto na musculatura mandibular. LAVIGNE et al. ${ }^{82}$ excluíram pacientes com DFM a fim de evitar que fatores relacionados à cronicidade da dor pudessem reduzir a eficiência do sono ou outros parâmetros (ex.: tempo total de sono ou latência do sono), podendo, levar à redução do índice episódios por hora, e à impossibilidade de identificar se a redução ocorrida dever-se-ia à dor muscular per se, ou à alteração dos parâmetros do sono. ARIMA; ARENDT-NIELSEN; SVENSSON $^{9}$ usaram como critério para classificar os bruxômanos a resposta à seguinte pergunta: "Você sente regularmente rigidez (stiff); sensação de aperto (tight) e/ou cansaço (tired) em seus maxilares pela manhã?” Os indivíduos que respondessem sim à questão eram considerados bruxômanos com dor. Todos os indivíduos desse grupo relataram dor ou desconforto na musculatura mandibular na manhã da noite prévia ao teste (EAV 13,0 \pm 4,9 mm). Apesar dos valores de EAV, a pergunta usada como critério não usa palavra dor (pain). No presente estudo, os bruxômanos com DMF apresentaram intensidade de dor média nos últimos seis meses de 43,2 $\pm 26,2 \mathrm{~mm}$ e 
intensidade de matinal (pós-PSG) de 12,2 \pm 18,1 mm. Além disso, a DMF representou um quadro clínico, cujo critério de diagnóstico envolveu queixa de dor, cronicidade e número mínimo de sítios musculares sensíveis à palpação, posteriormente comprovada pelos valores de LDP.

Como discutido previamente, a fim de evitar a ocorrência de fatores de confusão relacionados ao sono, foram excluídos da amostra quaisquer indivíduos com relato de desordens do sono ou com alguma manifestação das mesmas durante a primeira noite de exame PSG. Assim, os pacientes com DMF estudados não apresentaram diferenças estatisticamente significativas quanto aos parâmetros do sono (eficiência ou distribuição das fases do sono) - como poderia ter ocorrido devido à cronicidade da dor (Tabela 39).

Tomando-se a amostra de um estudo prévio ${ }^{115}$ (bruxômanos com e sem DTM) testou-se a mesma hipótese. Diferindo do presente estudo quanto à homogeneidade e tamanho da amostra [8 bruxômanos com DTM miogênica e/ou artrogênica versus 4 bruxômanos sem DTM], os testes mostraram que os bruxômanos com DTM apresentaram aumento de 21,7\% ( $\mathrm{p}=0,04)$ no número de bursts/hora e de 19,8\% no número de bursts/episódio $(\mathrm{p}=0,06)$. Os resultados obtidos por ambos os estudos sugerem que não apenas a condição dolorosa presente não se associou com menor atividade de BS, pelo contrário, relacionou-se com ARMM aumentada. Sugere-se cautela, porém, em concluir sobre relações de causalidade, pela mesma razão exposta previamente: desenho transversal do estudo.

Visando à análise do aspecto temporal dessa relação, realizaram-se testes de correlação entre os LDPs pré-PSG e a ARMM nas amostras de bruxômanos e nãobruxômanos com e sem DMF.

Os NÂO-BRUXÔMANOS assintomáticos apresentaram três correlações negativas entre LDP pré-PSG (lados esquerdo e direito considerados separadamente) e ARMM (Tabela 44) com $\mathrm{r}^{2}$ indicando a influência do LDP pré-PSG sobre a variabilidade da ARMM entre $20 \%$ a $25 \%$ (indicando baixo poder de previsibilidade). Os NÃOBRUXÔMANOS com DMF, apresentaram três correlações também negativas entre LDP préPSG (lados esquerdo e direito considerados separadamente) e ARMM, com $\mathrm{r}^{2}$ indicando influência moderada da DMF sobre a variabilidade ARMM de 44\% a 53\%. Os 
BRUXÔMANOS com DMF apresentaram apenas 2 correlações significativas, também negativas entre os LDPs pré-PSG e ARMM, com $r^{2}$ indicando baixa influência da DMF sobre o BS $(22 \%$ a $26 \%)$

Ou seja, LDPs prévios menores correlacionaram-se com mais ARMM e viceversa, fato que não suporta a hipótese do mecanismo de adaptação à dor nesses subgrupos. Para que as correlações entre LDP pré-PSG e ARMM indicassem a atuação do mecanismo de adaptação à dor, essas deveriam ser positivas. Pois, limiares de dor menores representam mais dor.

Apenas os BRUXÔMANOS assintomáticos apresentaram correlações positivas entre o LDP pré-PSG (considerados separadamente) e ARMM (Tabela 40), concordando com a hipótese do mecanismo de adaptação à dor. ${ }^{9,82,94} \mathrm{O}$ teste de regressão linear mostrou que os LDPs pré-PSG exerceram influência moderada (40\% a 53\%) sobre a variabilidade da ARMM.

Na presença de DMF, não se encontraram evidências da atuação do mecanismo adaptativo (correlações positivas). É possível que fatores relacionados à DMF interfiram, inibindo-o ou mascarando-o. Além disso, mesmo na ausência de DMF, os bruxômanos também não apresentaram evidências do mesmo. E, no subgrupo que reuniu as duas características (presença de DMF e ausência de BS), as correlações negativas tornaram-se significativas e em maior número (cinco - quando não houve distinção entre os os lados esquerdo e direito)- Tabela 44.

Isso sugere que o mecanismo de adaptação à dor tenderia a ocorrer em situações de intensa ARMM (BS) associada à ausência de dor ou dor leve (não-miofascial). Há, entretanto, a necessidade de estudos mais abrangentes, com amostra mais significativa de cada subgrupo para confirmação dessa hipótese. Pois, baseando-se no risco de erro tipo I, se se considera o $\alpha$ ajustado $(0,001)$, nenhuma correlação atingiu o nível de significância "adequado".

A literatura é controversa ao analisar atividade EMG de pacientes com diferentes quadros clínicos de DTM e relacionar os achados à influência da dor. Em geral, diferenças entre as amostras (subgrupo de DTM, severidade e cronicidade da dor) e metodologias são as 
responsáveis pelos resultados, às vezes, aparentemente contraditórios. Ao analisar a atividade EMG de repouso ou postural em populações com e sem DTM, encontram-se na literatura resultados distintos: 1) ausência de diferenças na atividade EMG entre os grupos, ${ }^{118} 2$ ) atividade significativamente aumentada nos grupos com dor ${ }^{15}$ e 3) leve aumento de aproximadamente $2 \mu \mathrm{V}$ nos pacientes com dor. ${ }^{47}$ Porém, a população estudada por PAESANI et al. ${ }^{118}$ era composta por pacientes com desarranjos internos da ATM; enquanto BODERÉ et al. ${ }^{15}$ compararam grupos de pacientes com DMF, dor neuropática, desarranjos articulares e assintomáticos, confirmando os achados de PAESANI et al. ${ }^{118}$ quanto à não elevação significativa da atividade EMG de repouso dos músculos masseter e temporal do grupo com desarranjos internos em relação ao grupo controle. E, GLAROS et al. ${ }^{47}$ empregaram uma amostra de pacientes com DMF com quadro clínico aparentemente bem menos severo que o BODERÉ et al. ${ }^{15}$ Essa comparação ilustra o poder de influência que características inerentes à condição estudada exercem sobre os resultados dos estudos.

A fim de minimizar as diferenças clínicas entre as populações deste e dos estudos de LAVIGNE et al. ${ }^{82}$ e ARIMA; ARENDT-NIELSEN; SVENSSON. ${ }^{9}$ foram selecionados do grupo experimental apenas os bruxômanos com relato de intensidade de dor leve ao questionário ( $\mathrm{n}=7$ - Tabela 45). Não houve diferenças estatisticamente significativas entre as variáveis oromotoras desses subgrupos, ocorrendo apenas 1 correlação positiva entre o LDP pré-PSG da origem do masseter e b/hora. Apesar de não ter ocorrido menor intensidade de ARMM nos sete bruxômanos com DMF leve, o fato desse subgrupo não ter apresentado maior intensidade de ARMM em relação aos bruxômanos controle e a presença de uma correlação positiva entre um LDP pré-PSG e bursts/hora $(r=0,77, p=0,04)$, são indícios da influência que a severidade do quadro clínico pode exercer sobre o mecanismo de adaptação à dor.

Um estudo polissonográfico ${ }^{84}$ mostrou redução da ARMM em bruxômanos com dor facial (não miofascial) em relação a bruxômanos sem dor facial, sugerindo que a dor poderia atuar como fator inibitório da ARMM, como um mecanismo de proteção - similar ao modelo de adaptação à dor proposto por LUND et al. ${ }^{94}$ Talvez, por tratar-se de uma amostra de bruxômanos com e sem DMF, não se tenham verificado resultados comparáveis. Com exceção do número de bursts/episódio, o qual foi significativamente maior nos bruxômanos 
com DMF, não houve diferenças entre as demais variáveis oromotoras (episódios/noite, episódios/hora e bursts/hora) dos bruxômanos com e sem DMF, concordando com os achados de CAMPARIS, ${ }^{18}$ que também não verificou diferenças estatisticamente significativas entre as variáveis oromotoras de bruxômanos com e sem DMF, não dando suporte à presença do mecanismo de adaptação à dor sobre o BS de pacientes com DMF crônica. No entanto, a maior intensidade do BS nos pacientes com DMF em relação aos bruxômanos sem DMF encontrada neste estudo mantém-se como divergência entre este e os demais estudos. 


\subsection{CONFIABILIDADE dO EXAME CĹNICO de BRUXISMO}

A literatura relata a baixa concordância do diagnóstico de bruxismo por meio do auto-relato versus exame físico (características físicas de apertamento e ranger de dentes ${ }^{\S \S}$ ). ${ }^{89}$ LOBBEZOO-SCHOLTE et al. ${ }^{88}$ observaram que mais pacientes com DTM miogênica relataram apertamento ou ranger de dentes do que os demais subgrupos de DTM (deslocamento de disco com e sem redução, osteoartrose e subgrupo misto), ao passo que, ao exame físico, o bruxismo distribuiu-se equitativamente entre os grupos. Embora o presente estudo não tenha comparado a freqüência de auto-relato de BS entre diferentes subgrupos de DTM, evidenciou-se que o auto-relato de BS no grupo controle (sem DMF) apresentou baixa sensibilidade $(40 \%)$, demonstrando uma tendência ao diagnóstico incorreto (maior percentual de falso-negativos). Por outro lado, o auto-relato de BS na população com DTM apresentou sensibilidade de $76 \%$, valor acima do nível mínimo recomendado $(75 \%) .{ }^{170}$ Isso reflete a discrepância nos níveis de consciência do hábito parafuncional entre as populações, indicando que a ausência de sintomatologia contribui para o desconhecimento do hábito, pois o indivíduo não sente necessidade de se auto-observar quanto a isso. $\mathrm{O}$ oposto ocorreu em relação à especificidade. Pacientes de DMF tenderam a relatar BS mais frequentemente (especificidade 66\%) do que a população assintomática (especificidade 79\%). A presença de sintomatologia dolorosa parece criar tendência nos pacientes a atribuírem-na ao hábito parafuncional (muitas vezes por sugestão do próprio dentista, médico ou familiar), gerando, por conseqüência, maior número de falso-positivos (Tabela 60).

Para a amostra total, o ECB apresentou $60 \%$ de sensibilidade e $71 \%$ de especificidade (valores inferiores ao mínimo recomendado para um teste de diagnóstico: 75\% e $90 \%$, respectivamente) ${ }^{170}$ (Tabela 55). Se se considera a influência que a DMF possa ter exercido sobre a confiabilidade do diagnóstico clínico, observa-se que, no grupo experimental, a sensibilidade aumenta (89\%) e a especificidade cai $(63 \%)$ - representando maior ocorrência de falso-positivos. Enquanto no grupo controle, a sensibilidade de $36 \%$ e a especificidade de $72 \%$ indicam valores inaceitáveis de resultados falso-negativos.

$\S \S$ Os autores não descrevem quais características físicas evidenciaram apertamento. O exame físico de ranger de dentes baseou-se na presença de desgaste dentário. 
Visto que, a repercussão clínica da sensibilidade e da especificidade de um teste de diagnóstico varia com a condição e a população estudada, pode-se tecer o seguinte raciocínio: considerando-se o BS como fator de risco da DMF, na população sintomática, a sensibilidade seria mais importante que a especificidade, pois, resultados falso-negativos privariam o paciente de medidas terapêuticas conservadores (ex.: placas oclusais), que poderiam, no mínimo atuar como placebo ou proteção das estruturas musculares e articulares. Ao passo que resultados falso-positivos implicariam em ônus desnecessário ao paciente.

Já em indivíduos assintomáticos, a especificidade seria mais importante. Resultados falso-positivos acarretariam na tomada de medidas totalmente desnecessárias e ônus adicional. Resultados falso-negativos privariam o indivíduo de alguma medida protetora, mas provavelmente desnecessária, visto que, em indivíduos assintomáticos não há evidências de que o BS, per se, possa atuar como iniciador de sintomatologia dolorosa persistente.

Essa análise relativamente simplista não leva em conta as possíveis conseqüências do BS à parte da DMF: desgaste dentário excessivo e fratura dentária, podendo levar à sensibilidade por exposição dentinária; ${ }^{* * *}$ trauma periodontal secundário; pericementite, $^{* * *}$ abfracções; ${ }^{* * *}$ danos às vezes irreversíveis a tratamentos restauradores (muitas vezes onerosos); ${ }^{* * *}$ dano potencial às estruturas do sistema estomatognático (sem sintomatologia dolorosa), por exemplo, desarranjos internos da ATM e cansaço mandibular. ${ }^{\dagger \dagger \dagger}$ Esses aspectos tornam importante a sensibilidade do diagnóstico também para a população assintomática.

*** Baseado em observações clínicas

†† Por se tratarem, na maioria das vezes, de condições clínicas multifatoriais, ainda não há evidência científica que suporte a associação entre muitos dos itens dessa lista de "danos em potencial” e BS. Entretanto, há evidências de associação entre relato de bruxismo e: desgaste dentário98. Magnusson T, Egermark I, Carlsson GE. A prospective investigation over two decades on signs and symptoms of temporomandibular disorders and associated variables. A final summary. Acta Odontol Scand. 2005 Apr;63(2):99-109. (caninos e pre-molares em homens de 20 a 40 anos),140. Seligman DA, Pullinger AG, Solberg WK. The prevalence of dental attrition and its association with factors of age, gender, occlusion, and TMJ symptomatology. J Dent

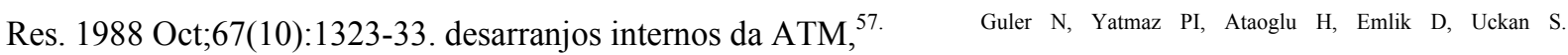
Temporomandibular internal derangement: correlation of MRI findings with clinical symptoms of pain and joint sounds in patients with bruxing behaviour. Dentomaxillofac Radiol. 2003 Sep;32(5):304-10. ruídos articulares e cansaço mandibular.98. 
Do mesmo modo, para a população sintomática a análise não é tão simples, visto que as medidas terapêuticas conservadoras comumente empregadas para BS, podem atuar também sobre a sintomatologia dolorosa, independentemente do bruxismo, por exemplo as placas oclusais, ${ }^{131}$ a higiene do sono e ainda, o controle de ansiedade/estresse.

Em razão disso, não se deve menosprezar a importância da especificidade do diagnóstico de BS para a população com DMF e de sua sensibilidade para a população assintomática.

Porém, o diagnóstico final do ECB não obedeceu a um critério específico de escores, e sim, à análise subjetiva do examinador. Optou-se por isso a fim de verificar a confiabilidade do diagnóstico clínico de BS, como ele geralmente é feito na clínica odontológica diária - de forma não padronizada e empírica. Ao mesmo tempo em que o ECB, assim concebido, forneceu essa informação, configurou-se uma limitação: quais parâmetros do ECB foram mais confiáveis?

A $\operatorname{ASDA}^{7}$ considera como critério diagnóstico de BS o relato de ranger ou apertar os dentes durante o sono, seguido de um ou mais dos seguintes critérios: desgaste anormal dos dentes (item 7 do ECB - facetas de desgaste); ruídos de ranger de dentes (item 6 do ECB - relato de terceiros) e desconforto muscular (item 2 do ECB - cansaço). O diagnóstico de BS na amostra total, segundo esse critério, alcançou sensibilidade de $64 \%$ e especificidade de $61 \%$, seguindo a mesma tendência do resultado subjetivo do ECB, aumentando em sensibilidade e caindo em especificidade no grupo com DMF e apresentando a tendência oposta no grupo controle. Considerando-se a amostra total, a confiabilidade de ambos os testes (ASDA e análise subjetiva do ECB foram bem similares). Buscou-se estabelecer, portanto, a combinação de respostas ao ECB com a maior confiabilidade possível para ambas as populações.

$\mathrm{Na}$ amostra geral, o auto-relato de BS associou-se significativamente com BSPSG obteve boa concordância $(\mathrm{k}=0,71)$ e alta sensibilidade (79\%) (Tabela 59). O relato de terceiros obterve a mais alta especificidade (84\%), apesar da não associação com BS-PSG (p 
$=0,153)$, obteve o segundo maior valor de kappa $(0,56)$. Após sucessivos testes, obtiveram-se critérios distintos para a população com DMF e assintomática (Tabela 63).

Considerando-se isoladamente, a sensibilidade para o grupo com DMF e a especificidade para o grupo assintomático, o critério da ASDA apresentou os valores mais elevados (79\% e 65\%, respectivamente) - Tabela 58. Pouco superiores aos valores isolados do critério derivado do ECB (71\% e 59\%, respectivamente) - Tabela 63. Não obstante, o critério ASDA apresentou as complementares (especificidade para o grupo com DMF e sensibilidade para o grupo assintomático) bem mais baixas (55\% e 33\%, respectivamente) do que o critério derivado do ECB (73\% e 71\%, respectivamente). Isso resultou na acuidade superior do critério derivado do ECB (73\% para o grupo com DMF e 62\% para o grupo assintomático) em relação ao critério ASDA (70\% para o grupo com DMF e 55\% para o grupo assintomático).

Obviamente, esses valores são relativos e dependentes do diagnóstico PSG (gold standard). É sabido, porém, que um verdadeiro gold standard deveria apresentar $100 \%$ de acuidade, característica que o exame PSG não possui, a despeito de sua excelente confiabilidade. Por essa razão, há necessidade de outros estudos de validação do ECB (semelhante ou modificado) que empregue como gold standard um outro critério, ex: o mesmo usado por LAVIGNE et al. ${ }^{83}$ no estudo de validação do exame PSG. 
CONCLUSDEES 


\section{CONCLUSÕES}

Os resultados do presente estudo sugerem que:

1) Encontrou-se associação estatisticamente significativa entre bruxismo do sono e dor miofascial.

2) A dor miofascial pode atuar como fator predisponente ou de suscetibilidade ao esforço muscular.

3) Aumentos na atividade rítmica dos músculos mastigatórios não se relacionam com menores índices de limiar de dor à pressão matinal em indivíduos assintomáticos.

4) Dentre os pacientes de dor miofascial, os não-bruxômanos parecem ser mais suscetíveis a níveis mais elevados de atividade rítmica dos músculos mastigatórios do que os bruxômanos. Isso pode sugerir que os bruxômanos possuem musculatura mais bem treinada e, portanto, mais resistente às variações da atividade rítmica dos músculos mastigatórios.

5) Não houve indícios de atuação do mecanismo de adaptação à dor nos pacientes com DMF (bruxômanos ou não). Mas, entre os bruxômanos assintomáticos, limiares de dor mais baixos correlacionaram-se com menos atividade de BS (com influência de até 53\%). Ou seja, bruxômanos assintomáticos com LDPs mais baixos podem apresentar ARMM menos intensa.

6) O Exame Clínico de Bruxismo não alcançou ou níveis mínimos necessários de sensibilidade $(75 \%)$ e especificidade $(90 \%)$. Mas pode ser utilizado como ferramenta complementar se utilizado com bom senso na clínica diária, mostrando-se mais adequado para a população com $\mathrm{DMF}$

7) Os maiores índices de sensibilidade e especificidade do Exame Clínico de Bruxismo foram obtidos para: a resposta positiva a pelo menos 3 perguntas do questionário (dentre estas, auto-relato ou relato de terceiros de bruxismo do sono), quando aplicado em pacientes com DMF. 
ANEXOS 
ANexo 1 
ANeXo 2 


\title{
ANEXO 3
}

\author{
Universidade de São Paulo \\ Faculdade de Odontologia de Bauru \\ Al. Dr. Octávio Pinheiro Brisolla, 9-75 - Bauru-SP - CEP 17012-901 - C.P. 73 \\ PABX (0XX14)235-8000 - FAX (0XX14)223-4679
}

\section{CARTA DE INFORMAÇ̃̃O AO PACIENTE}

A Faculdade de Odontologia de Bauru - USP realiza esta pesquisa, com a finalidade de verificar a existência de uma relação causa-e-efeito entre o bruxismo (hábito inconsciente de ranger os dentes durante o sono) e Disfunção têmporo-mandibular-DTM (dor na articulação da mandíbula e/ou nos músculos da face). Para tanto, os participantes da pesquisa passarão por um exame que constará de questionário, exame clínico e radiografia panorâmica (acompanhada ou não de radiografia da ATM), a fim de diagnosticar a presença ou a ausência de sinais e sintomas de algum dos tipos de alterações na ATM. Em seguida, todos os participantes da pesquisa dormirão por duas noites consecutivas no Instituto de Medicina do Sono - Dr. Alberto Luiz Moura dos Santos, situado à rua Dr. Annis Dabus, 1-23, Bauru, SP do Sono. Durante o sono, serão realizados um eletromiograma (EMG), um eletroencefalograma (EEG) e um eletrooculograma (EOG) e (ECG), além do registro áudio visual dos episódios de bruxismo (ranger de dentes acompanhado de som). Para a realização destes exames é necessária a colocação de eletrodos (peças flexíveis adesivas) em alguns pontos do corpo do paciente: na cabeça, no queixo, na lateral da face e no peito. Esta seqüência de exames pode trazer benefícios ao paciente, tanto pelo fato de diagnosticar o tipo de alteração da articulação têmporo-mandibular que o paciente apresenta, bem como a presença ou ausência de bruxismo e outros distúrbios do sono. Uma vez diagnosticada alteração articular, o paciente será encaminhado para tratamento na clínica de Disfunção Têmporo-Mandibular da própria Faculdade bem como no Curso de Oclusão realizado nas dependências do Instituto de Ensino Odontológico (IEO). A privacidade dos pacientes será preservada em todos os momentos deste trabalho. Assim, esperando contar com sua colaboração, antecipadamente agradecemos.

Atenciosamente,

Paciente ou responsável

Prof. Dr. Carlos dos Reis Pereira Araújo Orientador
Leylha Maria Oliveira Nunes

Cirurgiã dentista, doutoranda em Reabilitação Oral FOB-USP 
ANEXO 3

Universidade de São Paulo

Faculdade de Odontologia de Bauru

Al. Dr. Octávio Pinheiro Brisolla, 9-75 - Bauru-SP - CEP 17012-901 - C.P. 73

PABX (0XX14)235-8000 - FAX (0XX14)223-4679

\section{CARTA DE INFORMAÇÃO AO PACIENTE TERMO DE CONSENTIMENTO LIVRE E ESCLARECIDO}

Pelo presente instrumento que atende às exigências $\begin{gathered}\text { legais, } o(a) \\ \text { portador(a) }\end{gathered}$
Senhor(a)

da cédula de identidade $\mathrm{n}^{\circ} \ldots$, expedido por
Após leitura minuciosa da CARTA DE INFORMAÇÃO AO PACIENTE, devidamente explicada em seus mínimos detalhes, ciente dos serviços e procedimentos aos quais será submetido, não restando quaisquer dúvidas a respeito do exposto, firma seu CONSENTIMENTO LIVRE E ESCLARECIDO em concordância em participar da pesquisa proposta.

Fica claro que o paciente ou seu representante legal pode a qualquer momento retirar seu CONSENTIMENTO LIVRE ESCLARECIDO e deixar de participar do estudo alvo da pesquisa e ciente que todo trabalho realizado torna-se informação confidencial guardada por força do sigilo profissional (Art. $9^{\circ}$ do Código de Ética Odontológica).

Por estarem entendidos e conformados, assinam o presente termo.

Bauru-SP, de de

Paciente ou responsável

Prof. Dr. Carlos dos Reis Pereira Araújo Orientador
Leylha Maria Oliveira Nunes Cirurgiã dentista, doutoranda em Reabilitação Oral FOB-USP 


\section{ANEXo 4}

Data

\section{QUESTIONÁRIO INICIAL}

\section{Dados Pessoais}

Nome

Data de Nascimento

Sexo M( ) F ( )

Endereço residencial

Bairro

Cidade Idade

Telefone residencial

Telefone trabalho

CEP

\section{CRITÉRIOS DE EXCLUSÃO INICIAIS}

\section{QUESTIONÁRIO}

Você apresenta alguma queixa de sono?

Sua principal queixa de sono compreende: (marque todas se achar necessário e descreva)

( ) Problemas para dormir a noite

( ) Sonolência durante o dia

( ) Comportamento indesejado durante o sono (explique abaixo)

( ) Outros

Favor descreva os seus problemas de sono:

Sofre de insônia?

Toma remédios ou álcool para dormir?

Acorda muitas vezes durante a noite?

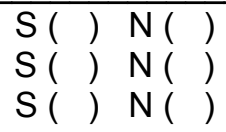

Profissão Celular

Por favor dê notas para você circulando o valor que melhor representa o grau ou a freqüência do que mais o aborrece em um determinado problema. É muito importante responder todos os itens.

\begin{tabular}{|c|c|c|c|c|c|c|}
\hline 1 & 2 & 3 & 4 & 5 & 6 & 7 \\
\hline $\begin{array}{c}\text { Nada ou } \\
\text { nunca }\end{array}$ & $\begin{array}{c}\text { Muito leve } \\
\text { ou raros }\end{array}$ & $\begin{array}{c}\text { Leve ou } \\
\text { às vezes }\end{array}$ & $\begin{array}{c}\text { Moderado ou } \\
\text { ocasionalmente }\end{array}$ & $\begin{array}{c}\text { Bastante ou } \\
\text { freqüente }\end{array}$ & $\begin{array}{c}\text { Muito ou muito } \\
\text { freqüente }\end{array}$ & $\begin{array}{c}\text { Excessivo } \\
\text { ou sempre }\end{array}$ \\
\hline
\end{tabular}

$1-1234567$

$2-1234567$

$3-1234567$

$4-1234567$

$5-1234567$

$6-1234567$

$7-1234567$

$8-1234567$

$9-1234567$
Quantas vezes você cai no sono durante o dia quando está parado ou sem fazer nada?

Quantas vezes a pessoa que dorme com você percebeu que você pára de respirar durante o sono?

Quantas vezes o seu sono é perturbado por outros problemas respiratórios?

Descreva:

Quão importante é o problema do ronco para você?

Quão importante é o problema de pegar no sono?

Quantas vezes você acorda durante a noite e tem dificuldade em voltar a dormir?

Quantas vezes a pessoa que dorme com você notou que suas pernas se mexem ou chutam durante o seu sono?

Quantas vezes você teve problemas com suas pernas não pararem de se mexer ou formigar a noite?

Quantas vezes você já se sentiu complemente paralisado quando acabou de pegar no sono ou de acordar? 


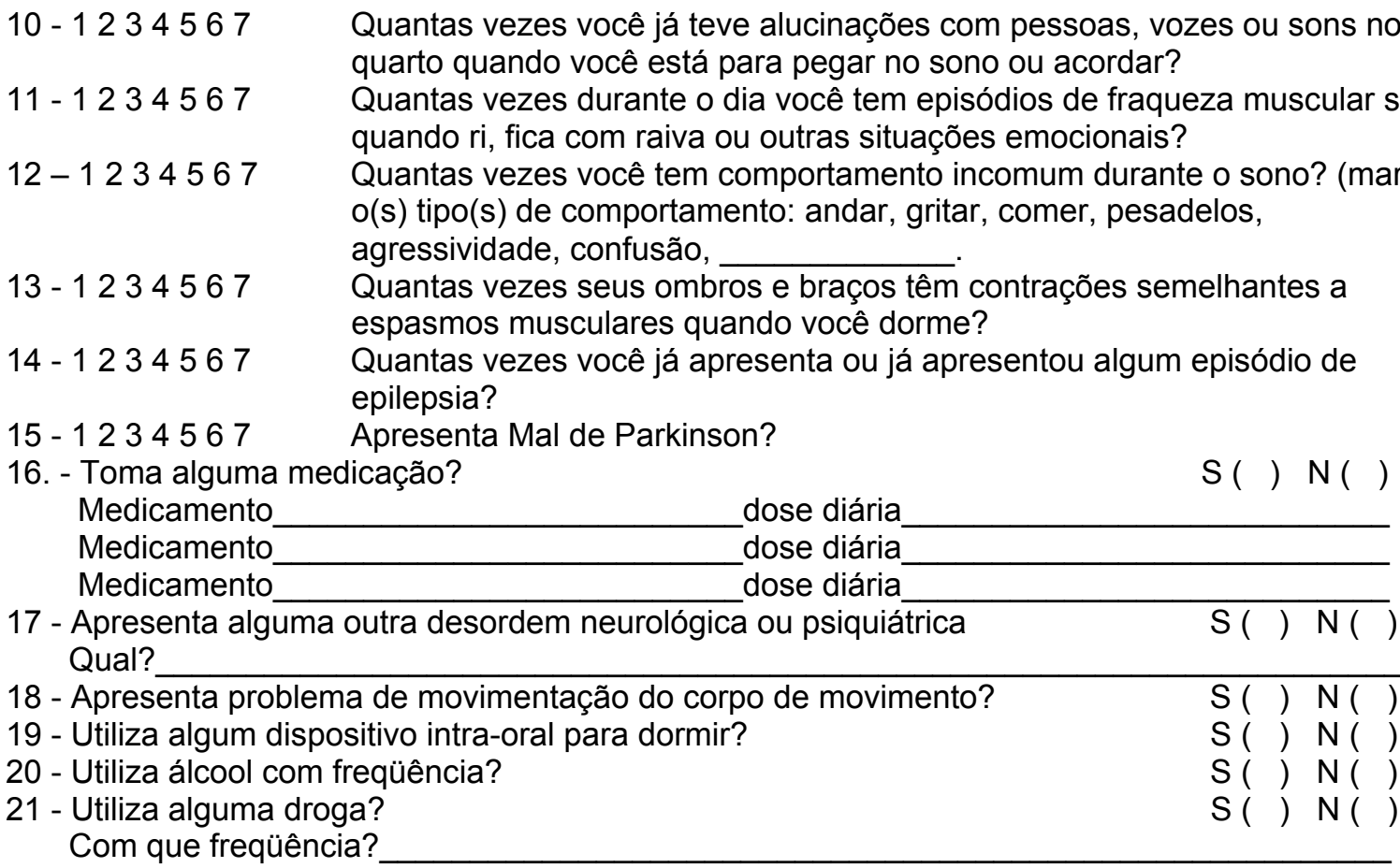

Tente ser específico nas questões seguintes evitanto usar aproximações (Por exemplo, não use "8 ou 10 da noite" ou então " 5 ou 6 vezes").

22 - A que horas você normalmente vai para a cama?

23 - Quanto tempo você leva normalmente par apegar no sono após decidir dormir?

24 - Quantas horas de sono total você consegue por noite: (Não contar com tempo na cama acordado)

25 - A que horas normalmente você acorda pela manhã?

\section{AVALIAÇÃO DENTÁRIA E OCLUSAL}

\begin{tabular}{|l|l|l|l|l|l|l|l|l|l|l|l|l|l|l|l|}
18 & 17 & 16 & 15 & 14 & 13 & 12 & 11 & 21 & 22 & 23 & 24 & 25 & 26 & 27 & 28 \\
\hline 48 & 47 & 46 & 45 & 44 & 43 & 42 & 41 & 31 & 32 & 33 & 34 & 35 & 36 & 37 & 38
\end{tabular}

Próteses

Trespasse vertical_ $\mathrm{mm}$

Trespasse horizontal_ $m$ _

Mordida aberta anterior

$\mathrm{S}(\mathrm{N}) \mathrm{N}($ )

Mordida cruzada unilateral

$\mathrm{S}(\mathrm{N}) \mathrm{N}($ )

Apresenta dois ou mais dentes perdidos? (exceto os terceiros molares)? $\quad \mathrm{S}($ ) $\mathrm{N}($ )

Utiliza prótese dental removível?

$\mathrm{S}(\mathrm{)}) \mathrm{N}($ ( )

Interferência no arco de fechamento com $\mathrm{RC} / \mathrm{MIH}>5 \mathrm{~mm}$

$\mathrm{S}(\mathrm{N}) \mathrm{N}()$ 


\author{
ANEXO 5 \\ QUESTIONÁRIO DE AVALIAÇÃO OBJ ETIVA \\ Data \\ Dados Pessoais \\ Nome \\ Data de Nascimento \\ Sexo $M(） F(）$ \\ Idade
}

\title{
Escala de análise visual
}

Indique a média de seu nível neste momento, marcando com uma linha vertical a escala abaixo.

A extremidade esquerda indica ausência total de dor e a extremidade direita indica a pior dor imaginável.

\section{sem dor}

\section{QUESTIONÁRIO}

1. Você sente dificuldade de abrir a boca?

2. Você sente dificuldade de movimentar sua mandíbula para os lados?

3. Você sente desconforto ou dor muscular quando mastiga?

4. Você sente dores de cabeça com freqüência?

5. Você sente dores no pescoço e/ou ombros?

6. Você sente dores de ouvido ou próximo a ele?

7. Você percebe algum ruído na ATM?

8. Você considera sua mordida "anormal"?

9. Você usa apenas um lado de sua boca para mastigar?

10.Você sente dores na face ao acordar? pior dor imaginável

\section{SM NÃO ÀSVEZES}

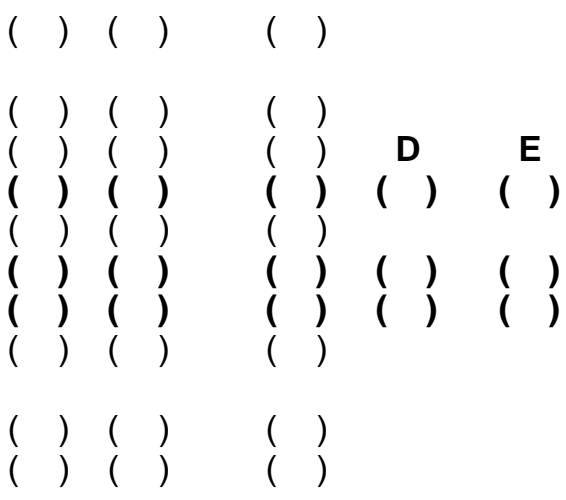

Obs.: ATM significa a articulação do seu maxilar

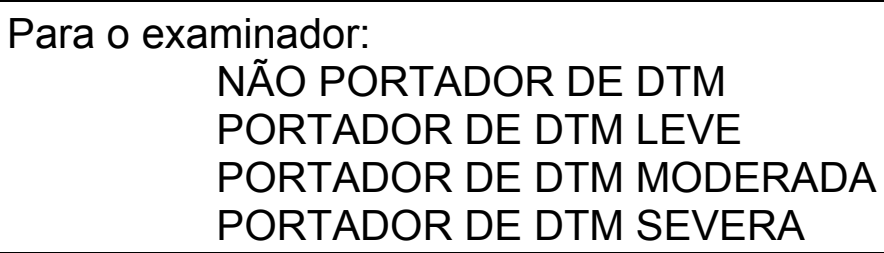

Para o examinador:

NÃO PORTADOR DE DTM PORTADOR DE DTM LEVE PORTADOR DE DTM MODERADA PORTADOR DE DTM SEVERA

As questões 4, 6 e 7 receberão valor 3 para cada resposta "sim" se corresponderem a sintomas bilaterais ou intensos, valor 2, se corresponderem a sintomas unilaterais ou leves; receberão valor 1 para a resposta "às vezes" e valor 0 para a resposta "não".O somatório dos valores obtidos permitirá a classificação da amostra em relação ao grau de disfunção temporomandibular em:

Valores de 0 a 3: não portador de DTM

Valores de 4 a 8: portador de DTM leve

Valores de 9 a 14: portador de DTM moderada

Valores de 15 a 23: portador de DTM severa. 
Data

Dados Pessoais

Nome

Idade

Sexo $M() F(）$

\section{QUESTIONÁRIO}

Queixa principal?

\section{QUESTIONÁRIO PARA DESLOCAMENTO DE DISCO COM REDUÇÃO}

Apresenta estalido na articulação?

O estalido é recíproco?

O estalido varia quanto ao momento de sua ocorrência?

O estalido é ou não acompanhado de dor?

Qual o histórico?

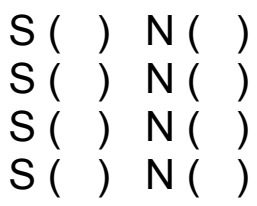

$\mathrm{S}(\quad) \mathrm{N}(\quad)$

$S() N()$

$\mathrm{S}() \mathrm{N}()$

\section{QUESTIONÁRIO PARA DESLOCAMENTO DE DISCO SEM REDUÇÃo}

Apresenta alguma restrição do movimento mandibular?

Não consegue abrir a boca?

Já apresentou travamento com a boca fechada?

Qual o histórico?
$\mathrm{S}() \mathrm{N}()$

$\mathrm{S}() \mathrm{N}()$

$S() N()$

\section{QUESTIONÁRIO PARA HIPERMOBILIDADE}

Já apresentou travamento com boca aberta?

QUESTIONÁRIO PARA SINOVITE/CAPSULTTE

Apresenta dor articular?

$\mathrm{S}(\quad) \mathrm{N}(\quad)$

Piora com a função?

$\mathrm{S}() \mathrm{N}()$

O que faz a dor piorar?

Apresenta dor articular em repouso?

Edema?

\section{QUESTIONÁRIO PARA DOR MOFAsCIAL}

Apresenta dor nos músculos da face?

$S() \mathrm{N}()$ Qual a característica da dor nos músculos?

Apresenta dor no pescoço e/ou ombros?

Quando notou os sintomas pela primeira vez?

Sente dor de cabeça com freqüência? 
Qual a freqüência?

Sofre de enxaqueca?

\section{QUESTIONÁRIO PARA MOSTTE}

Ocorreu algum trauma, infecção antes da dor ter início?

$S() N()$

O que você acha que causou estes problemas?

O início dos problemas relaciona-se a algum acidente?

Quando o seu problema teve início?

Qual a evolução desde que o problema começou?

( ) piorou ( )melhorou ( ) permaneceu estável
Em qual período do dia a sua dor é pior?

( )manhã ( )tarde ( )noite

\section{QUESTIONÁRIO GERAL}

\section{Você teve ou tem algum dos problemas abaixo?}

Cardiovascular

Gastrointestinal/Fígado

Musculoesqueletal

Endócrino

Genitourinário

Hematopoiético

Neurológico

Respiratório

Alergias

Você está bem de saúde?

Data da última consulta médica?

Está sendo tratado por outro problema?

Explique:
$\mathrm{S}() \mathrm{N}()$

$\mathrm{S}() \mathrm{N}()$

$\mathrm{S}(\mathrm{)}) \mathrm{N}(\mathrm{)}$

$\mathrm{S}() \mathrm{N}()$

$\mathrm{S}() \mathrm{N}()$

$\mathrm{S}() \mathrm{N}()$

$\mathrm{S}() \mathrm{N}()$

$\mathrm{S}() \mathrm{N}()$

S( ) N( )

$\mathrm{S}() \mathrm{N}()$

Liste qualquer acidente ou traumatismo e suas datas 


\section{EXAME FÍsco de DTM}

\section{Avaliação da ATM}

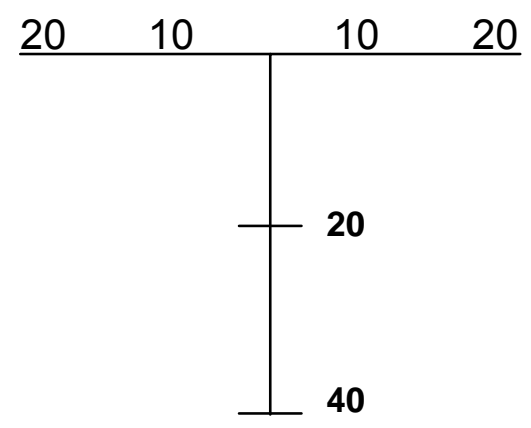

Ruídos Articulares
Abertura: ( ) Simétrica ( )Desvio ( )Deflexão

\section{Estalido}

Abertura

Fechamento

Crepitação

Abertura

Fechamento

$$
\begin{array}{ll}
\mathrm{S}() & \mathrm{N}() \\
\mathrm{S}() & \mathrm{N}() \\
\mathrm{S}() & \mathrm{N}() \\
\mathrm{S}() & \mathrm{N}()
\end{array}
$$

D
$\mathrm{S}(\mathbf{N}) \mathrm{N}(\mathbf{)}$

$S() N()$

$\mathrm{S}() \mathrm{N}()$

$S() N()$

Palpação da ATM (Dor)

D

Aspecto lateral

Aspecto posterior
$\mathrm{S}() \mathrm{N}()$

$\mathrm{S}($ ) N( )
$\mathrm{S}($ ) $\mathrm{N}($ )

$\mathrm{S}(\mathrm{)}) \mathrm{N}()$
EXAME MUSCULAR

D

E

Palpação

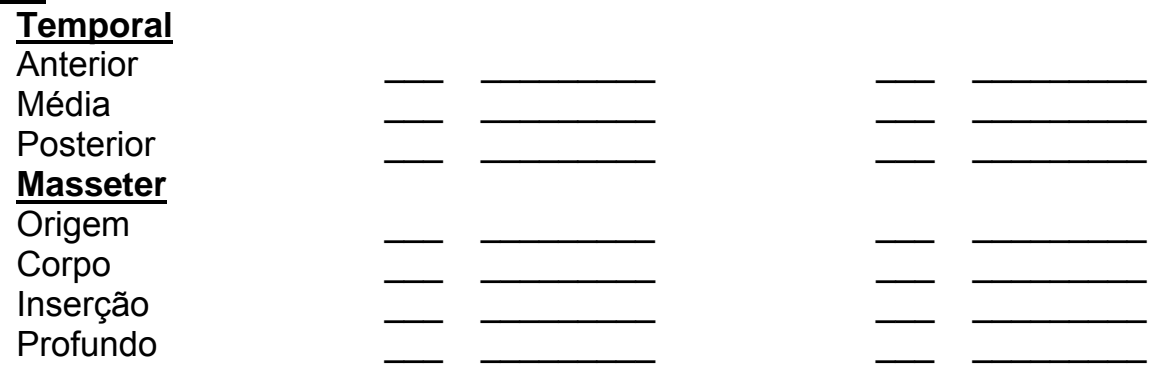

Palpação (escore) 
Digástrico posterior

Pterigóideo medial

Tendão do temporal

Esternocleidomastóideo

Trapézio (superior)

\section{GRUPO AO QUAL PERTENCE O PACIENTE}

$\begin{array}{ll}\mathrm{DMF} & (\mathrm{)} \\ \text { Controle } & (\mathrm{l})\end{array}$


ANeXo 6

\section{EXAME CĹNIICO DE BRUXISMO}

Avaliador:

Data

\section{Dados Pessoais}

Nome Sexo M( ) F ( )

Idade

\section{QUESTIONÁRIO DE BRUXISMO}

Acorda durante a noite ou pela manhã apertando ou rangendo os dentes? S ( ) N ( )

Sente cansaço nos músculos da face ao acordar?

Acorda pela manhã com as articulações travadas?

$\mathrm{S}($ ) $\mathrm{N}($ ( )

Sente desconforto nos dentes ao acordar?

Teve restaurações deslocadas recentemente?

Alguém já relatou que você range ou aperta os dentes?

Quem?

\section{EXAME CLÍNICO DE BRUXISMO}

Apresenta facetas de desgaste coincidentes?

Apresenta restaurações metálicas com pontos brilhantes?

$\mathrm{S}($ ) $\mathrm{N}($ )

Apresenta hipertrofia do músculo masseter?

\section{DIAGNÓSTICO}

Paciente com bruxismo ativo 


\section{ANEXO 7}

Data

Dados Pessoais

Nome

Sexo $M() F(）$

Indique a média de seu nível neste momento, marcando com uma linha vertical a escala abaixo.

A extremidade esquerda indica ausência total de dor e a extremidade direita indica a pior dor imaginável.

sem dor

pior dor imaginável

Palpação da ATM (Dor)

Aspecto lateral

Aspecto posterior

D

$\mathrm{S}(\mathrm{)}) \mathrm{N}($ )

$S() N()$
E

$S($ ) $N($ )

$S() N()$

\section{EXAME MUSCULAR}

Limiar de dor à pressão

Temporal

Anterior

Média

Posterior

Masseter

Origem

Corpo

Inserção

Profundo
D

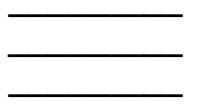

E

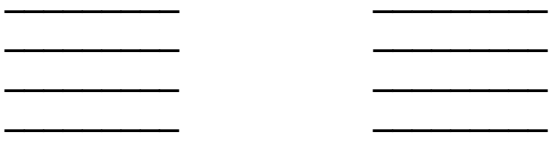

\section{Palpação (escore)}

Esternocleidomastóideo

Trapézio (superior)

Digástrico posterior

Pterigóideo medial 


\section{FICHA DE REAVALIAÇÃO}

Data

Dados Pessoais

Nome

Sexo $M() F(）$

Indique a média de seu nível neste momento, marcando com uma linha vertical a escala abaixo. A extremidade esquerda indica ausência total de dor e a extremidade direita indica a pior dor imaginável.

sem dor

\section{Palpação da ATM (Dor)}

Aspecto lateral

Aspecto posterior

\begin{tabular}{ll}
\multicolumn{1}{c}{ D } \\
$\mathrm{S}($ ) & $\mathrm{N}()$ \\
$\mathrm{S}(\mathrm{)})$ & $\mathrm{N}()$
\end{tabular}

D

Limiar de dor à pressão

Temporal

Anterior

Média

Posterior

Masseter

Origem

Corpo

Inserção

Profundo

\section{Palpação (escore)}

Esternocleidomastóideo

Trapézio (superior)

Digástrico posterior

Pterigóideo medial pior dor imaginável

$\begin{array}{ll} & \mathbf{E} \\ \mathrm{S}(\mathrm{)} & \mathrm{N}() \\ \mathrm{S}(\mathrm{)}) & \mathrm{N}()\end{array}$




\section{ANEXO 8}

Teste de calibração da atividade oromotora com os indivíduos em vigília.

\section{Após o preparo do paciente, e já tendo iniciado o registro, foram dadas aos participantes as seguintes instruções:}

Obs.: aguardar o intervalo de 5 segundos entre cada comando
a. Encaixe os dentes, agora aperte os dentes com o máximo de força que você conseguir
b. novamente
c. novamente
d. Encaixe os dentes, agora aperte os dentes com o força moderada
e. Encaixe os dentes, agora aperte levemente os dentes
f. desloque o queixo para o lado direito e aperte os dentes
g. desloque o queixo para o lado esquerdo e aperte os dentes
h. desloque o queixo para frente e aperte os dentes
i. abra e feche a boca
j. movimente o queixo para o lado direito
k. movimente o queixo para o lado esquerdo
1. movimente o queixo para frente
m. encaixe os dentes e aperte várias vezes
n. engula saliva

O paciente deve executar os seguintes movimentos mandibulares a fim de fornecer dados base em vigília - obedecer o intervalo de 5 segundos entre cada comando 
Anexo 9 Escores de dor à palpação, no momento da triagem, dos músculos Temporal e Masseter do Grupo CONTROLE

\begin{tabular}{|c|c|c|c|c|c|c|c|c|c|c|c|c|c|c|}
\hline & \multicolumn{14}{|c|}{ Escore de Dor Muscular à Palpação } \\
\hline & TAD & TAE & TMD & TME & TPD & TPE & MOD & MOE & MCD & MCE & MID & MIE & MPD & MPE \\
\hline APAM & 0 & 1 & 1 & 0 & 0 & 0 & 0 & 0 & 0 & 0 & 0 & 0 & 0 & 0 \\
\hline CSP & 0 & 0 & 0 & 0 & 0 & 0 & 0 & 0 & 0 & 0 & 0 & 0 & 0 & 0 \\
\hline CFEC & 0 & 0 & 0 & 0 & 0 & 0 & 0 & 0 & 0 & 0 & 0 & 0 & 0 & 0 \\
\hline DED & 0 & 0 & 0 & 0 & 0 & 0 & 0 & 0 & 0 & 0 & 0 & 0 & 0 & 0 \\
\hline DJ M & 0 & 0 & 0 & 0 & 0 & 0 & 0 & 0 & 0 & 0 & 0 & 0 & 1 & 1 \\
\hline EO & 0 & 0 & 0 & 0 & 0 & 0 & 0 & 0 & 0 & 0 & 0 & 0 & 0 & 0 \\
\hline FFAF & 0 & 0 & 0 & 0 & 0 & 0 & 0 & 0 & 0 & 0 & 0 & 0 & 0 & 0 \\
\hline FYI & 0 & 0 & 0 & 0 & 0 & 0 & 0 & 0 & 0 & 0 & 0 & 0 & 0 & 0 \\
\hline FFFT & 0 & 1 & 0 & 0 & 0 & 0 & 0 & 0 & 0 & 0 & 0 & 0 & 0 & 0 \\
\hline $\mathrm{GB}$ & 0 & 0 & 0 & 0 & 0 & 0 & 0 & 0 & 0 & 0 & 0 & 0 & 0 & 0 \\
\hline $\mathrm{HJ} F$ & 0 & 0 & 0 & 0 & 0 & 0 & 0 & 0 & 0 & 0 & 0 & 0 & 0 & 0 \\
\hline JAO & 0 & 0 & 0 & 0 & 0 & 0 & 0 & 0 & 0 & 0 & 0 & 0 & 0 & 0 \\
\hline KVC & 0 & 0 & 0 & 0 & 0 & 0 & 0 & 0 & 0 & 0 & 0 & 0 & 0 & 0 \\
\hline LP & 0 & 0 & 0 & 0 & 0 & 0 & 0 & 0 & 0 & 0 & 1 & 1 & 0 & 0 \\
\hline LC & 0 & 0 & 0 & 0 & 0 & 0 & 0 & 0 & 0 & 0 & 0 & 0 & 0 & 0 \\
\hline LVZ & 0 & 0 & 0 & 1 & 0 & 0 & 0 & 0 & 0 & 0 & 0 & 0 & 0 & 1 \\
\hline LP & 0 & 0 & 0 & 0 & 0 & 0 & 0 & 0 & 0 & 0 & 0 & 0 & 0 & 0 \\
\hline MFAF & 0 & 0 & 0 & 0 & 0 & 0 & 0 & 0 & 0 & 0 & 0 & 0 & 0 & 0 \\
\hline MG & 0 & 0 & 0 & 0 & 0 & 0 & 0 & 0 & 0 & 0 & 0 & 0 & 0 & 0 \\
\hline MR & 0 & 0 & 0 & 0 & 0 & 0 & 0 & 0 & 0 & 0 & 0 & 0 & 0 & 0 \\
\hline M) & 0 & 0 & 0 & 0 & 0 & 0 & 0 & 0 & 0 & 0 & 0 & 0 & 0 & 0 \\
\hline MPF & 0 & 0 & 0 & 1 & 0 & 0 & 0 & 0 & 0 & 0 & 0 & 0 & 0 & 0 \\
\hline MTK & 0 & 0 & 0 & 0 & 0 & 0 & 0 & 0 & 0 & 0 & 0 & 0 & 0 & 0 \\
\hline MAM & 0 & 0 & 0 & 0 & 0 & 0 & 0 & 0 & 0 & 0 & 0 & 0 & 0 & 0 \\
\hline PSC & 0 & 0 & 0 & 0 & 0 & 0 & 0 & 0 & 0 & 0 & 0 & 0 & 0 & 0 \\
\hline RSS & 0 & 0 & 0 & 0 & 0 & 0 & 0 & 0 & 0 & 0 & 0 & 0 & 0 & 1 \\
\hline S & 0 & 0 & 0 & 0 & 0 & 0 & 0 & 0 & 0 & 0 & 0 & 0 & 0 & 0 \\
\hline SG & 0 & 0 & 0 & 0 & 0 & 0 & 0 & 0 & 0 & 0 & 0 & 0 & 0 & 0 \\
\hline SG & 0 & 0 & 0 & 1 & 0 & 0 & 0 & 0 & 0 & 0 & 0 & 0 & 0 & 0 \\
\hline TP & 0 & 0 & 0 & 0 & 0 & 0 & 0 & 0 & 0 & 0 & 0 & 1 & 0 & 1 \\
\hline
\end{tabular}

$\mathrm{M}=$ Masculino; F = Feminino; GP = GRUPO; $\mathrm{C}=$ Grupo Controle;

$\mathrm{TAD}=$ Temporal Anterior Direito; TAE = Temporal Anterior Esquerdo; TMD = Temporal Médio Direito; TME = Temporal Médio Esquerdo; TPD = Temporal Posterior Direito; TPE = Temporal Posterior Esquerdo; MOD = Masseter Origem Direito; MOE = Masseter Origem Esquerdo; MCD = Masseter Corpo Direito; MCE = Masseter Corpo Esquerdo; MID = Masseter Inserção Direito; MIE = Masseter Inserção Esquerdo. 
Anexo 10 Escores de dor à palpação, no momento da triagem, dos músculos Temporal e Masseter do Grupo EXPERIMENTAL

\begin{tabular}{|c|c|c|c|c|c|c|c|c|c|c|c|c|c|c|}
\hline \multirow[b]{2}{*}{ PAC } & \multicolumn{14}{|c|}{ Escore de Dor Muscular à Palpação } \\
\hline & TAD & TAE & TMD & TME & TPD & TPE & MOD & MOE & MCD & MCE & MID & MIE & MPD & MPE \\
\hline $\mathrm{AOL}$ & 0 & 0 & 0 & 2 & 0 & 2 & 0 & 1 & 0 & 0 & 0 & 2 & 1 & 2 \\
\hline$A B$ & 0 & 2 & 1 & 2 & 0 & 3 & 1 & 2 & 2 & 1 & 1 & 2 & 1 & 2 \\
\hline CTBS & 1 & 2 & 0 & 2 & 0 & 2 & 0 & 1 & 1 & 1 & 0 & 2 & 0 & 1 \\
\hline DV & 0 & 0 & 0 & 0 & 1 & 1 & 0 & 3 & 0 & 0 & 0 & 0 & 3 & 2 \\
\hline EC & 0 & 0 & 0 & 1 & 0 & 0 & 0 & 0 & 1 & 1 & 1 & 1 & 1 & 1 \\
\hline EPM & 0 & 0 & 0 & 0 & 0 & 0 & 0 & 0 & 0 & 0 & 1 & 0 & 1 & 0 \\
\hline FGM & 0 & 0 & 0 & 0 & 0 & 0 & 1 & 1 & 0 & 0 & 2 & 1 & 0 & 0 \\
\hline IE & 0 & 0 & 0 & 1 & 0 & 0 & 0 & 0 & 0 & 0 & 0 & 1 & 0 & 0 \\
\hline J GRR & 1 & 1 & 0 & 0 & 0 & 0 & 0 & 0 & 0 & 1 & 0 & 0 & 1 & 1 \\
\hline J MBB & 0 & 0 & 1 & 0 & 0 & 0 & 0 & 0 & 0 & 1 & 0 & 0 & 1 & 1 \\
\hline $\mathrm{KCN}$ & 1 & 1 & 2 & 2 & 1 & 1 & 3 & 3 & 2 & 2 & 1 & 1 & 0 & 0 \\
\hline KCSG & 0 & 0 & 1 & 2 & 0 & 0 & 0 & 0 & 0 & 0 & 0 & 0 & 1 & 2 \\
\hline LM & 0 & 0 & 1 & 1 & 0 & 0 & 0 & 0 & 0 & 1 & 1 & 0 & 2 & 1 \\
\hline LSC & 0 & 0 & 1 & 0 & 0 & 0 & 0 & 0 & 0 & 0 & 1 & 2 & 0 & 0 \\
\hline LEB & 0 & 2 & 0 & 0 & 1 & 0 & 0 & 0 & 0 & 0 & 0 & 2 & 1 & 0 \\
\hline LGCB & 0 & 0 & 0 & 0 & 0 & 0 & 1 & 1 & 0 & 1 & 1 & 0 & 1 & 1 \\
\hline MP & 2 & 2 & 1 & 2 & 0 & 1 & 0 & 1 & 0 & 1 & 0 & 1 & 0 & 2 \\
\hline$M$ & 1 & 2 & 2 & 2 & 2 & 2 & 1 & 2 & 1 & 2 & 2 & 2 & 2 & 1 \\
\hline MP & 0 & 0 & 0 & 0 & 0 & 0 & 1 & 1 & 0 & 0 & 0 & 0 & 1 & 1 \\
\hline NB & 0 & 0 & 1 & 0 & 1 & 1 & 0 & 0 & 1 & 0 & 0 & 1 & 0 & 1 \\
\hline PDR & 1 & 2 & 2 & 1 & 1 & 1 & 0 & 1 & 1 & 1 & 2 & 2 & 0 & 0 \\
\hline MK & 0 & 0 & 1 & 0 & 0 & 0 & 0 & 0 & 0 & 0 & 1 & 0 & 1 & 0 \\
\hline PB & 0 & 0 & 0 & 1 & 1 & 1 & 0 & 0 & 1 & 2 & 1 & 2 & 1 & 2 \\
\hline RAB & 0 & 0 & 0 & 0 & 0 & 0 & 2 & 0 & 2 & 0 & 1 & 0 & 1 & 0 \\
\hline $\mathrm{RC}$ & 1 & 3 & 3 & 2 & 1 & 1 & 2 & 0 & 1 & 0 & 2 & 1 & 2 & 2 \\
\hline RDBG & 0 & 1 & 0 & 0 & 0 & 0 & 0 & 1 & 1 & 1 & 1 & 1 & 0 & 0 \\
\hline SRC & 0 & 0 & 0 & 0 & 0 & 0 & 1 & 1 & 1 & 1 & 1 & 0 & 1 & 0 \\
\hline$S$ & 2 & 3 & 1 & 1 & 1 & 2 & 1 & 3 & 1 & 1 & 2 & 2 & 0 & 2 \\
\hline SHS & 0 & 1 & 1 & 1 & 0 & 2 & 1 & 1 & 0 & 0 & 0 & 0 & 0 & 0 \\
\hline TAM & 0 & 0 & 0 & 0 & 0 & 0 & 1 & 0 & 0 & 0 & 0 & 0 & 2 & 0 \\
\hline
\end{tabular}

PAC: paciente; TAD = Temporal Anterior Direito; TAE= Temporal Anterior Esquerdo; TMD = Temporal Médio Direito; $\mathrm{TME}=$ Temporal Médio Esquerdo; TPD = Temporal Posterior Direito; TPE $=$ TempDoral Posterior Esquerdo; MOD = Masseter Origem Direito; MOE = Masseter Origem Esquerdo; MCD = Masseter Corpo Direito; MCE = Masseter Corpo Esquerdo; MID = Masseter Inserção Direito; MIE = Masseter Inserção Esquerdo.

Como já descrito anteriormente, na sessão de Material e Métodos, o escore 0 representa ausência de dor; 1 representa presença de dor leve, em que o paciente simplesmente relata que doeu; 2 representa dor de intensidade moderada, em que o paciente responde com reflexo palpebral e 3 representa dor intensa em que o paciente reage com afastamento da região avaliada. 
Anexo 11 Escores de dor à palpação nos músculos Esternocleidomastóideo, Trapézio Superior, Pterigóideo Medial e Digástrico Posterior, no grupo CONTROLE

\begin{tabular}{|c|c|c|c|c|c|c|c|c|c|c|c|}
\hline & PACIENTE & SEXO & GP & PTERIG D & PTERIG E & DIG D & DIG E & ECM D & ECM E & TRAP D & TRAP E \\
\hline 1 & APAM & $\mathrm{F}$ & C & 0 & 0 & 0 & 0 & 1 & 0 & 0 & 0 \\
\hline 2 & CSP & $\mathrm{F}$ & C & 0 & 0 & 0 & 0 & 0 & 0 & 0 & 0 \\
\hline 3 & CFEC & $\mathrm{F}$ & $\mathrm{C}$ & 0 & 0 & 0 & 0 & 1 & 0 & 1 & 1 \\
\hline 4 & DED & $\mathrm{F}$ & $\mathrm{C}$ & 0 & 0 & 0 & 0 & 0 & 0 & 0 & 0 \\
\hline 5 & DJ M & $\mathrm{F}$ & $\mathrm{C}$ & 0 & 0 & 0 & 0 & 0 & 0 & 0 & 2 \\
\hline 6 & EO & $\mathrm{F}$ & $\mathrm{C}$ & 0 & 0 & 0 & 0 & 0 & 0 & 0 & 0 \\
\hline 7 & FFAF & M & $\mathrm{C}$ & 0 & 0 & 0 & 0 & 0 & 0 & 0 & 0 \\
\hline 8 & FYI & $\mathrm{F}$ & $\mathrm{C}$ & 0 & 0 & 0 & 1 & 0 & 0 & 0 & 0 \\
\hline 9 & FFFT & $\mathrm{F}$ & $\mathrm{C}$ & 0 & 0 & 0 & 0 & 0 & 0 & 0 & 0 \\
\hline 10 & GB & $\mathrm{F}$ & $\mathrm{C}$ & 0 & 0 & 0 & 0 & 0 & 0 & 0 & 0 \\
\hline 11 & $\mathrm{HJF}$ & $\mathrm{F}$ & $\mathrm{C}$ & 0 & 0 & 0 & 0 & 0 & 0 & 0 & 0 \\
\hline 12 & J AO & M & $\mathrm{C}$ & 0 & 0 & 0 & 0 & 0 & 0 & 0 & 0 \\
\hline 13 & KVC & $\mathrm{F}$ & $\mathrm{C}$ & 0 & 0 & 0 & 0 & 0 & 0 & 0 & 0 \\
\hline 14 & $L P$ & $\mathrm{~F}$ & $\mathrm{C}$ & 0 & 0 & 0 & 0 & 0 & 0 & 1 & 0 \\
\hline 15 & LC & $\mathrm{F}$ & $\mathrm{C}$ & 0 & 0 & 0 & 0 & 0 & 0 & 0 & 0 \\
\hline 16 & LVZ & M & C & 0 & 0 & 0 & 0 & 0 & 1 & 0 & 1 \\
\hline 17 & LP & $\mathrm{F}$ & C & 0 & 0 & 0 & 0 & 0 & 0 & 0 & 0 \\
\hline 18 & MFAF & $\mathrm{F}$ & C & 0 & 0 & 1 & 0 & 2 & 1 & 1 & 0 \\
\hline 19 & MG & $\mathrm{F}$ & C & 0 & 0 & 0 & 0 & 0 & 0 & 0 & 0 \\
\hline 20 & MR & $\mathrm{F}$ & C & 0 & 0 & 1 & 1 & 0 & 0 & 0 & 0 \\
\hline 21 & M) & $\mathrm{F}$ & C & 0 & 0 & 0 & 0 & 0 & 0 & 0 & 0 \\
\hline 22 & MPF & $\mathrm{F}$ & C & 0 & 0 & 0 & 2 & 0 & 0 & 0 & 0 \\
\hline 23 & MTK & $\mathrm{F}$ & C & 0 & 0 & 0 & 0 & 0 & 0 & 0 & 0 \\
\hline 24 & MAM & M & C & 0 & 0 & 0 & 0 & 0 & 0 & 1 & 0 \\
\hline 25 & PSC & $\mathrm{F}$ & C & 0 & 0 & 0 & 0 & 1 & 0 & 1 & 0 \\
\hline 26 & RSS & M & C & 0 & 1 & 0 & 0 & 0 & 0 & 0 & 0 \\
\hline 27 & $\mathrm{~S}$ & $\mathrm{~F}$ & $\mathrm{C}$ & 0 & 1 & 0 & 0 & 0 & 0 & 1 & 1 \\
\hline 28 & SG & $\mathrm{F}$ & $\mathrm{C}$ & 0 & 0 & 0 & 0 & 0 & 1 & 0 & 0 \\
\hline 29 & SG & $\mathrm{F}$ & $\mathrm{C}$ & 0 & 0 & 0 & 0 & 0 & 0 & 0 & 0 \\
\hline 30 & TP & M & C & 0 & 0 & 0 & 0 & 0 & 0 & 1 & 0 \\
\hline
\end{tabular}

$\mathrm{F}=$ Feminino; $\mathrm{M}=$ Masculino; $\mathrm{GP}=$ grupo; $\mathrm{C}=$ Grupo Controle; ECMD = Esternocleidomastóideo Direito; $\mathrm{ECME}=$ Esternocleidomastóideo Esquerdo; TRAP D = Trapézio Direito; TRAP E = Trapézio Esquerdo; PTERIG D = Pterigóideo Medial Direito; PTERIG E = Pterigóideo Medial Esquerdo; DIG 
Anexo 12 Escores de dor à palpação nos músculos Esternocleidomastóideo, Trapézio Superior, Pterigóideo Medial e Digástrico Posterior, no grupo EXPERIMENTAL

\begin{tabular}{|c|c|c|c|c|c|c|c|c|c|c|c|}
\hline & PACIENTE & SEXO & GP & PTERIG D & PTERIG E & DIG D & DIG E & ECM D & ECM E & TRAP D & TRAP E \\
\hline 1 & $\mathrm{AOL}$ & $\mathrm{F}$ & DM & 0 & 1 & 0 & 3 & 2 & 3 & 3 & 3 \\
\hline 2 & $A B$ & M & DM & 0 & 0 & 3 & 3 & 2 & 0 & 0 & 0 \\
\hline 3 & CTBS & $\mathrm{F}$ & DM & 2 & 2 & 0 & 0 & 0 & 2 & 2 & 1 \\
\hline 4 & DV & $\mathrm{F}$ & DM & 0 & 0 & 0 & 1 & 0 & 1 & 3 & 1 \\
\hline 5 & $\mathrm{EC}$ & M & DM & 0 & 0 & 2 & 2 & 0 & 0 & 0 & 1 \\
\hline 6 & EPM & $\mathrm{F}$ & DM & 0 & 0 & 0 & 1 & 1 & 1 & 0 & 1 \\
\hline 7 & FGM & $\mathrm{F}$ & DM & 0 & 1 & 0 & 0 & 1 & 0 & 2 & 1 \\
\hline 8 & $\mathrm{IE}$ & M & DM & 0 & 0 & 1 & 1 & 0 & 0 & 1 & 1 \\
\hline 9 & J GRR & M & DM & 0 & 0 & 0 & 0 & 0 & 1 & 0 & 0 \\
\hline 10 & J MBB & $\mathrm{F}$ & DM & 0 & 0 & 1 & 1 & 0 & 0 & 0 & 0 \\
\hline 11 & $\mathrm{KCN}$ & $\mathrm{F}$ & DM & 2 & 2 & 1 & 1 & 2 & 2 & 3 & 3 \\
\hline 12 & KCSG & $F$ & DM & 0 & 1 & 0 & 0 & 0 & 1 & 2 & 2 \\
\hline 13 & LM & $F$ & DM & 0 & 0 & 1 & 1 & 0 & 0 & 0 & 0 \\
\hline 14 & LSC & $F$ & DM & 0 & 0 & 0 & 0 & 0 & 0 & 0 & 0 \\
\hline 15 & LEB & M & DM & 0 & 0 & 0 & 0 & 0 & 0 & 0 & 0 \\
\hline 16 & LGCB & M & DM & 0 & 0 & 0 & 0 & 0 & 0 & 1 & 1 \\
\hline 17 & MP & $\mathrm{F}$ & DM & 0 & 0 & 0 & 0 & 0 & 1 & 0 & 1 \\
\hline 18 & $M$ & $\mathrm{~F}$ & DM & 1 & 1 & 0 & 0 & 1 & 2 & 2 & 3 \\
\hline 19 & MP & $\mathrm{F}$ & DM & 0 & 0 & 0 & 0 & 0 & 0 & 0 & 1 \\
\hline 20 & NB & $\mathrm{F}$ & DM & 0 & 1 & 2 & 2 & 1 & 2 & 1 & 1 \\
\hline 21 & PDR & $\mathrm{F}$ & DM & 1 & 0 & 0 & 0 & 1 & 1 & 2 & 2 \\
\hline 22 & MK & $\mathrm{F}$ & DM & 0 & 0 & 0 & 0 & 0 & 0 & 0 & 1 \\
\hline 23 & PB & $\mathrm{F}$ & DM & 0 & 1 & 3 & 3 & 2 & 1 & 1 & 1 \\
\hline 24 & RAB & $\mathrm{F}$ & DM & 0 & 0 & 1 & 0 & 1 & 1 & 0 & 0 \\
\hline 25 & $\mathrm{RC}$ & $\mathrm{F}$ & DM & 1 & 0 & 0 & 0 & 3 & 1 & 1 & 0 \\
\hline 26 & RDBG & $\mathrm{F}$ & DM & 0 & 0 & 0 & 0 & 0 & 0 & 2 & 2 \\
\hline 27 & SRC & $\mathrm{F}$ & DM & 1 & 1 & 1 & 1 & 1 & 0 & 2 & 2 \\
\hline 28 & $S$ & $\mathrm{~F}$ & DM & 0 & 0 & 1 & 1 & 1 & 2 & 1 & 2 \\
\hline 29 & SHS & $\mathrm{F}$ & DM & 0 & 0 & 0 & 0 & 1 & 1 & 1 & 1 \\
\hline 30 & TAM & $\mathrm{F}$ & DM & 0 & 0 & 0 & 0 & 1 & 2 & 2 & 2 \\
\hline
\end{tabular}

$\mathrm{F}=$ Feminino; $\mathrm{M}=$ Masculino; $\mathrm{GP}=$ GRUPO; $\mathrm{DM}=$ Grupo Experimental (Dor miofascial); ECMD = Esternocleidomastóideo Direito; ECME = Esternocleidomastóideo Esquerdo; TRAP D = Trapézio Direito; TRAP E = Trapézio Esquerdo; PTERIG D = Pterigóideo Medial Direito; PTERIG E = Pterigóideo Medial Esquerdo; DIG 
Anexo 13 Valores pré-PSG dos Escores de Palpação da ATM no grupo CONTROLE

\begin{tabular}{|c|c|c|c|c|c|c|c|}
\hline \multirow{2}{*}{\multicolumn{2}{|c|}{ PACIENTE }} & \multirow[t]{2}{*}{ SEXO } & \multirow[t]{2}{*}{ GP } & \multicolumn{4}{|c|}{ DOR ATM } \\
\hline & & & & LAT D & LAD E & POST D & POST E \\
\hline 1 & APAM & $\mathrm{F}$ & $C$ & 0 & 0 & 0 & 0 \\
\hline 2 & CSP & $\mathrm{F}$ & C & 0 & 0 & 0 & 0 \\
\hline 3 & CFEC & $\mathrm{F}$ & $\mathrm{C}$ & 0 & 0 & 0 & 0 \\
\hline 4 & DED & $\mathrm{F}$ & C & 0 & 0 & 0 & 0 \\
\hline 5 & DJ M & $\mathrm{F}$ & C & 0 & 0 & 0 & 0 \\
\hline 6 & EO & $\mathrm{F}$ & C & 0 & 0 & 0 & 0 \\
\hline 7 & FFAF & M & C & 0 & 0 & 0 & 0 \\
\hline 8 & $\mathrm{FYI}$ & $\mathrm{F}$ & C & 0 & 0 & 1 & 0 \\
\hline 9 & FFFT & $\mathrm{F}$ & C & 0 & 0 & 0 & 0 \\
\hline 10 & GB & $\mathrm{F}$ & C & 0 & 0 & 0 & 0 \\
\hline 11 & $\mathrm{HJF}$ & $\mathrm{F}$ & C & 0 & 0 & 0 & 0 \\
\hline 12 & J AO & M & C & 0 & 0 & 0 & 0 \\
\hline 13 & KVC & $\mathrm{F}$ & C & 0 & 0 & 0 & 0 \\
\hline 14 & LP & $\mathrm{F}$ & C & 0 & 0 & 0 & 0 \\
\hline 15 & LC & $\mathrm{F}$ & C & 0 & 0 & 0 & 0 \\
\hline 16 & LVZ & M & C & 0 & 0 & 0 & 0 \\
\hline 17 & LP & $\mathrm{F}$ & C & 0 & 0 & 0 & 0 \\
\hline 18 & MFAF & $\mathrm{F}$ & C & 1 & 0 & 1 & 0 \\
\hline 19 & MG & $\mathrm{F}$ & C & 0 & 0 & 0 & 0 \\
\hline 20 & MR & $\mathrm{F}$ & $C$ & 0 & 0 & 0 & 0 \\
\hline 21 & M) & $\mathrm{F}$ & C & 0 & 0 & 0 & 0 \\
\hline 22 & MPF & $\mathrm{F}$ & C & 0 & 0 & 0 & 0 \\
\hline 23 & MTK & $\mathrm{F}$ & $C$ & 0 & 0 & 0 & 0 \\
\hline 24 & MAM & M & C & 0 & 0 & 0 & 0 \\
\hline 25 & PSC & $\mathrm{F}$ & C & 0 & 0 & 0 & 0 \\
\hline 26 & RSS & M & C & 0 & 0 & 0 & 0 \\
\hline 27 & $\mathrm{~S}$ & $\mathrm{~F}$ & C & 0 & 0 & 0 & 0 \\
\hline 28 & SG & $\mathrm{F}$ & C & 0 & 0 & 0 & 0 \\
\hline 29 & SG & $\mathrm{F}$ & C & 0 & 0 & 0 & 0 \\
\hline 30 & TP & M & C & 0 & 0 & 0 & 0 \\
\hline
\end{tabular}

$\mathrm{F}=$ Feminino; $\mathrm{M}=$ Masculino; $\mathrm{GP}=\mathrm{GRUPO} ; \mathrm{C}=$ Grupo Controle;

LAT D $=$ Aspecto Lateral da ATM Direita; LAT E = Aspecto Lateral da ATM Esquerda; POST D = Aspecto Posterior da ATM Direita; POST E = Aspecto Posterior da ATM Esquerda. 
Anexo 14 Valores pré-PSG dos Escores de Palpação da ATM no grupo EXPERIMENTAL

\begin{tabular}{|c|c|c|c|c|c|c|c|}
\hline & \multirow[t]{2}{*}{ PACIENTE } & \multirow[t]{2}{*}{ SEXO } & \multirow[t]{2}{*}{ GP } & \multicolumn{4}{|c|}{ DOR ATM } \\
\hline & & & & LAT D & LAD E & POST D & POST E \\
\hline 1 & $\mathrm{AOL}$ & $\mathrm{F}$ & DM & 0 & 1 & 0 & 0 \\
\hline 2 & $A B$ & M & DM & 0 & 0 & 0 & 0 \\
\hline 3 & CTBS & $\mathrm{F}$ & DM & 1 & 1 & 1 & 0 \\
\hline 4 & DV & $\mathrm{F}$ & DM & 0 & 0 & 0 & 0 \\
\hline 5 & $\mathrm{EC}$ & M & DM & 0 & 0 & 0 & 0 \\
\hline 6 & EPM & $\mathrm{F}$ & DM & 0 & 1 & 1 & 1 \\
\hline 7 & FGM & $F$ & $\mathrm{DM}$ & 0 & 0 & 0 & 0 \\
\hline 8 & $\mathrm{IE}$ & M & DM & 0 & 0 & 0 & 0 \\
\hline 9 & J GRR & M & DM & 0 & 0 & 0 & 1 \\
\hline 10 & J MBB & $\mathrm{F}$ & DM & 0 & 0 & 0 & 0 \\
\hline 11 & $\mathrm{KCN}$ & $\mathrm{F}$ & DM & 1 & 2 & 1 & 3 \\
\hline 12 & KCSG & $\mathrm{F}$ & DM & 1 & 0 & 0 & 0 \\
\hline 13 & LM & $F$ & DM & 0 & 0 & 0 & 0 \\
\hline 14 & LSC & $\mathrm{F}$ & DM & 0 & 0 & 0 & 0 \\
\hline 15 & LEB & M & DM & 0 & 0 & 0 & 1 \\
\hline 16 & LGCB & M & DM & 2 & 1 & 0 & 0 \\
\hline 17 & MP & $\mathrm{F}$ & DM & 0 & 0 & 0 & 0 \\
\hline 18 & $M$ & $F$ & $\mathrm{DM}$ & 1 & 0 & 1 & 1 \\
\hline 19 & MP & $\mathrm{F}$ & DM & 0 & 0 & 0 & 0 \\
\hline 20 & NB & $\mathrm{F}$ & $\mathrm{DM}$ & 0 & 1 & 0 & 0 \\
\hline 21 & PDR & $F$ & DM & 0 & 0 & 0 & 0 \\
\hline 22 & MK & $\mathrm{F}$ & $\mathrm{DM}$ & 0 & 0 & 0 & 0 \\
\hline 23 & PB & $F$ & $\mathrm{DM}$ & 1 & 1 & 2 & 2 \\
\hline 24 & RAB & $F$ & DM & 0 & 0 & 0 & 0 \\
\hline 25 & $\mathrm{RC}$ & $\mathrm{F}$ & $\mathrm{DM}$ & 0 & 0 & 0 & 0 \\
\hline 26 & RDBG & $F$ & $\mathrm{DM}$ & 1 & 1 & 0 & 0 \\
\hline 27 & SRC & $\mathrm{F}$ & $\mathrm{DM}$ & 1 & 1 & 1 & 1 \\
\hline 28 & $\mathrm{~S}$ & $\mathrm{~F}$ & $\mathrm{DM}$ & 0 & 0 & 0 & 0 \\
\hline 29 & SHS & $F$ & $\mathrm{DM}$ & 0 & 0 & 0 & 0 \\
\hline 30 & TAM & $\mathrm{F}$ & $\mathrm{DM}$ & 1 & 2 & 3 & 2 \\
\hline
\end{tabular}

$\mathrm{F}=$ Feminino; $\mathrm{M}=$ Masculino; GP = GRUPO; DM = Grupo Experimental (Dor miofascial)

LAT D = Aspecto Lateral da ATM Direita; LAT E = Aspecto Lateral da ATM Esquerda; POST D = Aspecto Posterior da ATM Direita; POST E = Aspecto Posterior da ATM Esquerda.

$\mathrm{C}=$ grupo controle; DTM = grupo experimental (Dor Miofascial) 
Anexo 15 LDP pré-PSG (kgf/cm2) nos músculos Temporal e Masseter do Grupo CONTROLE

\begin{tabular}{|c|c|c|c|c|c|c|c|c|c|c|c|c|c|c|c|}
\hline \multirow[b]{2}{*}{ PAC } & \multirow{2}{*}{$\begin{array}{c}\text { EAV } \\
\text { ini }\end{array}$} & \multicolumn{14}{|c|}{ LIMIAR DE DOR À PRESSÃO (Kg) } \\
\hline & & TAD & TAE & TMD & TME & TPD & TPE & MOD & MOE & MCD & MCE & MID & MIE & MPD & MPE \\
\hline APAM & 0 & 2,64 & 2,34 & 2,93 & 3,39 & 3,50 & 4,24 & 2,14 & 1,53 & 1,33 & 1,72 & 1,43 & 2,02 & 1,50 & 2,60 \\
\hline CSP & 0 & 2,49 & 1,76 & 1,89 & 2,54 & 2,98 & 2,27 & 2,10 & 2,05 & 1,41 & 1,45 & 2,49 & 2,27 & 2,12 & 1,98 \\
\hline CFEC & 0 & 5,09 & 4,59 & 4,84 & 4,26 & 5,32 & 4,65 & 3,85 & 3,23 & 3,89 & 2,61 & 3,49 & 3,49 & 3,83 & 3,32 \\
\hline DED & 0 & 2,01 & 2,32 & 2,97 & 2,97 & 3,29 & 2,78 & 1,02 & 1,50 & 1,00 & 1,60 & 1,81 & 1,24 & 1,50 & 1,60 \\
\hline DJ $M$ & 2 & 1,30 & 2,02 & 2,40 & 2,10 & 2,86 & 1,98 & 1,46 & 1,24 & 1,04 & 1,38 & 1,58 & 1,68 & 1,67 & 1,53 \\
\hline EO & 0 & 2,18 & 3,77 & 3,12 & 3,91 & 3,12 & 3,54 & 2,46 & 3,04 & 2,04 & 2,74 & 3,18 & 3,11 & 2,50 & 2,60 \\
\hline FFAF & 0 & 1,94 & 3,24 & 2,37 & 2,95 & 2,60 & 2,91 & 1,33 & 2,41 & 1,69 & 1,59 & 2,41 & 1,96 & 2,15 & 2,10 \\
\hline FYI & 0 & 2,12 & 1,51 & 1,61 & 3,28 & 2,11 & 2,78 & 1,19 & 1,83 & 0,84 & 2,11 & 1,29 & 1,62 & 1,51 & 2,03 \\
\hline FFFT & 0 & 2,11 & 1,67 & 3,59 & 1,89 & 2,18 & 2,28 & 1,50 & 1,18 & 1,60 & 1,77 & 1,36 & 1,07 & 1,55 & 1,94 \\
\hline GB & 0 & 2,58 & 3,00 & 2,25 & 3,31 & 2,97 & 2,62 & 2,24 & 1,81 & 1,92 & 1,73 & 2,33 & 2,35 & 1,80 & 1,90 \\
\hline $\mathrm{HJ} \mathrm{F}$ & 0 & 2,21 & 2,05 & 2,72 & 2,06 & 3,72 & 2,25 & 2,21 & 2,23 & 1,32 & 1,57 & 1,89 & 1,65 & 1,74 & 1,65 \\
\hline J AO & 0 & 3,16 & 2,16 & 3,85 & 3,28 & 2,50 & 2,52 & 2,63 & 2,35 & 2,09 & 1,88 & 2,14 & 2,27 & 2,00 & 2,15 \\
\hline KVC & 0 & 3,24 & 2,56 & 3,73 & 3,72 & 3,14 & 3,60 & 1,65 & 1,48 & 1,95 & 1,09 & 2,14 & 2,35 & 2,67 & 2,41 \\
\hline LP & 0 & 2,39 & 1,99 & 2,68 & 3,55 & 3,46 & 4,85 & 1,88 & 2,05 & 1,70 & 1,59 & 1,84 & 1,53 & 2,50 & 2,40 \\
\hline LC & 0 & 1,97 & 4,66 & 2,79 & 3,39 & 3,07 & 2,86 & 1,06 & 1,85 & 1,54 & 1,61 & 2,00 & 2,10 & 1,82 & 2,15 \\
\hline LVZ & 0 & 1,91 & 1,63 & 1,72 & 2,23 & 1,87 & 1,75 & 1,63 & 1,93 & 1,64 & 2,06 & 2,15 & 2,51 & 2,36 & 1,92 \\
\hline LP & 0 & 3,16 & 3,59 & 3,70 & 3,00 & 2,90 & 2,70 & 2,40 & 2,50 & 1,93 & 2,29 & 2,30 & 2,35 & 2,30 & 2,00 \\
\hline MFAF & 0 & 3,48 & 2,76 & 4,32 & 3,54 & 5,13 & 3,03 & 2,21 & 2,54 & 1,85 & 1,66 & 1,96 & 1,96 & 1,66 & 2,04 \\
\hline MG & 0 & 2,65 & 2,62 & 3,69 & 3,11 & 5,77 & 3,27 & 2,88 & 1,75 & 1,53 & 1,69 & 2,05 & 1,85 & 2,50 & 2,00 \\
\hline MR & 0 & 2,53 & 2,35 & 2,43 & 3,21 & 5,10 & 3,81 & 2,72 & 2,57 & 2,01 & 3,05 & 3,08 & 2,54 & 3,88 & 3,05 \\
\hline M) & 0 & 2,04 & 1,86 & 2,08 & 2,38 & 2,13 & 2,54 & 1,76 & 2,07 & 1,99 & 1,19 & 1,76 & 1,79 & 1,07 & 2,12 \\
\hline MPF & 0 & 2,23 & 1,98 & 2,10 & 1,76 & 2,90 & 3,37 & 2,29 & 2,23 & 1,70 & 1,13 & 2,02 & 1,49 & 2,21 & 1,89 \\
\hline MTK & 0 & 3,22 & 3,11 & 2,64 & 3,19 & 3,86 & 3,30 & 2,29 & 2,19 & 1,98 & 1,72 & 2,11 & 2,19 & 2,22 & 1,08 \\
\hline MAM & 0 & 3,17 & 3,42 & 3,34 & 4,12 & 3,10 & 5,86 & 1,80 & 2,40 & 1,49 & 1,86 & 3,00 & 2,52 & 2,65 & 1,93 \\
\hline PSC & 0 & 2,84 & 2,57 & 2,87 & 3,43 & 3,03 & 3,97 & 2,75 & 3,03 & 2,38 & 2,76 & 2,70 & 4,09 & 2,64 & 3,34 \\
\hline RSS & 0 & 1,20 & 1,36 & 1,38 & 2,95 & 1,26 & 2,30 & 0,70 & 1,10 & 0,80 & 1,46 & 1,01 & 1,79 & 1,58 & 1,91 \\
\hline$S$ & 0 & 3,13 & 2,95 & 3,13 & 2,63 & 2,91 & 2,51 & 1,79 & 1,22 & 2,07 & 1,68 & 1,53 & 1,45 & 2,05 & 2,32 \\
\hline SG & 0 & 2,33 & 1,70 & 2,11 & 1,82 & 2,24 & 1,76 & 1,70 & 1,64 & 1,38 & 1,19 & 1,53 & 2,10 & 1,78 & 2,12 \\
\hline SG & 0 & 2,73 & 2,57 & 2,08 & 1,91 & 2,32 & 2,58 & 1,17 & 1,67 & 1,45 & 1,67 & 1,56 & 1,45 & 1,97 & 2,00 \\
\hline TP & 0 & 2,71 & 0,77 & 3,50 & 2,89 & 2,99 & 3,06 & 1,53 & 1,57 & 2,08 & 1,99 & 1,98 & 1,93 & 1,69 & 2,55 \\
\hline
\end{tabular}


Anexo 16 LDP pré-PSG $\left(\mathrm{Kgf} / \mathrm{cm}^{2}\right)$ nos músculos Temporal e Masseter, do GE.

\begin{tabular}{|c|c|c|c|c|c|c|c|c|c|c|c|c|c|c|c|}
\hline \multirow[b]{2}{*}{ PAC } & \multirow{2}{*}{$\begin{array}{r}\text { EAV } \\
\text { ini }\end{array}$} & \multicolumn{14}{|c|}{ LIMIAR DE DOR À PRESSÃO (Kg) } \\
\hline & & TAD & TAE & TMD & TME & TPD & TPE & MOD & MOE & MCD & MCE & MID & MIE & MPD & MPE \\
\hline $\mathrm{AOL}$ & 15 & 1,27 & 1,30 & 2,88 & 1,30 & 3,26 & 1,76 & 1,40 & 2,02 & 1,65 & 1,20 & 1,84 & 1,87 & 1,71 & 1,57 \\
\hline$A B$ & 30 & 1,49 & 0,78 & 2,10 & 1,00 & 2,45 & 1,58 & 1,74 & 1,26 & 1,82 & 1,20 & 1,67 & 1,66 & 1,43 & 1,56 \\
\hline CTBS & 65 & 1,69 & 1,92 & 2,16 & 1,86 & 1,58 & 1,28 & 1,13 & 1,29 & 1,15 & 1,11 & 1,55 & 1,19 & 1,10 & 1,15 \\
\hline DV & 0 & 1,45 & 2,17 & 2,22 & 2,43 & 2,61 & 2,92 & 0,86 & 0,94 & 0,82 & 0,10 & 0,80 & 1,07 & 1,32 & 1,46 \\
\hline EC & 10 & 2,24 & 2,46 & 3,82 & 3,04 & 5,84 & 3,49 & 2,05 & 1,75 & 1,76 & 1,24 & 1,87 & 2,04 & 2,24 & 2,20 \\
\hline EPM & 26 & 1,96 & 1,73 & 2,02 & 2,31 & 1,68 & 2,44 & 1,36 & 1,22 & 1,52 & 1,55 & 1,38 & 1,60 & 1,54 & 1,61 \\
\hline FGM & 9 & 1,92 & 2,10 & 2,46 & 1,96 & 3,39 & 2,05 & 1,27 & 1,56 & 1,15 & 1,01 & 1,35 & 1,43 & 1,50 & 1,60 \\
\hline IE & 19 & 1,23 & 1,50 & 2,17 & 2,09 & 2,87 & 3,23 & 1,46 & 1,49 & 1,88 & 1,29 & 1,54 & 2,00 & 1,97 & 2,22 \\
\hline J GRR & 8 & 2,22 & 2,38 & 3,94 & 2,70 & 3,68 & 2,78 & 2,34 & 1,61 & 1,89 & 1,56 & 2,10 & 1,36 & 1,50 & 1,60 \\
\hline J MBB & 10 & 0,90 & 1,41 & 1,23 & 0,90 & 1,48 & 1,19 & 0,89 & 1,07 & 0,95 & 1,12 & 0,94 & 1,00 & 1,12 & 1,32 \\
\hline $\mathrm{KCN}$ & 39 & 1,76 & 1,54 & 1,33 & 1,56 & 1,63 & 1,91 & 1,25 & 1,15 & 0,89 & 1,09 & 0,98 & 0,73 & 1,12 & 1,11 \\
\hline KCSG & 0 & 1,04 & 0,92 & 2,04 & 1,43 & 1,72 & 1,50 & 1,08 & 0,80 & 1,13 & 1,20 & 1,09 & 1,07 & 1,10 & 1,15 \\
\hline LM & 6 & 1,57 & 0,82 & 1,33 & 0,97 & 1,54 & 1,32 & & 0,60 & & 0,75 & & & & \\
\hline LSC & 0 & 2,19 & 2,50 & 2,09 & 2,11 & 2,28 & 1,84 & 1,06 & 1,50 & 0,93 & 2,21 & 1,53 & 2,24 & 1,41 & 1,35 \\
\hline LEB & 22 & 2,15 & 3,46 & 2,03 & 2,64 & 2,84 & 3,52 & 1,70 & 1,70 & 1,78 & 2,39 & 2,09 & 1,75 & 2,40 & 2,34 \\
\hline LGCB & 2 & 2,97 & 2,10 & 3,11 & 3,45 & 2,62 & & & & 1,88 & & & & & \\
\hline MP & 32 & 1,05 & 1,17 & 1,47 & 1,45 & 1,33 & 1,71 & 0,68 & 0,97 & 1,06 & 1,15 & 0,79 & 1,13 & 1,15 & 1,05 \\
\hline$M$ & 18 & 1,97 & 1,19 & 2,35 & 1,57 & 2,05 & 1,83 & 1,57 & 1,41 & 1,41 & 1,39 & 1,84 & 1,60 & 1,78 & 1,85 \\
\hline MP & 11 & 2,08 & 2,24 & 2,00 & 2,37 & 2,04 & 2,90 & 1,61 & 1,47 & 1,37 & 1,09 & 1,21 & 1,00 & 1,42 & 1,36 \\
\hline NB & 15 & 2,39 & 2,38 & 2,20 & 1,74 & 2,28 & 2,71 & 1,51 & 1,54 & 1,25 & 1,67 & 1,84 & 2,29 & 2,19 & 1,86 \\
\hline PDR & 24 & 1,95 & 1,91 & 2,32 & 2,63 & 3,02 & 2,74 & 0,94 & 1,13 & 1,17 & 1,26 & 1,22 & 1,44 & 1,10 & 1,15 \\
\hline MK & 0 & 1,39 & 1,34 & 1,72 & 1,29 & 1,42 & 1,46 & 1,04 & 1,07 & 0,92 & 1,20 & 1,18 & 1,43 & 1,38 & 1,12 \\
\hline PB & 5 & 1,33 & 1,74 & 1,56 & 2,16 & 2,08 & 2,36 & 1,11 & 0,90 & 1,13 & 1,38 & 1,00 & 1,02 & 1,54 & 1,16 \\
\hline RAB & 0 & 1,53 & 2,14 & 1,76 & 2,53 & 1,75 & 2,39 & 0,90 & 1,20 & 1,11 & 0,96 & 1,17 & 1,29 & 1,06 & 1,42 \\
\hline $\mathrm{RC}$ & 47 & 1,18 & 1,62 & 1,46 & 0,91 & 1,94 & 3,06 & 0,69 & 1,42 & 1,02 & 1,12 & 0,99 & 1,2 & 1,19 & 1,51 \\
\hline RDBG & 8 & 2,54 & 2,06 & 3,20 & 2,41 & 3,49 & 2,34 & 2,39 & 2,11 & 2,09 & 0,90 & 1,40 & 1,14 & 1,10 & 1,15 \\
\hline SRC & 0 & 2,54 & 3,55 & 3,16 & 3,68 & 3,97 & 3,97 & 2,41 & 1,97 & 1,53 & 2,01 & 1,33 & 2,14 & 1,95 & 2,33 \\
\hline$S$ & 0 & 1,49 & 1,40 & 2,10 & 2,07 & 4,53 & 3,12 & 1,45 & 1,64 & 1,38 & 1,19 & 1,53 & 2,10 & 1,78 & 2,12 \\
\hline SHS & 3 & 2,25 & 3,08 & 4,19 & 3,73 & 3,03 & 3,14 & 1,78 & 1,67 & 1,45 & 1,67 & 1,56 & 1,45 & 1,97 & 2,00 \\
\hline TAM & 15 & 2,14 & 3,00 & 2,65 & 2,59 & 2,68 & 3,12 & 1,21 & 1,57 & 2,08 & 1,99 & 1,98 & 1,93 & 1,69 & 2,55 \\
\hline
\end{tabular}

EAV ini: EAV prévia à PSG ou EAV pré-PSG

$\mathrm{TAD}=$ Temporal Anterior Direito; TAE; Temporal Anterior Esquerdo; TMD = Temporal Médio Direito; TME = Temporal Médio Esquerdo; TPD = Temporal Posterior Direito; TPE = Temporal Posterior Esquerdo; MOD = Masseter Origem Direito; $\mathrm{MOE}=$ Masseter Origem Esquerdo; MCD = Masseter Corpo Direito; $\mathrm{MCE}=$ Masseter Corpo Esquerdo; MID = Masseter Inserção Direito; MIE = Masseter Inserção Esquerdo. 
Anexo 17 Escores de dor pré-PSG à palpação no Esternocleidomastóideo, Trapézio Superior, Pterigóideo Medial e Digástrico Posterior no GC

\begin{tabular}{|c|c|c|c|c|c|c|c|c|c|}
\hline \multirow[b]{2}{*}{ PACIENTE } & \multirow[b]{2}{*}{ SEXO } & \multicolumn{8}{|c|}{ DOR MUSCULAR } \\
\hline & & ECMD & ECME & TRAP D & TRAP E & PTERIG D & PTERIG E & DIG D & DIG E \\
\hline APAM & $\mathrm{F}$ & 1 & 2 & 1 & 1 & 0 & 1 & 1 & 0 \\
\hline CSP & $\mathrm{F}$ & 0 & 0 & 0 & 0 & 0 & 0 & 0 & 0 \\
\hline CFEC & $\mathrm{F}$ & 2 & 1 & 2 & 2 & 0 & 0 & 0 & 0 \\
\hline DED & $\mathrm{F}$ & 1 & 0 & 0 & 0 & 0 & 0 & 0 & 0 \\
\hline DJ $M$ & $\mathrm{~F}$ & 0 & 0 & 0 & 0 & 0 & 0 & 0 & 0 \\
\hline EO & $\mathrm{F}$ & 0 & 0 & 0 & 0 & 0 & 0 & 0 & 0 \\
\hline FFAF & M & 0 & 0 & 0 & 0 & 0 & 0 & 0 & 0 \\
\hline FYI & $\mathrm{F}$ & 0 & 0 & 0 & 1 & 0 & 0 & 1 & 1 \\
\hline FFFT & $\mathrm{F}$ & 0 & 2 & 0 & 0 & 0 & 0 & 0 & 0 \\
\hline GB & $\mathrm{F}$ & 0 & 0 & 0 & 1 & 0 & 0 & 0 & 0 \\
\hline $\mathrm{HJ} F$ & $F$ & 0 & 0 & 0 & 0 & 0 & 0 & 0 & 0 \\
\hline J AO & $M$ & 0 & 0 & 0 & 0 & 0 & 0 & 0 & 0 \\
\hline KVC & $\mathrm{F}$ & 0 & 0 & 0 & 0 & 0 & 0 & 0 & 0 \\
\hline LP & $F$ & 0 & 0 & 1 & 1 & 0 & 0 & 0 & 0 \\
\hline LC & $\mathrm{F}$ & 0 & 0 & 0 & 0 & 0 & 0 & 0 & 0 \\
\hline LVZ & $M$ & 1 & 0 & 2 & 2 & 0 & 0 & 1 & 0 \\
\hline LP & $F$ & 0 & 0 & 0 & 0 & 0 & 0 & 0 & 0 \\
\hline MFAF & $\mathrm{F}$ & 3 & 2 & 1 & 1 & 2 & 2 & 0 & 0 \\
\hline MG & $F$ & 1 & 1 & 0 & 0 & 0 & 0 & 0 & 0 \\
\hline MR & $F$ & 1 & 1 & 0 & 0 & 0 & 0 & 0 & 0 \\
\hline M) & $\mathrm{F}$ & 0 & 0 & 1 & 0 & 0 & 0 & 1 & 0 \\
\hline MPF & $\mathrm{F}$ & 0 & 0 & 1 & 0 & 0 & 0 & 0 & 0 \\
\hline MTK & $F$ & 0 & 0 & 0 & 0 & 0 & 0 & 0 & 0 \\
\hline MAM & $M$ & 0 & 0 & 0 & 0 & 0 & 0 & 0 & 0 \\
\hline PSC & $\mathrm{F}$ & 0 & 0 & 0 & 0 & 0 & 0 & 0 & 0 \\
\hline RSS & $M$ & 0 & 0 & 1 & 1 & 0 & 1 & 0 & 0 \\
\hline$S$ & $\mathrm{~F}$ & 0 & 0 & 2 & 2 & 0 & 0 & 0 & 0 \\
\hline SG & $\mathrm{F}$ & 0 & 0 & 0 & 0 & 0 & 0 & 0 & 0 \\
\hline SG & $F$ & 0 & 0 & 1 & 1 & 0 & 0 & 0 & 0 \\
\hline $\mathrm{TP}$ & $M$ & 0 & 0 & 0 & 0 & 0 & 0 & 0 & 0 \\
\hline
\end{tabular}

ECMD = Esternocleidomastóideo Direito; ECME = Esternocleidomastóideo Esquerdo; TRAP D = Trapézio Direito; TRAP E = Trapézio Esquerdo; PTERIG D = Pterigóideo Medial Direito; PTERIG E = Pterigóideo Medial Esquerdo. 
Anexo 18 Escores de dor pré-PSG à palpação no Esternocleidomastóideo, Trapézio Superior, Pterigóideo Medial e Digástrico Posterior no GE

\begin{tabular}{|c|c|c|c|c|c|c|c|c|c|}
\hline \multirow[b]{2}{*}{ PACIENTE } & \multirow[b]{2}{*}{ SEXO } & \multicolumn{8}{|c|}{ DOR MUSCULAR } \\
\hline & & ECMD & ECME & TRAP D & TRAP E & PTERIG D & PTERIG E & DIG D & DIG E \\
\hline $\mathrm{AOL}$ & $\mathrm{F}$ & 3 & 2 & 1 & 2 & 0 & 0 & 2 & 0 \\
\hline$A B$ & M & 2 & 2 & 0 & 1 & 0 & 0 & 1 & 2 \\
\hline CTBS & $\mathrm{F}$ & 0 & 2 & 1 & 2 & 1 & 1 & 1 & 1 \\
\hline DV & $\mathrm{F}$ & 0 & 0 & 1 & 3 & 0 & 0 & 1 & 0 \\
\hline $\mathrm{EC}$ & M & 1 & 0 & 0 & 0 & 0 & 0 & 1 & 1 \\
\hline EPM & $\mathrm{F}$ & 1 & 1 & 2 & 2 & 0 & 0 & 0 & 0 \\
\hline FGM & $\mathrm{F}$ & 1 & 0 & 2 & 2 & 1 & 0 & 0 & 0 \\
\hline IE & M & 0 & 0 & 2 & 0 & 0 & 0 & 0 & 0 \\
\hline J GRR & M & 1 & 0 & 1 & 1 & 0 & 0 & 0 & 0 \\
\hline J MBB & $\mathrm{F}$ & 1 & 1 & 2 & 2 & 0 & 0 & 1 & 1 \\
\hline $\mathrm{KCN}$ & $F$ & 1 & 1 & 2 & 2 & 1 & 0 & 0 & 0 \\
\hline KCSG & $\mathrm{F}$ & 0 & 0 & 1 & 1 & 0 & 0 & 0 & 0 \\
\hline LM & $\mathrm{F}$ & 2 & 1 & 1 & 1 & 0 & 0 & 1 & 1 \\
\hline LSC & $F$ & 0 & 0 & 1 & 0 & 0 & 0 & 0 & 0 \\
\hline LEB & $M$ & 0 & 0 & 0 & 1 & 0 & 0 & 0 & 0 \\
\hline LGCB & $M$ & 1 & 1 & 1 & 1 & 0 & 0 & 0 & 0 \\
\hline MP & $F$ & 2 & 2 & 1 & 2 & 1 & 1 & 0 & 1 \\
\hline M & $\mathrm{F}$ & 2 & 2 & 2 & 3 & 0 & 0 & 0 & 0 \\
\hline MP & $F$ & 1 & 2 & 0 & 0 & 0 & 0 & 0 & 0 \\
\hline NB & $F$ & 0 & 1 & 1 & 1 & 1 & 1 & 3 & 2 \\
\hline PDR & $\mathrm{F}$ & 2 & 1 & 1 & 0 & 0 & 0 & 0 & 0 \\
\hline MK & $\mathrm{F}$ & 1 & 1 & 0 & 1 & 0 & 0 & 0 & 0 \\
\hline PB & $F$ & 1 & 1 & 3 & 3 & 2 & 2 & 2 & 2 \\
\hline RAB & $F$ & 2 & 0 & 1 & 1 & 1 & 0 & 3 & 1 \\
\hline $\mathrm{RC}$ & $\mathrm{F}$ & 3 & 1 & 3 & 0 & 1 & 0 & 0 & 0 \\
\hline RDBG & $F$ & 1 & 0 & 1 & 1 & 0 & 0 & 0 & 0 \\
\hline SRC & $\mathrm{F}$ & 2 & 1 & 1 & 2 & 0 & 1 & 0 & 0 \\
\hline$S$ & $\mathrm{~F}$ & 1 & 1 & 1 & 1 & 0 & 0 & 0 & 0 \\
\hline SHS & $F$ & 1 & 1 & 1 & 1 & 0 & 0 & 1 & 0 \\
\hline TAM & $\mathrm{F}$ & 2 & 3 & 1 & 0 & 0 & 0 & 0 & 0 \\
\hline
\end{tabular}

ECMD = Esternocleidomastóideo Direito; ECME = Esternocleidomastóideo Esquerdo; TRAP D = Trapézio Direito; TRAP E = Trapézio Esquerdo; PTERIG D = Pterigóideo Medial Direito; PTERIG E = Pterigóideo 
Anexo 19 Escores pós-PSG de Palpação da ATM do Grupo Controle

\begin{tabular}{|c|c|c|c|c|c|}
\hline \multirow[b]{2}{*}{ PACIENTE } & \multirow[b]{2}{*}{ SEXO } & \multicolumn{4}{|c|}{ DOR ATM } \\
\hline & & LAT D & LAT E & POST D & POST E \\
\hline APAM & $\mathrm{F}$ & 1 & 0 & 1 & 0 \\
\hline CSP & $F$ & 0 & 0 & 0 & 0 \\
\hline CFEC & $\mathrm{F}$ & 0 & 0 & 0 & 0 \\
\hline DED & $\mathrm{F}$ & 0 & 0 & 0 & 0 \\
\hline DJ M & $F$ & 0 & 0 & 0 & 0 \\
\hline EO & $\mathrm{F}$ & 0 & 0 & 0 & 0 \\
\hline FFAF & $M$ & 0 & 0 & 0 & 0 \\
\hline FYI & $F$ & 0 & 0 & 0 & 0 \\
\hline FFFT & $\mathrm{F}$ & 1 & 1 & 0 & 0 \\
\hline GB & $\mathrm{F}$ & 0 & 0 & 0 & 0 \\
\hline $\mathrm{HJ} F$ & $F$ & 0 & 0 & 0 & 0 \\
\hline $\mathrm{AO}$ & M & 0 & 0 & 0 & 0 \\
\hline KVC & $\mathrm{F}$ & 0 & 0 & 0 & 0 \\
\hline LP & $F$ & 0 & 0 & 0 & 0 \\
\hline LC & $\mathrm{F}$ & 0 & 0 & 0 & 0 \\
\hline LVZ & $M$ & 1 & 0 & 1 & 0 \\
\hline LP & $F$ & 0 & 0 & 0 & 0 \\
\hline MFAF & $\mathrm{F}$ & 0 & 0 & 1 & 0 \\
\hline MG & $\mathrm{F}$ & 0 & 0 & 0 & 0 \\
\hline MR & $F$ & 0 & 0 & 0 & 1 \\
\hline M) & $F$ & 0 & 0 & 1 & 1 \\
\hline MPF & $\mathrm{F}$ & 1 & 0 & 1 & 0 \\
\hline MTK & $F$ & 0 & 0 & 0 & 0 \\
\hline MAM & M & 0 & 0 & 0 & 0 \\
\hline PSC & $\mathrm{F}$ & 0 & 0 & 0 & 0 \\
\hline RSS & M & 1 & 0 & 0 & 0 \\
\hline$S$ & $F$ & 0 & 0 & 1 & 1 \\
\hline SG & $F$ & 0 & 0 & 0 & 0 \\
\hline SG & $F$ & 0 & 0 & 0 & 0 \\
\hline TP & $M$ & 0 & 0 & 1 & 0 \\
\hline
\end{tabular}


Anexo 20 Escores pós-PSG de Palpação da ATM no Grupo Experimental

\begin{tabular}{|c|c|c|c|c|c|}
\hline \multirow[b]{2}{*}{ PACIENTE } & \multirow[b]{2}{*}{ SEXO } & \multicolumn{4}{|c|}{ DOR ATM } \\
\hline & & LAT D & LAT E & POST D & POST E \\
\hline AOL & $\mathrm{F}$ & 1 & 0 & 0 & 0 \\
\hline$A B$ & M & 0 & 0 & 0 & 0 \\
\hline CTBS & $\mathrm{F}$ & 1 & 1 & 1 & 1 \\
\hline DV & $\mathrm{F}$ & 1 & 0 & 1 & 1 \\
\hline EC & M & 0 & 0 & 0 & 0 \\
\hline EPM & $\mathrm{F}$ & 0 & 1 & 3 & 3 \\
\hline FGM & $\mathrm{F}$ & 1 & 1 & 0 & 0 \\
\hline IE & M & 0 & 0 & 0 & 0 \\
\hline J GRR & M & 1 & 2 & 0 & 0 \\
\hline J MBB & $\mathrm{F}$ & 0 & 0 & 0 & 0 \\
\hline $\mathrm{KCN}$ & $\mathrm{F}$ & 2 & 3 & 1 & 3 \\
\hline KCSG & $\mathrm{F}$ & 1 & 0 & 2 & 1 \\
\hline LM & $\mathrm{F}$ & 0 & 0 & 0 & 0 \\
\hline LSC & $\mathrm{F}$ & 0 & 0 & 0 & 0 \\
\hline LEB & M & 0 & 0 & 0 & 0 \\
\hline LGCB & M & 1 & 1 & 0 & 0 \\
\hline MP & $\mathrm{F}$ & 0 & 0 & 0 & 0 \\
\hline M & $\mathrm{F}$ & 1 & 1 & 1 & 1 \\
\hline MP & $\mathrm{F}$ & 1 & 1 & 0 & 0 \\
\hline NB & $\mathrm{F}$ & 0 & 0 & 1 & 1 \\
\hline PDR & $\mathrm{F}$ & 2 & 2 & 0 & 0 \\
\hline MK & $\mathrm{F}$ & 0 & 0 & 0 & 0 \\
\hline PB & $\mathrm{F}$ & 1 & 1 & 1 & 1 \\
\hline RAB & $\mathrm{F}$ & 2 & 2 & 2 & 2 \\
\hline $\mathrm{RC}$ & $\mathrm{F}$ & 0 & 0 & 1 & 1 \\
\hline RDBG & $\mathrm{F}$ & 1 & 1 & 0 & 0 \\
\hline SRC & $\mathrm{F}$ & 2 & 2 & 2 & 2 \\
\hline $\mathrm{S}$ & $\mathrm{F}$ & 1 & 1 & 1 & 1 \\
\hline SHS & $\mathrm{F}$ & 0 & 0 & 1 & 1 \\
\hline TAM & $\mathrm{F}$ & 1 & 0 & 3 & 0 \\
\hline
\end{tabular}


Anexo 21 LDPs pós-PSG $\left(\mathrm{Kg} / \mathrm{cm}^{2}\right)$ do Temporal e Masseter, no Grupo Controle.

\begin{tabular}{|c|c|c|c|c|c|c|c|c|c|c|c|c|c|c|c|}
\hline \multirow[b]{3}{*}{ PAC } & \multirow{3}{*}{$\begin{array}{l}\text { EAV } \\
\text { Pós } \\
\text { PSG } \\
\end{array}$} & \multicolumn{14}{|c|}{ LIMIAR DE DOR À PRESSÃO pós-PSG (Kgf/ $\left.\mathrm{cm}^{2}\right)$} \\
\hline & & \multicolumn{6}{|c|}{ Músculo Temporal } & \multicolumn{8}{|c|}{ Músculo Masseter } \\
\hline & & TADf & TAEf & TMDf & TMEf & TPDf & TPEf & MODf & MOEf & MCDf & MCEf & MIDf & MIEf & MPDf & MPEf \\
\hline APAM & 0,0 & 3,00 & 2,20 & 80 & 00 & 45 & 2,45 & 00 & ,20 & 00 & 00 &, 50 & 1,80 & 00 & 30 \\
\hline CSP & 0,0 & 2,93 & 3,88 & 3,91 & 3,41 & 3,29 & 3,38 & 81 & 2,60 & 2,07 & 50 & 1,91 & 1,66 &, 51 & 14 \\
\hline CFEC & 0,0 & 4,42 & 3,17 & 4,84 & 5,22 & 4,38 & 3,35 & 3,39 & 3,17 & 3,38 & 3,33 & 2,32 & 2,65 & 3,79 & 3,07 \\
\hline DED & 0,0 & 2,51 & 2,11 & 2,34 & 2,16 & 2,89 & 2,34 & 12 & 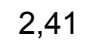 & 58 & 54 & 1,68 & 1,75 & 60 & ,70 \\
\hline DJ M & 0 & 1,52 & 2,49 & 2,78 & 2,46 & 2,67 & 2,61 & 26 & & 1,39 & 52 & 1,73 & 1,48 & & ,48 \\
\hline EO & 0,0 & 2,11 & 2,24 & 2,60 & 2,46 & 2,18 & 2,86 & 160 & 2,73 & & & 1,70 & 1,92 & & 2,60 \\
\hline FFAF & 1,0 & 2,74 & 1,85 & 2,95 & 2,39 & 2,79 & 2,03 & 2 & 1,87 & 8 & 1,82 & 2,06 & 1,90 & 5 & 10 \\
\hline FYI & 0 & 2,21 & 1,93 & 4 & 1,40 & & & & & & & 1,16 & 0,66 & & 26 \\
\hline FFFT & 0,0 & 2,50 & 2,1 & 3,27 & 2,70 & & 2,83 & & & & 1,82 & & 1,52 & & 73 \\
\hline GB & 0,0 & 1,82 & 2,28 & 2,45 & 2,00 & 2,45 & 2,4 & 1,08 & 2 & 1 & 1,92 & 2,05 & 1,55 & 0 & 1,90 \\
\hline $\mathrm{HJ} \mathrm{F}$ &, 0 & 2,30 & 1,95 & 2,90 & 2,00 & 3,56 & 2,37 & 7 & 2,00 & 1,45 & 1,68 & 1,92 & 1,62 & 1,83 & 1,62 \\
\hline J AO & 0 & & & & & & & & & & & & & & \\
\hline KVC & 0,0 & 3,03 & 2,77 & 3,13 & 3,66 & 4,07 & 4,3 & 2,42 & 2 , & 2 & 1,84 & 2,90 & 1,76 & 1 & 2,47 \\
\hline LP & 0,0 & 2,64 & 2,72 & 2,23 & 2,29 & 2,31 & 3,20 & 2,1 & 1,60 & 1,39 & 1,60 & 1,98 & 1,17 & 2,50 & 2,40 \\
\hline LC & 0,0 & 2,97 & 2,41 & & 1,85 & 2,78 & & & & & & 1,80 & & & 1,46 \\
\hline LVZ & 0,0 & 2,48 & 2,13 & 1,64 & 2,52 & 2,46 & 2,62 & 2,12 & 2,0 & 2,25 & 1,86 & 2,14 & 1,59 & 2,19 & 2,05 \\
\hline LP & 0,0 & 1,49 & 2,22 & 2,46 & 1,78 & 2,27 & 2,09 & 1,85 & 1,21 & 1,50 & 1,32 & 1,36 & 1,48 & 2,30 & 2,20 \\
\hline MFAl & 0,0 & 3,50 & 2,85 & 4,86 & 2,84 & 3,58 & & & & & & 2,20 & & & 2,23 \\
\hline MG & 0,0 & 2,60 & 2,28 & 2,15 & 2,32 & 2,20 & 2,21 & 1,68 & 1,55 & 1,58 & 1,13 & 1,58 & 1,20 & 2,50 & 2,00 \\
\hline MR & 0,0 & 3,76 & 4,03 & 4,92 & 3,68 & 4,24 & 4,37 & 3,26 & 3,42 & 2,21 & 2,42 & 2,63 & 2,21 & 3,27 & 3,35 \\
\hline M) & 0,0 & 2,73 & 1,89 & 2,40 & 2,18 & 2,30 & 2,08 & & & & 1,89 & 1,78 & 1,59 & 1,97 & 1,79 \\
\hline MPF & 0,0 & 2,54 & 2,15 & 2,20 & 2,62 & 2,63 & 3,15 & 2,13 & 1,37 & 2,32 & 1,97 & 2,51 & 1,42 & 2,35 & 1,96 \\
\hline MTK & 0,0 & 2,76 & 3,65 & 3,84 & 3,19 & 3,38 & 4,02 & 2,02 & 1,71 & 2,04 & 1,62 & 1,83 & 1,76 & 2,75 & 2,14 \\
\hline MAM & 0,0 & 3,28 & 3,04 & 2,66 & 2,99 & 3,21 & 3,23 & & 2,27 & & 2,15 & 2,69 & 1,87 & 3,21 & 3,07 \\
\hline PSC & 0,0 & 4,04 & 2,98 & 5,08 & 3,76 & 5,03 & 4,04 & 3,09 & 2,72 & 3,22 & 2,74 & 3,12 & 3,04 & 4,22 & 3,67 \\
\hline RSS & 0,0 & 2,06 & 1,98 & 2,83 & 2,59 & 2,33 & 2,16 & 1,40 & & 1,10 & 1,63 & 1,42 & 1,47 & 2,02 & 1,69 \\
\hline $\mathrm{S}$ & 0,0 & 3,34 & 3,02 & 3,13 & 2,35 & 2,02 & 2,21 & 1,86 & 2,32 & 2,02 & 1,48 & 1,91 & 1,66 & 2,53 & 2,15 \\
\hline SG & 0,0 & 2,97 & 3,14 & 2,53 & 3,20 & 2,53 & 2,99 & 2,55 & 2,65 & 1,73 & 2,72 & 1,52 & 2,24 & 2,59 & 2,73 \\
\hline SG & 0,0 & 1,65 & 1,95 & 2,14 & 2,57 & 3,43 & 2,65 & 2,44 & 1,55 & 1,86 & 1,95 & 1,79 & 1,59 & 2,03 & 2,06 \\
\hline TP & 0,0 & 2,89 & 2,47 & 2,58 & 3,19 & 3,87 & 3,15 & 2,10 & 1,86 & 2,81 & 1,86 & 2,54 & 2,35 & 2,05 & 2,14 \\
\hline
\end{tabular}


Anexo 22 LDPs pós-PSG $\left(\mathrm{Kg} / \mathrm{cm}^{2}\right)$ no Temporal e Masseter, do Grupo Experimental.

\begin{tabular}{|c|c|c|c|c|c|c|c|c|c|c|c|c|c|c|c|c|}
\hline \multirow[b]{2}{*}{ PAC } & \multicolumn{3}{|c|}{ EAV pós } & \multicolumn{13}{|c|}{ LIMIAR DE DOR À PRESSÃO pós-PSG (Kgf/ $\left.\mathrm{cm}^{2}\right)$} \\
\hline & sexo & PSG & TADf & TAEf & TMDf & TMEf & TPDf & TPEf & MODf & MOEf & MCDf & MCEf & MIDf & MIEf & MPDf & MPEf \\
\hline $\mathrm{AOL}$ & $\mathrm{F}$ & 5,0 & 1,81 & 1,68 & 2,68 & 2,48 & 2,63 & 2,88 & 1,37 & 1,18 & 1,46 & 1,14 & 1,55 & 1,89 & 1,63 & 1,58 \\
\hline$A B$ & M & 19,0 & 3,06 & 1,00 & 2,90 & 2,64 & 3,29 & 3,32 & 2,06 & 2,03 & 1,94 & 1,62 & 2,45 & 2,60 & 2,42 & 2,24 \\
\hline CTBS & $F$ & 51,6 & 2,03 & 1,53 & 2,33 & 1,68 & 2,30 & 1,44 & 1,20 & 1,20 & 1,13 & 1,18 & 1,40 & 1,37 & 1,30 & 1,15 \\
\hline DV & $F$ & 33,0 & 1,86 & 0,9 & 2,04 & 0,59 & 1,77 & 1,38 & 0,98 & 0,70 & 1,58 & 0,88 & 1,04 & 0,82 & 1,15 & 1,28 \\
\hline $\mathrm{EC}$ & $M$ & 0,0 & 2,02 & 2,02 & 2,35 & 2,2 & 3,29 & 2,32 & 2,03 & 1,75 & 1,99 & 1,48 & 2,02 & 1,65 & 1,94 & 1,69 \\
\hline EPM & $\mathrm{F}$ & 10,0 & 1,65 & 1,40 & 1,67 & 1,58 & 1,97 & 1,76 & 1,70 & 1,50 & 1,55 & 1,53 & 1,52 & 1,48 & 1,75 & 1,77 \\
\hline FGM & $F$ & 0,0 & 2,10 & 2,34 & 2,61 & 2,25 & 2,30 & 2,48 & 1,64 & 1,74 & 1,34 & 1,18 & 1,32 & 1,47 & 1,50 & 1,60 \\
\hline IE & $M$ & 16,0 & 1,67 & 1,54 & 2,45 & 1,94 & 3,00 & 2,04 & 2,00 & 1,65 & 1,54 & 1,55 & 1,80 & 1,24 & 1,58 & 1,54 \\
\hline J GRR & $M$ & 0,0 & 2,10 & 2,41 & 2,52 & 1,98 & 2,83 & 2,47 & 1,88 & 1,57 & 2,01 & 1,74 & 1,64 & 1,65 & 1,50 & 1,60 \\
\hline J MBB & $F$ & 0,0 & 0,83 & 1,18 & 1,23 & 1,23 & 1,15 & 1,41 & 0,80 & 1,14 & 0,86 & 1,25 & 0,87 & 1,06 & 0,84 & 1,22 \\
\hline $\mathrm{KCN}$ & $\mathrm{F}$ & 38,7 & 2,33 & 1,38 & 2,51 & 1,58 & 2,55 & 2,63 & 1,35 & 1,78 & 1,59 & 1,70 & 1,15 & & 1 & 1,10 \\
\hline KCSG & $\mathrm{F}$ & 0,0 & 1,29 & 1,48 & 1,86 & 1,28 & 2,60 & 2,44 & 1,87 & 1,42 & 1,32 & 1,65 & 1,43 & 0,95 & 1,10 & 1,15 \\
\hline LM & $F$ & 0,0 & 1,74 & 1,24 & 1,31 & 1,20 & 2,11 & 1,30 & 1,52 & 1,16 & 1,22 & 1,23 & 1,37 & 1,00 & 1,37 & 1,36 \\
\hline LSC & $\mathrm{F}$ & 0,0 & 2,72 & 1,69 & 2,11 & 2,12 & 2,26 & 2,29 & 2,07 & 2,15 & 1,98 & 1,74 & 1,54 & 1,55 & 2,59 & 1,72 \\
\hline LEB & $M$ & 0,0 & 1,96 & 1,90 & 1,96 & 2,96 & 2,82 & 2,96 & 1,55 & 1,92 & 1,74 & 1,42 & 1,26 & 1,08 & 1,80 & 1,78 \\
\hline LGCB & $M$ & 4,8 & 2,03 & 2,16 & 2,90 & 3,29 & 2,95 & 4,13 & 2,03 & 2,00 & 2,05 & 1,92 & 1,63 & 1,94 & 1,50 & 1,60 \\
\hline MP & $\mathrm{F}$ & 0,0 & 1,65 & 1,45 & 1,61 & 1,23 & 2,00 & 1,17 & 1,19 & 0,91 & 0,94 & 0,93 & 0,99 & 98 & 1,43 & 1,03 \\
\hline$M$ & $F$ & 18,0 & 2,09 & 1,87 & 2,72 & 1,27 & 2,20 & 3,37 & 1,72 & 1,46 & 1,36 & 1,71 & 1,30 & 2,03 & 1,71 & 2,05 \\
\hline MP & $\mathrm{F}$ & 20,0 & 1,98 & 1,58 & 1,65 & 1,54 & 1,44 & 1,57 & 1,52 & 1,78 & 1,61 & 1,24 & 1,08 & 1,40 & 1,33 & 1,52 \\
\hline NB & $F$ & 15,0 & 1,67 & 2,15 & 2,64 & 2,21 & 3,33 & 2,65 & 1,85 & 1,25 & 1,58 & 1,15 & 1,84 & 38 & 2,32 & 1,85 \\
\hline PDR & $F$ & 4,0 & 2,11 & 2,69 & 2,28 & 1,78 & 2,75 & 2,18 & 1,55 & 1,64 & 1,04 & 1,59 & 1,62 & 1,21 & 1,10 & 1,15 \\
\hline MK & $\mathrm{F}$ & 0,0 & 1,08 & 1,99 & 1,39 & 2,57 & 1,70 & 2,09 & 1,56 & 1,25 & 1,17 & 1,37 & 1,15 & 1,39 & 1,65 & 1,45 \\
\hline PB & $F$ & 5,0 & 1,86 & 1,93 & 2,48 & 1,70 & 2,27 & 2,45 & 1,36 & 1,47 & 1,46 & 1,33 & 1,47 & 1,46 & 1,60 & 1,46 \\
\hline RAB & $\mathrm{F}$ & 0,0 & 1,50 & 1,93 & 2,48 & 2,69 & 2,45 & 2,48 & 1,68 & 1,48 & 1,73 & 1,45 & 1,45 & 1,43 & 1,99 & 1,58 \\
\hline $\mathrm{RC}$ & $\mathrm{F}$ & 13,4 & 2,16 & 2,16 & 1,72 & 1,92 & 1,99 & 2,22 & 1,75 & 1,55 & 1,12 & 1,13 & 1,25 & 1,65 & 1,18 & 1,73 \\
\hline RDBG & $F$ & 2,0 & 2,48 & 2,44 & 2,24 & 2,61 & 2,51 & 2,34 & 1,92 & 1,71 & 1,29 & 1,30 & 1,69 & 1,46 & 1,10 & 1,15 \\
\hline SRC & $\mathrm{F}$ & 0,0 & 3,35 & 2,52 & 3,27 & 3,08 & 2,65 & 3,05 & 1,76 & 1,91 & 2,08 & 1,80 & 1,67 & 1,61 & 1,89 & 1,35 \\
\hline$S$ & $\mathrm{~F}$ & 52,6 & 1,43 & 2,67 & 2,38 & 2,39 & 2,83 & 2,81 & 2,06 & 1,66 & 1,88 & 1,63 & 1,45 & 1,18 & 1,45 & 1,77 \\
\hline SHS & $F$ & 5,0 & 2,72 & 2,58 & 3,24 & 3,66 & 3,18 & 3,52 & 2,05 & 1,74 & 2,14 & 2,17 & 2,32 & 1,76 & 2,58 & 2,53 \\
\hline TAM & $\mathrm{F}$ & 15,0 & 1,54 & 1,54 & 2,36 & 2,69 & 2,79 & 2,81 & 0,81 & 1,63 & 0,99 & 1,47 & 1,19 & 1,11 & 1,23 & 1,80 \\
\hline
\end{tabular}

TAD = Temporal Anterior Direito; TAE; Temporal Anterior Esquerdo; TMD = Temporal Médio Direito; TME = Temporal Médio Esquerdo; TPD = Temporal Posterior Direito; TPE = Temporal Posterior Esquerdo; MOD = Masseter Origem Direito; MOE = Masseter Origem Esquerdo; MCD = Masseter Corpo Direito; MCE = Masseter Corpo Esquerdo; MID = Masseter Inserção Direito; MIE = Masseter Inserção Esquerdo. 
Anexo 23 Escores de dor à palpação pós-PSG no Esternocleidomastóideo, Trapézio Superior, Pterigóideo Medial e Digástrico Posterior do GC.

\begin{tabular}{|c|c|c|c|c|c|c|c|c|c|}
\hline \multirow[b]{2}{*}{ PACIENTE } & \multirow[b]{2}{*}{ SEXO } & \multicolumn{8}{|c|}{ DOR MUSCULAR } \\
\hline & & ECMD & ECME & TRAP D & TRAP E & PTERIG D & PTERIG E & DIG D & DIG E \\
\hline APAM & $\mathrm{F}$ & 1 & 1 & 1 & 1 & 0 & 0 & 1 & 0 \\
\hline CSP & $\mathrm{F}$ & 0 & 0 & 0 & 0 & 0 & 0 & 0 & 0 \\
\hline CFEC & $\mathrm{F}$ & 2 & 3 & 2 & 2 & 0 & 0 & 0 & 0 \\
\hline DED & $\mathrm{F}$ & 1 & 0 & 1 & 1 & 0 & 0 & 0 & 0 \\
\hline DJ M & $\mathrm{F}$ & 0 & 0 & 0 & 1 & 0 & 0 & 0 & 0 \\
\hline EO & $\mathrm{F}$ & 0 & 0 & 0 & 0 & 0 & 0 & 0 & 0 \\
\hline FFAF & M & 3 & 2 & 0 & 0 & 0 & 1 & 1 & 0 \\
\hline $\mathrm{FYI}$ & $\mathrm{F}$ & 1 & 1 & 2 & 2 & 1 & 2 & 0 & 0 \\
\hline FFFT & $\mathrm{F}$ & 1 & 2 & 0 & 0 & 0 & 0 & 0 & 0 \\
\hline GB & $\mathrm{F}$ & 1 & 1 & 2 & 2 & 0 & 0 & 0 & 0 \\
\hline $\mathrm{HJ} \mathrm{F}$ & $\mathrm{F}$ & 0 & 0 & 0 & 0 & 0 & 0 & 0 & 0 \\
\hline J AO & $M$ & 0 & 0 & 1 & 1 & 0 & 0 & 0 & 0 \\
\hline KVC & $\mathrm{F}$ & 0 & 0 & 0 & 0 & 0 & 0 & 0 & 0 \\
\hline LP & $\mathrm{F}$ & 0 & 1 & 0 & 0 & 0 & 0 & 0 & 0 \\
\hline LC & $\mathrm{F}$ & 1 & 0 & 0 & 0 & 1 & 0 & 0 & 0 \\
\hline LVZ & M & 2 & 1 & 1 & 1 & 1 & 1 & 0 & 0 \\
\hline LP & $\mathrm{F}$ & 0 & 0 & 0 & 0 & 0 & 0 & 0 & 0 \\
\hline MFAF & $\mathrm{F}$ & 3 & 3 & 3 & 2 & 2 & 2 & 0 & 0 \\
\hline MG & $\mathrm{F}$ & 0 & 0 & 0 & 0 & 0 & 0 & 0 & 0 \\
\hline MR & $\mathrm{F}$ & 0 & 0 & 0 & 0 & 0 & 0 & 0 & 0 \\
\hline M & $\mathrm{F}$ & 0 & 0 & 1 & 1 & 0 & 0 & 0 & 1 \\
\hline MPF & $\mathrm{F}$ & 3 & 3 & 3 & 3 & 0 & 0 & 0 & 0 \\
\hline MTK & $\mathrm{F}$ & 0 & 0 & 0 & 0 & 0 & 0 & 0 & 0 \\
\hline MAM & $M$ & 0 & 0 & 0 & 0 & 0 & 0 & 0 & 0 \\
\hline PSC & $\mathrm{F}$ & 0 & 0 & 0 & 0 & 0 & 0 & 0 & 0 \\
\hline RSS & $M$ & 1 & 1 & 1 & 0 & 0 & 1 & 0 & 0 \\
\hline$S$ & $\mathrm{~F}$ & 2 & 1 & 1 & 1 & 0 & 0 & 0 & 0 \\
\hline SG & $\mathrm{F}$ & 0 & 0 & 3 & 3 & 0 & 0 & 0 & 0 \\
\hline SG & $\mathrm{F}$ & 3 & 3 & 2 & 2 & 1 & 1 & 0 & 0 \\
\hline TP & $M$ & 0 & 0 & 0 & 0 & 0 & 0 & 0 & 0 \\
\hline
\end{tabular}




\section{Anexo 24 Escores de dor à palpação pós-PSG no Esternocleidomastóideo, Trapézio Superior, Pterigóideo Medial e Digástrico Posterior no GE.}

\begin{tabular}{|c|c|c|c|c|c|c|c|c|c|}
\hline \multirow[b]{2}{*}{ PACIENTE } & \multirow[b]{2}{*}{ SEXO } & \multicolumn{8}{|c|}{ DOR MUSCULAR } \\
\hline & & ECMD & ECME & TRAP D & TRAP E & PTERIG D & PTERIG E & DIG D & DIG E \\
\hline$\overline{\mathrm{AOL}}$ & $\mathrm{F}$ & 3 & 3 & 3 & 1 & 0 & 1 & 0 & 1 \\
\hline$A B$ & $M$ & 3 & 3 & 3 & 0 & 0 & 1 & 0 & 0 \\
\hline CTBS & $\mathrm{F}$ & 3 & 3 & 3 & 3 & 2 & 2 & 3 & 3 \\
\hline DV & $\mathrm{F}$ & 3 & 3 & 0 & 3 & 3 & 1 & 2 & 2 \\
\hline EC & M & 1 & 0 & 0 & 0 & 0 & 0 & 0 & 0 \\
\hline EPM & $\mathrm{F}$ & 2 & 1 & 2 & 1 & 0 & 0 & 1 & 1 \\
\hline FGM & $\mathrm{F}$ & 2 & 2 & 2 & 2 & 2 & 2 & 1 & 1 \\
\hline IE & M & 0 & 0 & 3 & 1 & 0 & 0 & 0 & 0 \\
\hline J GRR & M & 1 & 3 & 2 & 2 & 1 & 0 & 0 & 0 \\
\hline J MBB & $F$ & 0 & 1 & 1 & 1 & 0 & 0 & 0 & 0 \\
\hline $\mathrm{KCN}$ & $F$ & 3 & 3 & 2 & 2 & 3 & 3 & 2 & 1 \\
\hline KCSG & $F$ & 2 & 1 & 3 & 3 & 0 & 0 & 0 & 0 \\
\hline LM & $\mathrm{F}$ & 1 & 1 & 0 & 1 & 0 & 2 & 0 & 1 \\
\hline LSC & $\mathrm{F}$ & 3 & 2 & 3 & 0 & 0 & 0 & 0 & 0 \\
\hline LEB & $M$ & 0 & 1 & 0 & 0 & 1 & 1 & 1 & 0 \\
\hline LGCB & $M$ & 2 & 1 & 2 & 2 & 0 & 0 & 0 & 0 \\
\hline MP & $\mathrm{F}$ & 2 & 2 & 3 & 2 & 0 & 1 & 1 & 0 \\
\hline$M$ & $F$ & 2 & 1 & 3 & 1 & 2 & 3 & 0 & 1 \\
\hline MP & $\mathrm{F}$ & 1 & 1 & 0 & 0 & 2 & 1 & 1 & 1 \\
\hline NB & $\mathrm{F}$ & 1 & 1 & 0 & 0 & 1 & 1 & 0 & 0 \\
\hline PDR & $\mathrm{F}$ & 3 & 3 & 3 & 3 & 3 & 0 & 0 & 1 \\
\hline MK & $F$ & 1 & 0 & 2 & 1 & 0 & 0 & 1 & 1 \\
\hline PB & $F$ & 3 & 3 & 2 & 2 & 2 & 2 & 1 & 2 \\
\hline RAB & $F$ & 2 & 2 & 0 & 0 & 2 & 3 & 1 & 1 \\
\hline $\mathrm{RC}$ & $\mathrm{F}$ & 3 & 0 & 3 & 0 & 2 & 0 & 2 & 0 \\
\hline RDBG & $F$ & 2 & 1 & 2 & 2 & 2 & 2 & 0 & 1 \\
\hline SRC & $F$ & 2 & 1 & 3 & 3 & 1 & 1 & 1 & 0 \\
\hline S & $\mathrm{F}$ & 2 & 3 & 3 & 2 & 2 & 2 & 3 & 3 \\
\hline SHS & $\mathrm{F}$ & 2 & 2 & 2 & 2 & 2 & 2 & 1 & 1 \\
\hline TAM & $\mathrm{F}$ & 2 & 0 & 3 & 2 & 0 & 0 & 0 & 0 \\
\hline
\end{tabular}


Anexo 25 Índices de apnéia/hipopnéia, microdespertares e movimentos periódicos das pernas nas primeira e segunda noites de PSG, no grupo controle

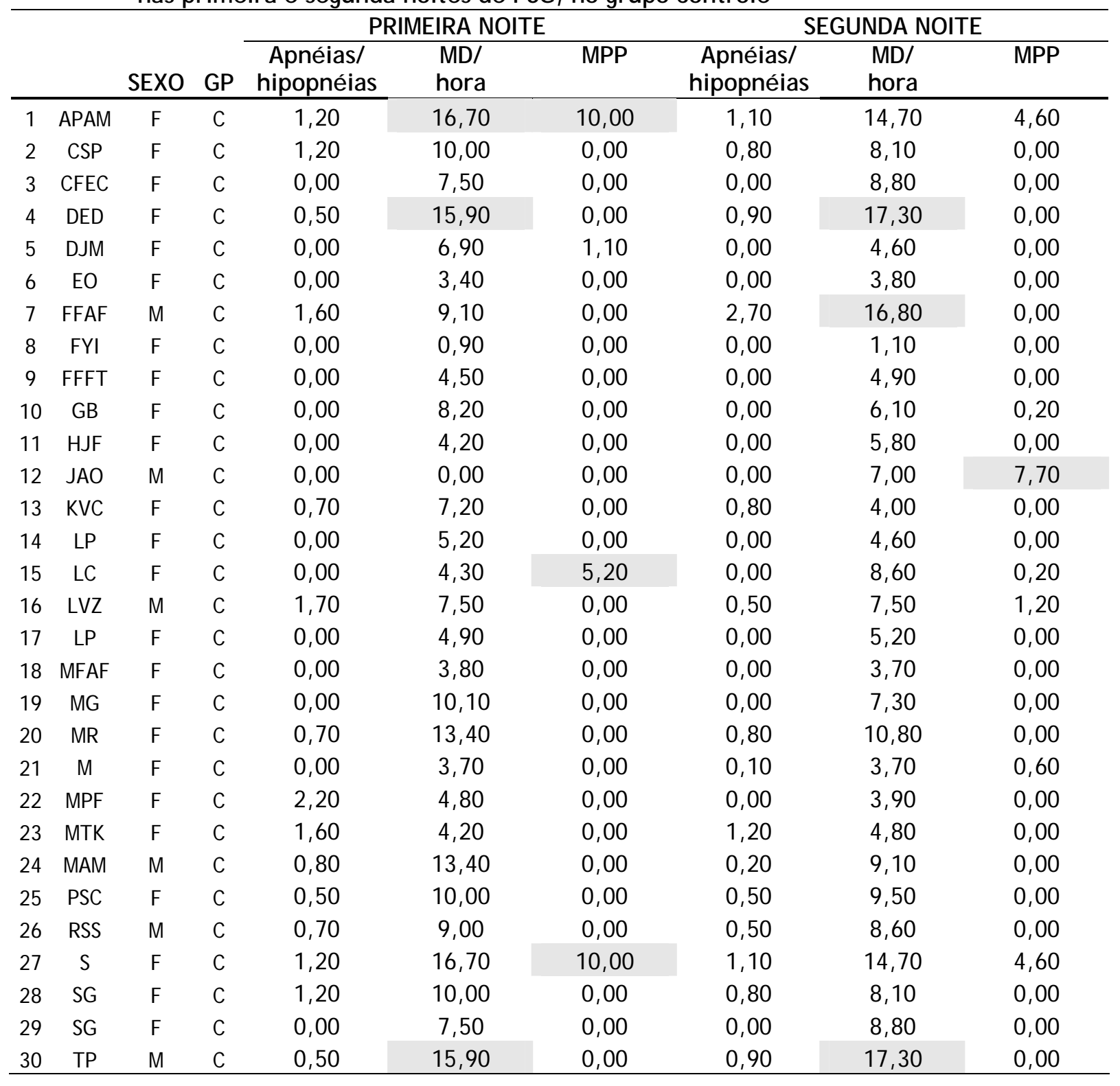


Anexo 26 Índices de apnéia/hipopnéia, microdespertares e movimentos periódicos das pernas nas primeira e segunda noites de PSG, no grupo experimental.

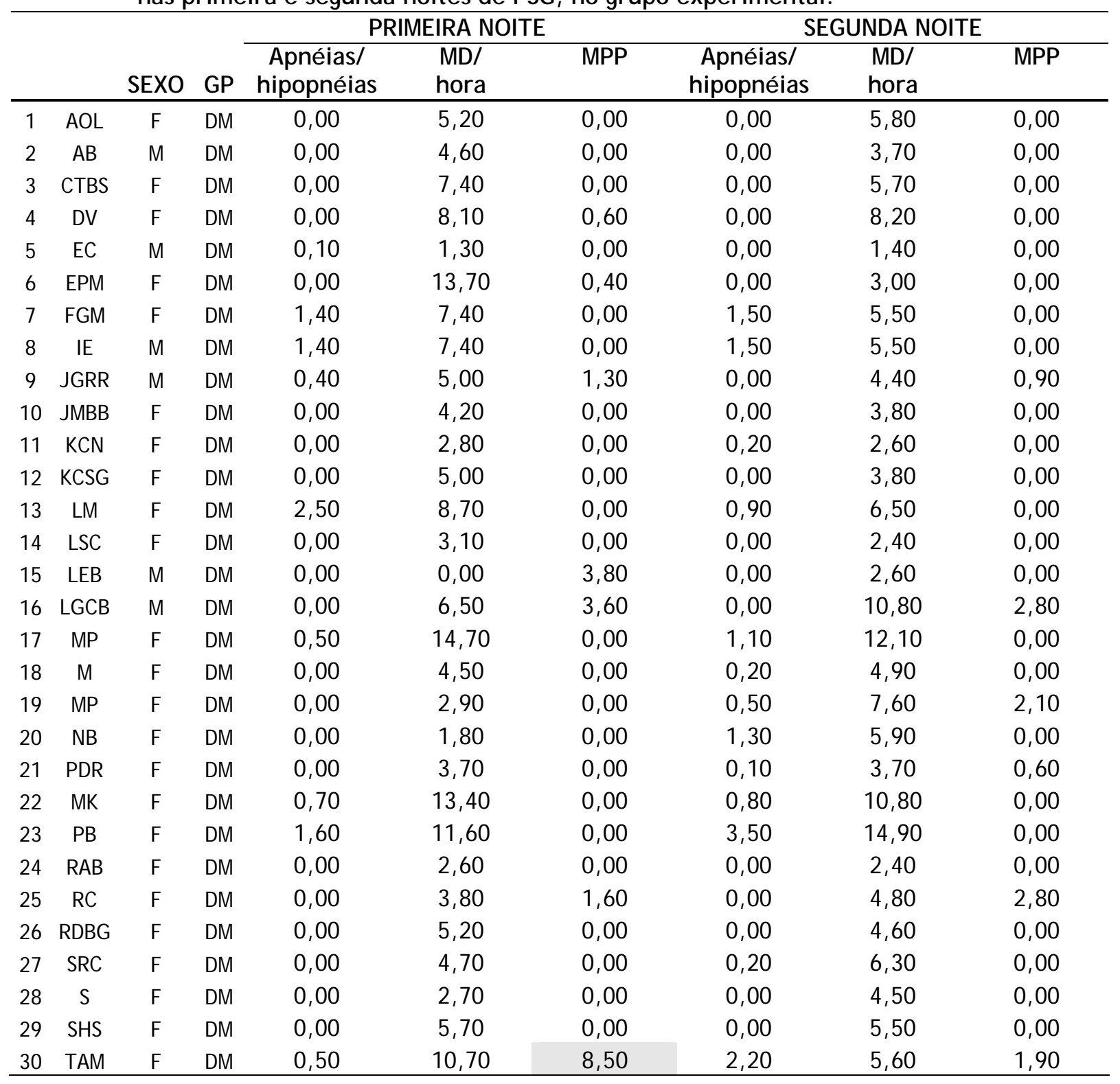


Anexo 27 Respostas dos indivíduos do grupo Controle ao Exame Clínico de Bruxismo

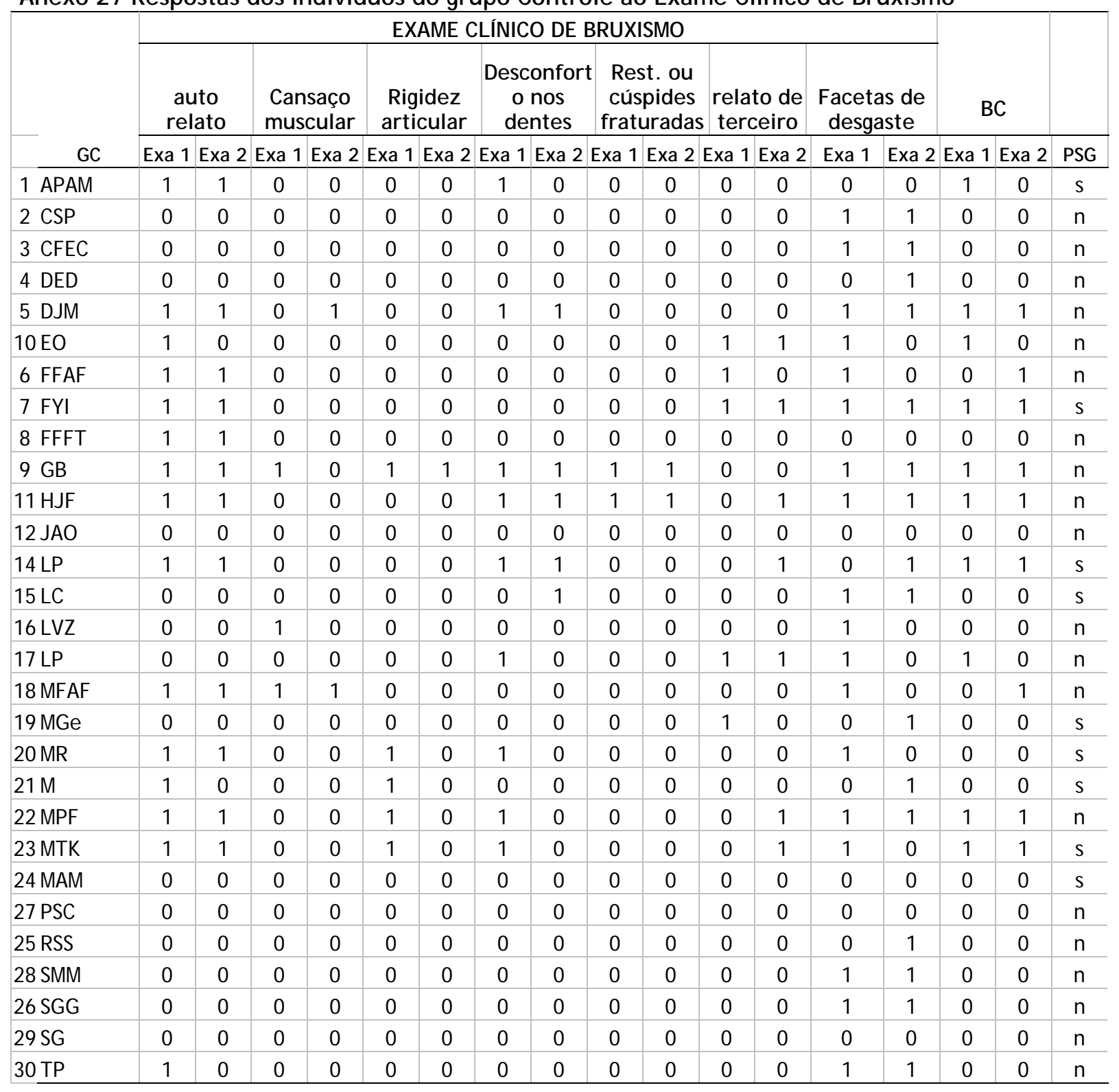


Anexo 28 Respostas dos Pacientes do Grupo Experimental ao Exame Clínico de Bruxismo

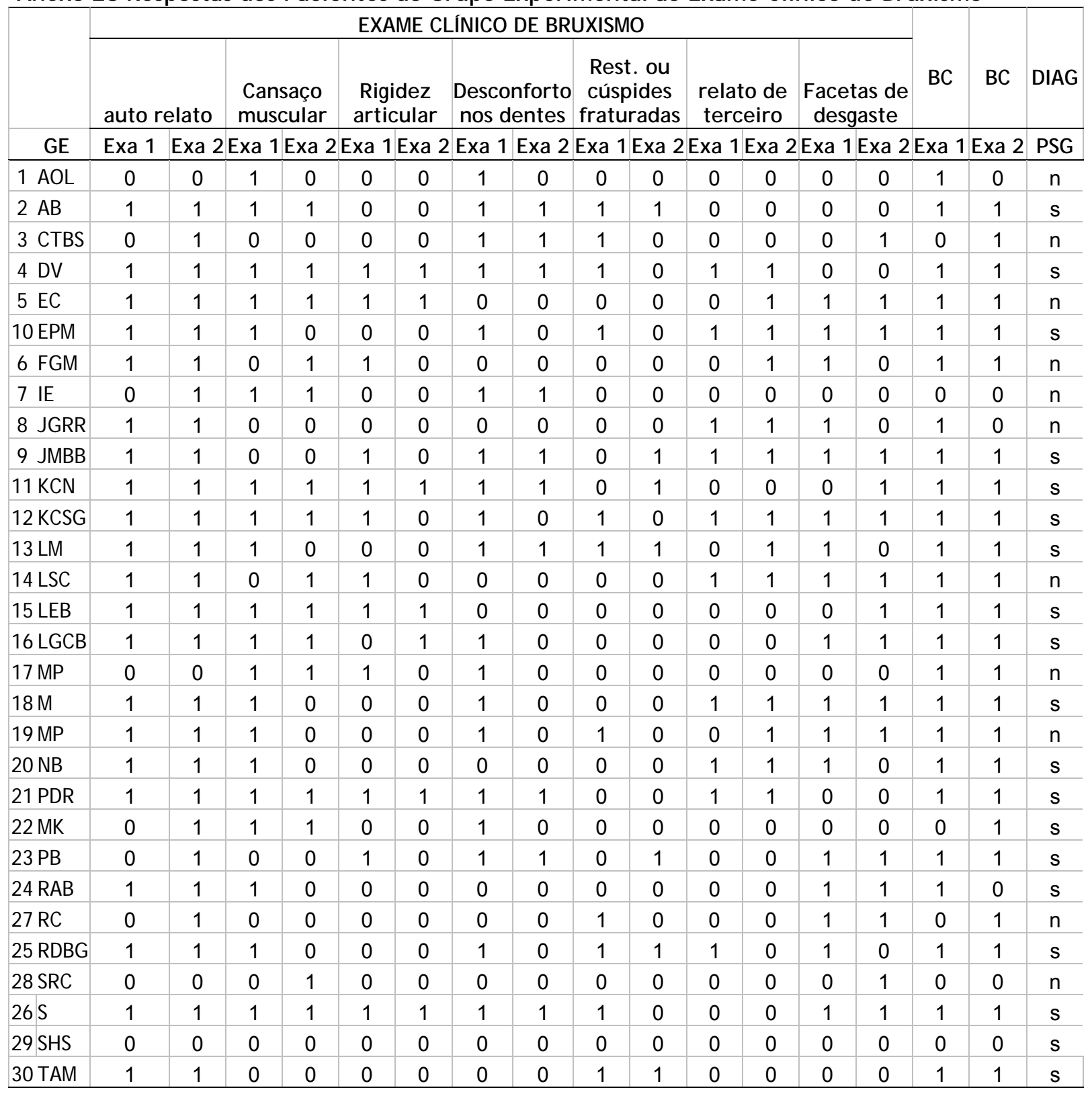


REFERÊNCIAS BIBLIOGRÁFICAS 


\section{REFERÊNCIAS BIBLIOGRÁFICAS}

1. Ahlberg J, Savolainen A, Rantala M, Lindholm H, Kononen M. Reported bruxism and biopsychosocial symptoms: a longitudinal study. Community Dent Oral Epidemiol. 2004 Aug;32(4):307-11.

2. Ahlberg K, Ahlberg J, Kononen M, Alakuijala A, Partinen M, Savolainen A. Perceived orofacial pain and its associations with reported bruxism and insomnia symptoms in media personnel with or without irregular shift work. Acta Odontol Scand. 2005 Aug;63(4):213-7.

3. Alderson P, Green S, Higgins JPT. Cochrane Reviewers'Handbook 4.2.1 [updated December 2003]. Chichester, UK: John Wiley \& Sons, Ltd; 2004.

4. American Academy of Orofacial Pain. Orofacial pain: guidelines for assessment, classification, and management. Chicago, IL: Quintessence; 1996.

5. American Academy of Sleep Medicine. Sleep-related breathing disorders in adults: recommendation for syndrome definitions and measurements techniques in clinical research. Sleep. 1999 Aug;22(5):667-89.

6. American Academy of Sleep Medicine. The international classification of sleep disorders, revised: diagnostic and coding manual. 2nd ed. Westchester: American Academy of Sleep Medicine; 2005.

7. American Sleep Disorders Association. The international classification of sleep disorders, revised: diagnostic and coding manual. Rochester: Allen Press; 1997.

8. American Sleep Disorders Association. Arousals scoring rules and examples: a preliminary report from sleep disorders atlas task force of American Sleep Disorders Association. Sleep. 1992;15(2):173-84.

9. Arima T, Arendt-Nielsen L, Svensson P. Effect of jaw muscle pain and soreness evoked by capsaicin before sleep on orofacial motor activity during sleep. J Orofac Pain. 2001;15(3):245-56. 
10. Arima T, Svensson P, Arendt-Nielsen L. Experimental grinding in healthy subjects: a model for postexercise jaw muscle soreness. J Orofac Pain. 1999;13(2):104-14.

11. Arima T, Svensson P, Arendt-Nielsen L. Capsaicin-induced muscle hyperalgesia in the exercised and non-exercised human masseter muscle. J Orofac Pain. 2000;14(3):213-23.

12. Baba K, JHaketa T, Sasaki Y, Ohyama T, Clark GT. Stress, sex, smoking, sounds, sleep, and sensitization - studies on associations, risk factors, and mechanisms in orofacial pain. J Orofac Pain. 2005 Summer;19(3):226-31.

13. Bader G, Lavigne G. Sleep bruxism; an overview of an oromandibular sleep movement disorder. REVIEW ARTICLE. Sleep Med Rev. 2000 Feb;4(1):27-43.

14. Bader GG, Kampe T, Tagdae T, Karlsson S, Blomqvist M. Descriptive physiological data on a sleep bruxism population. Sleep. 1997;20(11):982-90.

15. Bodere C, Tea SH, Giroux-Metges MA, Woda A. Activity of masticatory muscles in subjects with different orofacial pain conditions. Pain. 2005 Jul;116(1-2):33-41.

16. Brousseau M, Manzini C, Thie N, Lavigne G. Understanding and managing the interaction between sleep and pain: an update for the dentist. J Can Dent Assoc. 2003 JulAug;69(7):437-42.

17. Brunette DM. Reliability, sensitivity, and specificity of diagnostic tests and measurements. Critical thinking Understanding and evaluating dental research. Carol Stream, IL: Quintessence Publishing Co; 1996. p. 99-112.

18. Camparis CM. Bruxismo do sono e disfunção temporomandibular: avaliação clínica e polissonográfica. Araraquara: Universidade Estadual Paulista; 2005.

19. Camparis CM, Formigoni G, Teixeira MJ, Bittencourt LR, Tufik S, Siqueira JT. Sleep bruxism and temporomandibular disorder: Clinical and polysomnographic evaluation. Arch Oral Biol. 2006 Apr 1.

20. Camparis CM, Siqueira JT. Sleep bruxism: clinical aspects and characteristics in patients with and without chronic orofacial pain. Oral Surg Oral Med Oral Pathol Oral Radiol Endod. 2006 Feb;101(2):188-93. 
21. Carlsson GE, Egermark I, Magnusson T. Predictors of signs and symptoms of temporomandibular disorders: a 20-year follow-up study from childhood to adulthood. Acta Odontol Scand. 2002 Jun;60(3):180-5.

22. Carlsson GE, Egermark I, Magnusson T. Predictors of bruxism, other oral parafunctions, and tooth wear over a 20-year follow-up period. J Orofac Pain. 2003 Winter;17(1):50-7.

23. Christensen LV. Jaw muscle fatigue and pain induced by experimental tooth clenching: a review. J Oral Rehabil. 1981;8(1):27-36.

24. Christensen LV, Mohamed SE, Harrison JD. Delayed onset of masseter muscle pain in experimental tooth clenching. J Prosthet Dent. 1982;48(5):579-84.

25. Chung JW, Kim C, McCall WD. Effect of sustained contraction on motor unit action potentials and EMG power spectrum of human masticatory muscles. J Dent Res. 2002;81(9):646-9.

26. Ciancaglini R, Gherlone E, Radaelli G. The relationship of bruxism with craniofacial pain and symptoms from the masticatory system in the adult population. Journal of Oral Rehabilitation. 2001;28(9):842-8.

27. Clark GT, Adler RC, Lee JJ. Jaw pain and tenderness levels during and after repeated sustained maximum voluntary protrusion. Pain. 1991;45(1):17-22.

28. Clark GT, Beemsterboer PL, Jacobson R. The effect of sustained submaximal clenching on maximum bite force in myofascial pain dysfunction patients. J Oral Rehabil. 1984 Jul;11(4):387-91.

29. Clark GT, Beemstermoer PL, Rugh JD. Nocturnal masseter muscle activity and the symptoms of masticatory dysfunction. J Oral Rehabil. 1981;8(3):279-86.

30. Clark TT, Lynn P. Horizontal plane jaw movements in controls and clinic patients with temporomandibular dysfunction. J Prosthet Dent. 1986;55(6):730-5.

31. Cohen J. Statistical power analysis for the behavioral sciences. 2nd ed. New Jersey: Lawrence Erlbaum; 1988. 
32. Conti A, Freitas M, Conti P, Henriques J, Janson G. Relationship between signs and symptoms of temporomandibular disorders and orthodontic treatment: a cross-sectional study. Angle Orthod. 2003 Aug;73(4):411-7.

33. Conti ACCF. Avaliação transversal da relação entre sinais e sintomas das disfunções temporomandibulares e o tratamento ortodôntico [Dissertação (Mestrado)]. Bauru: Faculdade de Odontologia de Bauru, Universidade de São Paulo; 2000.

34. Costen JB. Syndrome of ear and sinus symptoms dependent upon disturbed function of temporomandibular joint. Ann Otol Rhinol Laryngol. 1934;3(1):1-4.

35. Curran SL, Carlson CR, Okeson JP. Emotional and physiologic responses to laboratory challenges: patients with temporomandibular disorders versus matched control subjects. J Orofac Pain. 1996 Spring;10(2):141-50.

36. Dao TTT, Lund JP, Lavigne GJ. Comparison of pain and quality of life in bruxers and patients with miofascial pain of the masticatory muscles. Journal of Orofacial Pain. 1994;8(4):350-6.

37. Dao TTT, Lund JP, Lavigne GJ. Comparison of pain and quality of life in bruxers and patients with myofascial pain of the masticatory muscles. J Orofac Pain. 1994;8(4):350-6.

38. Dao TTT, Lund JP, Lavigne GJ. Pain responses of experimental chewing in myofascial pain patients. J Dent Res. 1994;73(6):1163-7.

39. De Leeuw JRJ, Steenks MH, Ros WJG. Psychosocial aspects of craniomandibular dysfunction: an assessment of clinical and community findings. J Oral Rehabil. 1994;21(2):127-43.

40. Delcanho RR, Rem YJ, Clark GT. Haemodynamic changes induced by submaximal isometric contraction in painful and non-painful human masseter using near-infra-red spectroscopy. Arch Oral Biol. 1996;41(6):585-96.

41. Droukas B, Lindee C, Carlsson G. Occlusion and mandibular dysfunction: a clinical study of patients referred for functional distrubances of masticatory system. J Prosthet Dent. 1985;53(3):402-6. 
42. Dube C, Rompre PH, Manzini C, Guitard F, de Grandmont P, Lavigne GJ. Quantitative polygraphic controlled study on efficacy and safety of oral splint devices in tooth-grinding subjects. J Dent Res. 2004 May;83(5):398-403.

43. Dworkin SF, Huggins KH, Le Resche L, Von Korrff M, Howard J, E. T, et al. Epidemiology of signs and symptoms in temporomandibular disorders: clinical signs in cases and controls. J Am Dent Ass. 1990;120:273-81.

44. Dworkin SF, LeResche L, Fricton JR, Hollender L, Huggins KH, Mohl ND, et al. Research diagnostic criteria for temporomandibular disorders: Review, criteria, examinations and specifications, critique. J Craniomandibular Dis Fac Oral Pain. 1992;6(4):301-55.

45. Fricton JR, Kin YJ, Clark GL. Predictors of outcome for treatment of temporomandibular disorders. J Orofac Pain. 1996;10(1):54-65.

46. Glaros A. Incidence of diurnal and nocturnal bruxism. J Prosthet Dent. $1981 ; 45(5): 545-9$.

47. Glaros AG, Glass EG. Electromyographic data from TMD patients with myofascial pain and from matched control subjects: evidence for statistical, not clinical, significance. J Orofac Pain. 1997;11(2):125-9.

48. Glaros AG, Tabacchi KN, Glass EG. Effect of parafunctional clenching on TMD pain. J Orofac Pain. 1998;12(2):145-52.

49. Glaros AG, Williams K, Lausten L. The role of parafunctions, emotions and stress in predicting facial pain. J Am Dent Assoc. 2005 Apr;136(4):451-8.

50. Goulet JP, Clark GT, Flack VF, Liu C. The reproducibility of muscle and joint tenderness detection methods and maximum mandibular movement measurement for the temporomandibular system. J Orofac Pain. 1998 Winter;12(1):17-26.

51. Goulet JP, Lavigne GJ, Lund JP. Jaw pain prevalence among French-speaking canadians in Quebec and related symptoms of temporomandibular disorders. J Dent Res. 1995;74(11):1738-44.

52. Goulet JP, Lund JP, Montplaisir J, Lavigne G. Daily clenching nocturnal bruxism, and stress and their association with TMD symptoms. J Orofac Pain. 1993;7:120. 
53. Graven-Nielsen T, H. L, Arendt-Nielsen L, Danneskiol-Manöe B, Bliddal H. Inhibitory of maximal voluntary contraction force by experimentl muscle pain: a centrally mediated mechanism. Muscle Nerve. 2002;25(4):576-84.

54. Greene CS. The etiology of temporomandibular disorders: implication for treatment. J Orofac Pain. 2001;15(2):93-105.

55. Greene CS, Marbach JJ. Epidemiological studies of mandibular dysfunction: a critical review. J Prosthet Dent. 1982;48(2):184-90.

56. Gross A, Gale EN. A prevalence study of the clinical signs associated with mandibular dysfunction. J Am Dent Assoc. 1983 Dec;107(6):932-6.

57. Guler N, Yatmaz PI, Ataoglu H, Emlik D, Uckan S. Temporomandibular internal derangement: correlation of MRI findings with clinical symptoms of pain and joint sounds in patients with bruxing behaviour. Dentomaxillofac Radiol. 2003 Sep;32(5):304-10.

58. Hartman E. Bruxism. Principles and practice of sleep medicine. 2 ed. Philadelphia: WB Sanders; 1994. p. 598-601.

59. Hicks RA, Chancellor C. Nocturnal bruxism and type A-B behavior in college students. Psychol Rep. 1987 Jun;60(3 Pt 2):1211-4.

60. High AS, MacGregor AJ, Tomlinson GE. A gnathodynamometer as an objective means of pain assessment following wisdow tooth removal. Int J Oral Maxillofac Surg. 1988;26(4):284-91.

61. Ikeda T, Nishigawa K, Kondo K, Takaeuchi H, Clark GT. Criteria for the detection of sleep-associated bruxism in humans. J Orofac Pain. 1996;10(3):270-82.

62. Isselee H, De Laat A, Lesaffre E, Lysens R. Short-term reproducibility of pressure pain thresholds in masseter and temporalis muscles of symptom-free subjects. Eur J Oral Sci. 1997 Dec;105(6):583-7.

63. Jaeschke R, Guyatt G, Sackett DL. Users' guides to the medical literature. III. How to use an article about a diagnostic test. A. Are the results of the study valid? Evidence-Based Medicine Working Group. Jama. 1994 Feb 2;271(5):389-91. 
64. Johansson a, Haraldson T, Omar R, Killiaridis S, G.E. C. A system for assessing the severity and progression of occlusal tooth wear. Journal of Oral Rehabilitation. 1993;20:12531.

65. Johnstone D, Templeton M. The feasibility of palpating the lateral pterygoid muscle. J Prosthet Dent. 1980 Sep;44(3):318-23.

66. Junge D, Clark GT. Electromyographic turns analysis of sustained contraction in human masseter muscles at various isometric force levels. Arch Oral Biol. 1993;38(7):583-8.

67. Kampe T, Tagdae T, Bader G, Edman G, Karlsson S. Reported symptoms and clinical findings in a group of subjects with longstanding bruxing behaviour. Journal of Oral Rehabilitation. 1997 Aug;24(8):581-7.

68. Kato T, Rompré P, Montplaisir JY, Sessle BJ, Lavigne GJ. Sleep bruxism: an oromotor activity secondary to micro-arousal. J Dent Res. 2001;80(10):1940-4.

69. Kato T, Thie NMR, Montplaisir JY, Lavigne GJ. Bruxism and orofacial movements during sleep. Dent Clin North Am. 2001;45(4):657-85.

70. Kieser JA, Groeneveld HT. Relationship between juvenile bruxing and craniomandibular dysfunction. J Oral Rehabil. 1998 Sep;25(9):662-5.

71. Koltyn KF. Analgesia following exercise: a review. Sports Med. 2000 Feb;29(2):8598.

72. Kosek E, Ekholm J. Modulation of pressure pain thresholds during and following isometric contraction. Pain. 1995 Jun;61(3):481-6.

73. Kosek E, Ekholm J, Hansson P. Modulation of pressure pain thresholds during and following isometric contraction in patients with fibromyalgia and in healthy controls. Pain. 1996 Mar;64(3):415-23.

74. Laskin DM. Etiology of the pain-dysfuncion syndrome. J Am Dent Ass. $1969 ; 79(7): 147-53$.

75. Lauris J. Ajuste para correção do valor de "p". In: Paulo FdOdB-UdS, editor. Bauru; 2006. p. O ajuste consiste na divisão do valor de "p" desejável pelo número de comparações realizadas. 
76. Lavigne G, Kato T. Usual and unusual orofacial motor activities associated with tooth wear. Int J Prosthodont. 2005 jul-ago;18(4):291-2.

77. Lavigne GJ, Brousseau M, Montplaisir JY, Mayer P. Dor e distúrbios do sono. In: Lund JP, Lavigne GJ, Dubner R, Sessle BJ, editors. Dor orofacial: da ciência básica à conduta clínica. 1 ed. São Paulo: Quintessence; 2002.

78. Lavigne GJ, Guitard F, Rompre PH, Montplaisir JY. Variability in sleep bruxism activity over time. J Sleep Res. 2001 Sep;10(3):237-44.

79. Lavigne GJ, Kato T, Kolta A, Sessle BJ. Neurobiological mechanisms involved in sleep bruxism. Crit Rev Oral Biol Med. 2003;14(1):30-46.

80. Lavigne GJ, Montplaisir JY. Restless legs syndrome and sleep bruxism: prevalence and association among canadians. Sleep. 1994;17(8):739-43.

81. Lavigne GJ, Rompre PH, Guitard F, Sessle BJ, Kato T, Montplaisir JY. Lower number of K-complexes and K-alphas in sleep bruxism: a controlled quantitative study. Clin Neurophysiol. 2002 May;113(5):686-93.

82. Lavigne GJ, Rompré PH, Montplaisir J, Lobbezoo F. Motor activity in sleep bruxism with concomitant jaw muscle pain: a retrospective study. Eur J Oral Sci. 1997;105(1):92-5.

83. Lavigne GJ, Rompré PH, Montplaisir JY. Sleep bruxism: validity of clinical research diagnostic criteria in a controlled polysomnographic study. J Dent Res. 1996;75(1):546-52.

84. Lavigne GJ, Rompre PH, Montplaisir JY, Lobbezoo F. Motor activity in sleep bruxism with concomitant jaw muscle pain. A retrospective pilot study. Eur J Oral Sci. 1997 Feb;105(1):92-5.

85. Lavigne GJ, Rompré PH, Poirier G, Huard H, Kato T, Montplaisir JY. Rhythmic masticatory muscle activity during sleep in humans. J Dent Res. 2001;80(2):443-8.

86. Lindroth JE, Schmidt JE, Carlson CR. A comparison between masticatory muscle pain patients and intracapsular pain patients on behavioral and psychosocial domains. J Orofac Pain. 2002 Fall;16(4):277-83.

87. Lipinski D, Nelson RO. The reactivity and unreliability of self recordings. J Couns Clin Psysiol. 1974;42(1):118-23. 
88. Lobbezoo-Scholte AM, De Leeuw JRJ, Steenks MH, Bosman F, Buchner R, Olthoff LW. Diagnostic subgroups of craniomandibular disorders Part I: self-report data and clinical findings. J Orofac Pain. 1995;9(1):24-36.

89. Lobbezoo-Scholte AM, Lobbezoo F, Steenks MH, De Leeuw JR, Bosman F. Diagnostic subgroups of craniomandibular disorders. Part II: Symptom profiles. J Orofac Pain. 1995 Winter;9(1):37-43.

90. Lobbezoo F, Lavigne GJ. Do bruxism and temporomandibular disorders have a causeand-effect relationship? J Orofac Pain. 1997;11(1):15-23.

91. Lobbezoo F, Naeije M. Bruxism is mainly regulated centrally, not peripherally. J Oral Rehabil. 2001;28(2):1085-91.

92. Lobbezoo F, Soucy JP, Montplaisir JY, Lavigne GJ. Striatal D2 receptor binding in sleep bruxism: a controlled study with iodine-123-iodobenzamide and single-photon-emission computed tomography. J Dent Res. 1996 Oct;75(10):1804-10.

93. Locker D, Slade G. Prevalence of symptoms associated with temporomandibular disorders in a canadian population. Community Dent Oral Epidemiol. 1988;16(5):310-3.

94. Lund JP, Donga R, Widmer CG, Stohler CS. The pain-adaptation model: a discussion of the relationship between chronic musculoskeletal pain and motor activity. Canad J Physiol Pharmacol. 1991;69(5):683-94.

95. Macaluso GM, Guerra P, Di Giovanni G, Boselli M, Parrino L, Terzano MG. Sleep bruxism is a disorder related to periodic arousals during sleep. J Dent Res. 1998;77(4):565-73. 96. Macfarlane TV, Blinkhorn AS, Davies RM, Worthington HV. Association between local mechanical factors and orofacial pain: survey in the community. J Dent. 2003 Nov;31(8):535-42.

97. Magnusson T, Egermark I, Carlsson GE. A longitudinal epidemiologic study of signs and symptoms of temporomandibular disorders from 15 to 35 years of age. J Orofac Pain. 2000 Fall;14(4):310-9.

98. Magnusson T, Egermark I, Carlsson GE. A prospective investigation over two decades on signs and symptoms of temporomandibular disorders and associated variables. A final summary. Acta Odontol Scand. 2005 Apr;63(2):99-109. 
99. Manfredini D, Canini E, Romagnoli M, Bosco M. Prevalence of bruxism in patients with different research diagnostic criteria for temporomandibular disorders (RDC/TMD) diagnoses. J Craniomandib Pract. 2003 Oct;21(4):274-85.

100. Manfredini D, Ciapparelli A, Dell'Osso L, Bosco M. Mood disorders in subjects with bruxing behavior. J Dent. 2005 Jul;33(6):485-90.

101. Marcel T, Chew W, McNeill C, Hartcher D, Miller A. Magnetic resonance spectroscopy of the human masseter muscle in nonbruxing and bruxing subjects. J Orofac Pain. 1995;9(2):116-30.

102. Matre DA, Sinkjaer T, Svensson P, Aremdt-Nielsen L. Experimental muscle pain increases the human stretch reflex. Pain. 1998;75(2-3):331-9.

103. McMillan AS, Blasberg B. Pain-pressure threshold in painful jaw muscles following trigger point injection. J Orofac Pain. 1994 Fall;8(4):384-90.

104. Mense S. Considerations concerning the neurobiological basis of muscle pain. Canad J Physiol Pharmacol. 1991;69(5):610-6.

105. Mense S. Nociception from skeletal muscle in relation to clinical muscle pain. Pain. 1993 Sep;54(3):241-89.

106. Mense S, Simons DG. Muscle pain:. Baltimore: Lippincott Williams \& Wilkins; 2001.

107. Migraine D, Scholte AM, Tremblay RE, Montplaisir JY. Bruxism and onychophagy in children: prevalence and relative risk factors. J Dent Res. 1996;75:219.

108. Minagi S, Akamatsu Y, Matsunaga T, Sato T. Relationship between mandibular position and the coordination of masseter muscle activity during sleep in humans. J Oral Rehabil. 1998;25(12):902-7.

109. Moldofsky H. Sleep and pain. Sleep Med Rev. 2001 Oct;5(5):385-96.

110. Molina OF, Santos Junior J, Mazzetto M, Nelson S, Nowlin T, Manieri ET. Oral Jaw behaviors in TMD and bruxism: a comparison study by severity of bruxism. J Craniomandib Pract. 2001;19(2):114-22. 
111. Molina OF, Santos Junior J, Nelson SJ, Nowlin T. A clinical study of specific signs and symptoms of CMD in bruxers classified by the degree of severity. J Craniomandib Pract. 1999;17(4):268-79.

112. Montagna P. Sleep-related non epileptic motor disorders. J Neurol. 2004 Jul;251(7):781-94.

113. Nielsen IL, McNeill C, Danzig W, Goldman S, Levy J, Miller AJ. Adaptation of craniofacial muscles in subjects with craniomandibular disorders. Am J Orthod Dentofacial Orthop. 1990 Jan;97(1):20-34.

114. Nishigawa K, Bando E, Nakano M. Quantitative study of bite force during sleep associated bruxism. J Oral Rehabil. 2001;28(5):485-91.

115. Nunes LMO. Associação entre bruxismo do sono e disfunção temporomandibular. Bauru: Universidade de São Paulo; 2003.

116. Ohrbach R, Gale EN. Pressure pain thresholds in normal muscles: reliability, measurement effects, and topographic differences. Pain. 1989 Jun;37(3):257-63.

117. Okeson JP. Nocturnal bruxing events in healthy geriatric subjects. J Oral Rehabil. 1990;17(5):411-8.

118. Paesani DA, Tallents RH, Murphy WC, Hatala MP, Proskin HM. Evaluation of the reproducibility of rest activity of the anterior temporal and masseter muscles in asymptomatic and symptomatic temporomandibular subjects. J Orofac Pain. 1994 Fall;8(4):402-6.

119. Pergamalian A, Rudy TE, Zaki HSr, C.M. The association between wear facets, bruxism, and severity of facial pain in patients with temporomandibular disorders. J Prosthet Dent. 2003;90(2):194-200.

120. Piccione A, Coates TJ, George JM, Rosenthal D, Karkzmark P. Nocturnal biofeedback for nocturnal bruxism. Biofeedback Self Regul. 1982;7(4):405-19.

121. Pierce CJ, Chrisman K, Bennett ME, Close JM. Stress, anticipatory stress, and psychologic measures related to sleep bruxism. J Orofac Pain. 1995 Winter;9(1):51-6.

122. Pierce CJ, Gale EN. Methodological considerations concerning the use of bruxcore plates to evaluate nocturnal bruxism. J Dent Res. 1989;68(6):1110-4. 
123. Pinho JC, Caldas FM, Mora MJ, Santana-Penín U. Electromyographic activity in patients with temporomandibular disorders. J Oral Rehabil. 2000;27(11):985-90.

124. Pow EH, Leung KC, McMillan AS. Prevalence of symptoms associated with temporomandibular disorders in Hong Kong Chinese. J Orofac Pain. 2001 Summer;15(3):228-34.

125. Pullinger AG, Seligman DA, Dornbein JA. A multiple logistic regression analysis of the risk and relative odds of temporomandibular disorders as a function of common occlusal features. J Dent Res. 1993;72(6):968-79.

126. Rammelsberg P, LeResche L, Dworkin S, Mancl L. Longitudinal outcome of temporomandibular disorders: a 5-year epidemiologic study of muscle disorders defined by research diagnostic criteria for temporomandibular disorders. J Orofac Pain. 2003 Winter;17(1):9-20.

127. Raphael K, Klausner JJ, Janal MN, Sirois DA. Assessing bruxism. J Am Dent Assoc. 2005 Jul;136(7):858, 60; author reply 60, 62.

128. Raphael KG, Marbach JJ. A year of chronic TMPDS: relating patient symptoms and pain intensity. J Am Dent Assoc. 1992 Dec;123(12):49-55.

129. Raphael KG, Marbach JJ. Widespread pain and the effectiveness of oral splints in myofascial face pain. J Am Dent Assoc. 2001 Mar;132(3):305-16.

130. Raphael KG, Marbach JJ, Klausner J. Myofascial face pain. Clinical characteristics of those with regional vs. widespread pain. J Am Dent Assoc. 2000 Feb;131(2):161-71.

131. Raphael KG, Marbach JJ, Klausner JJ, Teaford MF, Fischoff DK. Is bruxism severity a predictor of oral splint efficacy in patients with myofascial face pain? J Oral Rehabil. 2003 Jan;30(1):17-29.

132. Rechtschaffen A, Kales A. A manual of standardized terminology: techniques and scoring system for sleep stages of human subjects. Los Angeles, UCLA: Brain Information Service/Brain Research Institute; 1968.

133. Reimão R. Parassônias: epidemiologia, diagnóstico, terapêutica. In: , editor. Sono:. 2 ed. São Paulo: Atheneu; 1996. p. 347-60. 
134. Rieder CE, Martinoff JT, Wilcox SA. The prevalence of mandibular dysfunction. Part I: Sex and age distribution of related signs and symptoms. J Prosthet Dent. 1983 Jul;50(1):818.

135. Ro JY, Svensson P, Capra N. Effects of experimental muscle pain on electromyographic activity of masticatory muscles in rhe rat. Muscle Nerve. 2002;25(4):57684.

136. Rugh JD, Harlan J. Nocturnal bruxism and temporomandibular disorders. 1988;49:329-41.

137. Rugh JD, Solberg WK. Electromyographic studies of bruxist bejavior before and after treatment. J Calif Dent Assoc. 1975;3:56-9.

138. Schwartz L. Disorders of the temporomandibular joint. Philadelphia,: WB Saunders; 1959.

139. Seligman DA, Pullinger AG. The degree of dental attrition in modern society is a function of age and of canine contact. J Orofac Pain. 1995;9(3):266-75.

140. Seligman DA, Pullinger AG, Solberg WK. The prevalence of dental attrition and its association with factors of age, gender, occlusion, and TMJ symptomatology. J Dent Res. 1988 Oct;67(10):1323-33.

141. Sheikholeslam A, Möller E, Lous I. Postural and maximal activity in elevators of mandible before and after treatment of functional disorders. Scand J Dent Res. 1982;90(1):3746.

142. Sherman RA. Relationship between jaw pain and jaw muscle contraction level: underlying factors and treatment effectiveness. J Prosthet Dent. 1985;54(1):114-8.

143. Shiau YY, Peng CC, Wen SC, Lin LD, Wang JS, Lou KL. The effects of masseter muscle pain on biting performance. J Oral Rehabil. 2003 Oct;30(10):978-84.

144. Silva R, Conti P, Lauris J, Silva R, Pegoraro L. Pressure pain threshold in the detection of masticatory myofascial pain: an algometer-based study. J Orofac Pain. 2005;19(4):318-24. 
145. Simons DG, Travell JG, Simons LS. Dor e disfunção miofascial: Manual dos pontosgatilho. 2 ed. Porto Alegre: Artmed; 2005.

146. Spilker B. Guide to clinical trials. Nes York: Raven Press; 1991.

147. Staud R, Robinson ME, Price DD. Isometric exercise has opposite effects on central pain mechanisms in fibromyalgia patients compared to normal controls. Pain. 2005 Nov;118(1-2):176-84.

148. Stock P, Clarke NG. Monitoring bruxism. Med Biol Eng Comput. 1983;21(3):295300 .

149. Stohler CS. Muscle-related temporomandibular disorders. J Orofac Pain. 1999 Fall;13(4):273-84.

150. Stohler CS, Asjtom-Miller JA, Carlson DS. The effects of pain from the mandibular joint and muscles on masticatory motor behavior in men. Arch Oral Biol. 1988;33(3):175-82.

151. Stohler CS, Zang X, Lund JP. The effect of experimental jaw muscle pain on postural muscle activity. Pain. 1996;66(2-3):215-21.

152. Stratmann U, Mokrys K, Meyer U. Clinical anatomy and palpability of the inferior lateral pterygoid muscle. J Prosthet Dent. 2000;83:548-54.

153. Svensson P, Arendt-Nielsen L. Effects of 5 days of repeated submaxiamal clenching on masticatory muscle pain and tenderness: an experimental study. J Orofac Pain. 1996;10(4):330-8.

154. Svensson P, Arendt-Nielsen L, Houe L. Sensory-motor interactions of human experimental unilateral jaw muscle pain: a quantitative analysis. Pain. 1995;64(2):241-9.

155. Svensson P, Arendt-Nielsen L, Houe L. Muscle pain modulates mastication: an experimental study in humans. J Orofac Pain. 1998;12(4):343-53.

156. Svensson P, Burgaard A, Schlosser S. Fatigue and pain in human jaw muscles during a sustained, low intensity clenching task. Arch Oral Biol. 2001 Aug;46(8):773-7.

157. Svensson P, Graven-Nielsen T. Craniofacial muscle pain: review of mechanism and clinical manifestations. J Orofac Pain. 2001;15(2):117-45. 
158. Svensson P, Wang K, Sessle BJ, Arendt-Nielsen L. Associations between pain and neuromuscular activity in the human jaw and neck muscles. Pain. 2004 Jun;109(3):225-32.

159. Travell J, Rinzler S, Herman M. Pain and disability of the shoulder and arm: treatment by intramuscular infiltration with procaine hydrochloride. J Am Dent Ass. 1942;120:417-22.

160. Türp J, Minagi S. Palpation of the lateral pterygoid region in TMD - where is the evidence? Journal of Dentistry. 2001 Sep;29(7):475-83.

161. Turp JC, Schindler HJ, Pritsch M, Rong Q. Antero-posterior activity changes in the superficial masseter muscle after exposure to experimental pain. Eur J Oral Sci. 2002 Apr;110(2):83-91.

162. van der Meulen MJ, Lobbezoo F, Aartman IH, Naeije M. Self-reported oral parafunctions and pain intensity in temporomandibular disorder patients. J Orofac Pain. 2006 Winter;20(1):31-5.

163. van Selms MK, Lobbezoo F, Wicks DJ, Hamburger HL, Naeije M. Craniomandibular pain, oral parafunctions, and psychological stress in a longitudinal case study. J Oral Rehabil. 2004 Aug;31(8):738-45.

164. Vazquez-Delgado E, Schmidt JE, Carlson CR, DeLeeuw R, Okeson JP. Psychological and sleep quality differences between chronic daily headache and temporomandibular disorders patients. Cephalalgia. 2004 Jun;24(6):446-54.

165. Velly-Miguel AM, Montplaisir J, Rompré PH, Lund JP, Lavigne GJ. Bruxism and other orofacial movements during sleep. J Craniomandibular Dis Fac Oral Pain. 1992;6(1):7181.

166. Visscher CM, Lobbezoo F, de Boer W, van der Zaag J, Verheij JG, Naeije M. Clinical tests in distinguishing between persons with or without craniomandibular or cervical spinal pain complaints. Eur J Oral Sci. 2000 Dec;108(6):475-83.

167. Visscher CM, Lobbezoo F, Naeije M. Comparison of algometry and palpation in the recognition of temporomandibular disorder pain complaints. J Orofac Pain. 2004 Summer;18(3):214-9.

168. Wagner MT. Controlling nocturnal bruxism through the use of aversive conditioning during sleep. Am J Clin Biofeedback. 1981;4:87-92. 
169. Ware JC, Rugh JD. Destructive bruxism: sleep stage relationship. Sleep. 1988;11(2):172-81.

170. Widmer CG, Lund JP, Feine JS. Evaluation of diagnostic tests for TMD. J Calif Dent Assoc. 1990 Mar;18(3):53-60.

171. Wildmalm SE, Christiansen RL, Gunn SM. Oral parafunctions as temporomandibular disorder risk factors in children. J Craniomandib Pract. 1995;13(4):242-6.

172. Yamaguchi $\mathrm{T}$, Satoh $\mathrm{K}$, Komatsu $\mathrm{K}$, Inoue $\mathrm{N}$, Minowa $\mathrm{K}$, Totsurka $\mathrm{Y}$. Electromyographic activity of the jaw-closing muscle s during jaw opening in patients with masseter muscle contracture. J Craniomandib Pract. 2002;20(1):48-54.

173. Yap AU, Dworkin SF, Chua EK, List T, Tan KB, Tan HH. Prevalence of temporomandibular disorder subtypes, psychologic distress, and psychosocial dysfunction in Asian patients. J Orofac Pain. 2003 Winter;17(1):21-8.

174. Yatani H, Studts J, Cordova M, Carlson CR, Okeson J. Comparison of sleep quality and clinical and psychologic characteristics in patients with temporomandibular disorders. $\mathrm{J}$ Orofac Pain. 2002 Summer;16(3):221-8.

175. Yemm R. A neurophusiological approach to the pathology and etiology of temporomandibular dysfunction. J Oral Rehabil. 1985;12(4):343-53. 
ABSTRACT 


\section{ABSTRACT \\ Association Between Sleep Bruxism and Myofascial Pain: a Polysomnographic Study.}

Objectives: To test 1) the association between sleep bruxism (SB) and miofascial pain (MFP); 2) the correlation between rhythmic masticatory muscle activity (RMMA) and pressure pain threshold (PPT) at morning, 3) the influence of previous tenderness over RMMA in bruxers and non-bruxers with/without MFP, and 4) the validity of a clinical diagnostic criteria of sleep bruxism (DCSB). Materials and Methods: Polysomnographic recording (PSG) (two consecutive nights) were performed in 30 MFP patients, selected according to RDC/TMD and 30 asymptomatic controls age and gender-matched. Pre and post-PSG PPT values were verified for masseter (origin, body, insertion, and deep portion), as well as for temporal (anterior, medium, posterior) muscles. Results: All MFP patients reported pain complaints on masseter and/or temporal muscles. Most of MFP patients reported mild or moderate pain (46.67\%, and $43.33 \%$, respectively), and only $3(10 \%)$ reported severe pain. Pain duration ranged from 2 to 120 months (mean of $34.67 \pm 36.96$ months). No differences in sleep architecture were observed in both groups. A significant association was observed between SB and MFP [Chi-Square=0.039, Odds Ratio=3.45 [CI 95\% 1.066-11.194)]. Only in MFP patients negative correlations were seen between ARRM and morning-PPT - indicating a dose-response gradient between ARRM and tenderness to palpation on morning. This gradient seemed more evident among MFP non-bruxers than on bruxers. There were positive correlations between pre-PSG PPT and RMMA only among asymptomatic bruxers. Conclusions: These findings indicate that: 1) Sleep bruxism is significantly associated with MFP; 2) MFP seems to be a predisposing factor that increases bruxism-related muscle sensitivity; 3) MFP non-bruxers seem to show more tenderness on palpation due to more intense RMMA than do MFP bruxers. 4) Only among asymptomatic bruxers was found some evidence of pain-adaptation model; and 5) The DCSB showed different confiability values for MFP and asymptomatic patients, presenting higher values for MFP patients, although not reaching adequate sensitivity (75\%) and specificity (90\%) levels.

Keywords: Sleep bruxism. Myofascial pain syndromes. Polysomnography. Pain threshold. 